口 July' August 1991

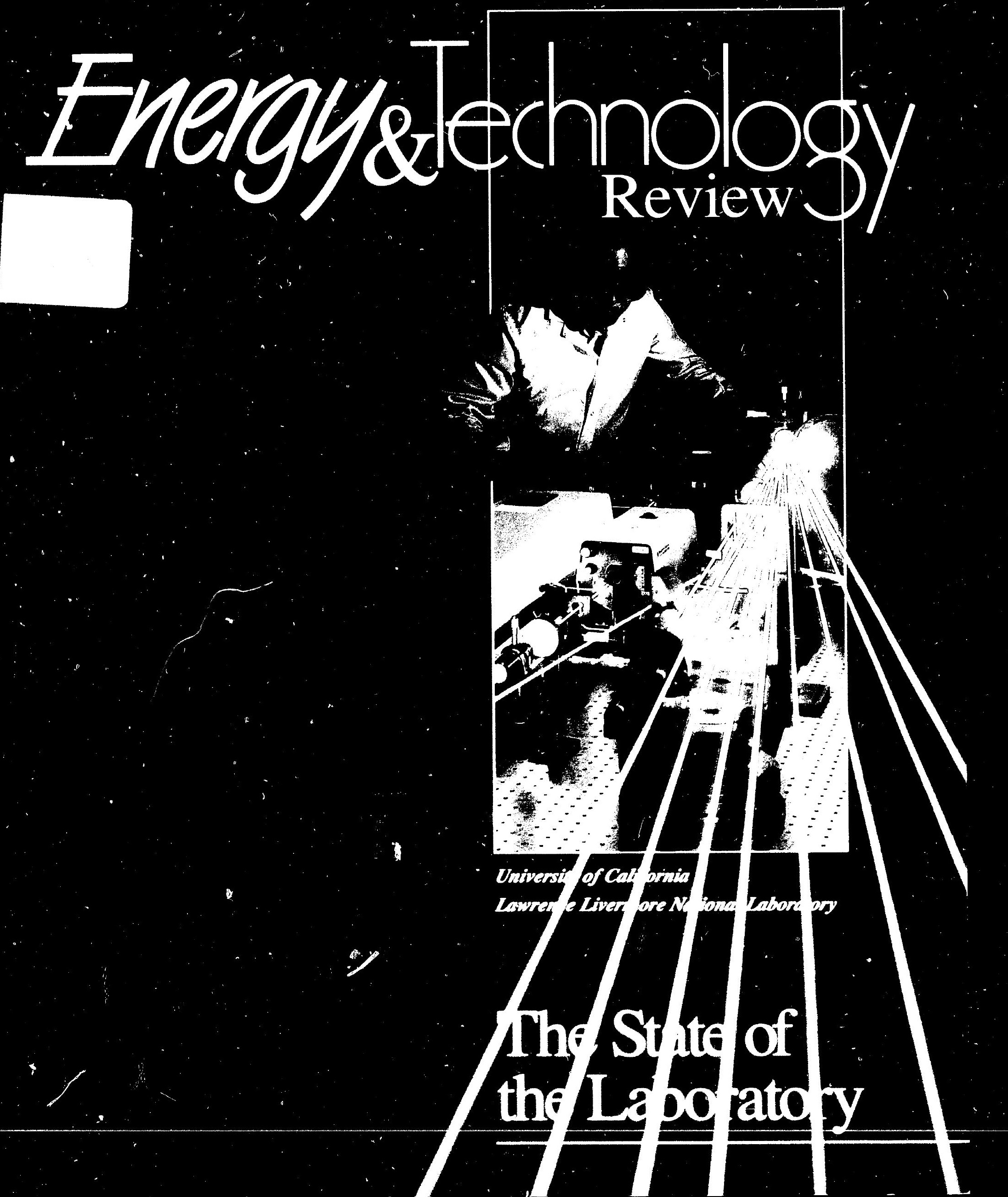




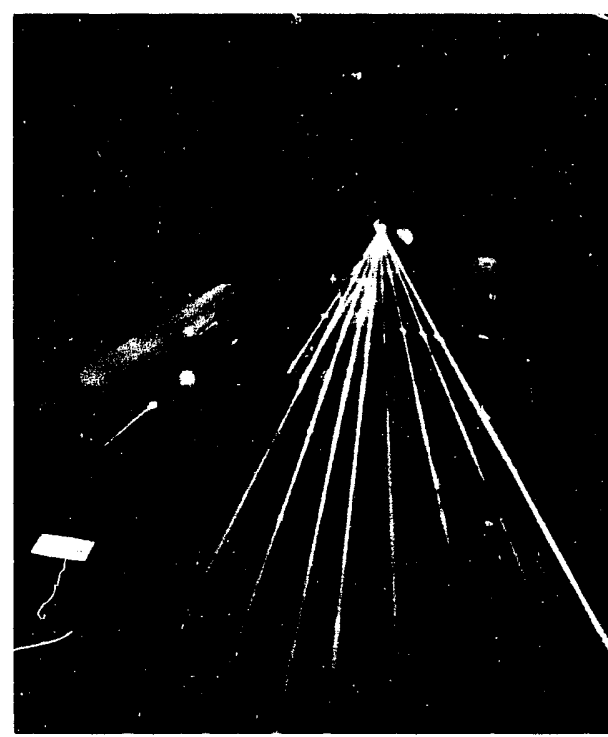

\section{Shout the cioser}

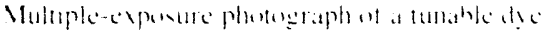

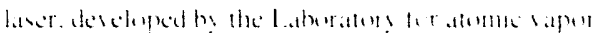

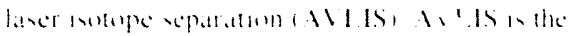

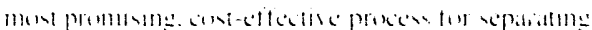

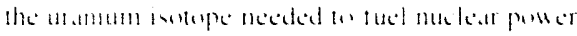

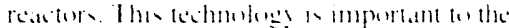

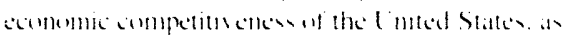
the internationst mathet for enriched aramtum is

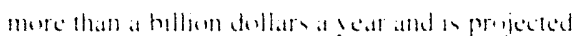

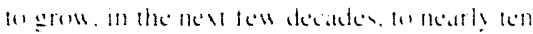

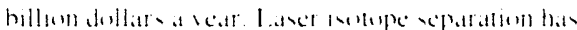

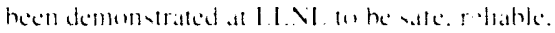
and athe to med the demande of the mathetplate

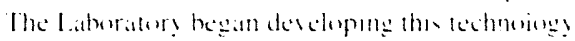

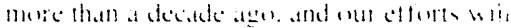

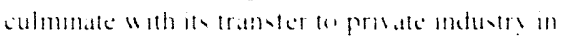

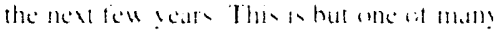

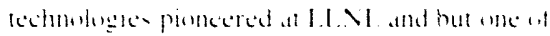

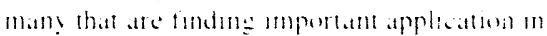

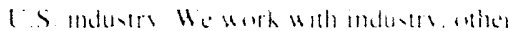

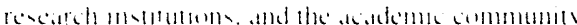

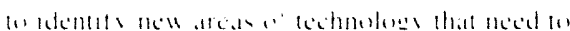

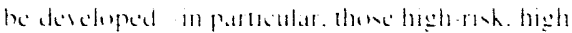

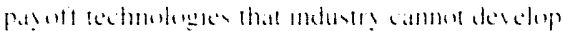

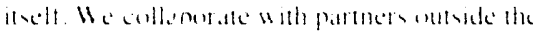

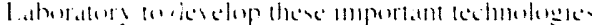
and then the trankes them on the prisate sector

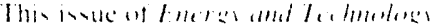

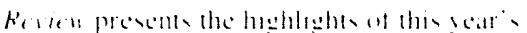

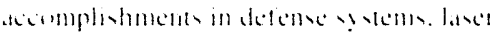

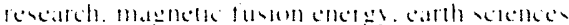

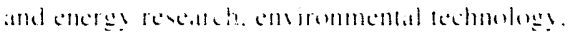

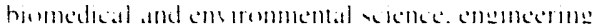

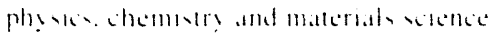
computatum. and atmonntratuc and support

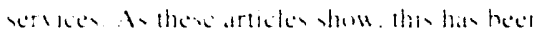

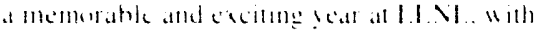

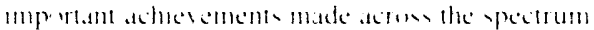
"1 the latheratur! program

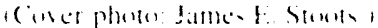
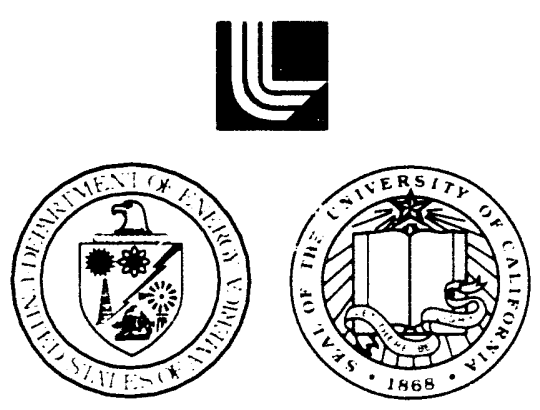

Prepared for DOOF under untract V. $11-715-1,110+4$

\section{About the Journal}

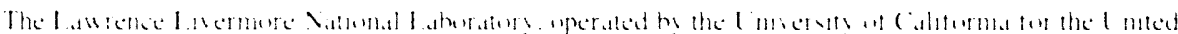

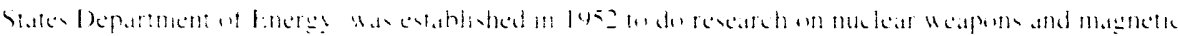

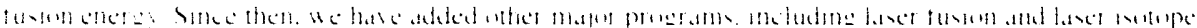

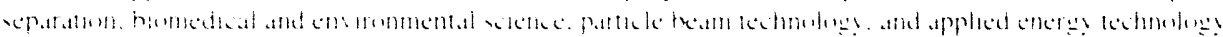

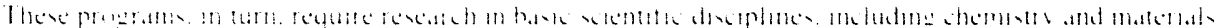

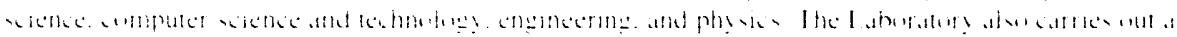

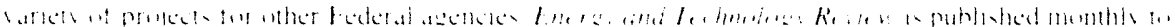

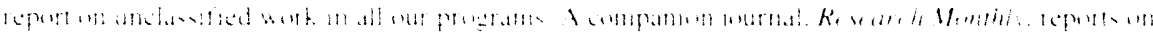

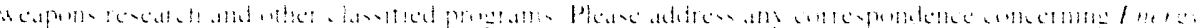

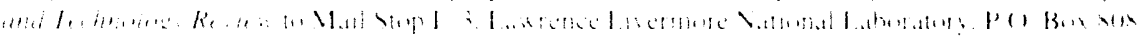

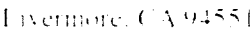




\section{$\square$ July $\cdot$ August 1991}

Scientific Fditor

Kent C Johnum

Editorial Staff

Framu-Cehulh!

Laturen de Vire

(imal Kuper

Maureen 1.. Donahue

Grethen I) Gidile =

Kerin Gieswon

Gicruld R. Girm

Herberr Highemente

\section{Art Staff}

Linn !1 Ciwt. Jinet Crompon-Pine

Putul il Harding

Kathrsn Hous

(ienrge Kitrmo

Marh ( MoLamel

Compositor

InumaCardira

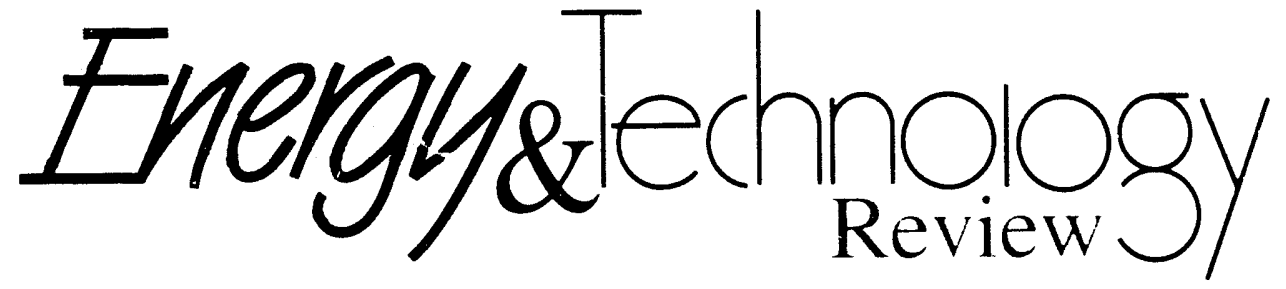

The State of the Laboratory

Defense Systems

Laser Research $\quad 22$

Magnetic Fusion Energy $\quad 38$

Energy and Earth Sciences $\quad 44$

Environmental Technology Program 5

Biomedical and Environmental Science $\quad 56$

$\begin{array}{ll}\text { Engineering } & 64\end{array}$

$\begin{array}{ll}\text { Physics } & 72\end{array}$

$\begin{array}{lr}\text { Chemistry and Materials Science } & \mathbf{8 0}\end{array}$

$\begin{array}{ll}\text { Computations } & 90\end{array}$

Administrative and Institutional Services $\quad 96$

$\begin{array}{ll}\text { Index } & 105\end{array}$

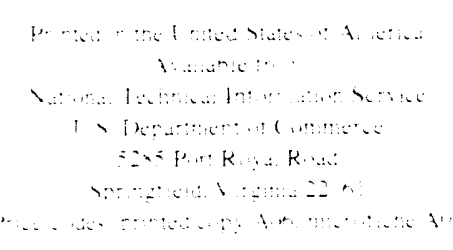

I ( RI - $=2(x)(x)-4)-7 x$

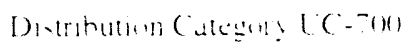

Jul: Augun igyl

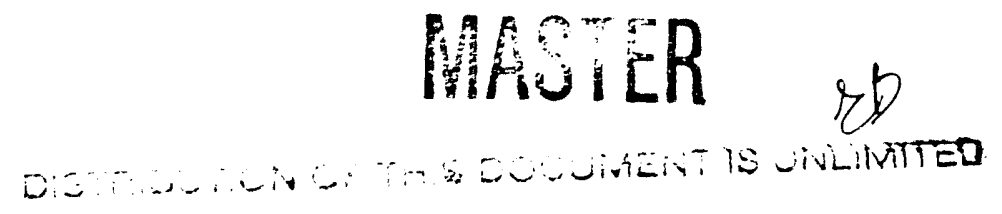




\section{The State of the Laboratory}

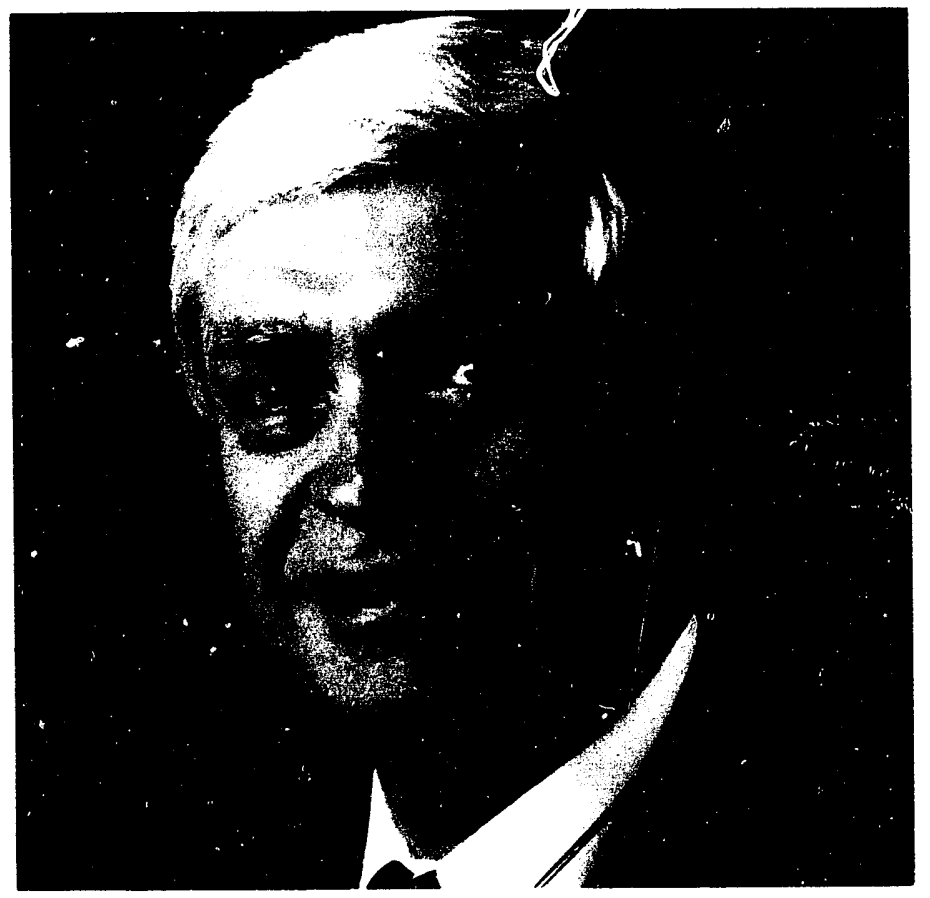

$\mathbf{T}$ his has been a memorable and exciting year for the Lawrence Livermore National Laboratory-a vear of change and achievement. The Laboratory continues to take a leading role in the defense of the United States and the free world. and is taking a growing role in meeting the nation 's civilian needs in the areas of energy. environment. health. the economy. and education.

Laboratory funding is projected to increase slighty in FY 1992. to more than 51.1 billion. This is an indicator of the strength and vitality of LL NL' multiple programs. particularly in view of the end of the Cold it ar. the continuing decline of tunding for our nuclear weapons programs 13()$^{2} \%$ in the past fiice lears. and the national hudget crisis. The Laboratory 's saff size has declined about $5 \%$ in the past fes years. 10790() full-time employees. Mas of this decline has heen in the weapon program. Today. LL. VL is one of the world - largest research and development (R\&D) laboratories. with a $\$ 3$ to $\$ 4$ billion plant that includes many state-of-the-art experinental facilities.

When the Laboratory was founded 39 years ago. the Liniversity of California recruited a world-class saientific. engineering. technical. and administrative workforce. Two important breakthrough technologiesnuclear energy and supercomputerswere acquired. developed. and applied to national needs. primarily in nuclear defense (o prevent World War III and secondarily in fusion power to provide clean. safe. inexhaustible energy for the 2lst century and beyond.

In the 1960s and 70s. the Laboratory acquired and developed additional core competencies. principally in high-performance lasers and in biological science and technology. The federal government has since expanded LLXL' missions (o) include environment and health and. most recently. the economy and science and math education. Todit. the
Laboratory is acquiring. developing. and applying breakthrough science and technology to meet major national needs and to create new opportunities for the 21 st century.

Driven by the needs of the nuclear weapons program. the Laboratory has for decades been a world leader in high-performance computing. We operate two major supercomputer centers: a classified center for the weapons program. and a national supercomputer center that supports Department of Energy (DOE) R\&D projects nationwide. Our overall supercomputing power has increased nearly tenfold every ten years. LL. NL spends $\$ 2(x)$ million per year on highperformance computing. somewhat more on software than on hardware.

The I-aboratory , laser programs are lunded at more than 5250 million annually. comparable o the funding of the nuclear weapon program. LI. VI in a world leader in the development of high-pertormance laner for fusio": 
isotope separation. and military applications. We have initiated an industrial applications program anmed at developing applications. such ats laser machining and x-ray lithography; to help U.S. industry become more competitive in today"s global markets.

Our programs in hiomedical science and technology are funded at about $\$ 25$ million amnually. The 1 wo principal components-human genome research and biodosimetry - are both growing rapidly. Last year. LLNL was designated as one of three DOE centers for human genome research. We are catalyzing biomedical research with the hig-science. multidisciplinary approach pionecered so successfully by the Laboratory"s founder. E. O. Lawrence.

We are applying core competencies in nuclear science and technology. high-performance computing. lasers. and biomedical science and technology to meet national defense and civilian necels.

Defense. With the end of the Cold War and the collapse of eommunism. the nuclear deterrent is entering a state of transition. This transition is constrained by two realitics:

- L'.S. nuclear forces must continue to meet two essential national security goals-to deter nuclear wars. and to deter major conventional wars.

- The Soviet Lnion is developing several new strategic nuclear missiles. eren in a period of internal economic collapse and political chaos.

Nevertheless. with the recent suceess of the START arms-control negrotiations. L.S. and Soviet nuclear foreses 11 ill be significantly reduced in this decalde. The Lathoratory is developing verification lechnologies that will facilitate the arms-control process.

Our nuclear ucapon program has recently made sereral outsanding contributions to the national security. I. NI. WSe warhead for the SR A.1/ II homber-carricd missile hats entered engencering and production development on schedule. The W89/SRAM II is particularly significant because its nuclear wathead comtains modern safety features.

When production of the W89 wats threatened by the continuing shutdown of the DOE Rocky Flats production facility, the Laboratory"s weapons program advanced a potentially revolutionary initiative-to use parts from retired nuclear warheads in new warhead designs that contain modern safety technologies. A nuclear test has clearly demonstrated that this idea could work. and more tests are planned to certify its feasibility.

LLNL has long pioneered the development and application of technologies to prevent nuclear explosions or plutonium dispersal in the event of an accident involving nuclear weapons. Unfortunately. most of the weapons in the U.S. stockpile are old and do not contain these modern safety features. Last year. a nuclear weapons salfely panel. chaired by Stantord professor Sidney Drell. was chartered by the Housc Armed Services Committee to examine the salfety of the U.S. nuclear weapon stockpile. The Drell Panel recommended substantial improvements in the safety of the stockpile: it also recommended that the weapons laboratories be lasked to make nuclear weapons as sate as possible. LI NL has developed two approaches to intrinsically safe nuclear weapons (weapons that are sate by design and are much less vulnerable to human error in transportation and field operations). We plan to validate these approaches in nuclear tests scheduled for FY 1991 and FY 1992.

The Laboratory has also contributed to the development of verification technologies that make possible new arms-control measures. In addition. L.L.NL persomnel made important contributions to the formulation of the Threshold Test Ban Trealy. Which was recently approved near unamimomsl! by the L.S. Senate.

Finally. the lateratory has made important contrihutions to the understanding of Third World nuclear weapon capahilitics. most recently in Irac. The L aboratory is supporting United Nations teams dispatched lo Irac (o) assess that country suckear weapon capabilities. Important lessons hate been learned from this cflort.

Desert Storm clearly emphasized the growing vulneranility of the world's population centers to attack by Third World weapons of mass destruction. Recently, the U.S. Strategic Defense Initiative has been redirected toward development of a limited defense system. The Laboratory's Brilliant Pebbles technology is the cornerstone of this initiative. Brilliant Pebbles puts in space the same kind of smarl. superaccurate technologies recently demonstrated so successfully in Desert Storm. Once in orbit, a constellation of Brilliant Eyes would encircle the earth creating "open skies." When activated. these orbiting missiles would intercept and destroy mid- and long-range ballistic missiles carrying weapons of mass destruction. A recent Brilliant Peb'les flight test was largely successful.

\section{Energy. Events in the Persian Gult} also emphasized the growing national and international energy needs. By the midklle of the 21 st century. the world's population is projected to hatre doubled. (1) I0 billion, while the world's oil resources are projected to have heen substantially depleted. If future gencrations are to be spared a global energy crisis, we must develop clean. salfe energy sources, such as fusion. These new energy sources also must be affordable. Otherwise. the developing labor-rich. capital-poor nations. where most of the population growth and new energy demand will oceur. will meet their energes needs by hurning coal -just as Western civilization did in the 19 th and early 20th centuries. (ombustion of this coal will more than double the amount of citrhon dioxick in the carth"s atmosphere in the next century, with allendant elfects on the global climate. 
LLNL's energy-related programs are funded at $\$ 250$ million per year. We have two major fusion programs. a major laser isotope separation program. and a small fossil energy program. The Laboratory is a world leader in the development of inertial confinement fusion. We also have a leading role in the international effort to develop the magnetic-confinement approach to fusion power. LLNL has been designated as the host institution for the L.S. Home Team during the engineering design activity for the magnetic-fusion International Thermonuclear Experimental Reactor (ITER). These (wo approaches to fusion-inertial confinement and magnetic-are key elements of the National Energy Strategy.

Environment. Internal and external funding of LLNL's en ironmental programs is approaching $\$ 100$ million. Our goals are to develop minimum-cost cleanup technologies and to protect the environment. We have a strong effort in the earth sciences. and we are leaders in the atmospheric sciences. Our stateof-the-art supercomputer codes have been applied to such problems as smog in the Bay Area. smoke plumes from the oil fires in Kuwait. global climate change resulting from the buildup of carbon dioxide in the atmosphere. and tracking the radioactive cloud from the Chernobyl nuclear accident. The Laboratory s multidisciplinary science and technology base together with our applications-oriented team approach are well suited to tackling these environmental challenges.

Health. The two major thrusts in biomedical science and technology are the human genome and biodosimetry. The Laboratory is a key participant in the international effort to decipher the human genome. We have made excellent progress toward mapping chromosome 19: we have processed more than $f()()()$, wable fragements from this chromosome and have located scores of genes on these fragments. Many new methods have been developed to prepare the DNA. to amplify it by cloning and other means. to "fingerprint" fragments. to characterize the genetic properties of these fragments, and to sequence selected regions. A map of the human genome will revolutionize health care and the quality of life in the next century.

Research on biological dosimetry is also making great progress. For example. we are using accelerator mass spectrometry to achieve a thousand-fold increase in sensitivity for measurements of certain DNA defects (adducts). We are seeing surprising reductions in the effects of food mutagens at low doses. Biodosimetry will also have high leverage. for example. by enabling a rational approach to solving environmental problems. on which the nation is currently s"yending $\$ 100$ billion a year.

Economy. We are accelerating the development of collaborations with U.S. industry. We have partners in the biochemical. oil. steel, and semiconductor areas. In this decade. we will transfer our laser uranium isotope enrichment technology to industry.

Laser isotope separation has a significant economic advantage over the competing centrifuge and gaseous-diffusion technologies. The internationai market for uranium enrichment is more than a billion dollars a year and may grow to ten billion dollars a year in the next few decades.

The Laboratory"s high-performance computing also has potentially high economic leverage. A government task force has estimated that implementation of the proposed federal high-performance computing and communications initiatives could increase the grom national product by several hundired hillion dollars per sear.
Education. The Laboratory has been involved in science education for more than 20 years. and this commitment is growing. Over the years. We have developed more than 6) programs in collaboration with teachers and educators. Nearly a thousand LLNL employees are involved in public education programs on a volunteer basis. Together with the Lawrence Berkeley Laboratory. Sandia National Laboratories. the Stanford Linear Accelerator Center. the University of Californial, and other institutions, we are part of DOE Secretary Watkins" initiative to upgrade science and math education in the Oakland schools during this decade. In collaboration with the University of California. the Glenn T. Seaborg Institute for Transactinium Science was established last fall. This institute will emphasize education and training as well as research and development.

\section{Administration}

The multitude of new environment. safety. and health (ES\&H) laws has created compliance problems at the Laboratory and at R\&D facilities nationwide. New laws have been enacted faster than compliance could be achieved. Our long-term safety record is about average for DOE facilities and is substantially better than that of the private sector. We have made a number of management changes and have devoled substantial resources in order to achieve excellence in complying with the growing number of ES\&H laus.

For nearly to years, the Laboratory has performed an important public service to the nation and the free world. In the next 4 ) years. this public service will be expanded to meet important national defense and civilian needs and to creale major new opportunities.

John H. Nuckolls Direcuor 


\section{Defense Systems}

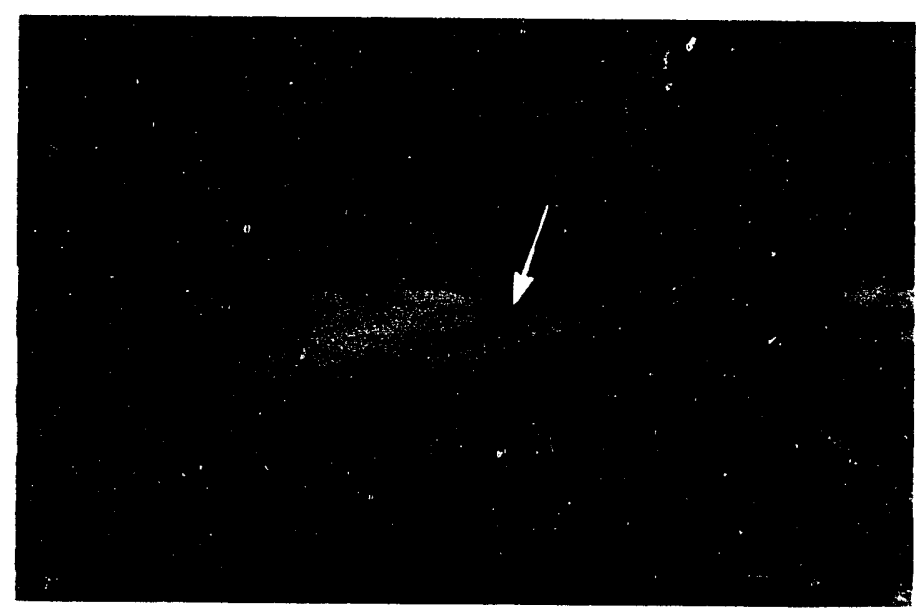

The Weapons Program mission remains

to assure a safe, reliable stockpile, to

modernize warheads as required, and to

sustain expertise in nuclear weapon

technology while responding to rapidly

changing external events such as the

Middle East war.

$\mathbf{T}$ he LLNL Nuclear Weapons Program continues to respond to several rapidly changing external events. The 1990) shutdown of the Rocky Flats plant brought the manufacture of new weapons plutonium components to an abrupt halt: the weapons materials production reactors at Salannah River remain inoperative. Concerns over certain aspects of nuclear weapons safety have aroused attention at the national level. The war in the Middle East has increased awareness of the dangers of nuclear proliferation and of the potential risks that ballistic missiles can deliver weapons of mass destruction. Finally. as plans for the future reconfigured DOE weapons manufacturing complex. Complex-21. have deseloped. it has been recognized that its scope and cost can be influenced by a broader set of factors than had first been thought.

In response to this pressure of external events, the Weapons Program is placing high priority on addressing safety concerns, accommodating near-term difficulties in manufacturing new weapons, and facilitating and contributing to planning for the acquisition of a reconfigured manufacturing complex. At the same time, the program must maintain the nuclear competence needed to sustain a safe. reliable nuclear weapons stockpile. For example. we recently worked with the Air Force to provide a mock W87 warhead for a realistic flight test of the Mk 21 Peacekeeper reentry vehicle. Results of this very successful test are shown above the arrow identifies the impact point). We also must maintain the competence needed to confidently arsess the nuclear capabilities of countries known or suspected to be pursuing such capabilities.

Despite shifts of emphases among the elements of the Weapons Program, the basic mission of the program remains unchanged: to assure that the stockpile is safe and reliable, to provide warhead modernization when required. and to sustain expertise and understanding of nuclear weapon technology. Consistent with our mission. we are placing highest priority on the near-term introduction of insensitive high explosives and fire safety properties into key systems that are subject to the greatest risk of exposure to fire or impact.

The W89 SRAM (Short Rarige Attack Missile) II warhead. slated to enter the stockpile in about two years. contains such features. The recent 
extended curtailment of plutonium component manufacturing at the Rock! Flats plant has complicated production planning for the 1189 . However. we are looking at the possibility of building a lersion of the 189 that reuses the plutonium components from old. retired. disassembled warhead. Such a strategy would permit the safety modifications embodied in the W89 io go into the stockpile on schedule. even without Rocky Flats production. We mat also be able to improve the overall stockpile safely and security by developing other applications of nuclear component reuse and selectively retiring older stockpile lleapons. We are also developing an approach to assessing "capon salfet! using probabilistic rish assessment.

In the longer term. the program is examining future designs that go heyond the sattety improvements offered by insensitive high explosives and fire safety. Such designs are called intrinsically safe because they have the potential to make fundamental improrements in both nuclear and plutonium scattering satety: they do so by physically separating the plutonium and the high-explosive system. If successful. they will provide near tolal assurance of nuclear and plutonium scattering safet! no matter what the upe or severity of the accident. Worh on these designs is underwaly. and the next mo years will see initial testing attivity.

Because of budgetar! and envirommental sately and health (ES\&H) comstraints and requirements. the future weapens complex must be smaller and more efficient. and thus also somewhat less flexible with potentially fewer capabilities. To ensure that these dom nscaled. modernized fatcilities can operate at lower eost and also meet current and future ES\&H demands. "le are exploring technologies that can support an integrated program of revised design requirements and improsed manufaturing kechniques.
LLNL people are serving on pancls working to identify appropriate candidate sites for the comsolidated fatcilities. to assess the impact of nonDOE production of most nonnuclear parts. to explore ways of reducing the number of independent nuclear weapons materials and processes in order to decrease production costs and facilits requirements. and to examine Mass of consolidating activities shared by the weapon design laboratories.

Arms control continues to be an important part of our current work and future planning. The Treaty Verification Program. part of LLNL's Special Projects Program. provides technical analysis and equipment to support verification activities related to a wide variety of arms-control treaties. Future Defense Systems activities must address Congressional legislation directing the national laboratories to ensure atl adequate L.S. deterrent with less reliance on nuclear testing. One way of reducing reliance on testing is to increase the performance margins of stockpile systems to the point that a warhead"s behavior is less likely to be sensitive to a variety of unforeseen problems that have the potential of producing degradations. Another way of reducing sensitivity is to change bie basic design of the nuclear explosive. There is reason to postulate that the intrinsically sate designs already mentioned may possess reduced sensitivity. Despite the ultimate goal of reducing reliancic on nuclear testing. we will have no choice in the near term hut to perform testing in order to verify the safely and reliability of the reconfigured designs. However. there is a complementary component of this design and nuclear test activity that would lead to these more robust designs: nonnuclear tests carried out in our aboveground testing facilities. We hate made improvements in three key aboveground facilities- the High Explosises Applications Faciiil! (HEAF). Site $3(1)$. and the Noval laserand hate conducted experiments in thems.
With increasing budgetary pressure. Weapons Program operations must adopt efficiencies and comsolidations that promise program economies. We are thus ageressively pursuing innovations in experimental science and field operations to improve the quality. productivity. and efficiency of our nuclear test operations. For example. at the Nevada Test Site (NTS) we have formed two teamsthe Test Operations Review Team (TORT) and the Support Operations Review Team (SORl)-to study essentially all NTS operations and to identify possible improvements in operational quality and efficiency. With respect to the test program. FY9l will be the first year in which we will be carrying out the verification provisions of the Threshold Test Ban Treaty (TTBT). Such activities will be taking place on an event scheduled for the summer of 1991.

With losses in DOE Weapons Research. Development. and Testing (WRD\&T) funding. such funding cannot alone adequately sustain certain key technologies of the Weapons Program. In such cases we have sustained critical masses of expertise by applying some of our nuclear expertise to other applications. such as the development of improved conventional weapons systems. Adranced conventional weapons recently demonstrated their tremendous potential in the field during the Iragi conflict.

Finally, the recent conflict has heightened our awareness of the importance of being vigilant with respect to important defense assets. including items such as weaponssensitive materials and sensitive facilities and equipment. Supporting this heightened ats areness is the Livermore Conflict Simulation Laboratory. which hats developed highresolution computerized simulations of various threats to determine optimum ways of stecessfully thwarting them.

(imnact II. H. Sanlin (415) +2.3-6.5/1). 


\section{The W89 Warhead Development Program}

T The $W 89$ is the warhead for the new Short Range Attack Missile (SRAM 11). now being developed by the Air Force. The original missile. SRAM A. with the W69 warhead. has been deployed with the Strategic Air Command (SAC) for about 20 vears. The SRAM II. like the SRAM A. would be carried by penetrating bombers to a point near a target and launched: the bomber would then turn away and fly on to its next target. In this way, the bomber does not have to fly through the terminal defenses that may be deployed near a high-value target. The missile is much smaller and faster than the bomber and thus is harder to shoot down. Boeing Aerospace and Electronics is the prime contractor for the missile development. with Hercules the subcontractor for the rocket motor. LLNL and Sandia National Laboratories. Livermore. are working together in the development of the $\$ 89$ warhead. with LLNL concentrating on the nuclear explosive package and Sandia on the surrounding electrical and structural components.

The Air Force is developing a new version of the missile to provide upgraded performance against future air defenses and to replace the aging SRAM A. which may be approaching the limit of its useful lifetime. The W69 warhead is bemg replaced in order to introduce modern warhead safets features that hatre been devejoped during ine two deciades

The W89 warhead for the new Short Range Attack Missile is now in Phase 4 (preproduction engineering). Because of the curtailment of plutonium operations at the Rocky Flats production plant, we are also looking at the possibility that a version of the W89 warhead could be built by reusing the pits from old warheads that have been retired and disassembled.

since the W69 was designed. One particularly significant improvement is the use of insensitive high explosive (IHE) in place of older. more sensitive explosive. In the event of an accident. IHE will not be detonated by impact. fire. or highvelocity fragments. Over the last decade. IHE has been introduced into other warheads carried by strategic bombers-the B61-7 homb. the W8()-1 in the air-launched cruise missile, and the B8.3 bomb.

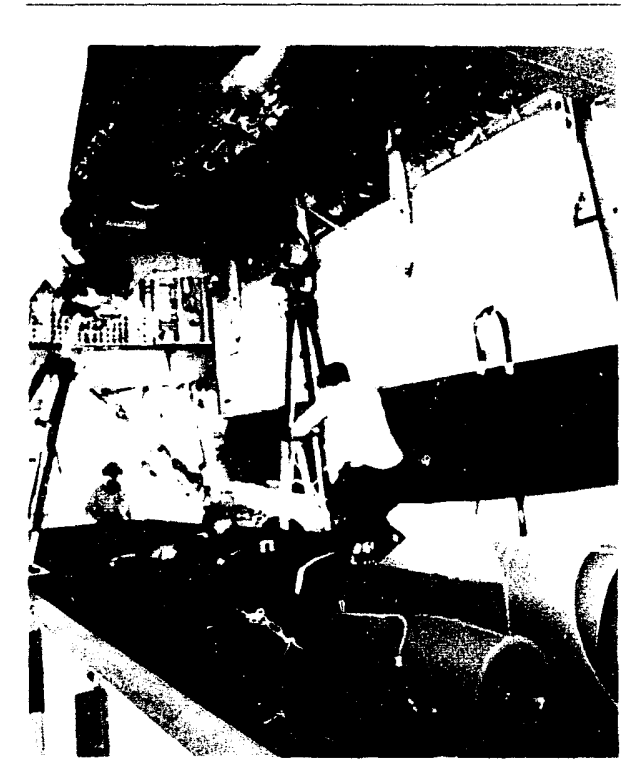

Figure 1. The static-ejection missile/warhead test unit resting in the paojed catcher box after ejection from the bomb bay of a B-1B aircraft. The cables connect the test unit to the instruments that measure the stresses resulting from the violent ejection. The box is soft enough that the test unit can be reused.
Replacement of the W69 with the W89 will bring the high-explosive safety of the SRAM II warhead into line with these other bomber-carried warheads. In addition. the W89 has been designed with fïre-resistance capability and can contain its plutonium in the erent of a jetfluel fire. IHE and fire resistance together dramatically reduce the probability. that plutonium would be dispersed in a warhead accident.

The nuclear explosive design of the W'89 is now mature. and its performance has been well established. However. much development work remains to be done. Engineering ground tests are being conducted to demonstrate that the warhead can survise and function reliably under the specified conditions of its operational environment. In addition. missile flights will be made with special telemetered test warheads to verify compatibility between the warhead and the missile and to demonstrate proper functioning of the warhead electrical components in flight. The ground tests have progressed well during the past year. but the flight tests have been delayed by problems in the missile development. Ahoremaining are safety tests and work with the DOE production plants to prepare for large-scale production. The scheduled date for producing the first $W 89$ warhead is January 1994. hut this date maty sip hecialuse of delats in the missile program. 
In an operational mission. the missile and warhead would be carried on a rotary launch rack in the bomb bay of a $B-1 B$ bomber. At launch. the bomb baly doors would open and the lowest missile would be violently ejected downward to clear the aircraft before its rocket motor fïred. During the past year. We successfully completed static ejection tests in which an instrumented mock warhead in a test missile was ejected downward from the bomb bay of a B-1B bomber parked at Edwards Air Force Batse. A catcher hox containing soft material was placed under the bomber and caught the ejected missile/warhead combination. These ejection tests measured the stresses imposed on the warhead by launch from the bomber. Figure 1 show the missile in the box after an ejection test. We then flew this test missile/warhead combination in the bomb bay of the B-IB and measured the vibration. shock. and thermal environments. In addition. an extensive series of vibration. shock. and thermal ground tests of a mock warhead continued throughout the past year. Figure 2 show s this unit mounted on a vibration testing machine. We have begun disassembly of this test unit for final inspection and demonstration that the warhead withstood all these stresses. Furthermore. we supplied warhead hardware to Sandia that was incorporated into test units and used in grround tests to demonstra : that the telemetered flight test warhead will function reliably and safely during captive carry launch. and missile flight.

In the important area of safety. we demonstrated that the W89" fire-resistance features are adequate for the specified accidental lire environments. We halle begun to investigate the very high temperature environments that may accompany an accidental fire in the missile"s solid rocket motor fuel. We have also begun a probabilistic risk analysis of all possible accidents during the time the W89/SRAM II is deployed with the Strategic Air Command. This study is similar in method to that often performed for nuclear reactors.

The W89 warhead development program has progressed well during the past year. The design was judged mature enough that the DOE production plants could begin largescale activities to prepare for stockpile production. In May 1990. the program entered Phase 4 (preproduction engineering 1 .

For some time LLNL has been investigating new approaches to nuclear device design. One concept that we have investigated is reusing the plutonium-containing components (called pits) from retired warheads.
The usual production process is to disalssemble the old pits. chemically reprocess the plutonium inside. and machine and assemble it into new pits for new warheads. This process generates significant amounts of 11- te and exposes workers to radiation. If instead of being rebuilt. the old pits could be reused in new warheads. we could greatly reduce waste and radiation exposure.

During the past year. we have investigated the possibility that a version of the $W 89$ warhead could be built with reused pits from old warheads. Use of a pit from another warhead in the W89 presents significant warhead design and system integration difficulties, but our early work has indicated that we can make such an approach work with acceptable design penalies. We are continuing to pursue this parallel option. so that it will be fully mature should it be needed in the future.

Contact: J. 1: Tyler $(\$ 1.5) \$ 2.3-1.307$.

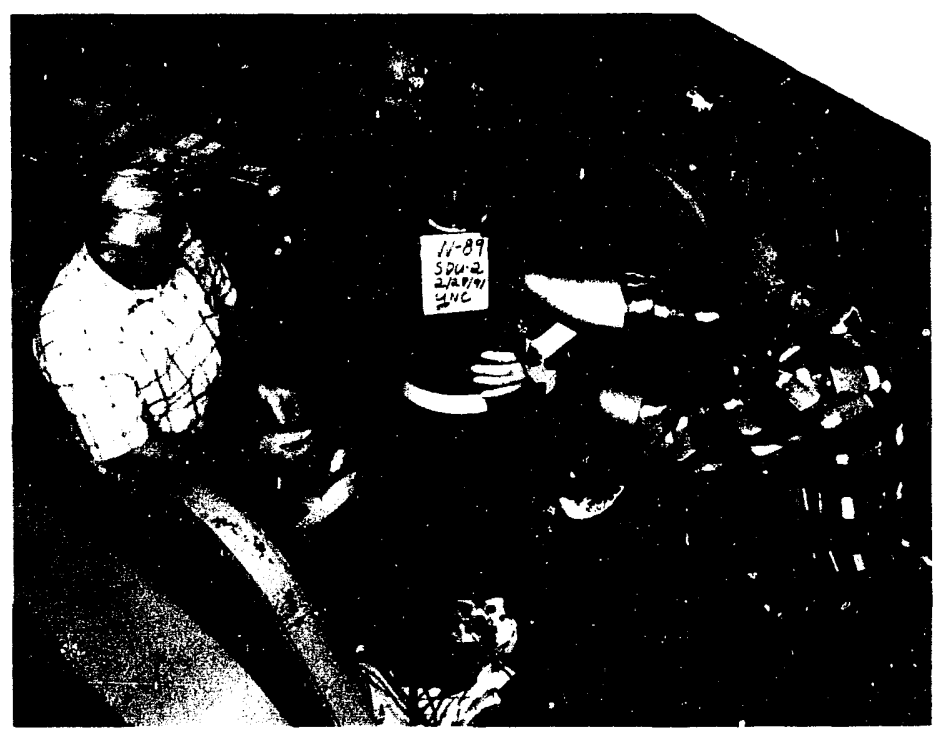

Figure 2. A mock warhead test unit (SDU-2) mounted on a machine that subjects it to vibrations like those it would experience in flight. Instruments inside measure the test unit's response. This unit has been subjected to specified vibrations, shocks, and temperatures. Aftcr ali the testing is complete, the unit will be disassembled and inspected for damage. 


\section{Research in Nuclear Weapon Safety}

$\mathbf{S}$ ince the beginning of the U.S. nuclear weapons program. presenting alcidents during peacetime operations has been of paramount importance. This concern is evidenced in the military service requirements for new nuclear warheads. Which give highest priority to the prevention of accidental nucleall vield. Such an accident has nerer occurred. Aroidance of nonnuclear accidents in which special nuclealr material. particularl! plutonium. is dispersed also is a high priority. but a few accidents of this type halle occurred. For example. aircralt crashes all Palomates. Spain. in 1960 and at Thule. Greenland. in 1968 caused the nonnuclear detonation of the weapons high explosive and the subseyuent dispersal of plutonium. No human injury is known to halle resulted from the accidental dispersal. hut the cleanup cons were very high. Concern over future such accidents II at a factor in the decision 10 abolish the praticte of maintaining strategic ancraft on airborne alert.

Orer the parst two decades. much effort has been deroted to reducing the likelihosed of accidental detonation of a nuclear weapon's high explosive, A very important ad ance was the development of insensitive high explosive (IHE) for the primaries (or ission triggers of the weapons. IHE will not detonate in at lire on ats a result of impated in an aircrate crash and is inert 10 smallarm- fire. Since the earl! 1980). IHE

Ensuring nuclear weapon safety is a top priority of our research, development, and testing efforts. Over the years, we have developed improved warhead electrical systems, insensitive high explosive, and fire-resistant pits. We are increasing our emphasis un safety still further and are working to design and develop intrinsically safe weapons.

has been incorporated in all new aircarried weapons. including the $\mathrm{B} 61$ and $B 83$ gravity bombs and the WS()-I cruise missile warhead: it hats also been incorporated in the warheads for the seat-launched cruis: missile (W8()-()). the groundlaunched cruise missile (W $8+$ ). the Pershing 11 missile (W85), and the Peacekeeper missile (W87). For all its IHE weapons. LLNL has also) developed a fire-resistant pit (FRP): the use of refractory materials to contain the molten fissile material prevents its dispersal in the esent of a jel fuel fïre. Significantly improsed designs for the safety of warhead electrical systems have also been implemented on all new weapons and

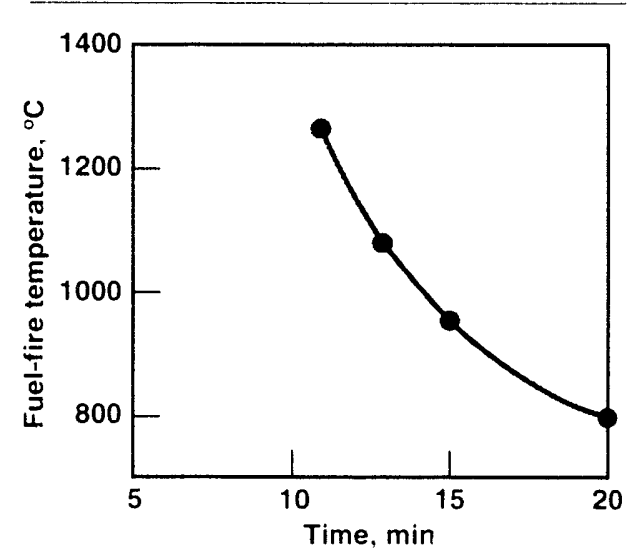

Figure 1. Time from ignition of the SRAM II missile motor as a function of temperature of the hydrocarbon fuel fire. The W89/SRAM II missile, which is carried on alert bombers. may be exposed to fuelfire temperatures of about $1000^{\circ} \mathrm{C}$ in an accident. The missile propellant. if ignited. burns at much higher temperatures of 2800 to $3000^{\circ} \mathrm{C}$. have been retrofitted onto some older systems.

Nevertheless. most warheads in the stockpile lack one or more of these modern safety features. In December 1989. the Office of the Secretary of Defense directed the military services to reexamine all the older stockpiled weapons and assess their salfety. Studies of several areas of weapon safety were initiated. including a review of transportation logistics and an assessment of the Air Force's Short Range Altack Missile (SRAM). After the SRAM A saffety analysis raised some serious concerns, the W69/SRAM A wals removed from alert aircraft in June $199($ ). Similar concerns within the DOE have led lo several active studies. and a Surety Program has been established to focus increalsed attention on research and development for weapon safety.

The House Armed Services Committer commissioned a panel. chaired by Sidney Drell and including John Foster and Charles Townes. wo covew the safely of the U.S. nuclear sieckpile. The panel conclud d its six-month review in December 1990. The Drell report assesses stockpile sately, recommends improvements (many of which hate alreads been implemented or are in progress). and suggests further salfely enhancements (including changes in process and safety criterial. In particular. the paned recommends: - Insemsitive high explosive (lHtes and lire-resistant pits in all arrcarried seapons. 
- A national policy review of ballistic missile systems with detonatable propellant near warheads without IHE and FRPs.

- Databases to facilitate safety assessments.

- Research. development. and testing efforts to develop intrinsically safe Weapons, that is. Weapons "as safe as reasonably achievable."

Although the Drell recommendations have not become official policy. we are actively studying the implications for current and future weapon designs. For example. the LLNL-designed W87 warhead for the Peacekeeper ICBM is currently the only ballistic missile warhead that includes IHE and a fire-resistant pit. We are participating on review teams with both the Air Force and the Nary to assess the implications of adopting such features on other ballistic missile systems.

We are also developing a general approach to analyzing weapon safety using probabilistic risk assessment. A complete risk assessment for a given weapon system includes

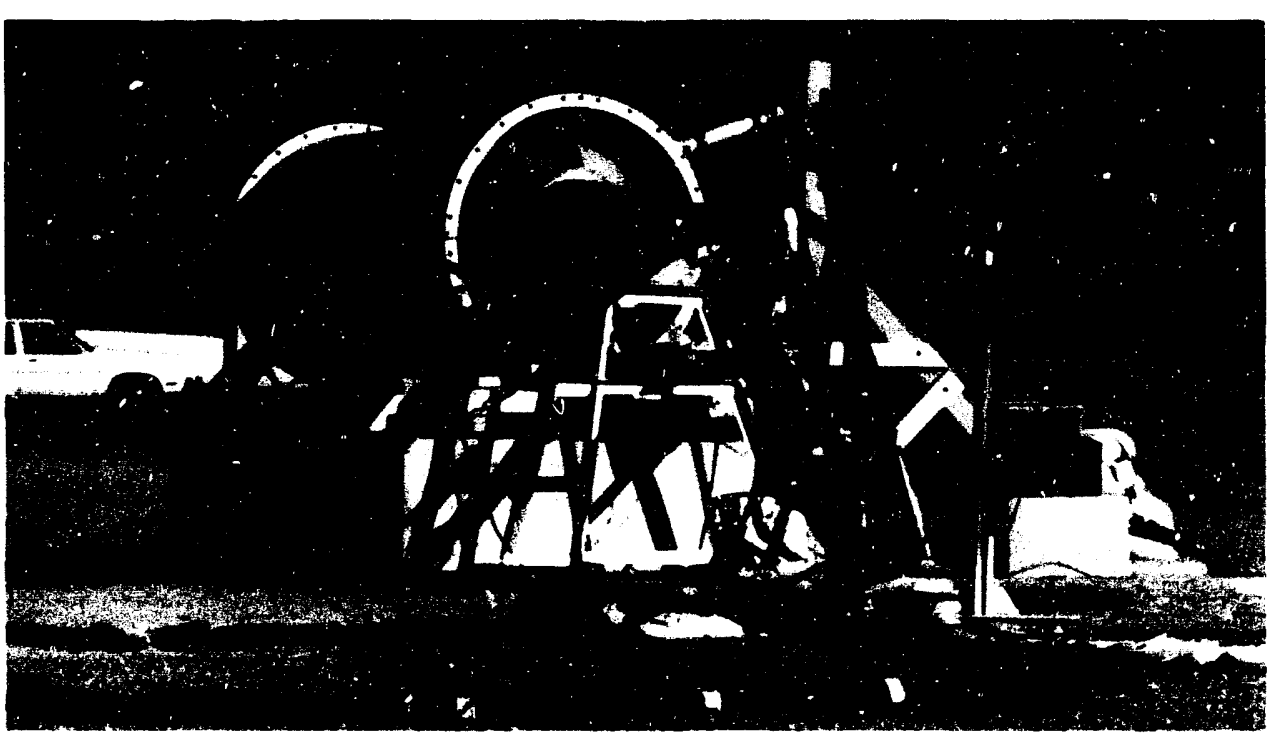

Figure 2. A simulated third stage of the Peacekeepe; missile and post-boost vehicle (in the canister) and a Mk 21 reentry vehicle with a mock W87, in prepai ation for an explosive test to determine accident environments and warhead response. analysis of the probabilities that various accidents could occur as well as calculations and experiments to define the environment (e.g.. temperature and duration of fires associated with each particular accident type. The weapon's response to the accident environment is assessed. and the consequences of plutonium dispersal are calculated using sophisticated air-transport computer models. Figure 1 gives an example of an accident environment calculation. showing the time for ignition of a SRAM II missile motor as a function of fuel-fire temperature. Such analyses help guide the design requirements for the W89 fireresistant pit by indicating how soon the warhead may be exposed to the much higher missile-propellant fire temperatures $\left(3000^{\circ} \mathrm{C}\right.$ ) in an accident begun by an aircraft fuel fire cabout $100\left(0^{\circ} \mathrm{C}\right.$ ).

In a weapon response experiment. a mock W87 warhead in a Mk 21 reentry vehicle was subjected to an exploding third stage similar to that of a Peacekeeper missile (see Figure 2).
The warhead behaved an designed: the IHE did not detonate and the mock pit parts were not dispersed as an aerosol. The hearily instrumented experiment yielded detailed information on shock pressures. temperatures. and the particle size and velocity of missile debris. Test results and subsequent analyses have been made arailable to the military services for their own safety review activities. We have used these results. together with further modeling. to show that a third-stage detonation of a Peacekeeper missile inside a silo would not lead to detonation of the warhead's IHE.

We are now increasing our research and development efforts to design weapons that maintain militar! viability with intrinsic nucleardetonation safety and plutoniumdispersal safety. Intrinsic safety is "designed in"--it uses design features instead of operational procedures to ensure a negligibly small risk of nuclear yield or plutonium dispersal in credible. abnormal environments. We are also considering warhead designs that are "multipoint safe." not just one-point safe. Such a warhead would not produce a nuclear yield in an accident. even if struck by multiple simultaneous fragments. Likewise. we are investigating designs in which it would he extremely unlikely to disperse plutonium in any credible. abnormal environment.

To ensure the success of these efforts. We require extensive computer capability to model warhead design. and accident scenarios. a plutoniumprocessing laboratory to conduct experiments. HE facilities for hydrodynamic chatracterization and formulation tests. test beds 10 evaluate weapon system response. and. most important. continued nticlear testing.

Contact: K. C. Johnsm $+415,+22-6.584$ 


\section{Nuclear Weapons Production Complex of the Future}

LLVL is heavily involved in DOE studies of the future nuclear weapons complex-studies that will have far-reaching implications for the character of the future facilities, the weapon design and production process, and the relationship between the design laboratories and the production plants. In parallel, LLNL is exploring new design approaches, technologies, and operating processes.
T he nation $:$ nuclear weapon.

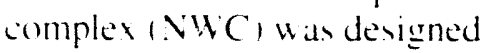
and huilt several decades ago and is in need of upgrading or replatement. In 198x. Congrew called for a plan for modernizing the $\mathrm{NWC}$. The resulting stud! considered such factors as population encroachment on presiously isolated production ites and the need to meet modern vandards for worker safely. environmental protection. and sitfeguard and security. However. it did not consider a number of recent issues of critical importance. including the changing international security environment and its implications for the requirements of the nuclear weapons stockpile. the markedly increalsed number of environmental latw and regulations that are expected in the future. and the decreasing NWC operational hudget.

Thus in September 1984. Secretary of Energ! Wathin established at Modernization Review Committee
(MRC) to reexamine the previous planning assumptions and to reassess the capacity and capability needed for the NWC. Six assessment teams developed projections for the size and characteristict of the future nuclear sockpile and for the environmental. safety. and health laws and regulations that could significantly affect the design and cost of the future NWC. These projections were then used to develop options for modernising the NWC and
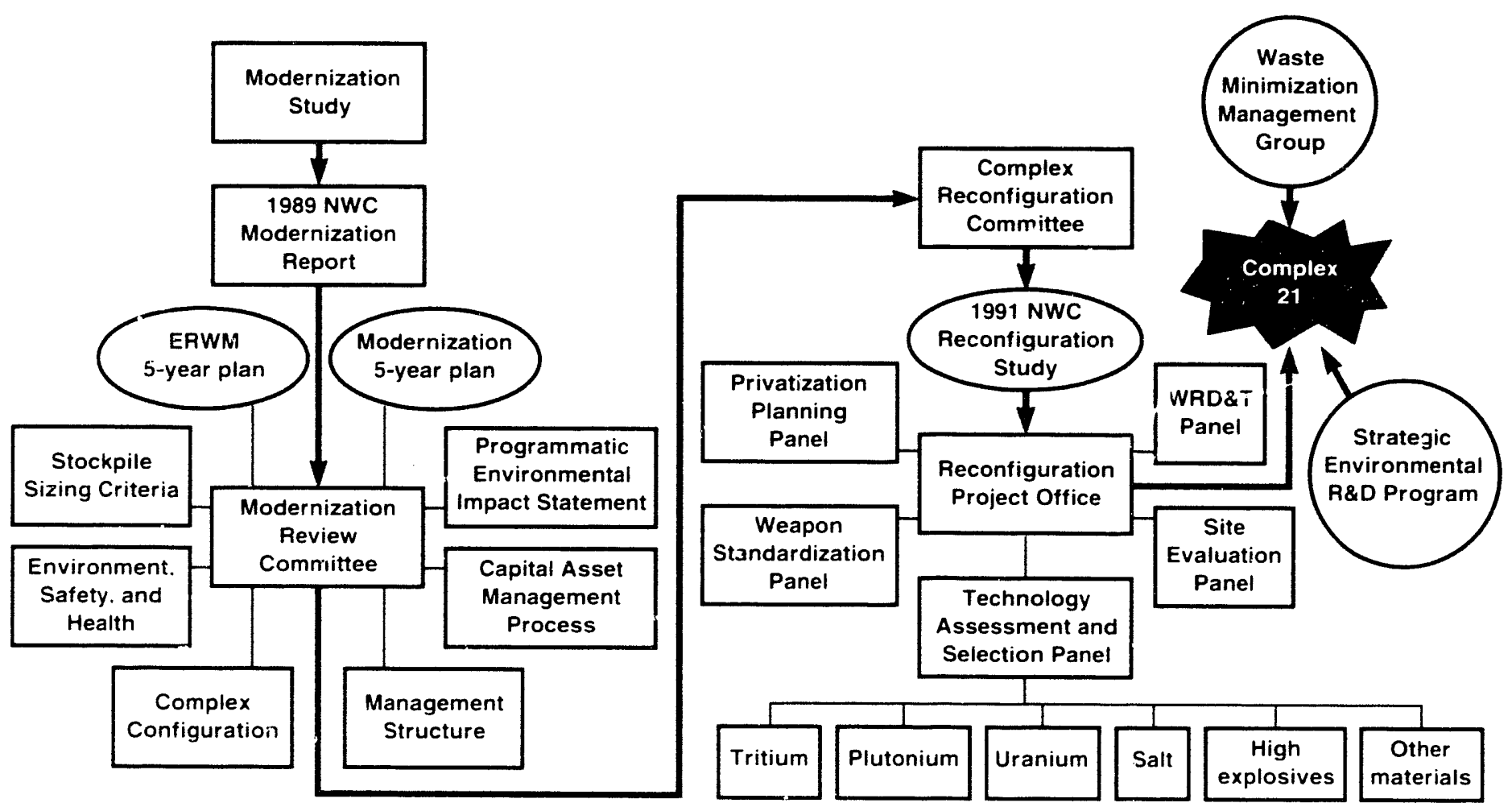

Figure 1. The nuclear weapons complex of the future (Complex 21) will be defined by the results of a number of interrelated studies. 
implementation strategies for several proposed changes. LL.NL participated on each of the teams and on the MRC itself. In August 1990. Secretary Watkin redirected the efforts of the MRC toward the reconfiguring of the NWC.

The "Nuclear Weapons Complex Reconfiguration Study" report. insued by the DOE in February 1991. describes several options for a future NWC. called Complex 21. that would be maller. less diverse. and less expensive to operate than the complex of todat and yet would still meet deterrence objectives. provide a degree of tlexibility to respond to contingencies. and comply with all applicable rules. regulations. and law-. Secretary Watkin preferred option is to relocate the Roch! Flats Plant. consolidate many of the other activities at one or a feu locations. and transfer as much of the nonnuclear manufacturing as possible to private industry.

Within the DOE. a Reconfiguration Project Office at an formed to oversee the Complex 21 planning procen idue to be completed by 19941. Panels are working to identify appropriate candidate site for the consolidated facilities. anses the impact of nonDOE production of most nonnuclear parts. explore was to reduce the number of independent nuclear weapon materials and processes to decrease production costs and facility requirements and examine way to consolidate activitie, shared by the weapon devign laboratories. One of these panels will be a semi-permanent hody to eraluate arailable and emerging lechnologien. Approximately a dozen I.L.XL people are sersing on the we panch: they are supported h! an elen lareer group of contributors from acrow the Laboratory. In addition. LL.XL is contributing to wher DOE efforts. wech as the Warke Minimization Management Group and the proposed Strategic Environmental $R \& D$ Program. that will influence the characteristics of the future NWC isee Figure 1). Much of the future work of LLNL in support of Complex 21 will be based on the work of these panels and other efforts.

Within LLNL. we are exploring several high-payoff design and technology concepts. The weapon design laboratories have "cradle-tograve" responsibility for the weapons they design. and through their designs they influence the specific technologies needed by the NWC. Even more important. however. the warhead design process itself offers a previously untapped potential for affecting future facility requirements. We expect that many of the anticipated regulatory changes will place stronger demands on the capabilities of the future NWC. Nell design approaches can mitigate the impact of these demands. Furthermore. the benefits of waste minimization and other operational improvements. achieved through new warhead design approaches and improved fabrication and processing technologies. can be folded together to provide the basis for future facility designs that are smaller and more efficient and pose lew environmental and worker satety risk than those designed according to current approaches. One that is of particular importance is plutonium processing and fabrication. operations are currently curtailed. and means of adequately treating many of the plutonium-related waster are not alailable. The reure of plutonium parts from retired weapons could sustain production in the near term w ithout the need for plutonium fahrication facilities. In the longer term. the development of designbaned on plutonium cart to tinal hape mat eliminate or significantly reduce the wate that resule from plutonium-machining proceses. This and wher devign approacher that de not call for the machining of plutonium can have a substantial bearing on the definition of the future facility capabilities.

Similarly. the consolidation of different types of alloys and enrichments of uranium and plutonium into a necessary few may have significant impact on plant design and efficiency. It appears likely that many of the regulations and problems that currently exist for plutonium will eventually apply to uranium and other weapon materials. Therefore. we are investigating a variety of material substitutions. including the use of other metals in place of depleted uranium for certain components. Designs that minimize tritium usage are also possible and could. in the long term. affect the sizing. cost. and strategy for acquiring new production-reactor capability.

There are also many research and development technologies that can be applied to plant reconfiguration. such as the plutonium-processing technology developed for special isotope separation (described on p. 34). Many of the technologien developed for fabrication and handling of plutonium can be applied to other materials as well. Automated production systems and integrated autonomous robotics systems will also have a significant impact on efficiency and safety.

Finally. it was recognized in the $N W C$ reconfiguration study that the seapon design laboratories need to take a more active role in the management of the production complex to increase their responsibility for the cost and manufacturahility of their design. We are currently exploring a wide range of option for achieving this goal.

(onfact: K. I). Wokinley $+15,522-8 / 5 \%$ 


\section{Nuclear Test- Experimental Science Program Innovations for Greater Quality, Productivity, and Efficiency}

We are aggressively pursuing innovations in experimental science and testing to improve the quality, productivity, and efficiency of our nuclear test operations.

A major component of the Viclear-Test Experimental Science Program mission is to conduct underground nuclear tests satels and in compliance w ith all applicable en ironmental. safety. and health standards. There experiments hatse erred to characterize the performance of nuclear derices. Concurrent with the erolution tou ard more complex experiments hat been the challenge presented by the decline in testing resources. Our reyponse has beento vrice for ever-greater efficiency and productis ity and to identify appropriate cont reduction so that progres and atd ances in experimental science can he sustatined.

While the emphatsis on yuality and productis ity gains hat an established history within the program. it is only recently that our efforts were expanded by the action of the Neradal Test Site (XTS) Planning Board. The planning Board is comprined of reprenentatives from the 1 teapons laboratories and the Defense vuclear Agency and erres an an ad inors board to the Mandeger of DOE, Verada operation. Thi Eroup chartered at comprehensive rudy of XTS attisities insolsing uners. contractors. and DOF staft. Twa keam-the Tene Operation Red iell Team IT(ORT) and the Support Operatem Reven Team ISORT) uere formed w stud! nearl! all CTS operation and on identify improsemente in operational yuality and efficienc! The kam hate made over $2(1)$ recommendations which afford ignificant cost reductions.

Four examples represent the progress that hats resulted from both internal LLNL efforts and collaborative work at the NTS.

Field resources can be conserved if events are conducted with multiple nuclear devices. One arrangement consists of a vertical array called a string of pearlss. In this way. We derive maximum benefit from our inventory of emplatement holes and the make efficient use of craft rescurces in preparing and supporting ground-zero operations. These benefits justify the added complexity of emplacement and the control of critical timing and firing signals.

For lears, the shock-mitigation ystems used to protect the sensitive recording instrumentation in the LL.NL. diagnostic trailers have depended on industrial-yuality foams. However. recent studies and field tests have heen aimed at adopting a Lon Alamos method that uses a honeycomb shockmitigation ystem. The TORT review confirmed that the honeycomb method offers cost salvings and higher reliability and simplifies the ordering. incentory, and testing of matterials. The net result should be higherquality shoch-mitigation ystems at reduced ocot.

TORT has recommended implementation of a four-diay worh wech for Mercur! operations at the XTS. Annual all ing in exces al
$\$ .50() .0(0)$ are projected with minimal impact on programmatic work. The four-day week will be tried for six months to verify the cost satings and identify any operational penalties. This study is typical of the collaborative effort being made to looh at new waly of doing business.

TORT has also recommended consolidation of NTS construction camps. All forward-area field construction support for both the Los Alamos and Livermore laboratories is being combined into one facility. This will allow the NTS contractors to manage their personnel more effectively and to staff to appropriate levels. It will also allow work to be conducted in facilities that meet all safety and environmental requirements and aroid the costs of upgrading aging and deficient facilities. As a result. operational costs will be reduced and unnecessary future costs aroided.

These innovations are typical of the improsements heing made to field experiments. Together with the technological adrances in experimental science. thes mathe possible signilicant gain in the oserall quality. productivity. and efficiency of our operations. In addition. they underscore our strong commitment to find and derelop new and imnoratise methods to conduct XTS experimeme and w full! comply with the applicathe em ironmential. safery. and health standard.

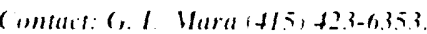




\section{Soviet Monitoring of U.S. Nuclear Tests}

A Ithough the L'S.-U.S.S.R. Threshold Test Ban Treaty (TTBT l limiting explosion yields to 150 kt was signeci in 1974. it went unratified for 16 years. in large part hecatuse of L'.S. concern over verifiability. L.S. negotiators pushed for on-site verification of nuclear tests. In June 199(), a Protocol outlining the processes and provisions for on-site verification was signed. and the TTBT. with its new Protocol. entered into force 11 December 1990).

The serification provision of the Protocol allows the Soviets to come to the Verada Test Site (NTS) for all tests w ith planned yields above $35 \mathrm{kt}$ and to conduct hoth seismic yield and hydrodynamic yield measurements on tests with planned vields over $50 \mathrm{kt}$ For events between 35 and $50 \mathrm{kt}$. yield is to be meatsured by national technical means. hut the Soviets are allowed to in rpect the geology of the test location and monitor test device emplatement. The seismic yield niessurements are carried out at Designated Seismic Stations at Tulsat. Oklahoma: Black Hills. South Dakota: and New port. Washington. The hydrody namic yield measurements are carried out in a satellite hole drilled $11-3 \mathrm{~m}$ from the derice hole. If the $S$ or iets exercise these rights at erery opportunity. there could be nearly continuous boviet presence at the NTS.

Becallue of the time and effort required to plan. corordinate. and implement the cerification activities allowed in the Proterol. the lesting part! mus proside nesification of

The L'.S. is entering a new era of nuclear testing. Soviet on-site inspection of U.S. tests will become the norm at the Nevada Test Site. An upcoming event will be the first $U$.S. test so monitored.

intent to conduct a test at least 2()) dals before the planned test date. This notification must specify the planned date. yield range. and location of the test. along with descriptions of the geology and geometry of the emplatement point. All tests with vieldsover $35 \mathrm{kt}$ and conducted at least 2()() days after 11 December 199() (the date the treaty entered into force) are subject to the provisions of the treaty. An upcoming event will be the first test to be so monitored.

Notified of our plans to conduct the event. the Soviets informed us that. on this first test. they intend only to log the emplacement hole and monitor explosive canister emplatement. To schedule the details of the Soriet activities at the NTS. a Coordinating Group Meeting (whose role and activities are defined in the Protocol) was held in Washington. D.C.. from I February to + March 1991 (Figure 1). The Soviets outlined in detail what Protocol provisions they intend to implement and what support they need. The key technical elements of their verification activities are 10 conduct gamma logs for stratigraphy. gamma-gammal logs for density. neutron loge for water content. and a caliper log of the hole. They also intend to monitor the emplacement of the explosite canister at the test location until it is irretriesably stemmed into place. Since this was the first-ever Coordinating Group Meeting. grealt care wats taken to outline all agreements in detail. The result wat an 87-page document outlining the coordinated schedule of activities (complete with 49 milestones) as well as $3+$ technical appendices describing in detail the conduct of key operations.

The Soriets arrived at NTS on 28 June 1991 for approximately 1 wo months. during which time they conducted their on-site inspection of the erent.

Contact: L. J. Ferderber ( $\$ 1.5)+2.3-7789$

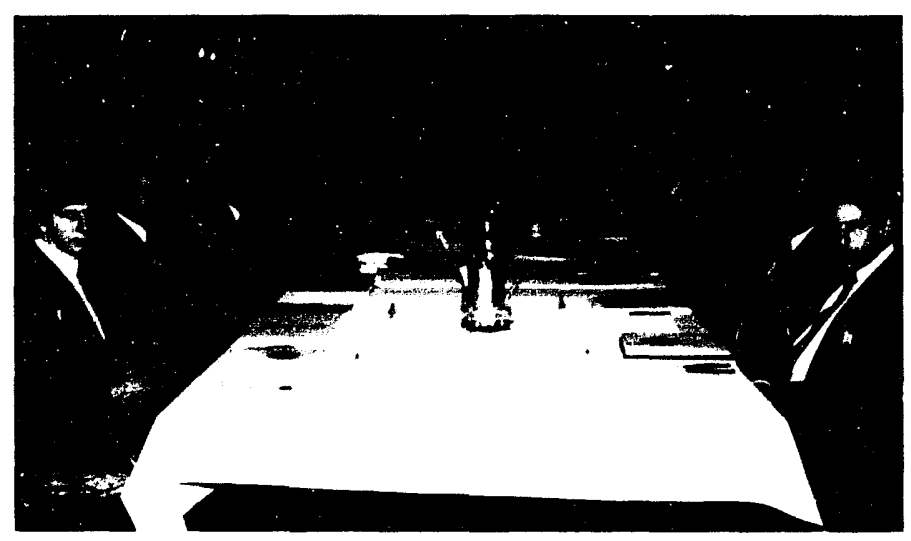

Figure 1. February 1991 meeting in Washington, D.C., of U.S. (on the right) and Soviet test experts to î Epare for Soviet monitoring of an LLNL event. 


\section{High-Explosives Testing}

$\mathbf{T}$ he High-Explosives Applications Facility (HEAF) and Site 3()() support the high-explosive needs of LLNL's Defense Systems Program. Small-scale testing and development of high explosives is done at HEAF. whereas larger-scale tests are done at Site 300 . HEAF is a new facility. dedicated in September 1990): Site 300 has been in operation for many years and is now being upgraded. Together. these facilities will significantl! enhance our highexplosice capabilities. improving the accuraty of the data obtained and increasing our understanding of high explosices.

\section{HEAF}

HEAF "as dedicated in September 1990) and is almost fully operational. The two remaining containment tanks 1+73-L capacity) and one additional major experimental capability-a 5()-mm-diameter gun sstem-will become operational next sear. Our HEAF studies focu on developing neu explosives and characterizing their performance and on fundamental studier of explosive behavior.

With HEAF. We are continuing our effort to sythesize high explosives w ith more energy than H.MX la widely uned high-energy explosive). Thi lear. We characterized a highdensit! polymorph of CL-2(). a new high-performance explosice that offers a potentially significant improvement in performance over H.MX-buned compositions. We

\author{
With the new High-Explosives Applications Facility and with the \\ recently upgraded Site 300, we are able to do important high-explosives \\ testing and development and to conduct large-siale tests of high- \\ explosive weapon components.
}

expect that CL-20 formulations will find applications in high-precision. shaped-charge munitions and metalaccelerating-fragmenting munitions.

We are also developing an explosive with the insensitivity of TATB (an insensitive high explosive) but with better performance characteristics. We have sinthesized and characterized a new. insensitive explosive $(H: X)$ that is predicted to be $10-15 \%$; more energetic than TATB: preliminary results from a series of small-scale sensitivity tests indicate that $\mathrm{HNX}$ has about the same insensitivity as TATB.

We are continuing efforts to formulate a paste extrudable explosive (PEX) based on HMX that will remain extrudable throughout its stockpile life and over the temperature range of $-5+\mathrm{to}+7 t^{\circ} \mathrm{C}$. We have developed a fracture-resistant formulation of HMX. TATB, and an energetic binder w ith about the same energ! an LX-17 la widely used insensitive explosive) and a much higher strain to failure (about $30^{c}$ ' is (j.3 c; for $L X-17$ ). We expect that this fracture-resistant formulation will also be classified as an IHE.

In addition. we are studying the chemical reactivity associated with the high-temperature, high-pressure combustion of energetic materials without detonation. Our goal is to understand the complex reaction path affecting an explosives performance and sensitisity. Ling a diamond-anvil cell (DAC) and pulsed-liser ignition. We can approsimate the condition that exist immediately behind the shock front in a detonating energetic material. By coupling pulsed-laser ignition of DAC samples with time-resolved streak camera records of the transmitted laser light. We measure the rate of propagation of the combustion front for deflagrating materials (e.g.. nitromethane. TATB. FEFO. HMX) at pressures up to 40 GPa. We have found. for example. a tenfold rariation in the propagation rates of nitromethane burn fronts from low to high pressure.

\section{Site 300}

At the open-air high-explosive test facilities at Site 300). located in the hills about $25 \mathrm{~km}$ southeast of Livermore. We test and evaluate the performance of the chemical highexplosive components in conventional or nuclear weapon systems (using substitute material for fissile components). Site 3()() has been used for decades. and substantial upgrades and improvements are being made for the Site 3()() Facilities Revitalization Project. This DOE-funded construction project is estimated to cost \$2 2.1 million and take at least four years to complete.

The Bunker 851 upgrade was completed this year. A new highspeed camera room and a new ballistic range were constructed. and we designed and installed a new safesy interlock stem and a new diagnostic and control ystem (D.ACS). The safety interloch sy stem 
is implemented with industry-proven technology and hased on current LLNL safety standards. All doors. run-sate boxes, status panels. etc.. are monitored and controlled by a stateof-the-art programmable logic controller system. The DACS is computerized to assist the operators with remow status indications and control functions. All routine hazardous operations are remotely controlled and/or initiated.

The technical and diagnostic upgrades planned to enhance hydrodynamic capabilities include: - Devejopment of a multibeam FabryPerot velocimeter system (Bunker 8.51). This system will enable experimenters to accurately measure changing velocities in a target at multiple points using laser and fiberoptic technology. The miltibeam Fabry-Perot velocimeter will provide designers with detailed velocity information. much as electronic "shorting pins" now provide detailed position information. This new information will tt ad to better calculational models for use in weapons design.

- Enhancement of the flash $x$-ray (FXR) machine (Bunker 8()/). The FXR upgrade will reduce the timeintegrated radiographic spot size. With improvements in the injector technology and in the alignment of the magnetic fields used to transport the beam. ve hope to reduce the spot

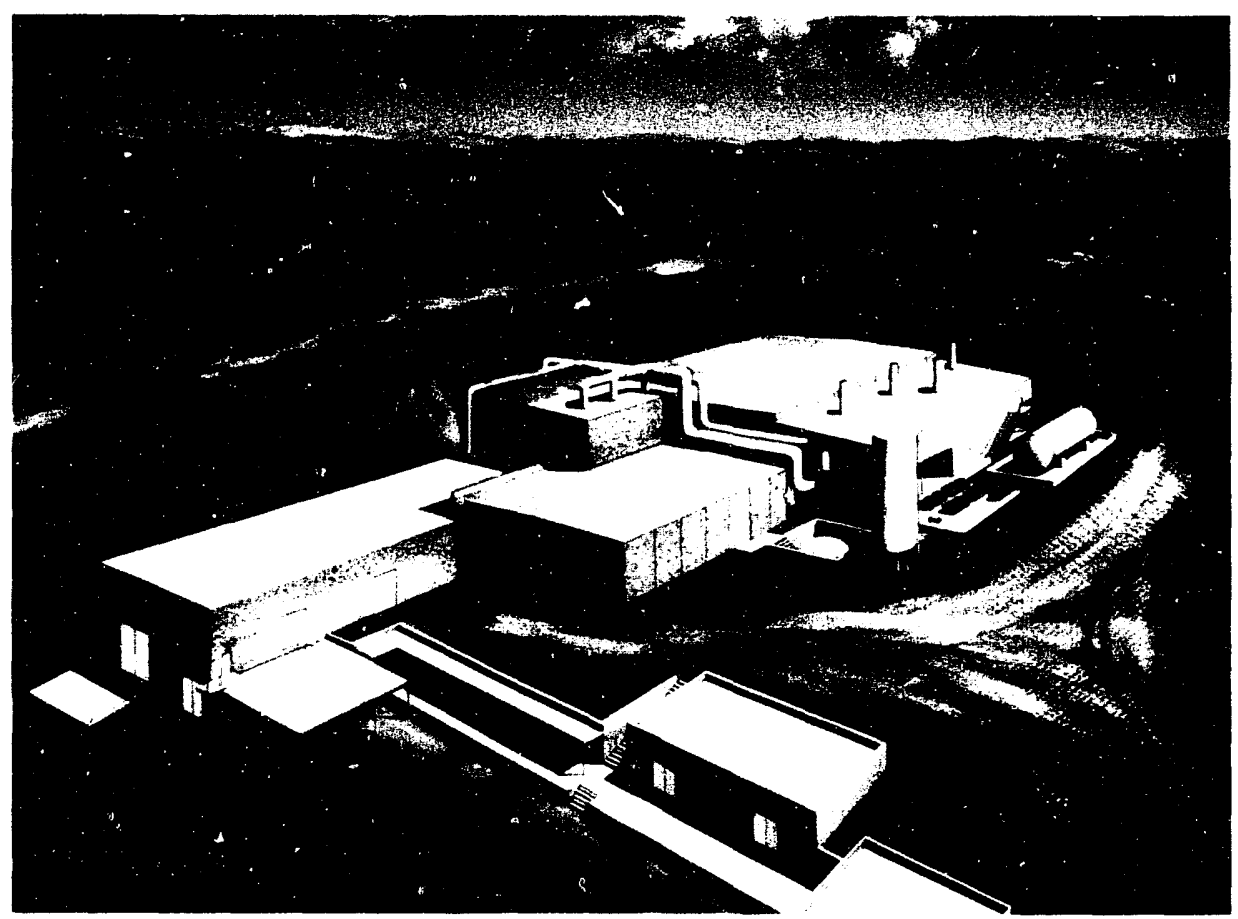

Figure 1. Artist's rendering of the Hydrotest Containment Facility. The existing FXR facility is the structure in the left foreground, and the existing Bunker 801 firing and other diagnostic facilities are located below ground level. The structure with the large piping on the roof is the proposed shot containment chamber, located at the target end of the FXR. The structure to the rear of the chamber is the support facility; it also houses the necessary mechanical utilities for the chamber itself. The structure to the right of the containment chamber is a new diagnostic facility. size to about half its present size $(2.4 \mathrm{~mm})$ while maintaining the current $x$-ray dose. This should yield significant improvements in resolution for radiographically imaging the center or core of the explosive test device.

Planned institutional upgrades for Site 3()() include:

- A new water supply from the City and County of San Francisco s Hetch Hetchy aqueduct. to be supplied by a new 240-m-long pipeline.

- On-site water system improvements. including $195 \mathrm{~m}$ of new piping and two new water storage tanks. one holding almost $800.000 \mathrm{~L}$ and the other over $180.000 \mathrm{~L}$.

- A new site entrance and 34() $\mathrm{m}$ of roadway improvements throughout the site.

- Construction of a new central control post and a new bunker support facility.

- Modification of another building used for high-speed optics work.

Also this year. we completed the conceptual design of the the Hydrotest Containment Facility. a containment system in which shots of up to $60 \mathrm{~kg}$ of high explosive can be safely tested (Figure 1). This facility will fully contain the gaseous and solid products of a hydrodynamics test in a new. completely contained firing chamber. to be constructed at the existing Bunker 801. When this contained hydrotest facility is completed, it will be the pacesetter in HE testing technology. It will minimize emissions of hazardous materials into the environment during and after explosive testing. reduce the amount of hazardous waste generated. and provide a safer work environment.

Contact: R. MI. Alire (+1.5) \$22-2419(HEAF) or R. (. Weingart (+1.5) +22-4.56.5 (Site 300$)$. 


\section{Mix Experiments with the Nova Laser}

M ix is the interpenetration of two materials at an accelerated interface that results from plasma/fluid instabilities growing from tiny perturbations or imperfections. Mix quenches thermonuclear burn and thus can have a severe effect on the vield of an inertial confinement fusion implosion or a nuclear device. We conducted a series of experiments with the Nova laser to measure the most fundamental property of the mixing layer-its width. Eight of Nova sen beams were used to drive a planar foil package composed of a polyphenylene sulfide (PPS) plastic ablator and a molyodenum metal payload joined by a smooth interface.

\section{We have completed an investigation of mix in radiatively driven planar interfaces and have embarked on a related study to determine how $x$-ray preheat affects plasma instability growth.}

The drive causes the plastic to ablate. which accelerates the mix packiage perpendicular to its interface. A planar shock propagates through the package. driving the instability and mixing the two materials; a combination of the shock and radiation from the drive causes the package (and the mix region) to decompress.

During the first $1.2 \mathrm{~ns}$, the mix package ablates and expands: then the shock crosses the metal payload and increases its density by a factor of 1.6. After this, the package decompresses to a point where it can be imaged and where the apparent mix width is large enough to be
Figure 1. Typical image data for two Nova shots, taken at $6.0 \mathrm{~ns}$ (a) and $8.5 \mathrm{~ns}$ (b). together with the corresponding density distributions and mix widths. The solid circles represent the maximum penetration depth of the metal into the plastic, and the solid squares represent the maximum penetration depth of the plastic into the metal.
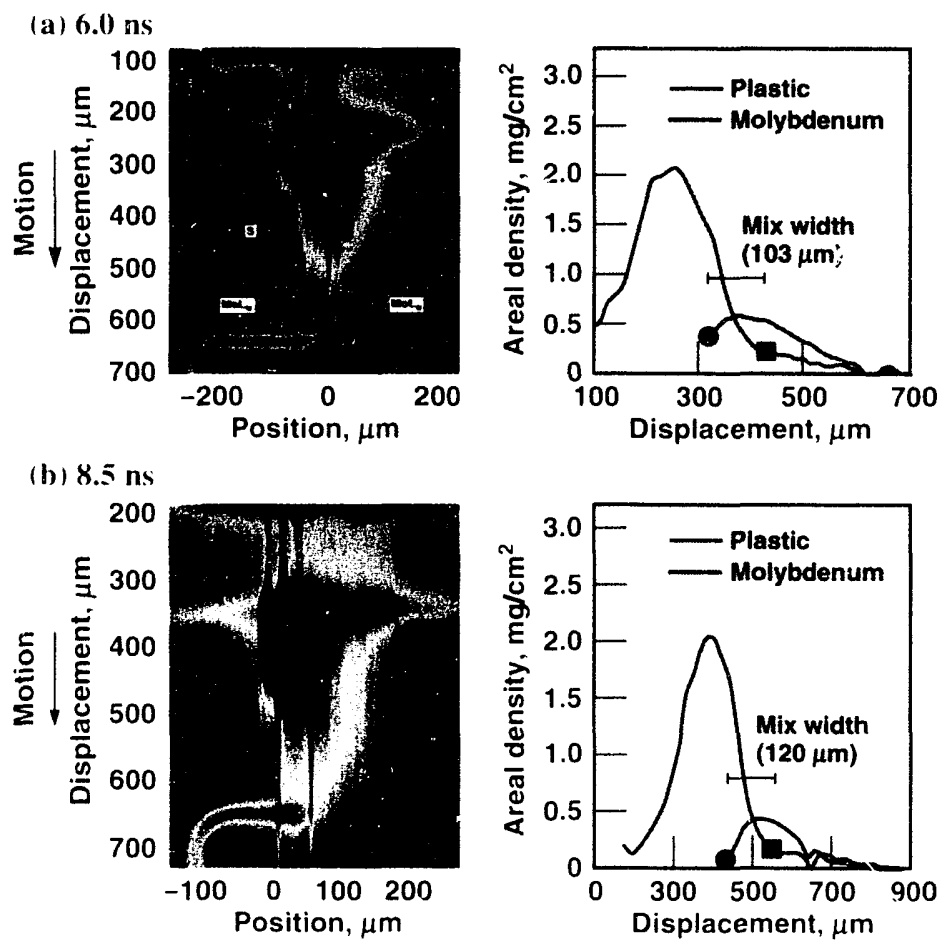

measured. Novals two remaining beams are then used to generate two point $x$-riay sources that image the mixing region and the entire package. Absorption spectroscopy is used to cuantify the mix width.

In our experiments, we measured the mix width resulting from a smooth interface. Image data from two different shot. are shown in Figure 1. where the vertical axis contains purely spatial information and the horizontal axis contains spatial information along with spectral dispersion. The features noted in the images are from atomic absorption in the plastic ablator (due to sulfur) and the molybdenum payload. from which we can determine the width of the mix layer. The images are shown in false color: blue denotes the highest transmission (open space). while green, yellow, red, and finally black indicate successively more opacue regions.

From these data we can determine the extent to which the materials have interpenetrated and mixed. This information is also shown in Figure 1. These images. obtained at different times, show the increase in mix width and density distribution with time. This experiment has provided a set of calibration data that will be compared with current mix model predictions. testing the various models in the regime attainable by using the Novalaser ats a driver.

(intact: J. I). Itolitoris $(41.5)+2.3-34 \%$. 


\section{Simulating Threats to the Security of Defense Assets}

Two interactive, real-time computer simulation codes-SEES and UCCATS-have been developed to evaluate site security and protecti"'?force tactics and to simulate combat in an urban terrain. Such simulations are proving extremely valuable in training military personnel and preparing for and supplementing live force-on-force exercises.
D elense assets- weapons. sensitive materials. facilities. equipment. and other high-ralue assets-hare become increasingly valuable largets for terrorists and potential adversaries and must be protected at deployment sites. in transit. and at storage depots. If even a few of these assets fall into the hands of terrorists. the results could be disastrous. (The use of a relatively few hand-held Stinger missiles by the rebel forces in Afghanistan had a major effect on the outcome of that war.)

Simulations developed by the Combat Simulation Laboratory (CSL) are finding increasing use for evaluating security for these important defense assets.' Live force-on-force exercises being people- and timeintensive. are expensive. and can be dangerous. CSL simulations can be used to prepare for and supplement live exercises: they can also be used to simulate attacks on a planned facility to evaluate its security integrity or to atsess the effect of modifications on

(a)
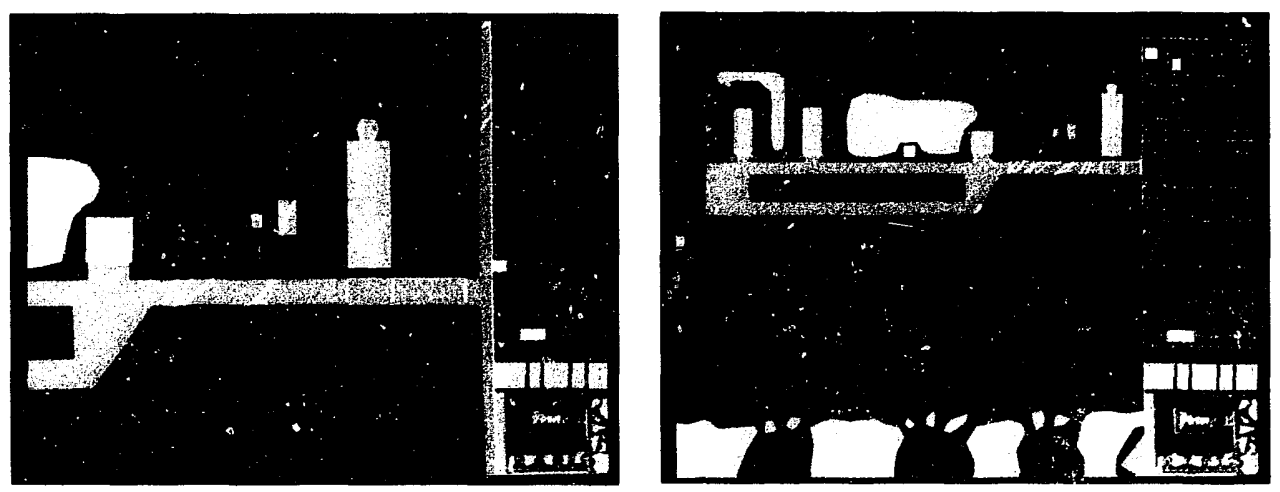

Figure 1. SEES simulation of an attack on a NATO training site: (a) blue view and (b) red view. (b)

protective-force tactics or siteprotection systems before time and money are invested.

CSL simulations model two-sided. force-on-force conflicts in a realistic. three-dimensional terrain at a high resolution that allows individual items to be tracked and distinguished. Janus. the first combat simulation code developed by the CSL. has become one of the armed forces" premier combat simulation tools (it was used in support of Operation Just Cause in Panama and Operation Desert Storm in the Middle East).

Two new systems hased on Janus can simulate attacks on defense assets at deployment sites. in storage. or in transit. The Security Exercise Evaluation Simulation (SEES) system. developed for the DOE, can model buildings. fences. alarms. and other security subsystems in some detail while retaining much of the basic Janus capability. - SEES supports a wide range of military and civil applications. including Special Forees

\section{b)}

operations. drug interdiction. alir-base defense. and weapons-depot security. SEES has been used to simulate attack on a site that is used by NATO for training protective forces (Figure 1 ). SEES is currently installed alt seven locations. includitio the DOE Central Training Academy. SEES has supported security exercises at LL NL.." and is being evaluated and validated by both the Defense Nuclear Agency and the Army Materiel Command as a site-security tool.

We are also developing the Lrban Combat Computer Assisted Training System (UCCATS). which simulates combat in a heterogeneous urban terrain: it expands significantly on the simulation capabilities of other urban-terrain models. Sponsors for this work include the U.S. Army Berlin Brigade. U.S. Army Europe. and USSOUTHCOM. UCCATS 1.0 was released in December 1990 , and version 2 .0 is scheduled for release in July 1991.

\footnotetext{
References

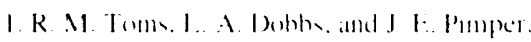

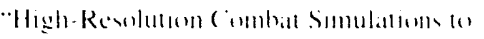

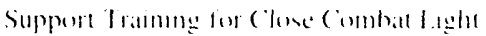

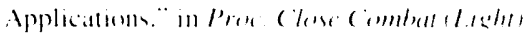

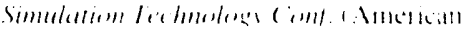

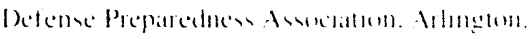

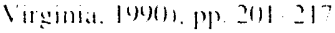

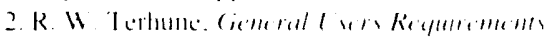

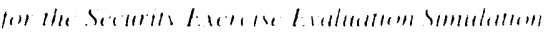

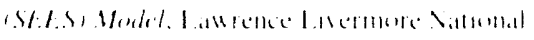

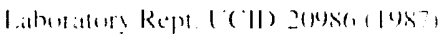

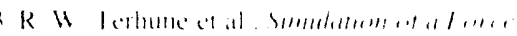

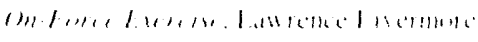

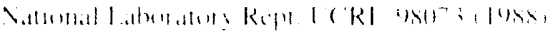

Contact: R. 1t. Tom ( $115,+2.3-9 \times 2.5$ 


\section{Advanced \\ Conventional Weapons}

We have developed advanced concepts, materials, and modeling capabilities that enhance the DOD's nonnuclear defenses. These new technologies also benefit the DOE in many areas of importance to the nuclear weapons program.
I n our work for the Advanced Conventional Weapons Systems Program. we are developing new computer codes, characterizing the behavior and performance of the various materials used in weapons. synthesizing and evaluating new energetic materials. and developing new types of anti-armor warheads and light and heary armor technology.

\section{Computer Codes}

Our experience in the development of hydrodynamics codes and the modeling of material response. gained in our nuclear weapons work. is directly applicable to advanced conventionali weapons. We hase generated 2D and 3D numerical simulation codes that accurately predict the hehavior of new weapon designs and can be run quickly enough to be an everydaly part of the design process.

Computer simulation of adranced conventional weapons requires hydrodynamics codes that combine high resolution with an ability to handle distorted material flow. Traditional Lagrangian or Eulerian methods can provide either good resolution or the ability to handle highly distorted flow, but not both. We are developing arbitrary Lagrangian-Eulerian (ALE) codes that combine the advantages of both methods. Our 2D code CALE is being distributed to the defense community, and our 3D code ALE3D is currently under development.

Computer modeling is essential in our work to develop the free-form shaped charge. We are using our ALE codes to develop a new type of shaped charge that implodes to form a jet with a very high tip velocity and a high mass efficiency, and thus should have better penetration than a conical charge (high tip velocity. low mass efficiency) or a uniform hemicharge (moderate tip velocity. good mass efficiency).

We also use computer codes to evaluate warhead design modifications. For example. the penetration-augmented munition (PAM) is a lightweight and portable multistage conventional munition designed to defeat a heavily reinforced concrete bridge pier. We are developing a rebar-culting charge that will make the PAM a still more versatile munition. On the basis of ALE simulations of several explosivecharge concepts. we selected two promising candidate designs. Actual tests were then conducted to determine the best design.

We also use computer simulation to study kinetic-energy projectiles. We recently developed a kineticenergy projectile that extends in flight. In-flight extension is desirable because longer projectiles penetrate targets better and shorter projectiles are easier to launch. A projectile that lengthens after launch therefore satisfies both objectives (Figure 1). Extending projectiles have been flown at velocities up to $2 \mathrm{~km} / \mathrm{s}$.

\section{Material Characterization}

To simulate and design structures that undergo large dynamic loads (e.g.. shaped-charge warheads. (a)

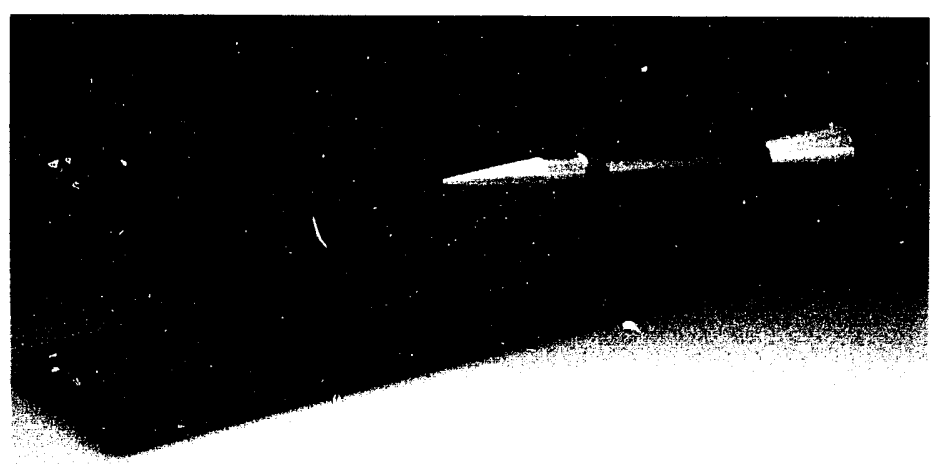

(b)

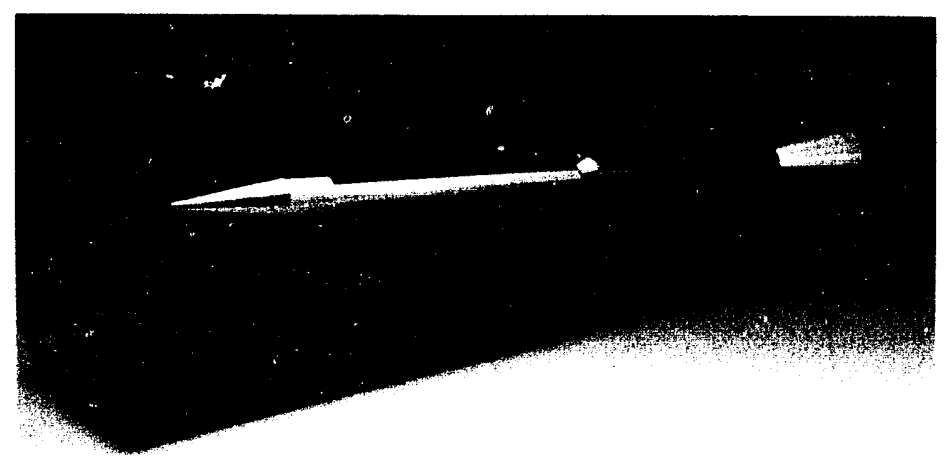

Figure 1. The extending projectile before (a) and after (b) launch. 
penetration/demolition munitions). we must be able to describe the physical properties of their component materials over a wide range of temperature. strain. strain rate. and material conditions. In particular. We need accurate models for predicting the behavior of metal liners in the design of shaped charges and explosidely formed projectiles.

Man! experimental studies have been performed to determine the effects of shoch loading on the microstructure of various metals. alloys. and examics. Mechanical testing is pertormed on shock-loaded materials over a wide range of strain rattes and temperatures. The test data are then used to develop more accuratc comstitutive models. We are exploring how shoch-induced changes in mechanical beharior affect a material s ductilits and how shoch loading affects the fracture hehas iof of metals: this mat prove valuable in selecting and processing liner malerials.

\section{Energetic Materials}

He are working to sy nthesise new insensitice explosives it ith hetter performance than TATB as well as new energetic compounds with more encerg! than HMX. Our groal is to developexplosises that are sater to handle and yor and less vulnerahic to hattlefield hatatrds (c.g.. sympathetic detomation. fire. fragments witheut salcrificing performance or increasing coms. Our I ulnerabilit! studies hate established correlations between the intensily of explosive response and the specific material charatioristic of a high explosire.

Ho hate recents demonstrated a low-cost relative high-pertormance explowe called lostex that meet the militars reyurements lor vou

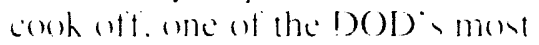

stringent satfely tests. 1 Conte off is at measure of the abilits of a munition to withstand exposure to radiant heat.) LOVEX is an excellent candidate for mass-use munitions that meet new requirements for explosice salety.

New high-energy-density materials (HEDMs) are being sought. The highenergy phases of horon and carbon appear to be promising candidates. HEDMs maly also be found in nuclear shape isomers that do not fission but release energy in the form of gammal rals without residual radioactioity. Calculations were done to predict candidates: some hale been verified experimentally. and their lifetimes hate been calculated to be longer than thousands of years.

\section{Armor/Anti-Armor Technology}

He develop new anti-armor warheads and new types of armor. Boron carbide/aluminum cermel la ceramic-metal composite) is five times more crack- and shatterresistant than contentional ceramics. Cermets hate demonstrated an unprecedented eombination of hardness. toughness. and lightness. and appear to be especially promising for adranced lightweight armor.

We are also studying wass to defeat new and existing ypes of armor. He are investigating the elfects of ad anced core bullets on monolithic. spaced-arra! . and ceramic-composite lightweight armor stems Tests hate revealed that the spared-anrat : 1 rmor system uned in sole current light combalt vehicles can he perforated by a "lesser" threat than it was designed to defeat. In addition. "we have developed ad anced multicomponent penetrators that hou execllent performance agations barious armor y yems

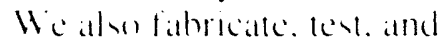

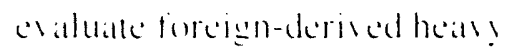

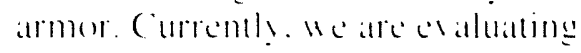

the erminal ballistic performance of a steel-alloy armor and four types of hear! ceramic armor. Our hallistic experiments are performed at laboratory scale with heary metal. kinetic-energy penetrators fired at ordnance specels as well as with precision shaped-charge warheads placed all sypical missile/projectile standofts from the armor.

\section{Other Tactical Technology Activities}

As part of the Temperature Evaluated Mine Position Survey project. We are developing ways of producing real-time-corrected surface temperature maps of buried. covered. and exposed land mines from an airborne system. Various methods can be incorporated to increase detection and reduce false alarms.

For antisubmarine wattalle. We are investigating several techniques to enhance submarine detectabilits. These include repeatable highpower. low-frequency acoustic projectors. signal processing using neural nets. sate long-life power generation for unmanned underwater vehicles. and reat-time computation using malched-field processing for the High-Gain Initiatios.

We are also investigating torpedo warhead lethalit! and submarine vulnerability. Analytical models used in conjunction with the danus battlefield simulation computer code provide independent estimattes of the military utility of selected munitions for land. seat. and air wartare. Amome these toapons are the Army is terminal-guided warhead. sense-anddestros armor (SADARM) submunitions.

(ontact: 1). Finger $(+1.5)+22-6.376$. 


\section{Arms Control and
Treaty Verification \\ Arms Control and
Treaty Verification}

$\mathbf{L}$ LNL: Treaty Verification Program is hearily involved in all active areas of arms control-the Nuclear Testing Talks (NTT), the Strategic Arms-Reduction Talks (START), the Comventional Forces in Europe (CFE) treat! the Chemical Weapons Convention (CWC), the Conference on Disarmament (CD). and the Defense and Space (D\&S) negotiations. The NTT ended at significant phase in June 1990 with the signing of the Verification Protocols to the Threshold Test Ban Treaty (TTBT) and the Peaceful Vuclear Explosions Treaty (PNET). Currently. the Bush Administration has completed START and is preparing for negotiations on shortrange nuclear forcen (SNF).

\section{Nuclear Testing Talks}

Liast sear. We provided important support for the DOE during the ratification of the Verification Profocols lo the TTBT and PNET. Drawing on our expertise in xeismolog! hydrodynamic measurements. and decision analysis. we helped define provisions of the Protocols and draft appropriate treally text.

He are also hearily involved in implementing these Verification Protecol. Wie contributed to the l's.-Sor iet resiew of the designated reismic stations that will be used for

We work with the $U$.S. verification and intelligence communities to provide the technologies needed to verify and monitor treaty compliance. Our support includes work on seismic monitoring, tagging, nuclear detection, directed-energy detection, and chemical sampling. We also forecast technology requirements, provide the Washington community and delegations with information about what technology can and cannot do, and respond rapidly when specific system requirements are identified by the negotiators.

monitoring the TTBT. and our seismic equipment for monitoring multiple peaceful nuclear explosions is being sent to the Soriet Union. We are serving as advisors for the coordination of the upcoming Soriet presence at the Nevada Test Site for the Hoya Event. We are part of the team that will carry out hydrodynamic measurements in the Soviet Union. In preparation for these and other verification interactions with the Soviets. 27 LLNL employees have completed the On-Site Inspection Agency"s training for inspectors.

Among the research achievements this year are state-of-the art advances in the application of neural networks to test-ban verification. Neural networks were successfully applied to the problems of yield estimation and discrimination. clearly demonstrating their value for applications in which large amounts of data are available for training sets. These applications were made possible. in part. by the development of an algorithm that greatly increases computational speed.

The U.S. government has committed to negotiations on further steps in nuclear testing limitations. The DOE and other government agencies are studying what next steps in nuclear test linitations would be in our national security interest. In support of these studies. we hatre assessed alternative test limitations and confidence-huilding measures. with particular focus on the impact that changes in the yield threshold would have on nuclear design options.

\section{Chemical Weapons Convention}

The U.S. is involved in complex negotiations on a CWC as part of the 3()-nation Conference on Disarmament. In addition to abolishing the use of chemical weapons, this treaty calls for the destruction of all current CW stockpiles along with a han on new production. Verification will require inspection and monitoring of commercial facilities producing possible $\mathrm{CW}$ precursors. The large number of treaty-limited items and the complexity of facilities involved make the CWC the most lechnically challenging treaty to implement.

We are working with DOE's Office of Arms Control to define and implement applicable technology. and are participating in the U.S. National Trial Inspection program and the International Round Robin Experiment to determine the needed technology. Our work includes evaluation of chemical analysis techniques for on-site inspections. Gas chromatography-mass spectrometry appears to be most useful. although other spectroscopic. chromatographic. and electrochemical methods are also being evaluated. In addition. We are investigating nondestructive evaluation methods. 
including a neutron interrogation technigue and a fregueney-response measurement technicue. io rapidly verify CW stockpiles. Reliability. sensitis ity, specificity. portability. and cost will he critical. Other technologies atre being investigated for possible remote monitoring. Technologien dereloped for the CWC maly also find application in the L:S.-Sovict Bilateral Chemical Weapons Treat!. currently under negotiation.

\section{Strategic Arms-Reduction Talks}

For START. our main focus has been on developing verification regimes and the technologies needed (1) implement them. Central to these efforts are the intelligence capabilities of the Laboratory is Special Projects Program and the decision-analysis capabilities dereloped by I.LNL's Engineering Kesearch Disision.

He have heen developing lechnologeies in two atreas. hoth of which are useful for on-sile inspections. The first is lages and seals. Whereby each treall-limited item would have a unique or nonreproducible identifie: permanently attached to it for inventors control and to mark it as a legally produced item. L.LNL has developed two tage concepts: a passive electronic tage and a fiber-optic tag/seal. In addition. we are doing adiersarial analyses to detect possible flaw and to identify wass of cheating or spoofing other tags developed for the DOE.

The second technology effort uses radiation detection. Some treaty verification regimes may require counting of the number of nuclear warheads present on a missile. The verification techniques used must have minimum impact on operations and on the facility and must pose little chance of revealing sensitive information. The LLNL-developed gamma-ray imaging system (GRIS) can count nuclear warheads at a distance and through intervening materials. GRIS is an array of miniature. coaligned gamma-ray cameras: it uses the intrinsic emissions from a nuclear weapon to form a crude image of the weapon. We have built a four-camera demonstration prototype of a GRIS warheadcounting system. Last December. He conducted a successful pöootof-principle test using this system to image the ten warheads in an operational Peacekeeper missile without entering the missile silo.

\section{Arms Control Studies}

The DOE has prepared a report w) Congress on the verification of warhead dismantlement and the control of special nuclear material possible in future treaties. We are responsible for the section on warhead dismantlement: we have developed a verification framework and have assessed the impacts on DOE $;$ mission for warhead design. modernization. and production.
We also eompleted a number of policy-guidance studies for the DOE Office of Arims Control. One of the most important considerations is the potential effect of arms-control meat ures on crisis stability and deterrence. To give this study a realworld focus, we considered various future cuts in U.S. and Sovict strategic nuclear forces as discussed in START. We included estimates of the effects of polential strategic defenses as well as hypothetical technological breakthroughs. Our results were incorporated in a paper reporting on a bilateral discussion of the changing U.S.-Soviet strategic balance.

In other papers. we examined NATO nuclear-related issues. We studied the new equilibrium about to result from the changing Soviet military presence in Eastern Europe. and examined the implications of German reunification for U.S. military forces in West Germany. For two other studies. We explored the future roles. missions. and force postures of U.S. battlefield and nonstrategic nuclear forces. Finally, in order to identify and characterize as precisely as possible upcoming changes or trends. we have been monitoring the European and Soviel open literature. focusing particularly on identifying and amalyzing the current Soriet views about nuclear weapons.

(ontact: I). W: Dorn (+15) $+2.3-5196$. 


\section{Laser Research}

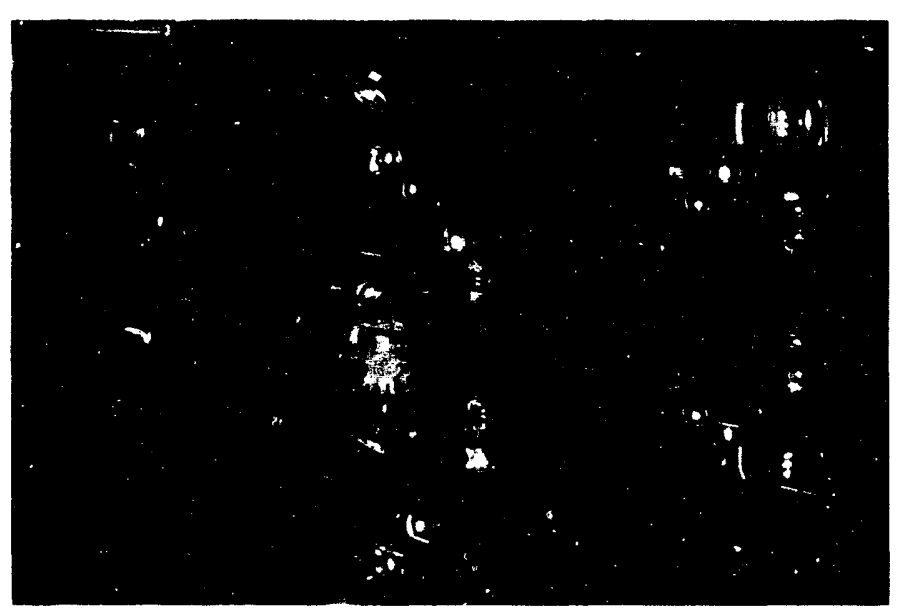

\section{The Laser Programs conduct research in directed energy, electro-optics, quantum electronics, laser-matter interactions, and materials processing, as well as for a wide spectrum of laser applications (such as the U-AVLIS dye laser shown) for the defense, industrial, and scientific sectors.}

W e have made important progress this past year in each of our five major programmatic areas: inertial confinement fusion (ICF). uranium atomic vapor laser isotope separation (U-A VLIS), special isotope separation (SIS), laser technology, and advanced applications.

The ICF Program mission is to develop and demonstrate the science and technology to establish that significant fusion energy yields can be achieved in the laboratory. 10 identify applications for $\mathrm{ICF}$. and to develop the most promising of these applications. ICF has defense applications in studies of atomic physics. radiation transport. and hydrodynamics important for weapons design. in simulations of the effects of nuclear weapons on hardware that must function in a nuckar enviromment, and in investigations of the hasic principles of advanced weapons concepts. ICF has a potential energy application ats a source of electrical power.

Before ICF can fulfill its promise. we must achieve net fusion gain (i.e.. the energy produced exceeds the driver energy). Experimental results obtained with our Nova laser indicate that a laser driver delivering 1 to $2 \mathrm{MJ}$ of energy could demonstrate fusion ignition and propagating burn leading to net fusion gain in the laboratory. We have developed a design for upgrading the Nova laser to the 1- 10 2-MJ level. Preliminary design estimates indicate that this upgrade would cost less than $\$+(0)$ million, and the five-year construction project could begin in 1994. The National Academy of Sciences and the Fusion Policy Advisory Committee issued tinal reports in 1990) strongly endorsing our Nova Upgrade initiative 10 demonstrate ignition and modest gain (2 10 10 ) before the end of the decade.
Our U-AVLIS Program is developing the most cost-competitive process for enriching uranium for civil nuclear power plants. This program is key to revitalizing the U.S. uranium-enrichment enterprise and to restoring and maintaining the U.S. position in the multibilliondollar-per-year international enricheduranium market. The AVLIS process was demonstrated at moderate scale several years ago. Since then. we have been developing highly reliable. costeffective. plant-scale lasers and separators. Secretary of Energy James D. Watkins submitted a "Plan for the Demonstration, Transition, and Deployment of U-A VLIS Technology" to Congress in January 1990) that calls for demonstration of the integrated AVLIS processes at plant scale. gathering of supporting technical and economic data for deploying a production plant. and expansion of the role of private industry. 
We have prepared the necessary environmental and safel! documentation and are completing uperades and modifications of facilities lasers and separator equipment to begin the demonstration tests in rate 1991. Concurrently. We are completing a detailed conceptual design and cost report for an enrichment plant that will use our AVLIS technology together with the uranium-processing technolog! developed by Martin Marrietta Energy Sy stems. On the basis of these demonstrations. Secretary Watkins will decide whether to authorize construction of a $\mathrm{L}^{-}$-AVLIS production plant.

We have incorporated the SIS Program and programs funded by the DOE Office of Technolog! Development. through LLNL $:$ Environmental Technology Program Ian automation and robotics program and several waste-minimization and "Iaste-treatment projects) within a new program area called Adranced Processing Technologies. As the SIS Program nears its completion at the end of the 1991 fiscal year. continuing work in plutonium processing and automation technologes is being focused on minimizing waste and is orter radiation exposure and on increasing process efficiency and plutonium utilization. Several accomplishments of the SIS Program. including plutonium electrowinning (which convers plutonium oxide to metal with minimal waste) and the tilt-pour furnace (which eliminates the ileed for consumable ceramic crucibles in plutonium processing) are directly applicable to this new focus. In addition. improved technologies are being diveloped for custing. mollen salt extration. electrorefining. and residue processing that all help minimize plutonium waste steams. He are al o engaged in at joint robotice and alutomation effort with IBNI to mechanis glovebox operations.

The Laner Technologes Program supports research. development. and deployment of the $L^{-}$-AVLIS and SIS processes. It also supports alternative applications of laser technologies. including the copper lasers. the process dye latsers. and the computers. networks. and controls. We hatie made significant progress in developing and demonstrating adranced and more-powerful copper lasers $(>150)$ W/chatin). more-powerful dye laser chains $(>1250 \mathrm{~W} / \mathrm{chain})$. and computer and control systems. We are continuing to collect reliability data for the copper lasers: more than 1.6 million device hours of copper-laser operation have been accumulated at the Laser Demonstration Facility. To support the plant-scale L'-AVLIS demonstrations planned for 1992. optical transport systems (including sophisticated fiber optics) and control systems have been designed and are being constructed and tested.

Last year. the National Academies of Science and Engineering reviewed alternative applications of the AVLIS technologies as requested by Secretary Watkins: the report is due to be released in late 1991. Currenty. AVLIS lechnologies are heing used in projects in next-generation microlithography and materials processing as well as in atmospheric correction of astronomical telescopes. These efforts are being pursued jointly with L'.S. industric's and universities.

The Adranced Applications Program in developing and demonstrating advances in three principal areas: solid-state laser and electro-optic technology. imaging and signal processing technology. and charged-particle beam and accelerator technolog!. This year. we demonstrated for the first time that near-diffraction-limited images of carth sillellites can be reconstructed with ground-based telescopes. Record-kevel optical power produced by semiconductor laser-diode arra!? hats been demonstrated. These arrits hare been used to pump a solid-state laser hout. A high-illerige-power. diode-pumped. solid-state laser is now operating in our laboratory.

The first phase of a lechnolegytransfer project with a major acrospace company has been completed with the laboratory demonstration of a very small. diode-pumped. solid-state laser. In addition. within the year. we will complete the transfer of technology for a flashlamp-pumped solid-state laser to a commercial firm for use in an x-ray lithography system. We have also initiated the development of high-power microwate sources using linear induction accelerators. Initial demonstrations indicate high promise for this technology. Such high-power microwate sources can be used for tokamak heating and for surveillance applications.

Over the past 19 years, the scope of LLNL: laser research has grown immensely. The small-scale. lewpower laser systems of our early days hate given way to high-power. high-reliability. record-hreaking laser facilities of plant-prototype scale. Numerous LLNL-dereloped laser technologies hate attracted a broad customer base within the DOE and DOD. and others are being transferred (1) prisate industry. We expect that within the next few years. our efforts will culminate in the commitment to construct a uranium-enrichment production plant. a major upgrade of the Nona laser facility to demonstrate ignition of deuterium-tritium fusion fuel. and transfers of technology for x-ray lithography. submarine communications. and optical imaging.

(ontact: J. I. Daris $1+1.5)+2.3-941.5$ or 1. I. I.ey $(+15)+23-8730$. 


\section{Nova Upgrade}

$\mathbf{T}$ he mission of the national Inertial Confïnement Fusion (ICF) Program is to establish the feasibility of achieving significant fusion energy yield in the laboratory. and to develop that capability to meet the requirements of major defense applications. In recent years LLNL has made very substantial progress toward achieving these goals in the Nova program and in underground nuclear tests (Halite-Centurion). Accordingly. the DOE. in 1987-88. requested designs for a defense applicati ns facility that could achieve fusion energy vields of log) to 100) MJ. The Laboratory Microfusion Facility (LMF) would surpass any present or planned above-ground facilities for evaluating nuclear weapons effecti, and assessing the vulnerability of U.S. weapon.. sysiems to nuclear threats. The LMF would also significantly augment underground testing and would be invaluable should underground tests be halted. LLNL has proposed an experimental facility that would meet the needs of most defense applications: a 5- to (1)-MJ. ().35-um. neodymium-glass laser driver and target capable of fusion energy gains of up to 100 with yields up to 1000 MJ.

In 1989-90). having extensively reviewed the ICF program. the National Academy of Sciences (NAS) and the Fusion Policy Advisory Committee (FPAC) recommended a focus on achieving fusion ignition in the laboratory before undertaking the L.MF. On the basis of target physics from Nova and the Halite-Centurion series. LLNL has determined that an upgrade of the Nova laser to an

\section{Current achievements on the Nova laser promote the next step toward the goal of 100- to 1000-MJ fusion entrgy yields}

energy of 1 to $2 \mathrm{MJ}$ at a peak power of $>500 \mathrm{TW}$ could achieve ignition and modest gain (2 to 10 ). From that point. extension to the high gains $(>50)$ needed for many defense applications is straightforward. Demonsirating ignition and gain is thus the final step in establishing the scientific feasibility of ICF. Both the NAS and the FPAC have strongly enciorsed the Nova Upgrade as the optimal path to achieving that demonstration.

Nova Upgrade's experimental capabilities will encompass such defense applications as weapons physics research. simulating weapons effects, developing instrumentation and diagnostic methods for nuclea testing. and exploring advanced weapons concepts. In a series of meetings sponsored by the Defense Nuclear Agency. ICF's potential significance in nuclear weapons effects testing was clearly established. The LMF would test for effects from four sources: hot $x$ rays, soft $x$ rays. short-pulse neutu!ns. and gamma rays and neutrons combined. Issues associated with each area have been identified and can be addressed by Nova Upgraris' experiments using the 1- to 2-MJ laser itself or fusion yields of up to $20 \mathrm{MJ}$ fro.: ICF targets. These higher energies allow moredetailed experiments than Nova allowed. with longer pulses and larger samples. Nova Upgrade could also accomplish proof-of-principle experiments to validate the utility of the LMF and other defense applications facilities. Nova Upgrade and the LMF together would provide experimental access to challenging weapons physics problems. including capsule implosion and genition physics, hydrodynamic instability phenomena, radiation transport and opacity measurements. and equations of state of matter at high temperature and density. This capability will be essential to maintaining a trained. motivated scientific staff with nuclear weapons compeience in the event of a declining nuclear test program.

Continuing the traditional role of defense in stimulating civilian technology applications. Nova Upgrade experiments also would be essential to realizing the potential of ICF for energy production in the next century. We could explore high-gain target designs and study reactor concepts and materials, and could define requirements for driver energy and target illumination. Results produced by the current. defensesupported ICF veapons program, if positive. could thus form the basis for an energy applications program.

Recent advances in ICF target design and Nova holhraum performance have made possible the achievement of ignition and moderate gain with 1 to $2 \mathrm{MJ}$ of laser drive energy. Increasing the hohlraum temperature to raise the pressure driving the imploding fusion capsule achieves ignition and propagating burn in a moderate fuel mass capable of producing gain up to about 10 with 1 to $2 \mathrm{MJ}$ of laser energy. Recent experiments on Nova have indeed demoristrated a hohlraum temperature 1.3 times higher than LMF designs. This demonstration is the key achievement leading to the Nova Upgrade proposal. Figure 1 summarizes how predicted target gain depends on laser energy. The two sets of gain curves correspond to 
the LMF hohlraum temperature and the higher temperature demonstrated by Vova experiments. Target gain rises sharply when laser energy reaches the ignition threshold. then rises more slowly as laser energy increases further. The Nova L pgrade energy of I to $2 \mathrm{MJ}$ exceeds the ignition threshold by a factor of 2 . a substantial safety margin for achieving ignition and gain.

The Vova Lpgrade Facility is an 18-beamline. high-power. neodymiumglass laser of advanced. cost-effective design. and a target area capable of safely containing the proposed experiments. Laser energy output will be 1 to $2.1 \mathrm{~J}$ at a $(0.35-4 \mathrm{~m}$ wavelength: peak power will be $\approx 550 \mathrm{TW}$ at a 3.5-n. pulse and $\approx 700 \mathrm{TW}$ at a 2-ns pulse. The target area will be designed for pealk fusion of 20 to $30 \mathrm{MJ}$. The advance in performance projected for the Vora Lpgrade laser is comparable in magnitude to that required of previou, LL.NL-built and -operated neodymium-glan laser sytems for ICF and weapons physics research. The facility would be built within the existing LL.YL Vova building for less than $5+()()$ million. If construction began in 1994. We could have confirming experimental results before 2000). The present experiment area requires no major modification to meet Nova Upgrade scientific and safety requirements. The experiment area houses the target chamber. diagnostics. and final focusing optics. The target chamber will be a 5 -cm-thick spherical aluminum shell of $4-\mathrm{m}$ radius backed by $70 \mathrm{~cm}$ of polyethylene shielding. The aluminum wall provides the vacuum barrier. a soft $x$-ray shield. and shrapnel protection. Achievement of ignition and yields to $20 \mathrm{MJ}$ produce radiation levels greater than previously produced in ICF facilities. For maximum personnel and environmental safety. Nova Upgrade design specifications substantially exceed regulatory standards.

The ability to upgrade Nova in the existing building. at significant savings per unit energy. results from major advances in laser architecture and components and from improvements in the damage thresholds of optics. The damage threshold of optical components determines their size and cost. Since Nova's construction. LLNL. in collaboration with industry has developed adranced materials and components with thresholds 3 to $t$ times higher. significantly reducing costs.
Nova Lpgrade uses a multipass architecture: the laser pulse is amplified by making multiple passes (four. in the current design) through the amplifier. reflecting back and forth between mirrors on either side of the amplifier. This architecture lowers the laser's cost by eliminating the numerous different size amplifiers in Nora-style. single-pass amplifier designs. The Nova Lpgrade multisegment optical components will allow multiple laser beams to be packed close together. The entire laser will deliver pulses with 25 to 50 times Nova s energy. Each of the 18 beamlines will consist of 16 optically independent laser beamlets. By the end of 1993. before Nova Lpgrade construction. we will have demonstrated an entire prototype laser beamlet at full performance specifications. Beamlet design will be sufficiently flexible that we can explore alterations to enhance performance or reduce cost. Construction of the No:a Lpgrade Facility will follow the accomplishment of milestones that validate target physics and complete the technical and cost basis for the facility.

Contact J. D. Lindl $(\$ 1.5)+22-5+31)$

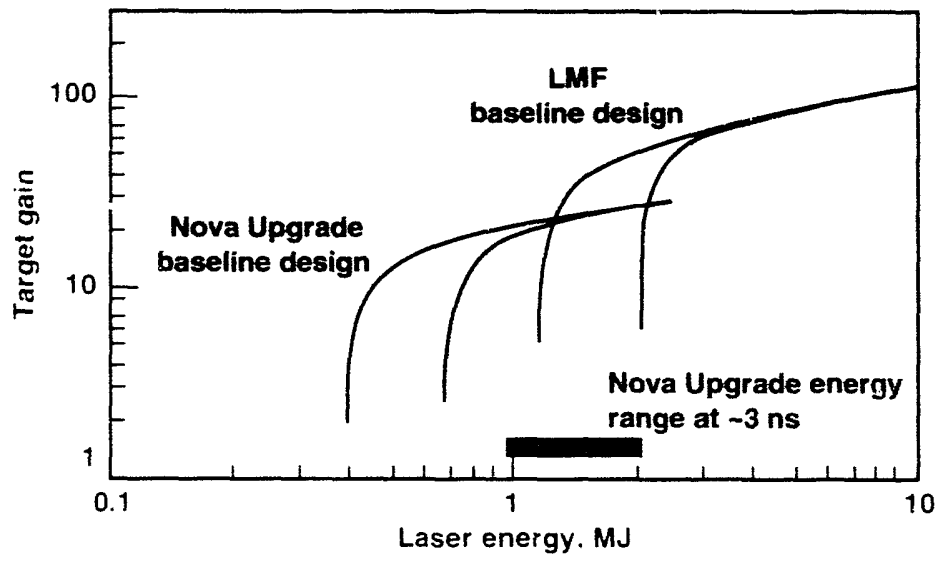

Figure 1. Target gain rises sharply when laser energy reaches the ignition threshold, then rises more slowly for further increases in laser energy. (Ignition threshold width reflects the expected range of capsule surface roughness.) The two gain curves, for the modest-gain Nova Upgrade design and the high-gain LMF design, were calculated using the same hohlraum coupling efficiency. The Nova Upgrade curve assumes the higher hohlraum radiation temperature, recently achieved on Nova, which raises implosion velocity and allows ignition at a lower driver energy. 


\section{Beam Smoothing on Nova}

$\mathbf{T}$ o reach the temperature and density conditions for fusion ignition. a direct-drive inertial confinement fusion (ICF) target requires stringent drive symmetry to keep the target spherical as it is driven inward. For targets directly driven by the laser. nonuniform beam intensities produce hydrodynamic instabilities that destroy this symmetry. The nonuniformity produced by the sum of all beams on target must be $\sim 1 \%$ or less. Indirect-drive ICF. our primary approach. achieves symmetry by creating a high-temperature radiation bath that uniformly illuminates the target: however. We are also stud ving direct-drive ICF because it could require less laser energy for fusion ignition. For these studies. we recently installed and tested a system for smoothing the Nova laser beam at the target. Our system may also be useful for studying laser-plasma interactions relevant for the indirect-drive regime.

We have two methods of beam smoothing on Nova: breaking the beam up spatially into finer-scale structures that the target can smooth by thermal conduction. and causing that fine-scale structure to change
To get uniform intensity on the target, we modify the beam to get a fine-scale focal pattern, which we then move rapidly to give a timeaveraged smooth beam.

rapidly to give a time-averaged smooth beam. Although these schemes were invented elsewhere. our implementation on Novat is unique and is the largest-scale application to date. We can illuminate 1 -mm-diam regions with a smoothed beam at a 527-nm wavelength with energies up to $3500 \mathrm{~J}$ and powers up to $2.5 \times 10^{12} \mathrm{~W}$.

To produce a fine-scale structure at focus. we insert an 8()-cm-diam random phase plate into the $7(0-\mathrm{cm}-$ diam Nova beam. Our phase plates. consist of a regular array of transparent hexagonal elements $(3 \mathrm{~mm})$ randomly chosen to be on or off. The on elements impose a $\pi$ phase shift relative to the off elements via a thin coating of $\mathrm{SiO}_{2}$. LLNL fabricated the plates using large-scale photolithography to create the pattern. and Spectra Physics Optics Corporation deposited the $\mathrm{SiO}_{2}$ layer.

The plates enlarge our focal spot from $\sim 200 \mu \mathrm{m}$ to $1 \mathrm{~mm}$. where the focal pattern of a single hexagonal element determines the overall shape. Superimposed on this shape is fine-scale speckle caused by the interference of randomly phased fields from the individual hexagonal elements. Figure I (a and b) compares the normal Nova beam on target at $+\mathrm{mm}$ past focus and with the phase plate at best focus. The large-scale structure in (a) results frem optical obscurations and beam phase errors. The phase plate produces a more uniform overall profile with less large-scale structure, but it has individual small-scale intensity peaths as large as those seen without it.

For further smoothing. We incoherently add many $(-80)$ speckle patterns produced by different frequency components. We use a grating to spectrally disperse a broad-bandwidth $(1.5-\mathrm{nm})$ beam and then amplify it through the Nova laser chain. frequency convert it. and focus it on the target through the random phase plate. This technique. called smoothing by spectral dispersion. causes the focal spot structure to change in time. yielding a time-averaged smooth focal spot (Figure lc). We are now investigating hydrodynamic instabilities and laser-plasma interactions with this smoothed Noval beam.

Contact: H. T. Powell $(+15)+22-61+4$
Figure 1. (a) A normal Nova beam focused to $1 \mathrm{~mm}$ diam, (b) with a random phase plate, and $(c)$ with smoothing by spectral dispersion. (a)

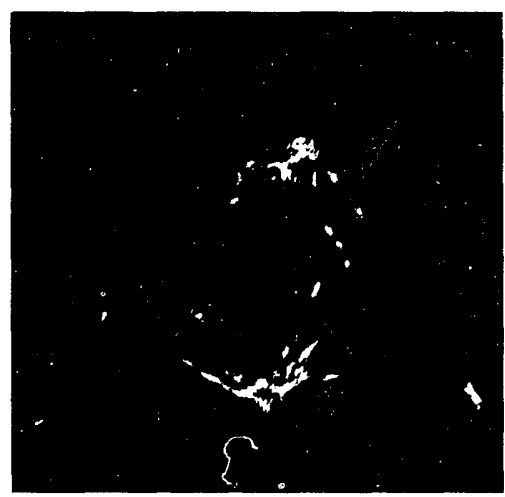

(b)

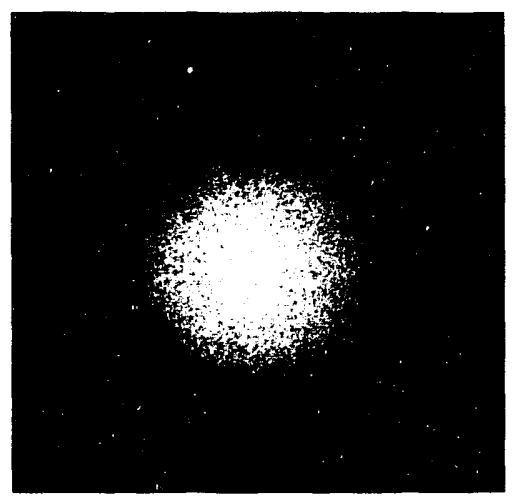

(c)

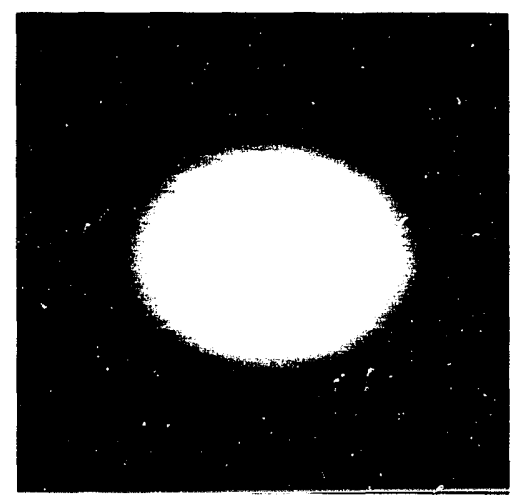




\section{Microthin Lenses}

I mplatis of artificial intratocular lenses (IOL) in human eyes have given vision to people who would otherwise be hlind or severely. impaired. Since the mid $1970^{\circ}$. IOL implantation has become a relativels common procedure for restoring vision to patients with cataracts. Before an artificial lens can be implanted. the natural lens must be remored. With current technology. this len cian be removed through a 1-mm-diam. suturelen incision bs ultrasonic emulsificattion a simple. inexpensive procedures. However. a consentional artificial lem is ly picall! a 6 - to 7 -mm-diam. ().5-mm-thick object of hard plastic: implanting such a lem requires a $6-107-\mathrm{mm}$ incision. potentially leading to such problems as scarring. astigmatism. the ponsibility of infection. and prolonged recuperation. Folding the artificial lens hefore implantation has reduced the required incision length. hut no: 10 les than about $+\mathrm{mm}$. A lens that could be inserted into the ele through a small iabout $1 \mathrm{~mm}$. sutureles incision could revolutionize the technology of correcting or restoring human vision.

We hare developed an ultrathin. very flexible len-the microthin len: (NTL1-that could be a simpler. lese expensive alternative a IOL implants (Figure l1. It mas be pomible to implant the ultraflexible. MTL in

\section{We have fabricated microthin lenses that may make possible a radical new procedure to correct certain human vision problems, either with surgery on a very reduced scale or without surgery.}

the human eve through a sutureless incision or to place it directly on the corneal without surgery. Not only could these procedures be less costly (salvings are estimated in the billions of dollars in the L'.S. alone). but they could restore sight to millions in the Third World who go untrealted because of limited finances and unarailable hospital facilities. These lenses could correct such conditions as aphakia (absence of the natural lens). myopia (nearsightedness). and hyperopia (farsightedness).

Our. WTL employs diffractive optic... which normally are unacceptable for human vision because of severe chromatic aberrations. However. we hate developed the first broadband diffractive optics. Which can image a broad spectrum of wavelengths to a common focal point. The achromatic lens has a nearly constant focal length over wavelength. including the range of human imaging. Our MTL is the first single diffractive lens to produce white-light images. White light is composed of all colors. but traditional diffractive lenses are chromatic and can image only one color.

The technique for correcting chromatic aberration in diffractive optics was developed by members of the LL.NL Adranced X-Ray Optics Program. It was the recipient of an R\&D 1(0) award. given by Research and Derelopment $(R \& D)$ magazine. as one of the hundred most important technological advances in 1990.

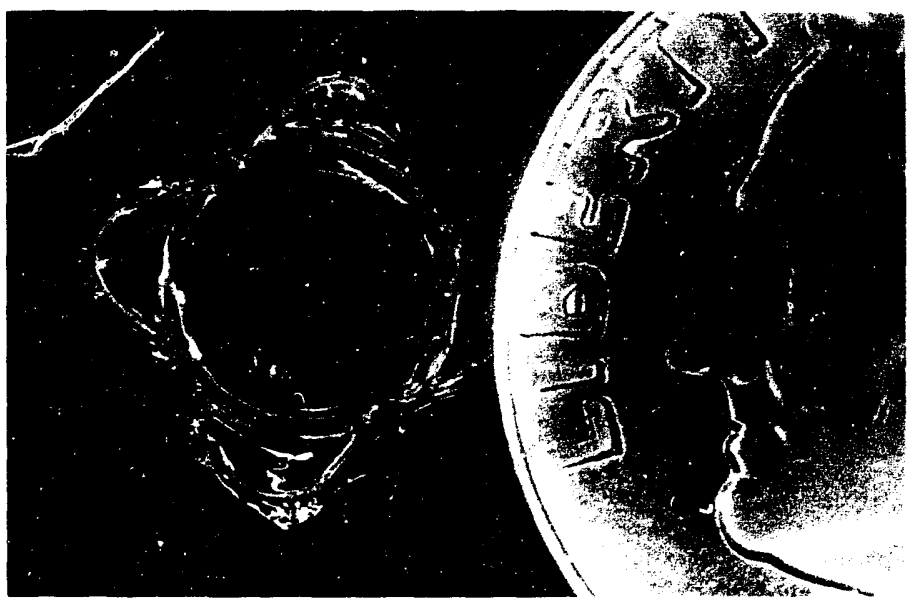

Figure 1. A microthin lens. Dime indicates lens size. 


\section{Differential Optical Profilometry System}

$\mathbf{T}$ he differential optical profilometry system (DOPy) maps the thickness and surface finish of small planar laser target components. The previous inspection technique was tedious. manpower intensive. and of limited resolution (causing otherwise good components to be rejected because they could not be measured). DOPy employs opposed optical profilometers that translate the components between them. differencing the bottom surface profile from the top surfiace profile (hence the name differential optical profilometry). DOPy also can mealsure the surface finish and figure of implosion capsules.

Witness plates and Rayleigh-Taylor targets require this type of scan. Witness plates determire the drive temperature created by high-power laser pulses. The drive temperature is inferred from the measured transit times of shock waves developed by the drive. Accurate temperature determination thus requires precise

\section{Some surfaces are inaccessible or too fragile to be measured for thickness and finish by contact methods. Our noncontact method yields high resolution characterization of Nova laser targets.}

knowledge of the plates' thickness profiles. Usually the thickness varies from $\sim 50$ to $\sim 150 \mu \mathrm{m}$ on a $\sim 1-\mathrm{mm}-$ diam disk, and the thickness needs to be known to within $1 \mu \mathrm{m}$ over a $1(0)-\mu \mathrm{m}$ band down the center of the witness plate.

Rayleigh-Taylor targets are used to study initial perturbation growth in the ablation front. This growth results from the Rayleigh-Taylor instability. which occurs when a low-density. highpressure material is used to accelerate a high-density material and a fairly sharp interface exists between them. We also measure Rayleigh-Taylor instability growth in the implosions of spherical capsules with purposely created initial surface perturbations of certain scale lengths and amplitudes. The scale lengths of interest. on $\sim 0.5$-mm-diam capsules, are from 5 to $100 \mu \mathrm{m}$ and amplitude ranges from 0.1 to $10 \mu \mathrm{m}$.

The laser stylus probe uses a focused infrared beam with a $8(0)-\mathrm{nm}$
Figure 1. Schematic of the DOPy system.

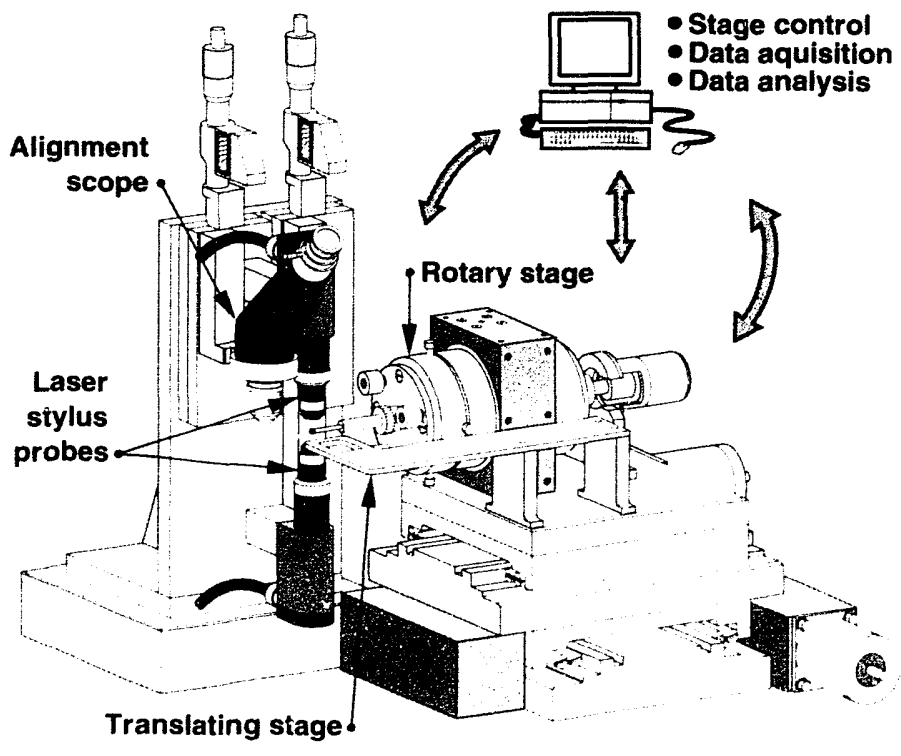

wavelength and a spot size of $1 \mu \mathrm{m}$ to probe surfaces. The reflection off the sample is diverted to a focus sensor.

The error signal generated governs the position of the focusing objective. which translates along the optic axis to keep the surface in focus. A displacement transducer monitors the position of the focusing objective. The probe controller transmits the analog displacement signal plus several control signals to the datat acquisition board in a computer.

The probes are in opposition, and the samples are either translated or rotated between them (Figure 1). The translating $(X-Y)$ stage is computer controlled with a positional accuracy of $1 \mu \mathrm{m}$ and induced height variations of less than $0.01 \mu \mathrm{m}$. For measuring implosion capsules, the DOPy incorporates an air-bearing rotary stage with a vacuum chuck to hold the capsule. The rotational stage has a wobble of less than $(0.1 \mu \mathrm{m}$ and a positional accuracy of 0.01 deg.

Ar: Apple Macintosh II reads the stylus inputs. controls the stages. manipulates datia and displays the results. Data can be output as a lineout. a 3D image resembling that of a scanning electron microscope, a wireframe plot. a contour map. a Fourier transform in the form of a power spectrum. or at simple good/bad response. All programming was done using a high-level data acquisition language that significantly reduced the system integration time. The user need only mount the sample. focus the probes on the surfaces. and choose the scamning pattern. Use of precise sample fixtures allows many samples to be scanned per run.

Contact (;. J. Mauger ( 15.5$)+2.3-76852$ 


\title{
Advanced Applications Program
}

\author{
This year the Advanced Applications Progiam has made major \\ advancements in three technologies: lasers and electro-optics, \\ charged particle beams and accelerators, and imaging and detection.
}

with the appropriate hardware, can successfully image extended objects. such as satellites, through the atmosphere.

\section{Micro-Optics Lenses}

We have made excellent progress in designing and fabricating novel diffraction-limited microlenses for integration with laser diodes to substantially reduce their divergence. We can couple the low-divergence beams from these integrated structures to solid-state lasers using standard optics.

The emission aperture of typical laser diodes is $1 \mu \mathrm{m}$ normal to the electrical junction. The resulting $\sim 60$. deg beam divergence makes the desigil of efficient optical systems using diodes difficult. We concentrate? on developing diffraction-limited cylinder lenses $200 \mu \mathrm{m}$ wide. Placed in front of a laser diode bar, these lenses collimate the light from the diode, significantly reducing its beam divergence.
Although simple round optical fibers will work as cylindrical microlenses, large spherical aberration severely limits collimation of the diode laser light. We fabricated shaped optical fibers as diffraction-limited $2(0)-\mu \mathrm{m}$ wide cylinder lenses. We heated a glass preform and drew it into a fiber in a manner similar to that used for fabricating standard optical fibers. The preform has an elliptical cross section designed to provide the needed focusing properties. Use of the elliptical fiber preform has nearly eliminated spherical aberration.

\section{High-Power Semiconductor Diode Lasers}

The amount of waste heat generated limits 2D diode laser array technology to a very low duty factor. We developed a low-cost packing technology allowing high-average-power operation of laser diode arrays and set up a production line to produce them. The thermal management strategy exploits (a)

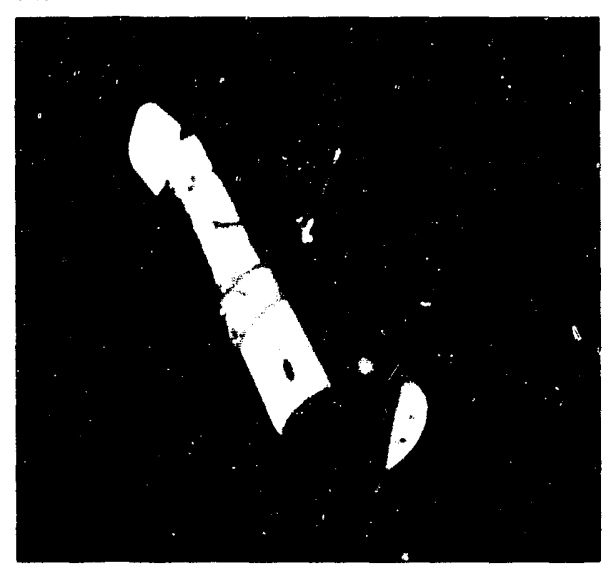

(b)

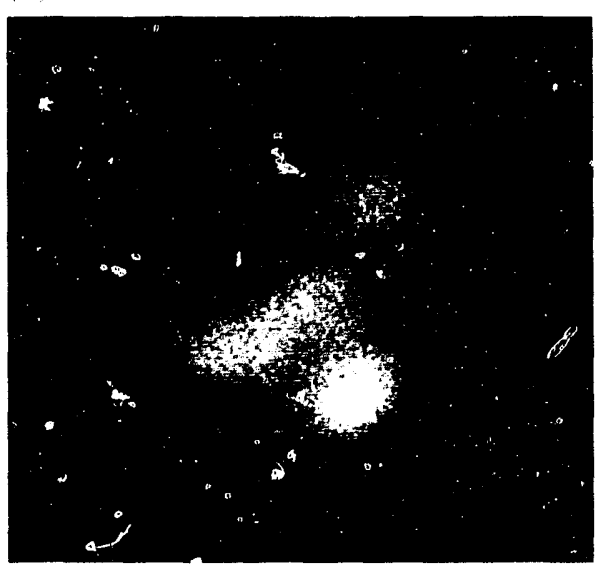

(c)

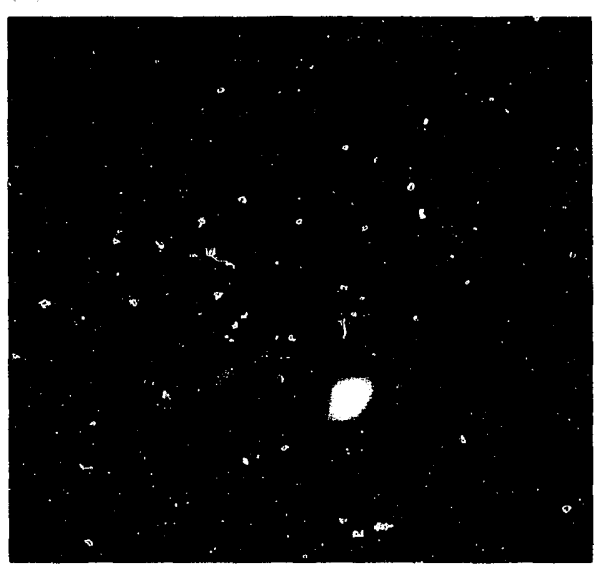

Figure 1. (a) Photograph of the Hubble Space Telescope; (b) a short-exposure speckle image; (c) reconstruction from 50 short-exposure speckle images taken when the telescope made a sunlit pass $800 \mathrm{~km}$ from the observatory. 


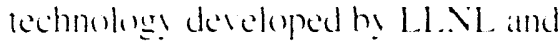

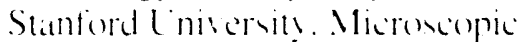
channels elched into vilicon 1 ater

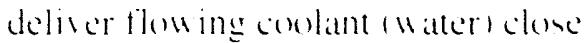
(1) the heat-generatting later diode. Ensuring faminar flow through the micrechannels enhancer effïiciencl. A maximally thin condant beundart laser combined w ith adequate conlant flow heeps thermat impedance low.

fdjusting the channel width eontrols

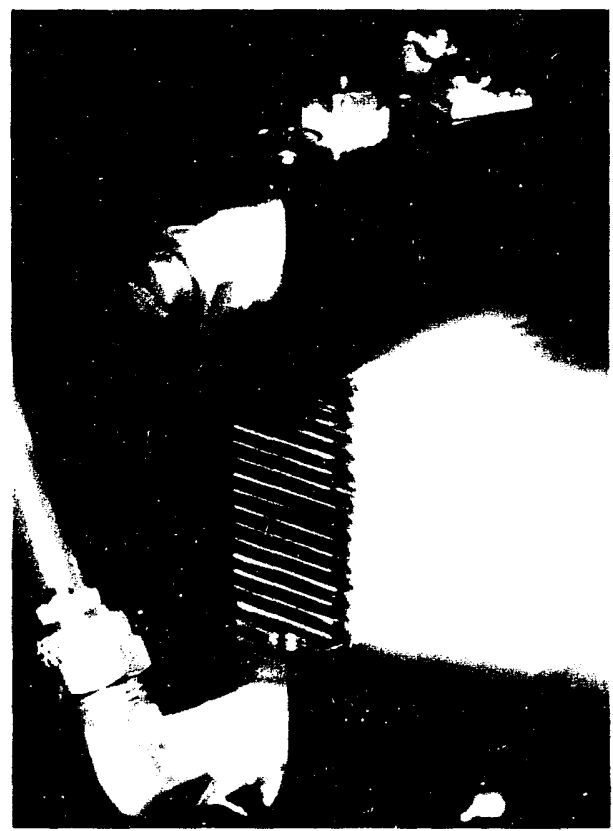

Figure 2. A stack of 16 laser diode packages was tested at $1500 \mathrm{~W}$ (peak) and $270 \mathrm{~W}$ (average) power. the highest demonstrated to date. fluid houndar! later thicknew: optimum performance oceurs at widths of $25, \mathrm{~mm}$. The result is at compact. modular packigese. Arhitrarily large 2D arra! s can be fabricated b! stacking palchages (Figure 2). Peah optical fluences are $22514 \% \mathrm{~cm}^{2}$ and alerage fluences atre 100$) 11 \% \% \mathrm{~m}^{2}$. In life cests such latser desices operated for more than three hillion shots. comesponding ocomtinuous operation for ten years at a l()-He repetition rate. With only mareginal degradation in performance.

\section{Diode-Pumped Solid-State Laser Testhed}

Adrancer in modular. high-power. semiconductor diode laser pump sures make possible high-aleragepower. compact. efficient solid-state lasers with improsed beam quality. for use in defense and adranced manutacturing. We began operating a Vily Y G lab laser testhed using high-power diode laser pump packager deseloped all L.L. VL: our gral is to produce $20(1)$ to 30()$) \mathrm{W}$ of alcrage optical power w ith good heam yualit!. For initial tershed operation uc contigerured 16 dicide laser pump modules ane fifth that required for the full-scale pump source into $140-8-c m-l o n g$ linear pump sources. A eylindrical rod lems focuses eateh line source inte the center of the sath. Both straght-
Figure 3. Tests of the Nd:YAG laser testbed with both straight-through and zigzag laser configurations yielded the highest average power reported for a diode-pumped solidstate laser.

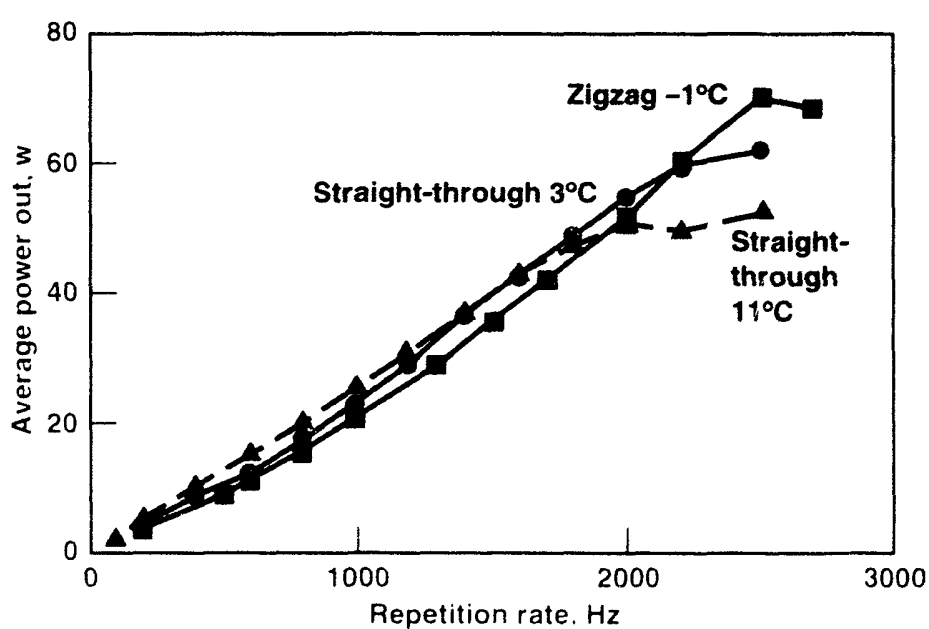

through and riglag laring configurations 11 ere teded (Figure 31.

At $2.5(K)-H /$ and 1()$(1-\mu)$ pulser. Ite shtained $7(1)-1$ arerage power with the riglage configuration-the highest arerage power reported for a diodepumped solid-state laser. The optical(1)-opticit efficiency is $19 \%$. For both configurations the meatsured heam yualit! is ahout eight times diffraction limited. Tus fo-diode package slacks will be used to pump the slath lasere and demonstrate operation alt alerage powers of $2(x)$ (1) $10(x)() \mathrm{H}$.

\section{Compact Laser Transmitters}

We developed a compact diodepumped solid-state laser for Rockwell Internatiomal under a technologe! transter program. integrating innowatice laser technologies to minimise size. Weight. and complexity Power oscillators are the obvious chorice when a compact. lightweight laser is required. Oscillators operating in a stable cas it! configuration are limited (o) pulse energies $10 x$ small (o) meet the requirements. However. we showed that an unstable callits resonator using an output mirror with properly tailored reflectivity can generate the needed pulse energs in a near-diffration-limited beam. At these same pulse energices. we achiered pulso durations under 10 m asing a saturable ahsorber Q-switch hased on color center Lif. He atchieved Q-switched operation w ith pulse energies reduced hy only 20); from that achieved in free-lasing operation. Since these Qwitches are inexpensise. compate and require no electrical eonnections. thes offer considerable sysem adsantages orer consentional electror- or acoustouptical suitches.

\section{Electron Beam Control for the Free- Electron I aser}

In a frecelectron laser. the hinctic enereg af an electron heam in directl! comerled to electromatenelic radiation 
at watelenghs ranging from microwate do infrared. Energes and position of the electron beam must be accuratel controlled and random transterse motions of the indisidual electrons must he kept small. Comtrolling beam energy requires matching the pulse power tratin which prosides the short high-voltate pulses) to the electron heam: controlling beam position requires both controlling beam anergy and accurately aligning the magnetic fields guiding the beam.

11 e designed and built a prototype high-loltage feed stsem for the ETA Il linear induction accelerator. The new ysem peranits a much better controlled coupling of the high-roltage pulses 10 the electron heam and dramaticalls reduces the beam energy sweep through each $5($-ns pulse. The guide magnetic field wats aligned with a new technique that uses the response to short current pulses of a wire stretched along the magnetic fields.

Horking w ith the Magnetic Fusion Energ: Program. we implemented the se modifications on ETA $I I$ and increased "energ! flattop" - that portion of the pulse within +1 ri of the al erage eneres-from $13 n$ s to over $t$ (1) ns. and reduced the beam s transterse wander from $=1 \mathrm{~cm}$ to $6(x)$ um. Implementing these improsements on all the accelerating calls af ETA II will yield a much-improved millimeter 14 alle
FEL for the Micromatic Tokamak Experiment (Sec p. f()).

\section{Induction Accelerators for Heavy Ion Fusion Drivers}

As fusion target drivers. heary ion accelerators offer major advantages in electrical efficiency, reliabilits. and repetition rate, but the use expensise accelerating cells. We are evaluating using induction accelerator technolog! in a recirculating configuration 10 reduce costs. The introduction of bends, varying magnetic fields. higher repetition rates. and longer inaccelerator ion residence times lead to complexities nom being evaluated. Wi developed several point designs for possible driver configurations $\mathrm{Hc}^{\circ}$ hate compared the costs of a linear induction accelerator driver and a recirculation induction acceleration driver: reductions of (wo to three can be achieved for accelerator sy stems it ith comparable vutput parame!ers: beam energy, ion mass. and ion charge state.

Ion beam instabilities and beam quality degradation in a recirculating configuration will be issues of concern. The impact of the vacuum requirements on the recirculator design must he understord. We developed a new "envelope" code (CIRCE) to model ion beam dynamics and tramsport through a recirculating accelerator. A

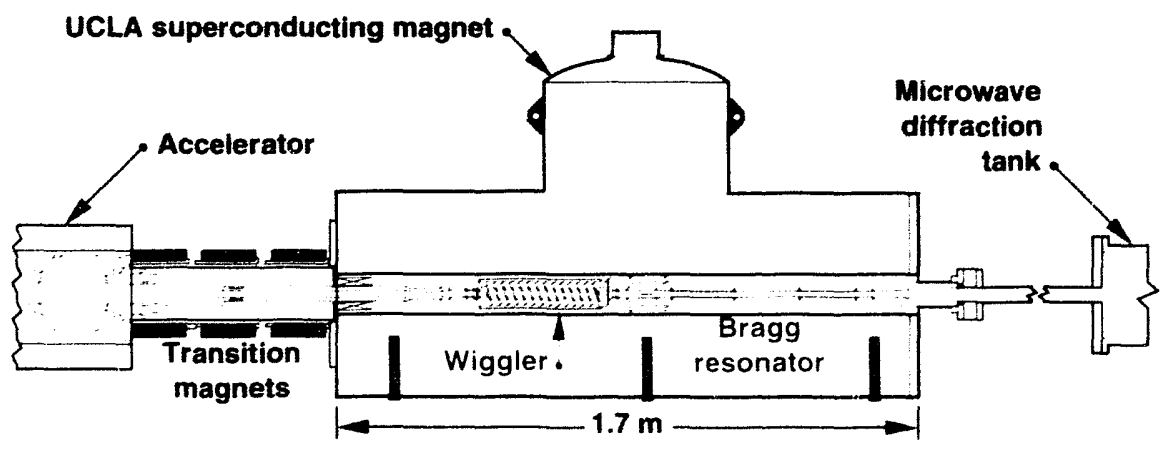

Figure 4. LLNL's CARM produced the first observed broadband megawatt power in the 140- to 250-GHz frequency range.

recirculating configuration brings ncus enginecring challenges. The induction eclls. which comple eneres to the ion beam. require agile. high-repetition-rate (1)-kH/) modulators. and extremel! efficient. pulsed diode magnets are required to bend the beam around the accelerator. He hate exallatled seleral posible ystem design.

\section{High-Power Millimeter Wave Sources}

Since decreasing device sise mathes interaction between an electron beam and a som wate structure more diflicult. deteloping high-porter sources at millimeter waselength is a challenge. He and I C $\mathrm{Cl}$. A researchers demomstrated for the first time cyclotron resonance interaten using a high-current $(60)($ A) relatisistic electron beam transpored through a 7-mm pipe in a 2(1)- $1(1+4)-k(i$ axial magnetic fich. Our goal is a 250-( $\mathrm{jH} /$ source that can gencrate hundreds of megawalls of peak power and he used for tokamat plasmat heating or as a high-poser radar.

He designed. huilt. and tested an experimental 250-(iH/ ceclotron atloresonant maser ( $(\mathrm{ARM})$ oscillator driven bo the 2-Mel. 1-k.t. 3(1-m electron beam induction linate all 1.I. . VI.

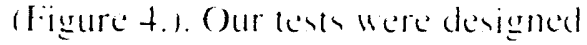
(1) excile a standing 11 alle in an 18 -cmlong. "Bragge" xection of the heam pipe. L sing high-pars wateguide cutoff filters, we ohserved hroidhand. megall all-kel porter in the 1 +1$)-11$ 25()-(iHz rangere. This is consistent with operattion at a superradiant amplifier dricen hy noise. Power in the 25-to f()-(jH/ ranger resulting from excitation of 9 rentrom interation neatr wallegende cullofl. Wa atse

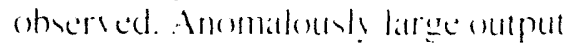

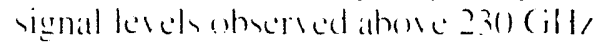
stegerest that the high-() Braters

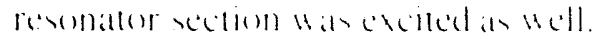

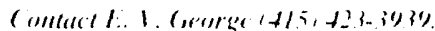




\section{Uranium Atomic Vapor Laser Isotope Separation}

Demonstrations of plant-scale hardware for this uranium enrichment technique will provide the key economic and technical basis for the decision to start plant construction.
$\mathbf{T}$ he uranium enrichment enterprise of the Department of Energy (DOE) is vital to the fuel supply of nuclear power plants. Sales to Li. $\dot{S}$. utilities provide a secure domestic source of nuclear energy: sales to overseals customers contribute about $\$ 5()$ million yearly to the U.S. trade balance. If nuclear power expands in the next century as expected. the low-cost technology offered by laser isotope separationa technology pioneered in the U.S. in which we currently have an international competitive advantagecould contribute several billion dollars (o) the balance of trade.

The U.S. role in the international enrichment market has important effects on this country s energy security. national security. technological and business competitiveness, balance of trade. safeguards and nonproliferation policy. and employment. Until 1974. the United States was the sole supplier of enrichment services to the free world. Since then. foreign enrichment capacity and market share have grown significantly in an expanding. intensely competitive market. and L.S. market share is about $50 \%$.
To reverse market share erosion and reduce vulnerability to foreign competition. DOE has developed at LLNL. jointly with Martin Marietta Energy Systems. a lower cost enrichment technology. This process. Uranium Atomic Vapor Laser Isotope Separation (U-AVLIS). under development since 1973, consists of three major subsystems: lasers. separators, and uranium chemical processing for the interface with the nuclear fuel cycle. Lasers selectively charge the $235 \mathrm{U}$ isotope in the separator where it is collected as enriched product. After removal from the separator, the product is chemically processed into a form acceptable as fuel for nuclear reactors.

The U-AVLIS process is believed to be the lowest-cost enrichment technology known; significant savings come from the conservation of electric energy. Replacing existing U.S. enrichment plants with U-AVLIS would conserve the output of two 1-GW electric power plants. Another characteristic of U-A VLIS technology is its potential to mitigate adverse environmental. safety. and health impacts. The fuel cycle interface of U-AVLIS can use uranium oxide.

\section{Figure 1. Artist's}

rendering of the

\section{Separator}

Demonstration

Facility (SDF).

Module optics and separator pods are enclosed within the existing building.

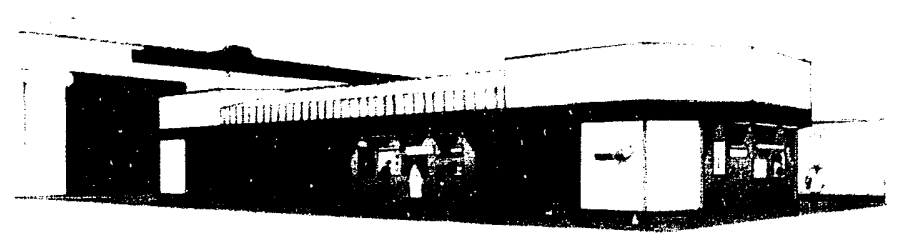

which is less hazardous. produces significantly less low-level nuclear waste, and is less expensive than the current interface. uranium hexalfluoride.

We have operated large-scale laser and separator hardware since 1985. and integrated enrichment demonstrations in 1987 and 1988 have verified performance predictions. The DOE plan calls for demonstrating enrichment performance with plantscale hardware in 1991 and 1992 so that we can begin plant construction as soon as possible. As part of the deployment plan for this technology. other industrial companies will be able to bid on plant construction. ownership, and operation.

We are constructing the Uranium Demonstration System (UDS), which will allow us to demonstrate plantscale. integrated uranium enrichment in a multi-unit separator. From this demonstration and the engineering data derived from construction and operation. we will be able to evaluate the economic and technological competitiveness of U-AVLIS and DOE will be able to make a deployment decision.

Separator Demonstration Facility (SDF) modifications are nearing completion to support UDS operations. which are scheduled to hegin in the fall of 199l (Figure 1 ). We have also completed detailed separator pod engineering refinements and are beginning plant-scalce separator pod operations in the Mars test facility. This pod concept effects a simpler design. offers a more resilient operating plan. and lowers enrichment costs. 
Wie have identified and are dereloping industrial fuel crele intertates appropriate for the metalbased L'-AVLIS. These near-term interfaces use existing industrial calpacity. hut to improve safety and economic and reduce waste. we are also developing long-term adranced technologies, such as the continuous magnesium reduction of $\mathrm{CCl}_{+}$to produce uranium feed.

This year the reliability and pertormance of the Laser Demonstration Facility (LDF) has continued to improve an it is also heing prepared to support the upcoming enrichment demonstrations. The LDF copper laser system. $(6)$ selfcontained laser packages. routinely generates between 8 and $9 \mathrm{kll}$ of optical power around the clock. Dye lasers consert this fixed-watelength light into tunable light to power the L-AVLIS process. This year the dye laser mstem has reached record power. A ingle chain generated more than 125010 for more than 130 hour at greater than 9()$^{\prime}$; power avalability. In the same series of demonstrations. two chairis of dye laners were combined to yicld over 2200$) \mathrm{W}$ of precisely tuned optical power for a run time of 1.50 hours at 9()$^{6}$; al ailability.

We hate made 140 adrances in high-power isible-laser technolog! $\mathrm{He}$ demonstrated al new copper rapor laser that has twice the unit output power of its predecensors. with a single laser amplifier producing oser $6(0) 11$ of opticial power. An engineering prototype chatin of three of the ne new amplifiers has been operated continuously at orer $1.5(1)$ If for das al a time. The recond generation of this devign is being fabricaled with two chains of be deplosed in LDF this year.

The exeond ad ance is the use of optical fibers of transport high-power copper laner light to dec later amplifier. which dramaticall! reduces the cost and complevity of existing discrete optical transport ystems while improving reliability and operabilit!. One de laser chatin is heing fitted with the new fiber optic sstem. Full-power lesting of this chain will hegin by the end of thi vear. Figure 2 shows the fiberequipped laser chain now operating in LDF: the fibers are visible as illuminated "wires."

The extensive optical transport $\because$ stem that delivers the dye laser light to the uranium separator is also heing deployed for LDS. Laser beams tratersing several thousand meters of path length must remain aligned within at few millimeters. Optical power handling capability. precision heam control. wave front control. and stable long-term operation make this system the first of its kind. We developed sophisticated control and diagnostic strategies and state-ofthe-art optical components to meet these requirements. Initial testing of the transport sytem has begun. with full-power testing scheduled for this summer.

The $L-A$ VLIS program now focuses on engineering and demonstrating plant-scale hardware to begin deployment. The LDS at L.L.NI and Oith Ridere National Laborators will proside economic and technical data for the decision to start plant construction. Key activities (o) run concurrently and support at decision include completion of the plant Conceptual Design Report (CDR ): compliance assessments (emvironmental. health. and sately): site selection: proposed NRC licensing: and establishing pricate sector participation.

Beciluse of the importance of L-AVLIS technology to L'S. economic competititeness. the National Academy of Science is conducting a study of other applications. such as reducing nuclear radioatctive waste through reenrichment. inotopic tailoring of hurnable neutron absorbers and reactor materials. refined chemical processing. improving safety in the enrichment industry. laser materials processing. and purifying industrial materials. Many industrial firms have expressed interest in using L-AVLIS technology in several of these areas. including uranium enrichment.

Contact: R. S. Hargrowe (+15) +22-6178.

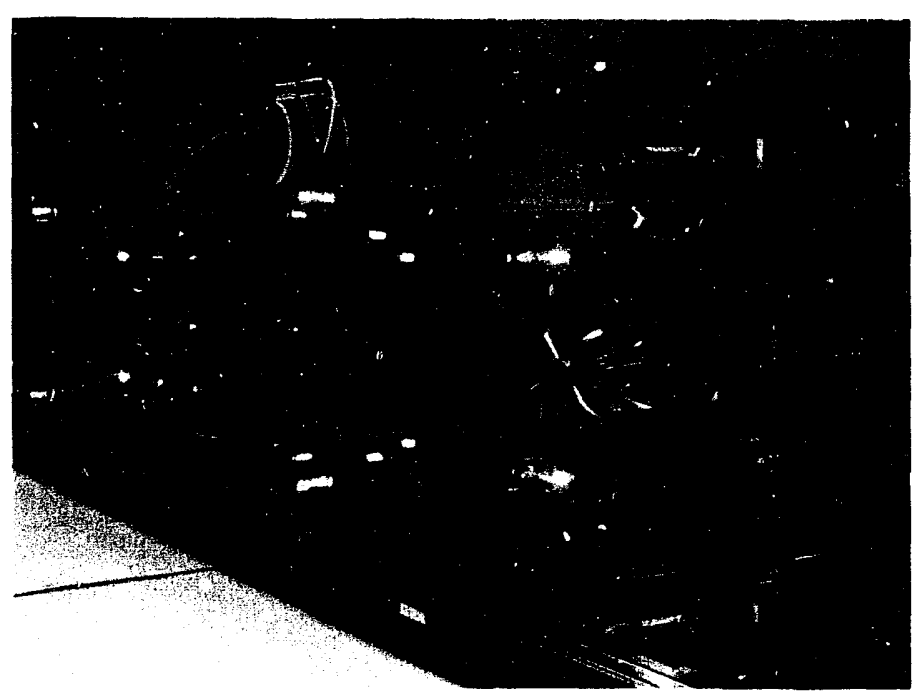

Figure 2. The plantscale dye laser chain featuring fiber optic " ansport of the copper laser pump light. Fibers are visible as luminescent "wires." 


\section{Plutonium-Processing Technology for Complex 21}

Hardware and processing technologies developed at LLL.NL for special isotope (plutonium) separation are w'ell suited for plutonium processing in the future nuclear weapons complex.
T he Secretary of Encres recently approsed plian for a reconfigured nuclear weapons complex. called comples 21. that will be:

- Smaller. less diserese and kes conds wo operate that the current complex.

- Comstructed and operated lo comply with all applicable federal. statle. and locall regulations.

- Able a vapport safels and reliabls. l's. nuckar deterrence and stockpile abjectives.

()ne concept heing elalualed for comples 21 cappitalies on the research atnd development. archicetural. and enginecring worh alreads done hy our Special locotope Separation I SIS Program. A plutonium-xeparation plant has heen derigned at part of our SIS effort: this plant mould be a full! compliant plutonium facility producing on! unable product and divporable "rate. The highen lesel of sateguards and security as well al all of the safetsand heath-protedion features necesars for working 1 ith plutonium hate heen dergened into this facility Thi, SIS plant derign could be moditied. all relativels low expense. (1) handle plutonium rectcling (from scapom revired from the stockpiles and plumonum-pit fahrication. A plutomium-procesong/pit-fabrication facilit! o replace the Rock! Flats production plant could be complested more yuichly and al lower cost hy adapting the SIS dergen than hy sarting with at new design.

He hate laken particular care with the SIS plant design to atchiese the hes porsible balame amonge cost. performances schedules and rish. Wi hate deseloped procesere and cyupment that enhance worker satel! minmme operatar radiation dose (without transferring the dore to maintenance personnel). make maximum use of the plutenium. minimise "aste at the point of generation. and proside for huilt-in recycling of residues and processing chemicals. Tocomply with present and anticipated federal. state. and local regulations. changes are needed in plutonium-processing operations. chemistry. and equipment (sec Table 1).

Several technologien currently being developed for the SIS plant mat! be ideal for use in Complex 21. in particular those for plutonium extraction and purification. In addition. three of the processing media chosen for the SIS AVLIS process-calciumchloride-based molten salt extraction. nitrate-based aqueous chemistrices. and

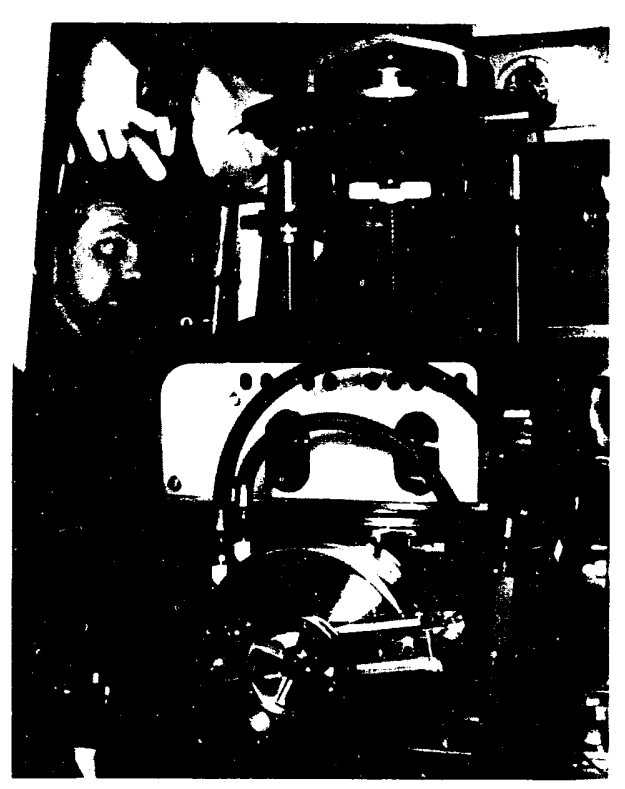

Figure 1. The tilt-pour furnace, with its thermal-shock-resistant metal crucible and computer-controlled process automation. provides high throughput and reduced operator radiation dose. gats-solid chemistries-are well suited wo the new pit-fabrication facility. and we are developing unique equipment for each of these chemistries.

The molten-salt chemistrices ane the kes to high-densits. rapid plutonium throughpul and low waste generation. for these chemistries. we are developing two new reation furnaces-a stationary and a tilt-pour furnace. The stationary furnatec can transfer. on demand. either the molten salt or the molten metal. This furnate would be suitable for several reations in plutomium processing. including the direct reduction of axides to metal (DOR). molen-salt extraction (MSE) of americium-241. plutonium purification by electrorefining (ER). and MSE and ER salt regeneration (salt scrub). This furnace and these processes maty also be suitable for low-solume production of high-value metals (e.g... rare-earth metals).

The tilt-pour furnace (Figure I) uses thermal-shock-resistant metal crucibles and computer-controlled process automation. He are also working with IBM to develop robotio for loading and unkading the furnate. The tiltpour furnate offers several adrantages in at plutomium-processing plant. In particular. it eliminates the need fir waste ceramic crucibles. It permits a high throughput 12-hour eycle times for MSE and DOR 48616 hours for a standard stationars furnate. and a 2t-hour cocle time for ER is 120 heurs). It alse reduces the operator radiation dose hy $f(1)$ lo 60 ) $;$ per and throughput oser that of at sandard stationats furnate

He smoision combining the tilt-pone

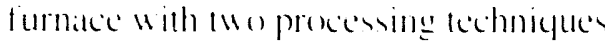
currentls under derelepment sall 
scrub w ith calcium for MSE and ER silts. and HCl/Ca( ) metathesis or electrow imning for DOR salts for the off-line regeneration of salts. Thes should reduce sall waste by more than $s()^{2} ;$. In addition. alutomating the process should reduce operator radiation exposure to less than 10 er that of a standard stationary furnalce. The tilt-pour furnace has demonstrated very high reliabilit! in extensive nomplutonium tess. Two tilt-pour furnates hate been installed in our Materials Processing Laborators and are reads to begin plutomium operations.

In addition. two new types of valles are being developed for the stationars furnace: an external freese plug. and at thermal valle based on a weir concept. If these valve designs are suceesstul. gars-solid reation furnates could be stacked with stationar! molten-salt furnaces. An operator could then insert a matcrial with plutonium metal adhering to it. hydride the plutonium to separate it from the substrate. dehy dride the plutonium back 10 molten metal. transfer the molten metal to an MSE furnace to extract the americium241. and then cast the purified plutonium metal either into ER anodes for further purification or into ingots. all without physically intervening to transfer either the plutenium metal or the salts.

Ke! to high utilization of plutonium are the residue recovery and recycle processes. We are developing a mediated electrochemical oxidation ststem for use with high-value. lowrolume feedstocks (solids and either ayueous or organic solutions and slurries. The heart of this system is an electrolytic cell that continuously regencrates a strongly oxidizing. mediating charge-transter ion le.g.. Agril). Co(III). Ce(IV). Fe(IV)I.

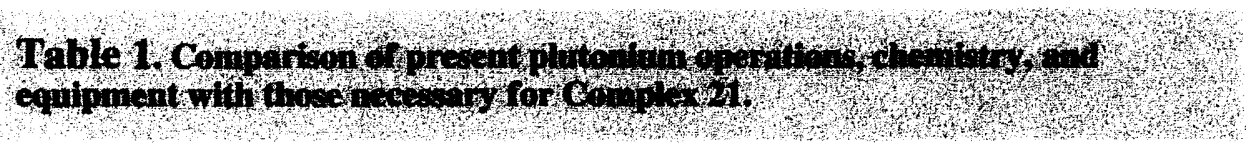

Present

\section{Operations \\ Labor intensive, hands-on \\ High-maintenance equipment \\ High intrinsic waste generation (e.g., gloves, wipes) and inadequately designed processes}

Aging and obsolete equipment

\section{Chemistry}

Solids-producing reagents

Single-pass reagents and solvents

Poorly understood side-reaction

\section{Equipment}

Batch operations. long cycle times

Single-use items

Labor-intensive accountability, hand breakdown and cleanout of equipment

Poor corrosion resistance

\section{Complex 21}

\begin{abstract}
Automated, mechanically assisted
Simplified equipment, fewer moving parts

More efficient processes that eliminate multiple recycling, decrease glovebox requirements, and lower intrinsic waste generation per unit throughput
\end{abstract}

Modern equipment with low corrosion, low maintenance requirements, and reduced operator attendance

Gas-producing reagents or reagents that can be regenerated in situ

Regenerable/recyclable reagents and solvents

Chemistry understuod, parasitic reactions chemistry controlled

Multiple-unit operations per workstation

Multiple-use items

On-line accountability (via nondestructive analysis) with equipment designed to satisfy safeguards and security requirements

Process chemicals and equipment matched to each other to reduce or eliminate corrosion
Applications of interest to the D()I: include the dissolution of oxidizathle refractory materials (c.g... Pu( $)_{2}$ ) and the comversion of havardous organics in mixed maste to $\mathrm{CO}_{2}$ and $\mathrm{H}_{2} \mathrm{O}$. Other potential applicätions include the destruction of hazardous organic materials, such as chemical pesticides. chemical wartare agents. and infectious biological materials le.g.. tisstac or blood sampless. Mediated electrochemical dissolution of $\mathrm{PuO} 2$ offers a number of important advantages over the standard cascatde dissolvers. Depending on scrap type. these include a two- (1) tenfold increase in dissolution rate. an increatse in dissolution completeness (to) $>9.5$ (1) $99+\%$ from $<40$ (o $-9(1) \%$ ). a threeto fourfold (minimum) reduction in waste generation, a three- to fourfold reduction in operator radiation exposure. and the elimination of secondary residues requiring lault storage and reprocessing.

In conclusion. we are confident that plutonium-processing technologies and related hardware developed for our SIS Program can be applied directly (1) plutonium-processing and pitfabrication operations. Development of both the technologes and the hatrdwate is well along. and demonstrations of hardwatre reliability and durability are already under way for some of the critical equipment. The projected advantages of these SIS processes over conventional processes include the elimination of process residues reyuiring storages the reduction of process wastes. a reduction in eycle times, an increatse in the utilisation of the plutonium. and a reduction in operator radiation exposure. Incorporation of these SIS processing technologies into a plutoniumprocessing lacility will make it possible of design and operate the plant in lull compliance with all applicable laws and regulations.

Contact: I. (ira) (115) +2.2-15.54 


\section{Robotics for In response to concerns for worker safety and the environment, we are Automated developing robotic technologies for plutonium processing. Our goal is to increase productivity while reducing operator dose and nuclear waste.} Plutonium Processing

$\mathbf{T}$ he plutenium procesing capatilit! of DOE: nuclear "lapons complex War deretoped with 1940 and 195(h technologies in response to wartime and cold 17 ar prewures. Since the gammat-ra! and neutron radiation doses from plutonium were not high. handling techniques relied on glove-box indation technolog! to prevent alpha particle contamination. This technologe! has continued until todaly. since the complexity of operations and the small number of units being built did not warrant modernization solels on economic grounds.

Howerer. increasing concern about worker alfels and the ens iromment are providing new impetur for uning automated technologien for plutonium procesing. Plutonium worker radiation dones. while not dangerousl! high. are approalching regulator! limis for mant processing operations In addition, since manual operation require larese quantities of protectice cluhing. plastic hagrs filters. and clean-up materials. large quantities of plutonium-contaminated waste are generated. The need to reduce these "lase streams and the operattor radiation dose are motis atting a new

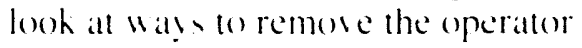
from the processing ens ironment. A costerffective approach is to develop automated plutonium processing stems that use robotic material handlere for process operations and rely on glore-box access to the yisem for maintenance and repair operations.

L.L.NL tarted this option as part of the devign and development of its Special hotope Separation Program plant and is continuing this development as part of the modernization of the DOE nuclear weapons complex. In carrying out this lask. L. L. L formed a team with IB.M. Westinghouse. Scientific Apnlication International Corp. Lon Alamor National Laboratory. and Sandia National Laborators io analyze proces operations and $(1)$ develop atutomation concepts. Two basic atutomation lools were detined: at gantry robot material handler in a glove-hox enclosure and a "smart"
Figure 1

Plutonium automation demonstration mockup using the IBM ECR robot.

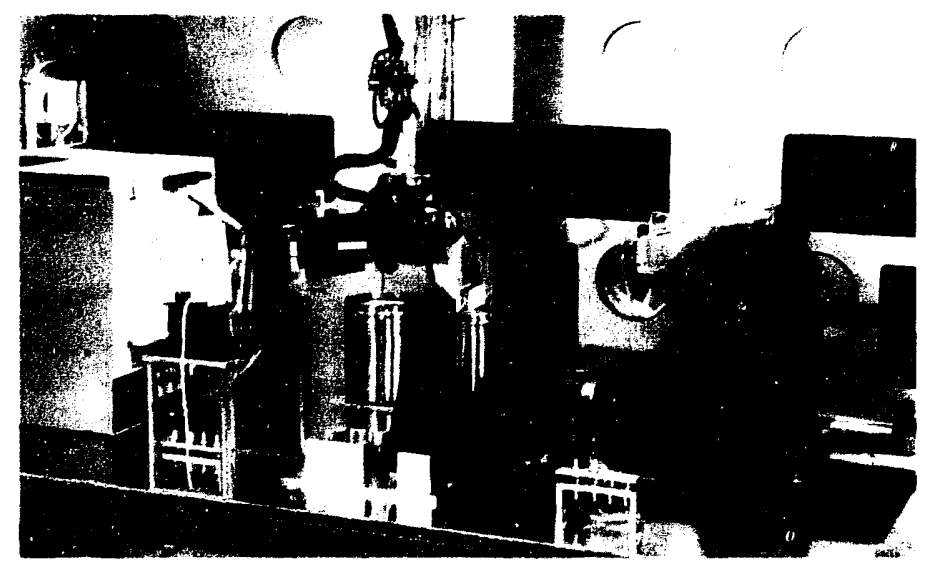

roboric control sysem that allowi operator intervention and assistance. These combined lools matie porsible a wide range of plutonium processing operations. either atutonomous! or with operater assistance from at remole location. The "smart" stsem. using multiple sensors, hardened gantr! robotic stems. vision ystems. and a supervisor! ystem control. will allow the operator to continue or correct off-normal operations and complete complex or unusual operations without hating (1) enter into the glose brox.

The first phase of the projecel was (1) construct a mock-up plutonium processing demonstration using the alutomation concepts and an IB.M ECR robot. The demonstration (Figure l) in fall 1990) at the IB:V remote ststems facilits in Austin. Texas. showed the complete atutomation of the process operations required on comsers plutomium oxide into plutonium metal. The results prosided additional information that Was uned to design a protolype of at completely atumated plutonium processing glowe-box station. The comstruction and installation of this prototype are nearing completion. and it will be demomstrated this leal at 1.L.XL. using cerium oxide for concersion to cerium metal as a Pa surrogate. Future plans include installing this prototype deses in the plutenium facilits and testing it "ith plutonium hefore undertaking plutonium production operations.

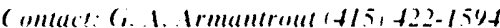




\section{Innovative
Applications of \\ Innovative
Applications of AVLIS Technology}

We are investigating new applications of technology developed for the Atomic Vapor Laser Isotope Separation (A VLIS) Program, including other isotope separations and novel uses of AVLIS lasers.

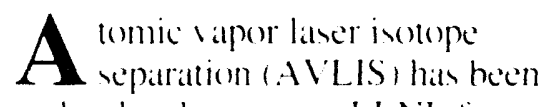
under development at L.L.NL. for more than 15 years. Over this period. the AVI.IS program hats focused on enriching 250 for use as civilian lightWaler reater fuel and purify ing Pu for use in nuclear weapors. In cosperation with a stud! hy the National Academy of Sciences and National Academ of Engineering. we hate solicited and reviewed alternatice applications for AVLIS technolog! identifying more thatn 60). The ape applications (Figure !) include une of the AVLIS sy stem 10 separate other isotopes: other uses of major vobs stems. particularly the uniquely pewerful and precise copper lapor and dye lavers: and the direce commercial use of individual components.

One application ues AVLIS to enrich the 157 incolope of gadolinium. Dattural cid in uned in nuclear power reactors as a hurnable poison to control neatron flus loads. and the 1.57 isotope has a uniquely high thermal neutron ahororption croms ection. Substituiton of highly enriched 15 Gol lowers the end-rit-cicle neutron ahororption levei. permitting longer operation and increared hurnup between shutdown for refueling. improsed thermal performance. and significint economic sal ings through redilced requirements for uranium enrichment.

A eecond innoration unes AVLIS (1) strip the 9) incetope from circomium. Catural Zr is uned as at construction material in nuclear porter reactors hecatuse of it lom thermal neutern ahworption erom ection. high mechamial serength. and corrouson restance. Reducing the 91 wrotepe trom 11 16 3'i would hate the neutron aborption crom section. This would he particularly beneficial for permanent Zr structures in natural uranium-hea!! water reactors. Both the $\mathrm{Gd}$ and $\mathrm{Zr}$ missions can use the laser systems developed for uranium. Separator wstems would need to be modified to match each mission.

A third proposal suggests using AVLIS laner hardware to create an artificial guidestar. a device that corrects the images of ground-based telescopes for the effects of atmospheric turbulence. The technology already developed for the AVLIS program is remarkably similar to that needed to create these devices. The gruidestars are formed by illuminating sodium atoms naturally present in the mesosphere w jth narrow-band laser radiation tuned to the sodium fluorescence line. The wavefront of the backscatlered radiation returning through the atmosphere is measured. and the information is used to deform a mirror in the optical train of the teleseope and correct the image. AVLIS lasers for material processing. Lasers are increasingly being used in industrial cutting and welding operations. The characteristic of greatest importance for such operations is laser radiance. the measure of the power that can be delivered in the laser s focal spot. Compared with the $\mathrm{CO}_{2}$ and $\mathrm{Nd}: \mathrm{YAG}$ lasers that are the present industry standard. Laser Program copper lasers. copper-laser-pumped dye lasers. and solid-state slab latsers have greater radiance becaluse of their better optical quality. shorter wavelength. and high average powers at these shorter wavelengths. These propertien can lead to more precise cutting or welding and up to a tenfold increase in processing speeds. Material processing tests are currently under way for several industrial sponsors.

(imlact: R. C: Stern (41.5) +22-6.2J.3.
Yet another imnovation would use

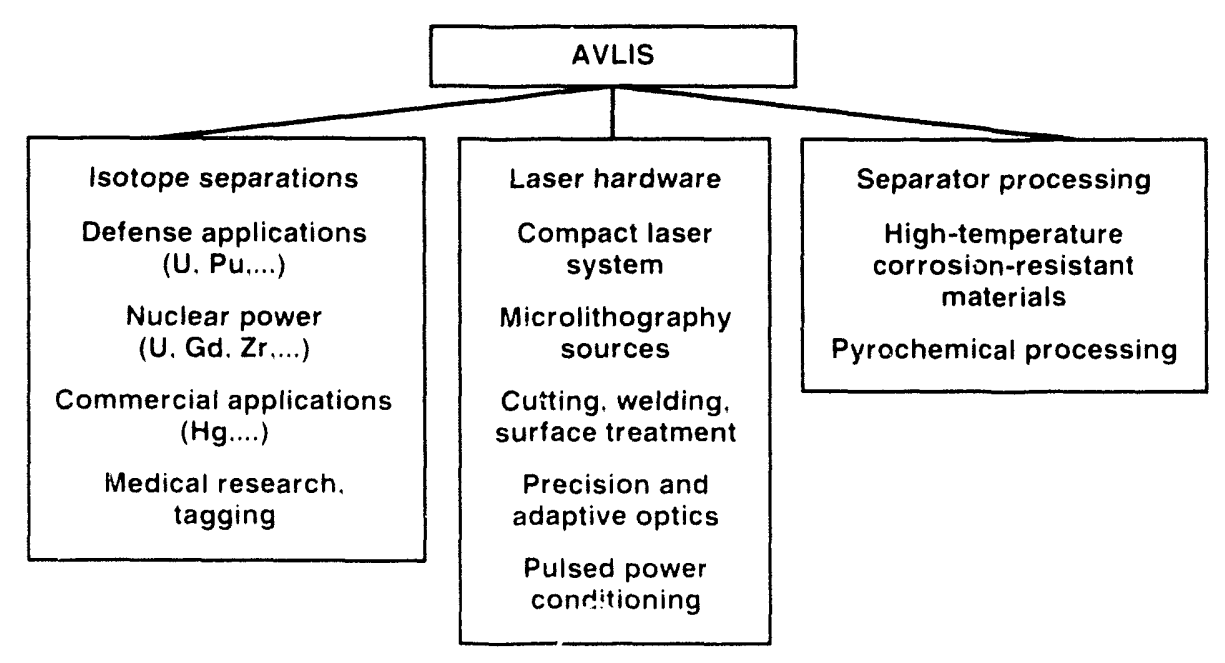

Figure 1. Alternative applications tree. 


\section{Magnetic Fusion Energy}

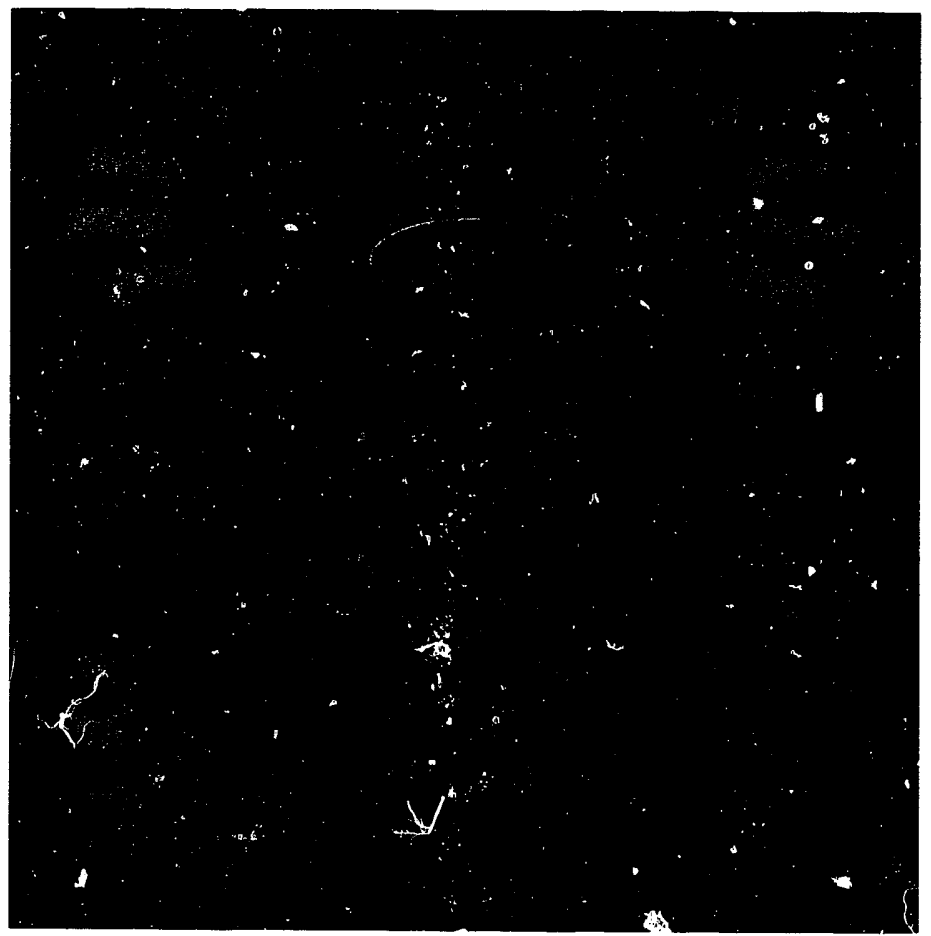

\section{Fusion energy is now a national goal. Our magnetic fusion research in the Microwave Tokamak Experiment (MT:) continues, as does progress in the International Thermonuclear Experimental Reactor (ITER).}

M agnetic fusion energy resecitch at the Lawrence Livermore National Laboratory is supported by the Department of Energy as part of a global effort to harness the potential of thermonuclear fusion for the production of electricity. In the DOE , recently published (1991) National Energl: Strateg!: the development of fusion energy was identified as a national goal. with the ohjective of operating an electricityproducing. demonstration fusion power plant in the first quarter of the twenty-first century. To reach this objective requires a broad program of physics research and technology development. LLNL. contributes to both the scientific and technological efforts in the program. Indeed. one of the Laboratery"s earliest activities was research in magnetic fusion.

The centerpiece of the LLNL experimental program is the Microwave Tokamak Experiment (MTX). In this experiment. millimeter-wavelength pulses. generated either with a high-power gyrotron tube or the induction-linatdriven free-electron laser (IFEL) in the Experimental Test Accelerator
(ETA-II) facility. are injected into a plasma confined in the MTX tokamak. The objective of the experiment is to investigate the interaction of intense pulses of microwave energy with a magnetically confined plasma through electron-cyclotron resonance. Electron-cyelotron resonance is a technique for heating magnetically confined plasmas that is proposed for use on several large tokamaks currently under design or in operation. In these experiments. we are collaborating with the Beam Research Program in developing the 
free-electron laser. The Japanese Atomic Energy Research Institute (JAERI) has developed a diagnostic instrumentation package for MTX. and a team of JAERI researchers is participating in the experiments.

$W e^{2}$ also maintain a team of scientists at the DIII-D facility at the General Atomic laboratory. in San Diego. This team has concentrated on experiments to elucidate the physics of the edge region of the plasma. and on divertor development. Conditions at the plasmal edge are of critical importance in determining how well at plasmal can be contined in a tokamak. The divertor plats a dual role. both in removing impurities from the plasma and in shaping the magnetic field.

In addition to providing theoretical analsis of experimental data developed by LL.NL researchers. our Theors Program has pioneered the development of more efficient techniques for modeling the complex proceses that gotern the transport of energy in a magnetically contined plasma. We hare made significant adrances in the use of gyrokinetic codes: these are codes that treat the average motion of charged particles analyticall! and apply numerical method only to model departures from the arerage motions. Gyrokinetic codes. when combined wh more efficient numerical technicyues. make it possible to model plasma processes on the scale of real devices within an acceptable computational time.
The next generation of tol.amaks will hate to be capable of eontinuous operation. For this they will require superconducting magnets. At LLNL. we have constructed the FENIX facility to test large. superconducting magnetic coils. The facility started operation early in 1991. and we are currently testing coils develop d by the NET Project in Europe.

In 1987. the Lnisd States. Japan. the Soviet Lnion. and the European Community laurched a collaborative effort to design. develop. and construct a fusion engineering test reatctor. This project. carried out under the auspices of the International Atomic Energy Agency. is called the International Thermonuclear Experimental Reactor (ITER). LLNL was designated as Lead Laboratory for the first phase of the project. a three-year Conceptual Design Activity (CDA). The CDA "Ia completed in December 1990.

The four parties are current! negotiating entry into the next phase of the project. the Engineering Design Activity (EDA). The EDA is expected to take six years. and will provide a complete data base (o) support a decision whether to build the ITER machine. The ITER tohamak will produce a thousand megawatts of fusion power. and will be capable of providing extensive testing of engineering and nuclear components. in preparation for constructing a demonstration reactor. It construction starts immediately upon completion of the enginearing design. ITER could be operating as carlia als $20(15$.

LL NL has been designated as host for the Lnited States Home Team during the ITER EDA. As such. LLNL will be the site of the project office for L'.S. participation in the international project. There will also be a Central Design Team. in which LLNL scientists and engineers will participate. Activities of the Central Design Team will take place in San Diego. California: Garching. Germany: and Nata. Japan.

For several years. we have been working on the development of a technique to accelerate and comprest at self-contained plasmatoroid. With support from the Laboratory's Exploratory Research and Development (ER\&D) Program. we have constructed an innovative facility. the Ring Accelerator Experiment (RACE). Which hats demonstrated the acceleration of compact plasma toroids to velocities as high as 3()$(0) \mathrm{km} / \mathrm{s}$. We are currently investigating the compression of these high-velocity plasma rings to high energy densities. RACE technology could be applicable to inertial confinement fusion and to the simulation of nuclear weapons effects.

Contact: D. Baldu'in $(+15)+2.3-1+1.5$. 


\section{Microwave Tokamak Experiment}

$\mathbf{T}$ he goal of the Microwate Tokimak Experiment (MTX) is to investigate electron plasma heating and control in a magnetically confined fusion device. MTX experimental results will guide the implementation of electron heating on future tokamaks such als the Burning Plasma Experiment (BPX) or the International Thermonuclear Experimental Reactor (ITER).

Electron heating in a tokamak such as MTX is acomplished by injecting high-frequency electromagnetic walles having a frequency equal to the rotational (cyclotron) frequency of the electrons confined in the plasma: hence the term electron cyclotron resonance heating (ECRH). The mangetic field of the device sets the elclotron frequency: most future tokimaks are planned to operate in the 5-10 T range. corresponding to a cyclotron frequency of $1+(0)-280 \mathrm{GH} \%$ High-frequency waves in this range microvales) can be generated in several waly s. including by a freeelectron laser (FEL, or a gyrotron: we are addressing the physies and technology issues of both methods on MTX.

Initial experiments using the FEL were reported in the 1990) State of the Laboratery issule. We have since instatled a high-power gyrotron and an improved plasma fueling system and run a short series of experiments using gyrotron-gencrated microwates. We also helped the Beam Research Proeram on make cechnologeical adtances in operating the FEL.

We conducted plasma heating experiments with 100-ms microwave pulses up to $400 \mathrm{~kW}$ generated by a newly installed 140-GHz gyrotron system. Improvements to the ETA-II accelerator are under way to prepare for experiments using FEL-generated bursts of multiple highpower microwave pulses to achieve an average injected power of $\geq 1 \mathrm{MW}$.

Microwaves generaled by either the FEL or the gyrotron are transmitted to the MTX tokamak through a unique quasi-opticial transport system: the microwates are transmitted as a Galussian "optical" beam rather than in al waveguide. This system has no windows. which are susceptible to damage at high power. Our measurements have shown that transmission losses are low. and the spatial quality of the microwalve beam is preserved. The FEL microwave beam can be coupled directly to this system. because the output is a nearly pure $\mathrm{TE}_{() 1}$ mode with the proper polarization 10 propagate in the plasma. (We use the central lobe of this mode. which contains $80 \%$ of the power.) On the other hand, the gyrotron generates

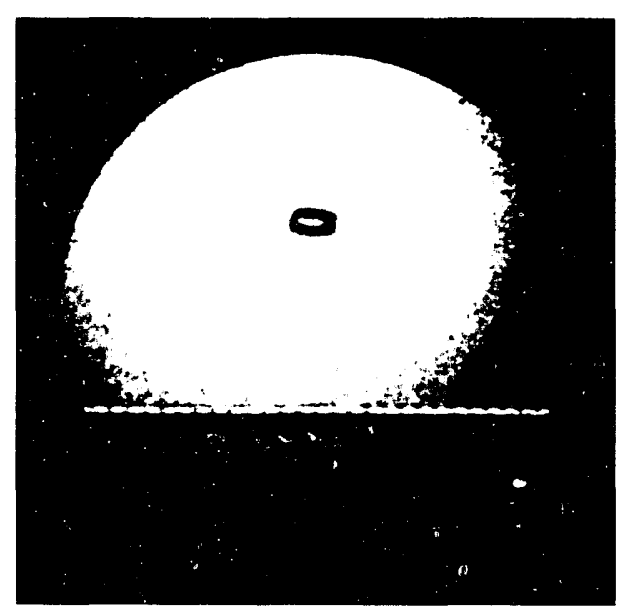

Figure 1. Seen through a diagnostic port, a frozen deuterium pellet (the darker spot at upper center) is being injected into the MTX plasma. The $2-\times 1-\mathrm{mm}$ pellet is traveling from left to right. microwates in a high-order mode $\left(\mathrm{TE}_{15.2}\right)$. so we have used a special high-power ("Vlasov") output coupler to convert the mode to a nearly Gaussian beam. Other special couplers are being developed. The gyrotron is configured so that it can heat the MTX plasma directly or be used as a master oscillator providing input to the FEL amplitier.

We carried out ECRH experiments on MTX using the 14()-GHz highpower Varian gyrotron. Pulses of $200 \mathrm{~kW}$ for $100 \mathrm{~ms}$ were injected into plasmas at a toroidal field of $5 \mathrm{~T}$. electron density of $1 \mathrm{to} 2 \times 10^{2(1)} \mathrm{m}^{-3}$. and electron temperature of $1 \mathrm{keV}$. Increases in the electron temperature of $\sim 100 \mathrm{eV}$ were measured with a special multichannel electroncyclotron-emission diagnostic installed in 1990). We tested a new diagnostic that measures the radial profile of the plasma current. Changes in the current profile during heating were observed: hence it may be possible to tailor the distribution of current with localized ECRH. We measured the profile of the microwate power with a microwave calorimeter under several experimental conditions: without plasma (incident beam shape). with plasma (refraction plus absorption), and with plasma but with the tokamak magnetic lield off-resonance (refraction only).

Data analyses indicated that heating efficiency was not as high ats expected. Low-power microwate tests hate since shown that the polarization of the transmitled gy rotron beam was not perfectl! 
aligned with the MTX magnetic field. (When launching waves from the low field side-that is. outside-of the tokamak. efficient heating is obtatined only when the microwave electric field is parallel to the tokamak magnetic field.) We are now installing a system that can rotate the microwave polarization to align it parallel to the MTX field. Heating efficiency with the gyrotron system will be tested during 1991 .

The MTX tokamak is normally fueled with at deuterium gas. In 1991 we installed an additional plasma fueling ststem that peaks the electron density profile and that on previous experiments has increased energy confinement time. This technique uses frozen pellets of deuterium injected by a high-pressure gas pulse at a velocity of $\sim 1 \mathrm{~km} / \mathrm{s}$ (see Figure 1 ). Our sisten canl inject up to four pellets into at tokamak discharge. The pellets cain be of varying size and can be injected at various intervals. Each pellet quickly ablates in the plasma and nearly doubles the electron density. The resulting peaked electron density profile persints for tens of milliseconds. during which time the eneroy confinement time of the plasmal is enhanced. Figure 2 shows the plasma response: the line-atverage density increases dramatically as measured by al multiple-chord interferometer. We plan to combine this fueling technique with EĆRH to investigate heating in this enhanced continement regime.

Progress in 1990 with ECRH using the FEL was primarily in the technolog!. With work carried out by the Beam Research Program. Our ultimate gaal is to conduct experiment producing FEL-generated microwates in a hurst of wer! short. high-power (several GWi) pulses at a repetition rate of athout $5 \mathrm{kH} /$. resulting in an atserage injected power of $\geq 1 . \mathrm{MW}$.
Each burst will have about 5() of these short pulses.

The main physics issue of this method has been addressed in detail theoretically: whether these short pulses will be absorbed efficiently by the plasma. It has been shown theoretically that nonlinear absorption mechanisms become significant al a power level of about $1 \mathrm{GW}$. Nevertheless. even incorporating nonlinear physics. ECRH heating with the FEL is predicted to be efficient. ECRH heating with an FEL hals several advantages. Because the FEL is principally an amplifier. the frequency can be varied during the tokamak shot. thus varying the heating zone to allow control of the plasma. In addition. with present technology, the FEL can be extended to higher power and frequency than the gyrotron. In FEL experiments conducted in 1989. single pulses of $10-15$ ns duration and a power of 0.2 MW at 140 GH\% were injected into the MTX tokamak. As expected. we did not see any indication of nonlinear effects in these tests.
Since those carlier experiments. substantial technological progress has been made testing improvements to the ETA-II accelerator. These modifïcations will allow the generation of longer pulses of higher power. We are currently installing these upgrades. to the full ETA-II accelerator. which will operate al 6-7 MeV. 2-3 kA. and with a 3()$-5()$ ns pulse length. A new steady-state Intense Microware Prototype (IMP) wiggler is being installed. and this will allow multiplepulse operations.

We are also installing new diagnostics that will focus on the FEL experiments. One example is a collaborative effort with the Japan Atomic Energy Research Institute (JAERI) to determine the electric field of the FEL microwates in the plasma with a Stark-effect type measurement. Single-pulse FEL. experiments. using the upgraded accelerator. are scheduled to start in the fall of 1991. and multiple-pulse burst experiments will begin in 1992.

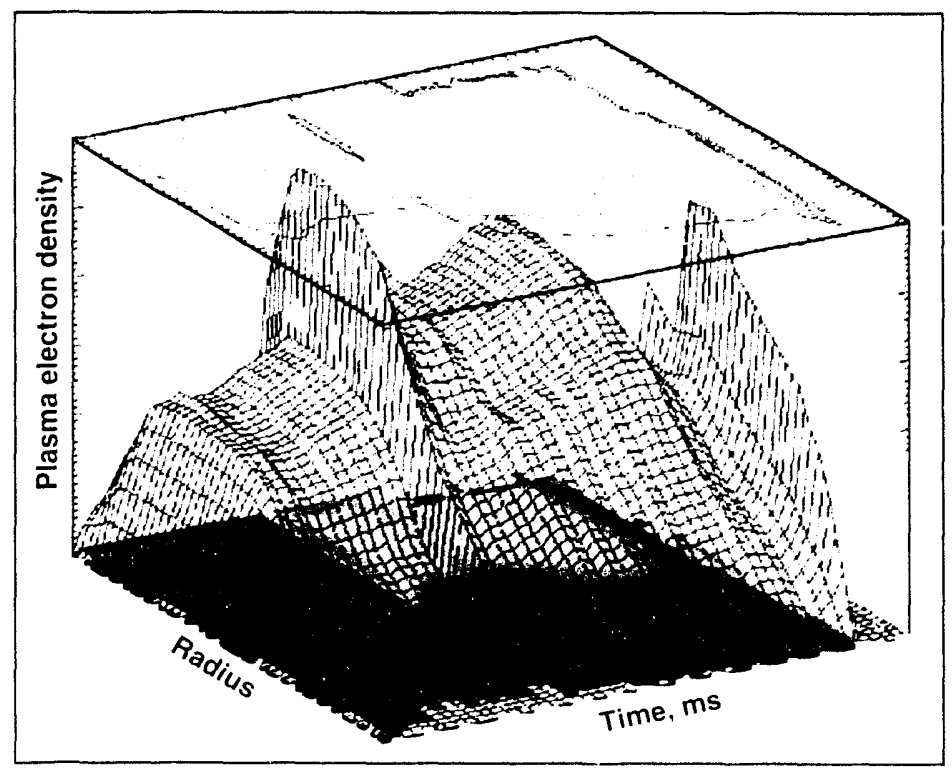

Figure 2. The plasma electron density jumps when a frozen deuterium pellet is injected at $100 \mathrm{~ms}$. The contour plot across the floor of the graph also inciicates plasma density. with red the highest density and purple the lowest. 


\section{The International Thermonuclear Experimental Reactor}

$\mathbf{R}$ cearch in magnetic fusion eneres will eroma major thresold in lyel when the Lnited Slater. the European Community. Japan. and the Sorvet L nion agree proceed it ith the enginearing design of the International Thermonuclear Experimental Reatior (ITER I. ITER is being designed as a lest reactor (1) demonstrate the scientitic and technologrical fearihility of fusion power. The conceptual devign of ITER. completed in December 1yyol. will serse as the starting point for the Engincering Dengen Actility (EDA) LL. VL will he the site of the project affice for the L.S. Home Team during the six-lear EDA phate. The L.S. Home Team w ill he at national effort. draw ing upen national lahorattorices unicersts research programs, and private induers. With LL. V. providing administratise support (Figure 1 ).

\section{Scientific Importance}

ITER has vientific venificance on multiple kesh. It. at the conclusion of the EDA. a decision is reathed in converuct ITER. thi superconducting: tohamah desice in cexpected to produce I(A) . IIt of fusion power in at hurning deuterium-tritium plasmat. ITER will he aned not onl! wexplore

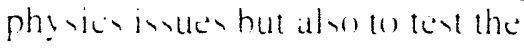
barios integraled iechnologeres and componentereyuired lor a fusion reactrer. pas ing the wa! for a demonetration reatore that would produce electric pores. To date. all
International collaboration continues as engineering design begins for this $1000-\mathrm{MW}$ fusion test reactor. "roldu ide fusion experiments hate focused on physice imues: ITER will be the first experimemal facilits designed to address the lechr , ges insues.

Equally significant is hou this project is being aceomplished. Worldwide fusion research. throughout the past four decades. has benefited from gored international cooperation and mant multinational agreements. hut ITER represents a new exel of eollaboration. From the start. the four partices hate comtrihuted eyuall! whe ITER effort in term of coss manpouser. and scientitic know ledge. Thus. ITER is a promenpe of how major scicntific projeck ma! he carried out in the future. The bencefits of this joint endeavor are both tinancial cimportant in a time of tigsh hudgets and echnical. hecature ITER drat , upon the knowledere and expertice al all the world i fueion programs.

\section{Conceptual Design Completed}

During the conceptual dengen phate. which hegan in carly 1986. a unilied cam of scientists and engineers from the four partice rincluding a number ef L.L.N. peoples detined ITER , basic parameter and produced at conceptual derign of the tohamak derice and its supporting ysems. The central design worh. conducted in a series of wrorhing xeson, all the Mas Planch

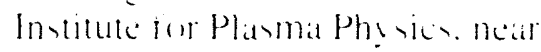
Munich. (jerman! was -upponted

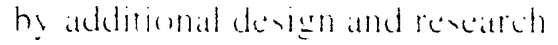
and development work pertarmed by each of the partices. IL. NL. as the lead laheratory for the l'.S. during conceptual design. corsdinated lechnical worh performed nationwide.)

ITER is planned os operale in two phases. In the physice phase. the objective will be to explore longpulce igntion and control of a burning plasma. Near-ignition conditions will he sustained for pulse durations of seleral hundred seconds. In this phase. ITHE will address critical insue of hum phy ics. refueling. and helium removal. as well as plasma sabilization. In the kesting phase. ITER will serve as a test facility for neutronics. blanket modules. rétium regencration. and adranced plasma technologies. External current drive will he used to extend the pulse length. with the ultimate goal of conimumus uperation. ITER will incorporate a tritiom-brecding blanket and. in continuens operation. is expected to regenerate more than si) ', of it tritium requirement.

In Fetruary 1901. at panel of technical experts from the L.S. fusion program revieucel the ITE:R conceptual design. Thes concluded that this design prosides an adeyuate has for procededing to the EDA Although they ohverted that the derign will need further develupment (1) as $x$ ure a greater margin for aches ing the devired operating conditions. thes concluded that the

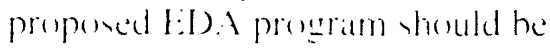
safficient wappert a comstruction

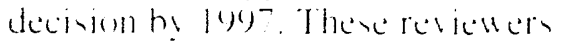
empharised the importance os 
establishing the testing mission as the primary objective of ITER.

\section{Moving to the Next Phase}

The four parties are currently negotiating the agreements and protecols for the EDA. As in the conceptual design. the work will be performed under the auspices of the International Atomic Energy Ageney. The EDA phase has five main goals: - To estahlish detailed design. including tender-ready specillications. for the tokamak device and all auxiliars systems and facilities. - To establish site requirements for ITER and perform the necessary safety. ensirommental. and economic analyses.

- To establish both the proposed program and the requisite cost. manpower. and schedule estimates for the operation. exploitation. and decommissioning of ITER.
- To carrs out validating rescarch and development work. including the development. manutacturing and testing of scalatble models to ensure the engineering feasibilit! of ITER.

- To pronose approaches for how the four parties could jointly implement the eonstruction. operation. and decommissioning of ITER.

The ITER organization during the EDA phase will differ from that of the earlier phase. The four parties will appoint an ITER Council to serve as a "board of direciors" and will designate a Project Director and sereral Deputy Directors. Each party will establish a Home Team organization and a Home Team Leader.

A Central Team. staffed with personnel seconded from the four parties. will be responsible for design integration. project coordination. and much of the overall enginecring design. Central Team design activities

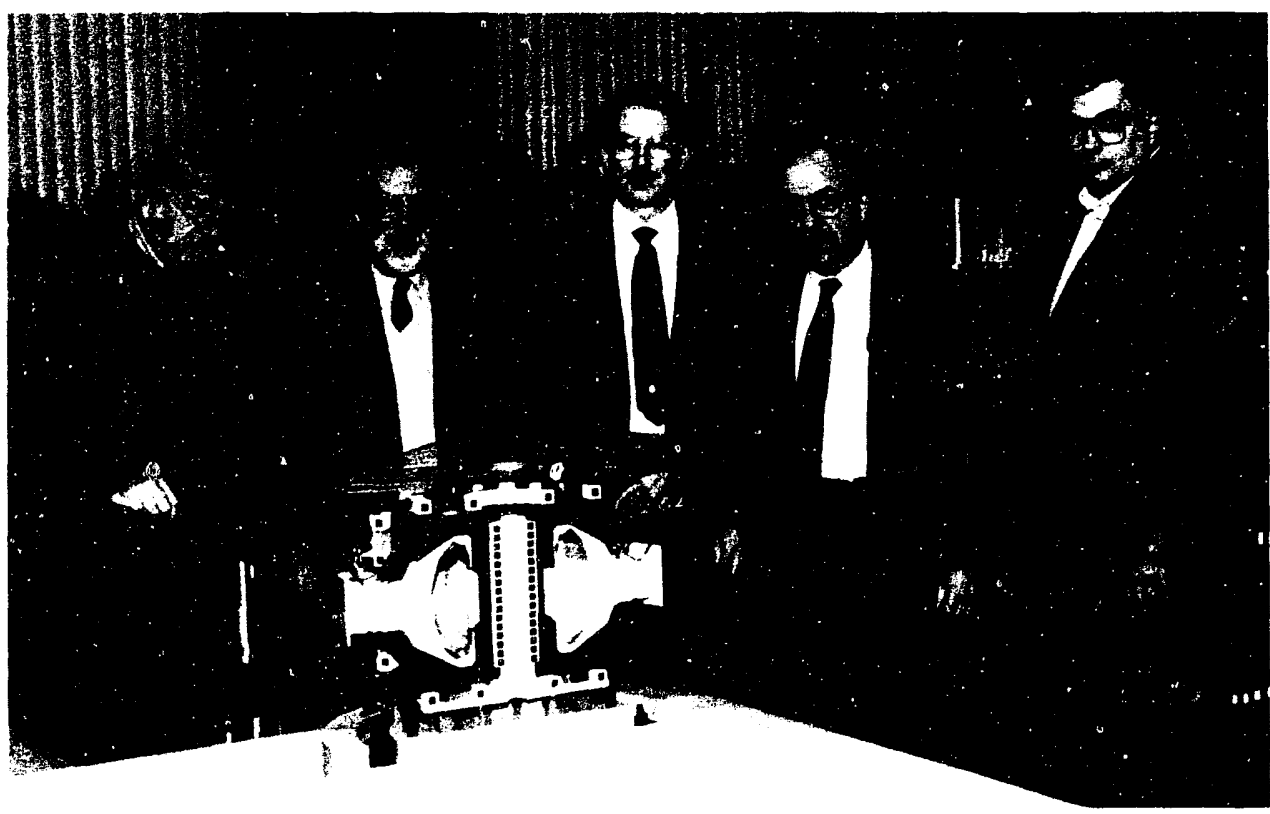

will be locilled in San Diego. California: Garching. Germany: and Nakia. Japan. The ITER director and design integration team $"$ ill be located in San Diego. The four Home Teams will undertake specifie design tasks and will be responsible for developing and testing all critical technologies.

Preliminary estimates (in 1989 LS dollars) are that the design work during the EDA will cost about \$250 million and require about 1200 professional person-years. Engineering research and development is expected to cost about $\$ 385$ million. The research and development of scaliable models, including prototype testing. is estimated at $\$ 397$ million.

Dereloping and testing scalable models of all critical technologies needed for the construction of ITER is a major EDA objective. Both nationally and internationally, the project is commitled to having these components built by industry. thus preparing an industrial base for bidding on ITER construction. The national laboratories and universities must team with industry to transfer the necessary technology. so that industry can manufacture the final components.

The preliminary capital cost estimate for ITER construction is St.9 billion. with construction expected to take about seven years. The EDA targets being ready for a construction decision in the mid-199()s.

ITER is the culmination of our understanding of fusion physics. and starting the EDA represents a major step in the development of practical fusion energy.

Comtact: 1. J. Gilass $(+15)+22-98(14$

Figure 1. Heading the U.S. Home Team for ITER are (1. to. r.) Jim Doggett of LLNL. Manager for Engineering: Chuck Flanagan of Oak Ridge National Laboratory. Project Coordinator: Doug Post of Princeton Plasma Physics Laboratory. Manager for Physics: Alex Glass of LLNL. Team Leader: and Charlie Baker of Oak Ridge. Manager for Technology . 


\section{Energy and Earth Sciences}

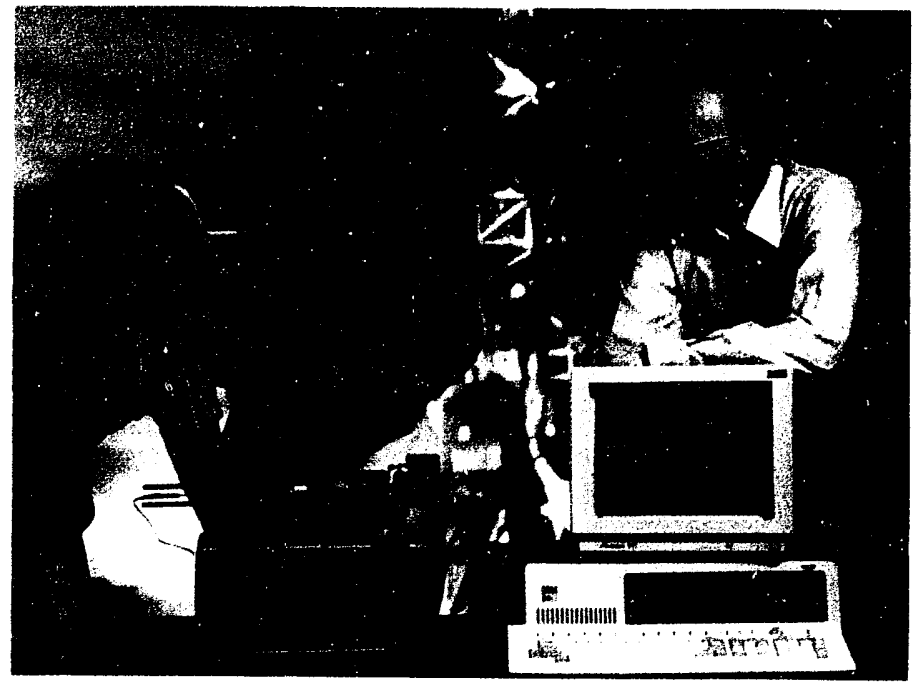

In support of research toward assuring affordable future energy supplies, our work ranges from exploring unproven alternative energy technologies, to designing for safe isolation of nuclear wastes, to increasing U.S. energy options for liquid hydrocarbon fuels.

$\mathbf{T}$ he Energy Program conducts research over a range of science and technologe to help ensure that the nation will hate adequate. atfordable enerey supplies in the future. In recent years. the mission of the Program has expanded to include the development of methods 10 reduce DOE process stream waste and 10 characterize and remediate contaminated DOE sites. We rescarch technologien that appear promising but are unproven or have not been explored by the private sector becaluse of the long lead-time from research to entrance into the marketplace.

L. . Yl is Environmental Technology Program (ETP) was organized in FY 1990 (o) consolidate and condinate L.LNL s work to research. develop. demonstrate. kest. and evaluate new technologies for making environmental restoration and waste management more effective at less cost. This work is described in the section heginning on p. 50 ).

\section{Nuclear Waste Disposal}

Future development of fission power requires a safe means to isolate the highly radioastive waste from the environment for more than ten thousand vears. Since 1977 L_L_NI has supported DOE efforts to characterize a candidate repository site at Yuccal Mountain. in Nevadat. We have been dereloping the waste package (WP) and engineered barrier stsem to encapsulate the waste in the repository. The scope of the assignment geres besond traditional engineering design. We mus define the W'P service environment: chatrateriac various materials degratation processes and select suitable container materials and fabrication processes: characterize how wasteforms and other man-made materials would behave in the geochemical environment of the repository: and develop an understanding of how radionuclides would be transported through the rock near a failed WP. Finally. we must develop models and computer codes for these processes that can predict the performance of the system for thousands of years. We have significantly advanced our understanding of both groundwater flow in fractured unsaturated rocks and the fundamental mechanisms of waste glas dissolution. and have incorporalted our new understanding in at series of new computer codes for predictive modeling. 


\section{Fossil Energy}

Beciatue the dependence of the L.S. tramportation $y$ sem on licutid petroleum fuel mates us vulnerable co price increases. LL.NL. - fomil encrge! program is amed at increasing the country is energes options in liquid hy drocarbon fuels to mits:ate the impact of future fluctuations in their cout and arailahility. Our largest foril energ! project deals with retorting of oil thate. an dexcribed on p. th. A result of this work has been improved understanding of how gramular solids flow a problem encountered in a hroad range of applications. ranging from soil mechanics on industrial processes. Our new numerical method for calculating the hy drody namic interation beticen particles are lers intensive computationall! so "e recently deseloped a new algorithm hated on a $3 \mathrm{D}$ lattice gas. Initial tests hate bown that obersed particlepartick interactions are yuantitatiols reproduced by thi lecthnique.

From our understanding of how herogen is concerted ar shate vil in at returt we have deseloped models for hou oil and natural gas (methane) deporit form in nature. A new compuler code. PMOD. which is more flexible. eavier to une. and computationally more efficient than our carlier codes. can simulate petroleum formation in hoth nature and the latheratury. Thi work is funded in part hs at conortium of $1+$ induerial sponors.

We are uning electromagnetic A.M induction method lo track the thermal front asseciated w ith the veam injected duringe conhanced oil reconery. In lygll. we staged the firs full-nate fickd kes of a cromhorchole E.M unem at a joint British Petroleum/S()Hle les ste in Derine. Texar. Tenting in a controlled retting housed that the "yem will acquire data trom which tomographic images of wheurface tedure can he crealed
Coupling inorganic caltals is research with hiofechnoless. we are dereluping new material for cattaly /ing the tram formattion of methane 10 more valuable liquid product. B! study ing the ens? mes that certain bateriat ue to cattaly the formation of methatnol from methane and oxy gen. "we can erentuall! derelop new eattaly ser for induntrial use.

\section{Conservation and Renewable Energy}

Our principal enerey conservation effort has been in combustion technologe. developing chemical kinetic model for the oxidation of hydrocarbons and other fuels. In the part year we identified the detailed chemical reatetions responsible for engine knoch. and developed a set of correlation between ignition hinetios and cotane number that are being uned to examine the role of tarious chemical additise in hnocking ignition.

In the areat of alternative energ! . We are developing and testing geoph sical techniques for monitoring subsurfate procenes to ultimately reduce the cost of operating a geothermal field. Working w ith Lnocal Geothermat Corp. we hale conducted at preliminar! seismic imagng stud! of The Gevers a producing gerothermal field in northern California.

\section{Earth Sciences}

The Earth Sciences Department comprises 9t profesionals who support project in the Eneres? Program and ETP. The department alor support defene research in the arcas of treat! lerification. nuclear cer comtainment. and hosk phosicy This pare cear. "ac prosided support for the implementation of the recents? concluded Thre hold Ten Ban Treat! and the Peateful Vuckeall Kaploriom Treally. For our contrihution we drew on rour ecismic and hedreds namic monituringe expertine. We are aldo

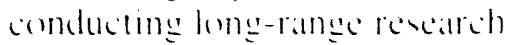
related to the nuckear -

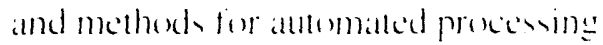
of xeismic data unge neural networhand other antificial intelligence exhmiques. The Contamment Program worh w w ensure the containment of radionatise dehris from the Latherator! - undereround nuclear con all the veradit Ten Site. The Shoch Phovic effort prosider calculational upport to the Containment. Verification. and Weapon Effect programs at the Laborator!

The Earth Sciences Department aloo has an adtice basic research program. largely funded by the DOE: - Office of Baric Energ? Sciences, in such areas an apply ing seismic tramsminson imaging to the stud! of the Earth s crust and upper mantle. study ing (ny! geen and catton diffusion in geological materials. and invertgating the rheologic properties of solid and partially molien roch and the electrical properticent important mantle minerals. As part of the Continental Scientitio Drilling Program. we participated in the geroph sical expedition w the Foraruptat area of the Valle? of Ten Thousand Smokes. in Alarkat. acquiring electromatenetic and gralsily data for use in elucidatting subsurfiace stuctures and deformittion

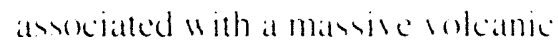
cruption in 1912 .

Our hasic rescarch program continues lo be enriched by the (enter for (jersciencer in the Institute for

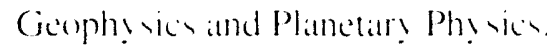
The Center promele collathoratise revearch betseen seitentise at the Laborators and all Linersit! of Calitornat campuese In recent years. (ome li) 10 15 -mall profect hate heen w supported.

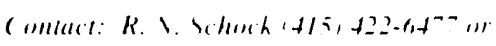
I. II. Sounher $1+15,+2-1)^{-2}$ 


\section{LLNL's Oil-Shale Project}

W e hatce made major strides this vear in laboratory studies of the fundamental chemistry of oilshale retorting. We dereloped new equipment and techniques for studying oil-shale pyrolysis and combustion under rapid heating conditions in a laboratory fluidized bed. and have published our kinetics results for western and eastern shales over a range of conditions. Using a computercontrolled triple-quadrupole mass spectrometer (TQMS), we are measuring key properties of shale oil to atseses its long-term stability. quality. and upgrading needs and to determine under what conditions shale oil can be prodiced and transported without the need for field hydrotreating. (Refinery hydrotreating would eliminate expensive duplication of equipment in the field and thus greatly reduce plant costs.) We are also using the TQMS 10 measure individual species evolved during ramped heating of oil shale. including trace sulfur and nitrogen compounds. We are developing specific technicyues for meatsuring nitrous oxide $\left(\mathrm{N}_{2} \mathrm{O}\right)$ during shale combustion: although commercial stack-gas monitors do not currenty measure $\mathrm{N}_{2} \mathrm{O}$, it is a greenhouse gas and an ozone depleter. and future emission limits will certainly be imposed.

We continue to make progress in our studies of shale oil coking and cracking. The kinetics of oil vapor coking hate been studied experimentally by passing a pulse of oil vapor through at hed of shale particles. These experiments hate

Successful completion of our oil-shale project, in 8 to I0 years, will enable U.S. industry to begin commercial development and use of oil shale early in the next century. Vast oil-shale resources in the western U.S. will provide an important alternative domestic source of liquid transportation fuels.

shown that the mass transfer step in the adsorption/desorption of the oil is very important. In addition. We are investigating particle size and

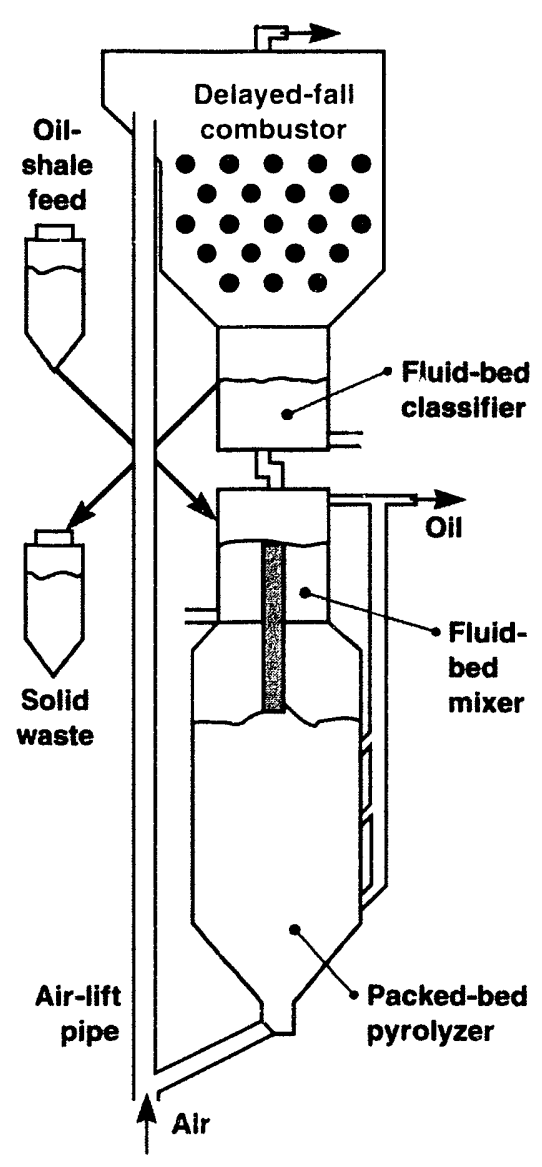

Figure 1. Diagram of the hot-recycledsolid (HRS) oil-shale retorting process as used in our 4TU pilot plant. Raw and recycled shale are mixed in the fluid-bed mixer and sent to the packed-bed pyrolyzer for oil generation. The shale is then lifted pneumatically to the delayed-fall combustor. where residual carbon is burned to provide process heat. Solid waste is discharged from the fluid-bed classifier. porosity effects both in the laboratory and by mathematical modeling.

Our field efforts revolve around further development of the hotrecycled-solid (HRS) process for retorting oil shale (Figure 1). In this LLNL-developed process. hot spent shale is used to heat the raw shale. Retorts using hot solids as the heat carrier offer distinct advantages over hot-gas retorts, including rapid throughput. higher oil yield. better product quality, the ability to scale to larger sizes. fewer restrictions on processing fines (small particles). and reduced environmental impact resulting from the self-scrubbing of sulfur.

We are studying second-generation hot-recycled-solid (HRS) processes in our t-tonne-per-day. continuousloop retorting test unit ( $4 \mathrm{TU}$ ). The tTU facility was completed in September 1990). and we produced our first shale oil in December 1990). In February 1991. we began a series of runs during which we collected enough oil (approximately 10 gallons per run for detailed characterization studies. Through these runs. we will determine the major process operating parameters on which to base a detailed design of a field-test unit. al a scale of approximately $10(0$ tonnes per day. 10 be sited in western Colorado.

We are in the process of forming a consortium of companies to further develop our HRS retorting technology. With our industrial partners and the DOE. we will develop a program plan for field demonstration and exentual commercialization of the HRS process.

Gontact: R. J. (inut+1.5) +22-7.3.36. 


\section{Locating Subsurface Steam Reservoirs Using Seismic Tomography}

Our seismic tomography method, tested successfully this year at The Geysers geothermal field, show's great promise for exploring for new geothermal resources or for studying the decline of mature steam reservoirs. widtho for compressional water from microeartheyaties at the lield asing data provided by LNOCAL: Geohermal Division). Lnlike previous imaging with local earthyuakes att The Gevsers. He solved for hoth velocily and allenuation images. Since compressional waves change both relocity and attenuation when thes pas through rocks with seam-filled pores. it is theoretically pomsible wo distinguish between seam- and liquid-11 ater-filled rochs and rocks that contain at tate-phatse ! stem of steam and liquid water. If a lluidfilled rock is stouly dried. altenuation increases while velecity remain relatively unchanged. When the rock s pores are complicisly filled (a) Velocit!

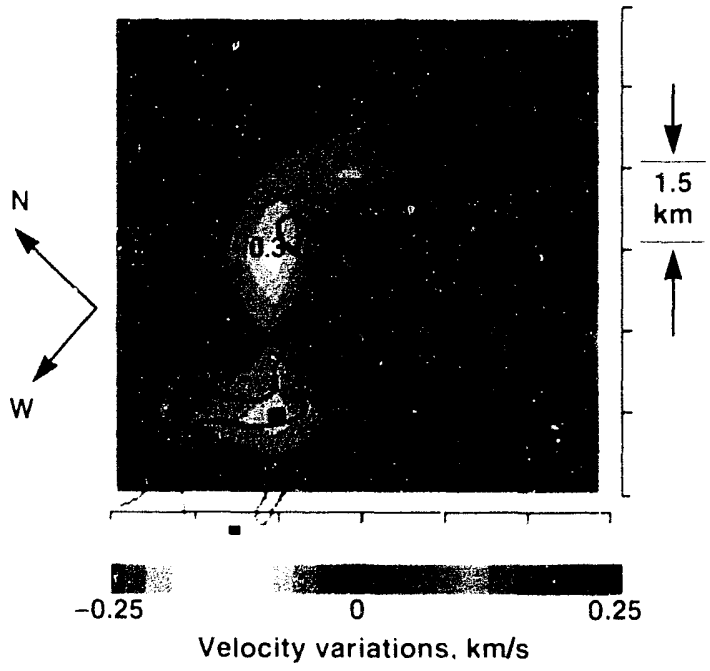

(b) Altenuation

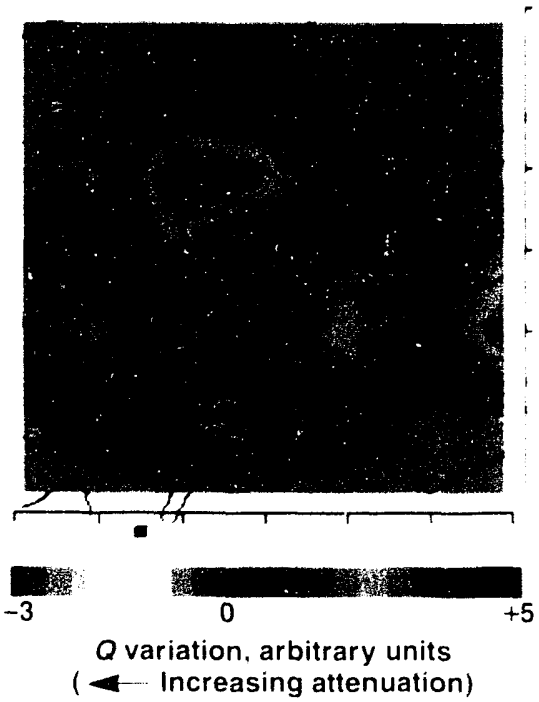

Figure 1. Comparison of the seismic image with the depth to the known dry steam reservoir as a function of velocity (a) and attenuation (b). Contours show depth to the dry steam reservoir below sea level. These images are "slices" $0.5 \mathrm{~km}$ below sea level: the red contours highlight the depth closest to the image slice. The black squares show the locations of the geothermal power-production plants. "with dry scam. both relocity and attenuattion decrease. L'sing seismic tomography. We can map out these velocit! and attenuation patterns and interpret them to locate steam and tilo-phase water in the rocks.

Figure 1 plots our preliminary results from The Geyers. The contours show the depth below seat level to the known dry steam renervoir. These callouts are plotted on top of colored horizontal slices through the volumetric tomographic image. These results reveal lowvelocity. low -altenuation signatures within the red contours. indicating the presence of dry steam: this is particularly evident within the red contour in the upper part of the image. The red contour in the lower part of the image actually has high attenuation. indicating the presence of both liquid water and steam thowever. He do not hate drilling information to confirm this finding!). The red contour on the right edge of the image is not well resolved and is uninterpretible.

This experiment clearly demonstrated the potential of our seismic tomography method. vext vear. we plan 10 monitor a well where watter is being injected bateh into the reservoir to replenish the seam supply. He hope wo be able to map the distribution of the water around the well an it flow sack into the reservolir. This methed shows greall promise as a lool for mamaging geothermal resulares.

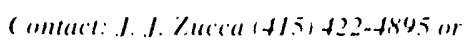

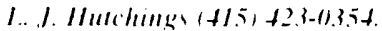




\section{Episodic Nonequilibrium \\ Fracture-Matrix Flow and Waste Repository \\ Performance}

LLNL must assess how well the Waste Package/Engincered Barrier System performs and predict its interaction with the near-field environment of the potential nuclear repository site at Hacca Mountain. Our numerical models and comprehensive theory describe the flow regimes that arise from fracture-matrix interaction.
$\mathbf{T}$ he potential Yuceas Mountain sile of a nuclear-waste repositurs lices in the unsaturated /onc. about $27.540 .525 \mathrm{mbel}$ be the eroundsurface and $225 \mathrm{~m}$ abore the walce table. To be suitable. the site must préent gas-or liquid-phase radionuclide tranyport to the aceessible ensironment for $10.0(1) 0$ years. In most fatlure mechanisms. Water contacts the wask pachate ( WP) hastens WP failure and tramyports radionuclides to the water table. (iiven the ver! small matrix permeabilit! of the cuff units all Yucea Mountain, fracturedominated flow - particularly along lertically connected fracture neturitis-is a much more likely problem than matrix-dominaled flom In the unsiaturated /one. the depth to which fracture flow persists below a source of thater is extremely semsitice to incraction with matrix thow. We hate deseloped numerical models and a comprehensise theory dexcribing the flow regimes that arise from fracture-matrix interaction.

Becallse of its impact on WP performance. We hale been analy /ing lomg-term. near-ficld. thermohidrological response (o) WP emplacement. ming our models. latoratory experiments. and in situ testing. We must determine the ent irommental parameters required la asees $\mathrm{WP}$ performance and predict radionuclide tranyport from an! tailed WP. Becalue Yueca Mrountain lall has small matrix pores. Haller is held under ver! high capillary suction potential. casusing the fratetures. and the W'P horeholes. to he drained of water under ambient reyuilibrium or scady-state) saturation conditions (Figure 1). This capillars harrier between the WP and the borehole wall is a primary hydrological performance attribute of the $W$ aste Pachage/Engineered Barrier System (WP/EBS). As long ats rock around the WP remains partially saturated and the capillary barrice is intact ono conticet with the borehole walls or sloughing of rock into the horeholes).

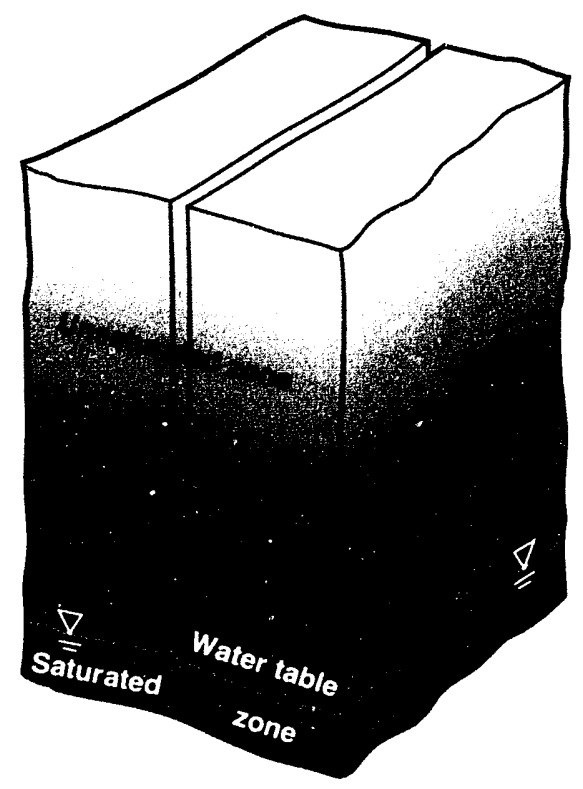

Figure 1. For zero recharge flux the system is in gravity-capillary equilibrium. with the fractures drained of water above the water table. only fracture flow will allow water to contact the WPS.

Measurements of homb-pulse ${ }^{36} \mathrm{Cl}$ ffalloul from aboveground nuclear tests) and saturation and water poremtial data are comsistent with the occurrence of episolic nonequilibrium fracture-matrix flow from the groundsurface to considerable depths. Since assessment of the Yucca sites suitability must accoumt for these measurements. He model and analye nonequilibrium fracture-matrix flow and radionuclide transport. To understand semi-yuantitatively how bomb-pulse $36 \mathrm{Cl}$ might penetrate deep into the mountain under transient llow conditions. We incorporated sitespecific datta into idealized systems.

We analyzed fracture-matrix flow interaction using several approximations. ranging from effective ecro order. through effective fïst order. to second order. as described below: the equivalent continuum model (ECM) assumes fractures and matrix to be in local capillary equilibrium. The dualporosity model represents mass transter between fractures and matrix blocks by a mass transter coefficient times the difference in potential between the fractures and matrix blochs. which assumes quasi-steady state flow. The fracture matrix model (1) MM) discrelely aceoume for frateture and matris propertices. therehy accoumting for nonequilibrium. mom-skady-stale. fracture-matrix

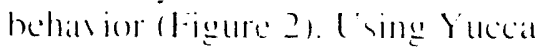


Mountain fracture and matrix data. we have shown that the ECM has an extremely limited domain of applicability. and the FMM predicts flow behar ior identical to the ECM when the latter is valid.

To develop a comprehensive theory describing the principal flow regimes arising from fracturematrix interaction. we performed numerical modeling and developed analytical and semi-analytical models. With sufficiently small flux into a fracture. the matrix near the inlet imbibes most of the water before it can move far along the fracture. The liquid front in the fracture lags behind the front in the matrix. and the matrix properties dominate the wetting front speed. For this condition. which corresponds to matrix-dominated flou. ECM is saltisfactory.

Fracture-dominated flow occurs at higher fluxes. The licpuid front in the fracture moves ahead of the from in the matrix. and most matris flow is perpendicular to the fracture: competition between gravity drainage in the fracture and capillary imbibition into the matrix governs the front speed in the fracture.

In studying the depth to which water could penetrate along a vertical fracture from a ponded source. we found that little additional penetration occurs after the source is removed. Twokes factors determine whether water will contact a WP: intensity and duration of the maximum possible infiltration episode. Matrix saturations in Yuccia Mountain welded tufte decar to their initial values within several monthe of an episodic infiltration. Maximum infileration could be by a series of closely spaced episodic events.

From fracture and matrix property datla for Yucear Mountain. we studied episodic transient flow from the groundsurfice to the water lable. To evaluate how fracture and matrix properties contribute to flow within each of the major hydrostratigraphic units. we modeled idealized systemssets of uniformly spaced. constantaperture fractures penetrating the entire thickness of the mountain from groundsurface to water table. Over a broad range of apertures. $h$ $(10<b<10(0) \mu \mathrm{m})$. We found that the relative impact of lateral matrix flow varies from a $b^{-1}$ dependence for large $b$, to a $b^{-3}$ dependence for small $h$. Fracture-dominated flow is greatest in the low-permeability welded and zeolitized nonwelded tuff. The large matrix permeability of the vitric nonwelded tuft results in matrix-dominated flow for small(o-medium aperture fractures and fracture-dominated flow for large aperture fractures. The high permeability of the vitric nonwelded luffs mat cause substantial lateral

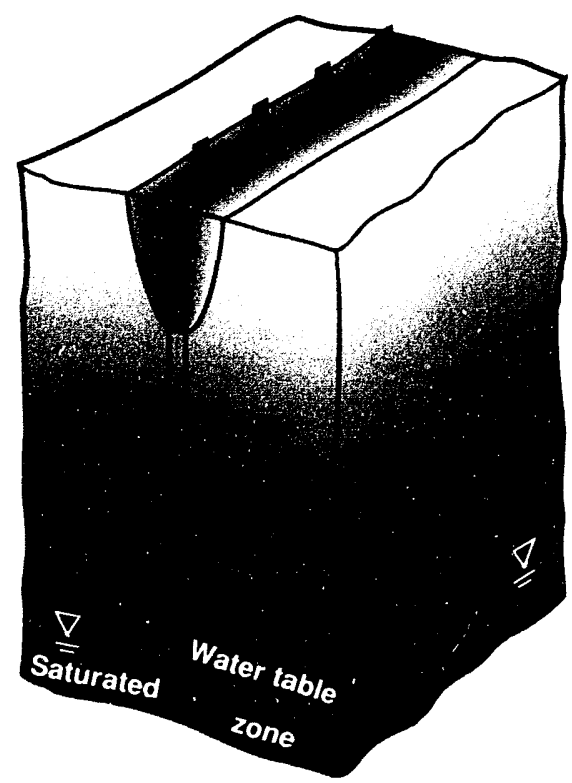

Figure 2. Episodic infiltration event causes capillary disequilibrium between fractures and matrix blocks. matrix flow. Lateral llow interatetion with rertically contiguous structural features (e.g.. fitults) maly be among the most problematic preferential pathways to the water table.

A liquid pulse descending a fracture continually loses water to the matrix. If water from a sufficiently intense pulse reached a failed WP. it could dissolve radionuclides and transport them loward the water table. Shortly after the end of the episodic event. the matrix will have imbibed all liquid in the fracture and any dissolved radionuclides. Subsequent liquid pulses would not displace to greatter depths radionuclides inbibed during earlier events. becaluse typical molecular or ionic diffusivities do not exceed matrix imbibition diffusivity. Hence. advection by imbibition away from the fracture will dominate diffusion toward the fracture. A radionuclide front not driven to the water table during a single infiltration episode will be governed subsequently by matrix-dominated flow.

We will continue to analyze episodic nonequilibrium fracturematrix flow. from the repository horizon to the water table. for somewhall idealized fracture geometries. We also plan to assess flow channeling in fractures and fracture networks. We will validate our models with data from laboratoryscale radionuclide transport experiments and field-scale transpont studier using natural geochemical isotopes. We will then create largescale models by developing fracturematrix interaction representations. possibly including a modified dualporosity approximation.

(ontact: T. A. Busheck (11.5) +2.3-9.391) 


\section{Environmental Technology Program}

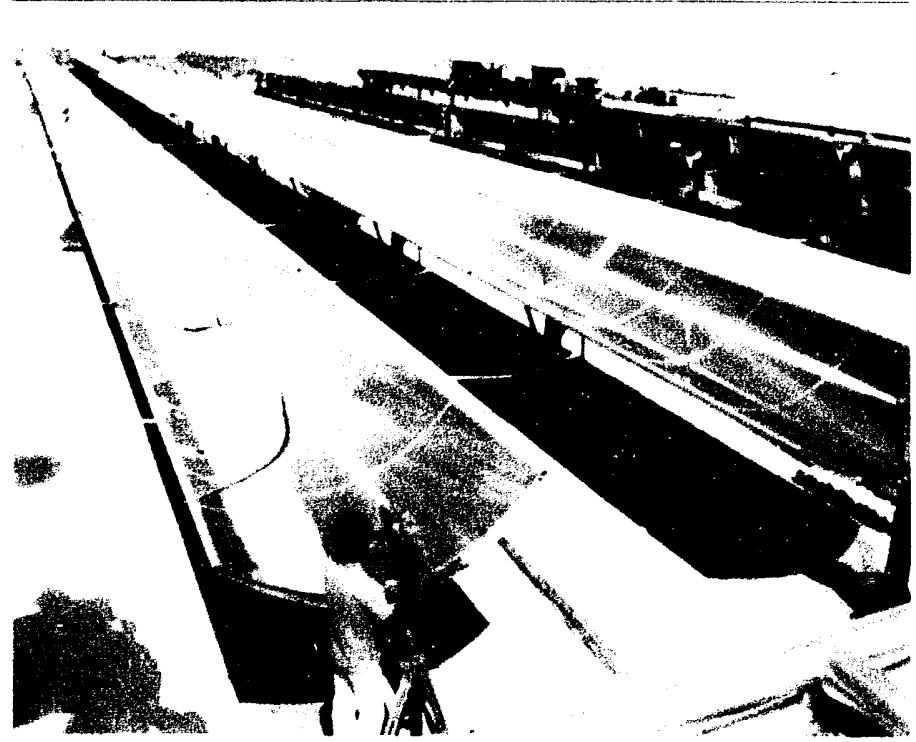

The Environmental Technology Program serves as the focal point for developing and applying LLNL technologies to meet the wide range of needs in environmental restoration and waste management.

$\mathbf{T}$ he Envirommental Technolog: Program was formed in 1990) 10 proside a structure and cohesion for lechnologs development activities in "I alse management and envirommental restoration being conducted under the auspices of many different Eaboratory organizations. The charter for this new program is to research. develop. demonstrate. test. and evaluate innovative technologies for reducing the cost and increasing the effectiveness of waste management and ems irommental restoration efforts. The Environmental Technology Program embraces six clements:

- Hazard assessment and rish management.

- Characterisation. monitoring. and anals is
- Subsurfiace (groundwalter and soil) remediation.

- Waste treatment.

- Waste minimization.

- Education initiatives.

Hazard assessment and risk management require evaluating the risks associaled with existing and new alternative environmental lechnologies. In addition. methods for ranking havards and evaluating proposed solutions are developed and tested. A recent aceomplishment in this area wats the development of methods by which the D()t: ()flice of Technology Development could set the relative priorities amome resarch activitics.

Characterization. monitoring. and analysis insole the dere! proment and iesting of fook for delecting and measuring contaminant compounds (both in situ and in samples and process streams). for monitoring the transport and fate of contaminants. and for simulating. evaluatling. and extrapolating the effects of treatment alternatives. The objective is 10 obtain quantitalise information about the contaminants and their envirommental selting. Accomplishments include numerical analysis of in situ atir stripping of comtaminamts through horizontal wells, development of fiber-optic sensors. and clevelopment of methods for measuring retardation factors and distributions al subsurfates contaminamts.

Subsurface remediation adderesses the chatlenge of removing. destroying. or comtaining subsurlace comtaminams. 
We are generating state-ol-the-all allermatives for treating subsurfices contamination and are defining the needs for characterization. monitoring. annalysis. and treatment lechnologies. In particular. He are insestigating latcum-induced icnting for fuel hydrecarbon and volatile organic compound $\mathrm{VOC}$ icontaminants We are also researching the use of microbial fifters for treatting underground $V O C$ contaminants in situ (i.e.. without pumping the contaminated "later to the surface).

Waste treatment includes dereloping and keving kechnologies for remor ing. destrosing. or treating contaminams that are alleady under contanment or that are being generated b! manufacturing. remediation. or experimental proceses. Accomplishments include the deselopment of approaches for horemediation of high-explosive waster in processing watlers. for molen-salt destruction of mixed wases. and for remosing VoCs from groundwater and wante water.

Waste minimization is concerned with developing wat 10 minimize the generation of havardous waste or contaminants during manufacture. remediation. or experimental procenes. ()ur aim in to identify oserall whem improsements that will reduce the amount of waster generated at the source. A rewable. ckanate. seel HEPA highefficienc! particulate arr filler is heing dereluped we replace the currenty uned glan-fither paper HEPA filler and eliminate the anscrated dieporal oms. Robotion !bem are heing developed 10 reduce procesong waster wenable remote field characterisation. and

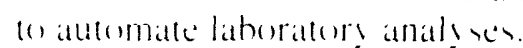

Educatton initiative are needed to help verengthen the peol of technical lalent at ailable to the Laboratory and the nation for work in en irommental restoration and waste mandecement. He are collaborating with unicersitics. industry. and other government lahoratories and agencien to encourage edacation and career training in hey lechnicial areans.

The Environmental Technolog! Program dratus from the Laboratory many capabilitien dereloped in our defense-related work. These captahilities include the derelopment. derign. and analysio of large engineered systems and field tess, the design and implementation of advanced iristrumentation. measurement. and calihration systems. the numerical imulation of complex wistems and procesese. and the development of specialized materials processing and manufacturing methods. In turn. the program prosides new kechnologies 16) the defene complex and to other national and international uners to support waske-treatment and waskeminimization activities and to expedite the resolution of subsurface contamination problems.

The work of the program is interdisciplinary. reguiring expertise in chemistry and matierial science. computations. carth sciences. energes and laver research. engineering. biomedical and envirommental siences. emsirommental protection. hatards control. nuclear chemistry. and physics. The program therefore exploit the Laborator! " matris sracture on huild multidisciplinar!

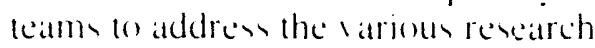
topicr.

In addition to intrat Laborators collaboration. program scientiste and engincer are collaborating with unisersities. industry. and sther gorermment organizations. effectiols transterring technoleges into and out of I.I.NI an meded. Industrial comnections include specialised consultants who help with techonology desedement and companies that are interested in licensing technolugies developed by the program. Academic connections include Stanford Lnisersity and several campuses of the Lniversity of California through the Institute for (ieophysics and Planetary Physics and ihrough other agreements. We are also working with the Nattional Institute of Standards and Technologe. the Soldar Energ! Reseatreh Instiute. and the U.S. (icological Survey. In addition. since many lechnologe developed by the program will be applied wa activities requiring regulatory compliance, we are working clonely with cognizant regulattory agencies. We are also collaborating with a number of other national laboratories in the context of DOE: Integrated Demonstration Projects, including Westinghouse Sallannah River Laboratory. Sandia National Laboratories. Idaho National Engimerring Laboratory. (Oak Ridge

Vational Laboratory. and Pacific Northuest Laboratory.

Even in its first vear. the Environmental Technology Program has prosen its effecticeness in focusing the Laboratory sefforts in environmental restoration and waste management. Expertise dereloped in our defense-related work is being applied of devise innorative solution to the difficull challenger pored by ens ironmental restorallion and waste management. (o)llaborations With academiat. industrs. and wher gerermment instituter are facilitating the rapid transter of technologe into and out of I.I.XI.

(ontact: I. I. Son. Ir. $+115,+22-352)$ 


\section{In Situ Microbial Filter}

Subsurface biodegradation of volatile organic compounds offers minimal environmental impact and potential cost savings over pumpand-treat methuds. We are researching a novel in situ microbial-filter containment and treatment strategy.
$\mathbf{T}$ he soils and groundwater of several DOE sites. including LLNL. are contaminated with low levels of volatile organic compou ids (VOCs). The DOE and LLNL arc investigating methods of cleaning up such sites. One novel but complex approach is to use naturally accurring. harmless microbes to break w. Wh the VOCs to nontoxic byproducts via a "microbial filter" that is placed in situ. For this purpose. we plan to grow select naturally occurring. pollutantdestroying bacteriat in the laboratory to the needed quantities. However, to use this novel strategy predictably. We must understand the flow and transport phenomenat. aqueous environmental chemistry. microbial chemicalconversion atetivities. and cell population dınamics. We have therefore formed an interdisciplinary team of microbiologists, biochemists. geochemists. hydrologists. engineers. hydrogeologists. and physicists.

Otten subsurface $V \dot{C}$ contamination manifests as large moving. expanding plumes. Theoretically, bacteria injected into the ground in vertical or horizontal zones along the downstream boundaries of a spreading contaminant plume will metabolize the VOCs as rapidly as hydraulic flow transports the chemicals to the "filter." Bacteria applied at the contaminant source could also reduce the amount of VOCs entering the plume.

We have identified as a prime injection candidate a naturally occurring methanotrophic bacterium. Methylesimus. that can rapidly degrade two representative chlorinated VOCs.

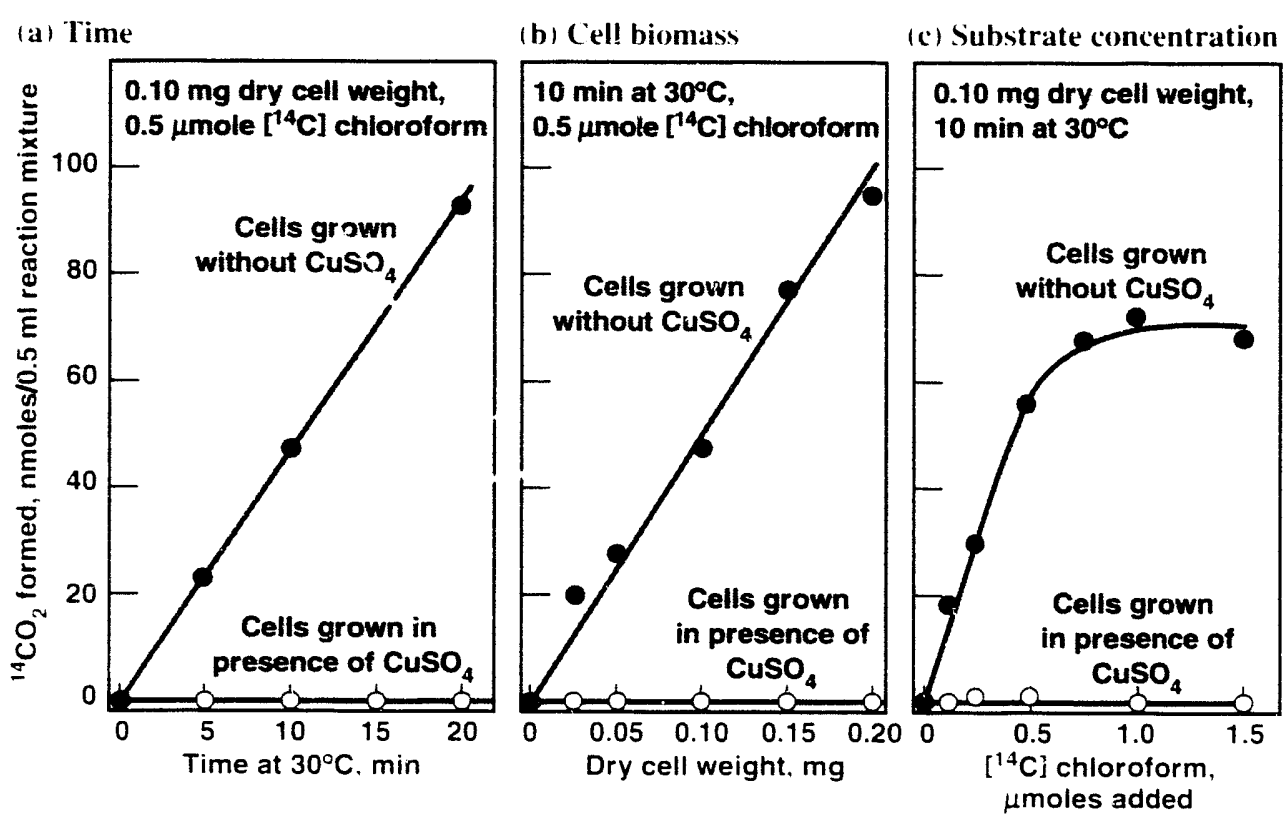

Figure 1. Oxidation of $\left[{ }^{4} \mathrm{Clchloroform}\right.$ to ${ }^{14} \mathrm{CO}_{2}$ by sMMC-containing Methylosinus as a function of (a) time. (b) cell biomass. and (c) substrate concentration. Cells grown in the presence of added copper sulfate $\left(10 \mu\right.$ molar CuSO $\mathrm{J}_{\downarrow}$ exhibit a total lack of [ ${ }^{1.4} \mathrm{C}$ ]chloroform oxidative activity. The same applies to oxidative biodegradation of TCE by this microorganism. trichloroethylene (TCE) and chloroform. We have defined the culture conditions that maximize the intracellular level of the VOCdegrading protein biociatalyst. methane monooxygenase ( $\mathrm{MMO}$ ). within Methrosinus.

We have also developed simple microvolume radioactive assalys for measuring the cellular conversion rates of $11.2-{ }^{1+} \mathrm{C}$ ITCE and $1^{1+} \mathrm{C}$ chloroform to nontoxic "I ater-soluble oxidation products (Figure 1). From these rattes. we extimate that a $1-m$-thick zone containing only $1 \mathrm{mg}$ of cell mass per liter could treat the TCE plume boundary at the LLNL site for several weeks.

TCE and chloroform degradation are biocatalyzed by Methylosimus bacteria provided that they contain a soluble intracellular form of the MMO enzyme (sMMO). If grown in the presence of copper ions (at micromolar levels). these bacteria synthesize a distinctly different particulate (membranebound) form of $\mathrm{MMO}$ (pMMO). Cells containing pMMO cannot biodegrade TCE. chloroform. or a variety of aromatic VOC pollutants such ats benzene and toluene.

From 5-L bioreattor experiments. we established the growth conditions for obtaining large yuantities of Methylosinus with exclusiveis sMMO. and for markedly influencing the whole-cell s.MMO catalytic half-lite. which we hate extended to at leatst $3(0)$ hours. Through future work on this intracellular stahilization biochemistry. we will optimize the effectienes of this methanoureph fior subsurfice injection- $\left.{ }^{\circ}\right)($ hiockegratdation.

(omeact: R. T. Tarlor $+15,+22-56.52$, or R. B. Knapp it15, t23-332. 


\section{Destruction of Mixed and Hazardous Wastes in Molten Salt Media}

We are developing a two-stage pyrolysis process that will rapidly, safely, and economically destroy radioactive and toxic combustible wastes using controlled oxidation within beds of molten salts.
$\mathbf{L}$ L.VL and Rockwell International are dereloping a process using controlled oxidation in beds of molten salt to devtro! waster containing both radiontice and tovic components (mixed watstes). This alternative to incineration reduces latge lolumes of combustible solids and liyuids to small inorganic reviduals that can be immobilized in eement for burial or procesed further for actinide or toxic metall recosers.

Molten siltiviarbonate and halide eutection proside the heall transter and reaction medium for pyrolsis or ovidation. caltaty es the oxidation of organics. and present atcidic galse te.g.. HCli from forming by forming solution of their stable salts reg.. $\mathrm{NaCl}$. Molten salt at $7(0)-9(k) \mathrm{C}$ in a ceramic-lined rend r Figure 1 , reduce the "laste to inorganic mixtures of "inh" and sodium chloride. An ayuesur proces then separater the miverures into disposable products and recseles unreacted carbonite to the prols is unit. The mele restricts the formation of potentially fugitice radediatise particulates and molecular species by a combination of particle wetting. encapsulation. and disolution. The proces will operate as and ox! genfed. electrically controlled "cheded" $\because$ pem. temporaril! retaining all gat produch rualer and carbon dosides until the cion be tesed. This metherd deciupler llaste treatment from product dircharge and prevents ilcidentat emisioms.

We are e alluating a refinement of the current molten sald ovidation

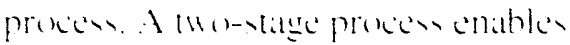

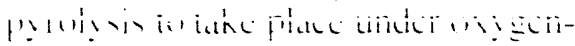

deficient conditions. followed bs complete oxidation of the pyrolyis gases. The oxygen-lean mediat present the oy gen-citalyzed polymerization of alumina and silical components which could freeze the melt and clon the pipingl. so we can treat alluminatand silicatrich wastes. The lower gats exit temperature-about $7(0) \mathrm{C}$ broidens our choice of comstruction materials and retards salt evaporation. simplifying outgats cleanup. Totert these concepts. our two-stage benchscalle apparatus. two 15-cm-diam by I-mexternally heatted stainlen-sted esoch will pyrolyze common waste surrogates.

Wie mokeled the rolatilities of $L^{\prime}$ and $\mathrm{Pu}$ in molten salt and other thermal oxidation processer because the extent of wolatilization affeces the design of oulgar cleanup processes. We found that gaseous species might erole according to the reactions

$1 / 3 \mathrm{~L}_{3} \mathrm{O} \mathrm{O}_{4}(\mathrm{~s})+1 / 6 \mathrm{O} \mathrm{O}_{2}(\mathrm{~g})+\mathrm{H}^{2} \mathrm{O}(\mathrm{g})=$ $\mathrm{CO}_{2}(\mathrm{OH})^{-1}(\mathrm{~g})$

$\mathrm{PuO}_{2}(\mathrm{~s})+1 / 2 \mathrm{O}_{2}(\underline{2})+\mathrm{H}_{2} \mathrm{O}=$ $\mathrm{PuO}_{2}(\mathrm{OH})_{2}(2)$.

Ling bond energy and entropy correlations for related species. we estimated the free energies of formation of gaseous L and $\mathrm{Pu}$ oxwhydroxides to be $(-1272+(1.22 \mathrm{~T})$ and $(-1122+0.237 \mathrm{~T})(\mathrm{kJ} / \mathrm{mol}$. $\mathrm{T}$ in K). respectively. which atgrees reasonably well with experimental atinide oxyhydroxide datat.

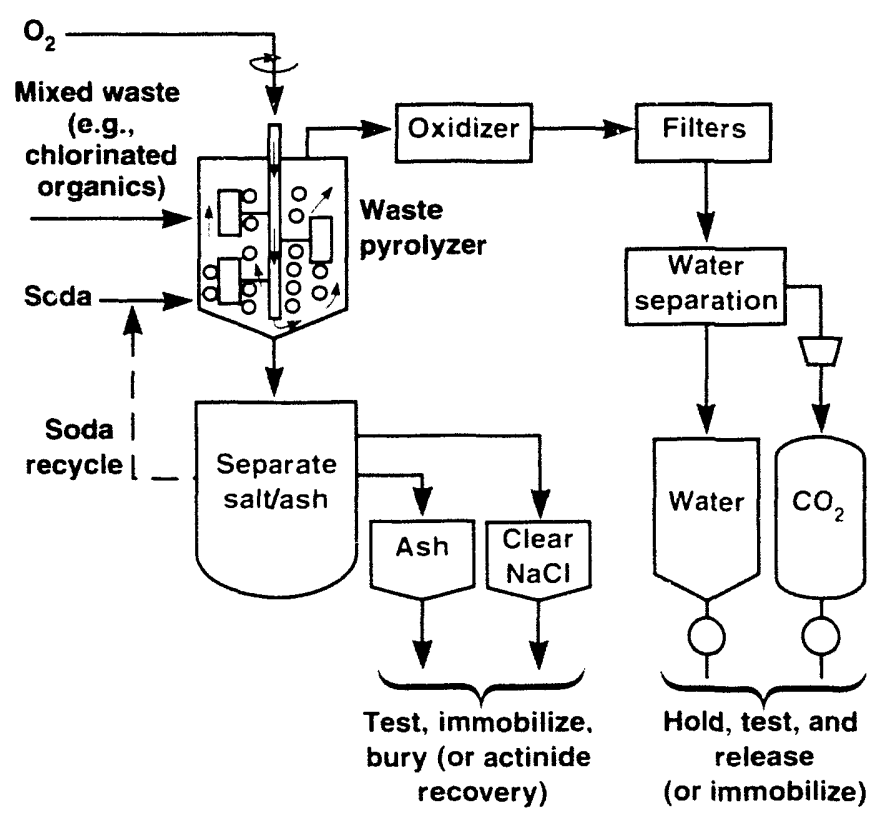

Figure 1. The molten salt process oxidizes the combustible fractions of mixed waste, temporarily retaining the product gases as liquids pending assay. The solid products are immobilized ash and a nontoxic salt containing the halide fraction of the original waste. 


\section{A Fiber-Optic Sensor for Monitoring TCE}

$\mathbf{E}$ nvironmental monitoring requires measuring contaminant concentrations. often at trace levels and in difficult-to-realch locations. We hate invented a fiber-optic chemical sensor for detecting the chlorinated hydrocarbons trichloroethylene (TCE) and chloroform. The chemical basis of this sensor is the irreversible development of color in specific reagents when exposed to various target molecules. In our original single-measurement sensor. at small amount of reagent $(20 \mu \mathrm{L})$ is placed in a capillary tube sealed at one end with a porous Teflon membrane. Two optical fibers are sealed into the other end of the tube. with their ends immersed in the reatgent to a depth of about $0.5 \mathrm{~mm}$. Target molecules-
We have developed a fiber-optic chemical sensor with an accuracy and sensitivity sufficient for environmental monitoring of trace levels of trichloroethylene (TCE) and chloroform.
TCE. for example-pass through the membrane and produce color in the reagent. The color decreases the transmission of $54($ )-nm light. The amount of eolor in the reagent provides a quantitative measure of the concentration of the target molecule. Since the reaction is irreversible, the reagent must be replenished for every measurement: this is accomplished by using replaceable, disposible capillary tubes. A newly developed continuous-measurement sensor differs from the single-measurement version only in the addition of $t w 0$ microcapillary tubes to supply fresh reagent to the sensor (Figure 1 ).

Light for the sensor comes from a miniature tungsten-halogen lamp. The "input" optical tiber transmits

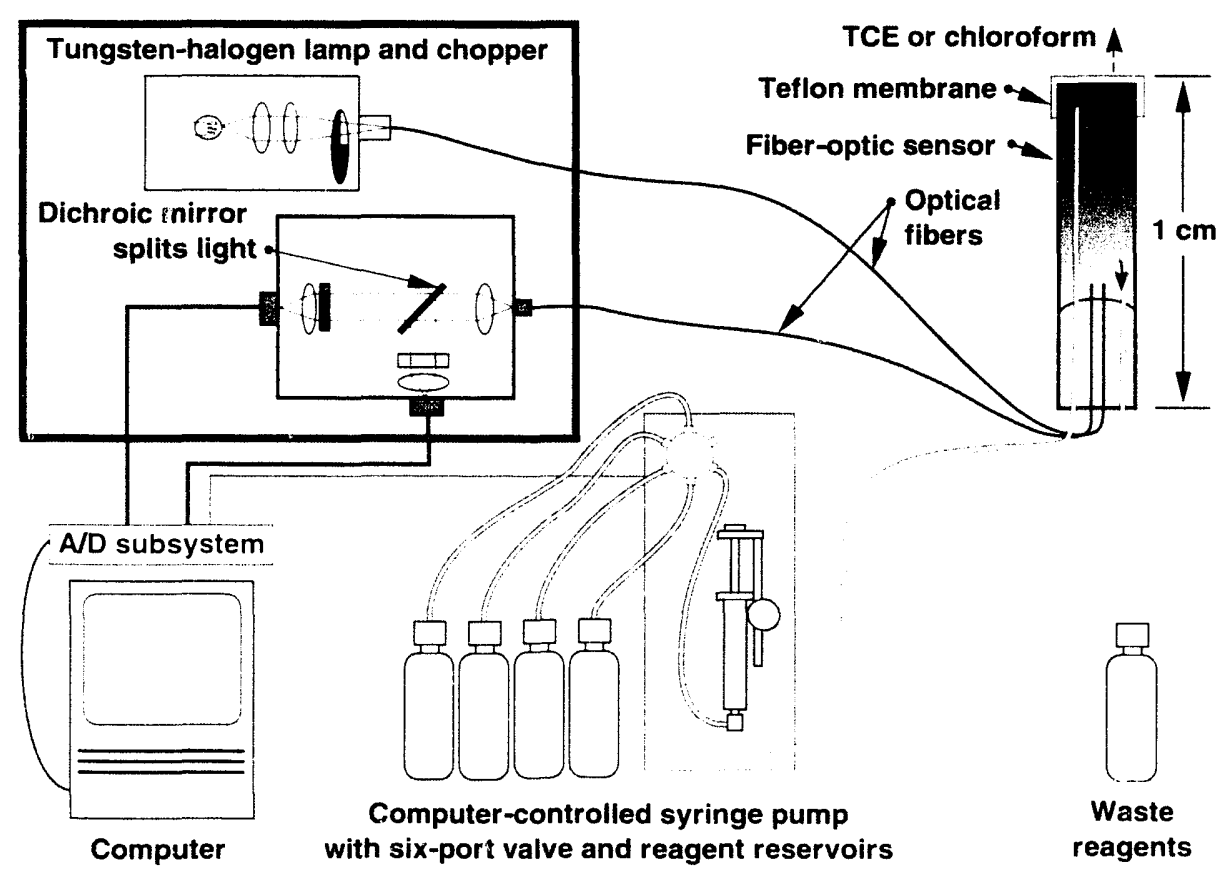

Figure 1. Diagram of the continuous-measurement fiber-optic sensor and readout. this light to the sensor, where it passes through the chemical reagent. rellects off the Teflon membrane. and is collected by the second, "output" optical fiber. This second fiber transmits the reflected light back 10 an optical block. where a dichroic mirror divides it into two beams. The two beams are optically filtered at $5+()$ and $640 \mathrm{~nm}$ : the ratio of 54()$-\mathrm{nm}$ to $6+()-n m$ light gives a nearly driftfree measure of $54($ )-nm absorption and thereby a measurement of contaminant concentration.

For groundwater monitoring. the single-measurement liber-optic sensor was evaluated against gatschromatograph measurements of TCE. Samples from 4) LLNL on-site monitoring wells were analyzed by both methods. The results from the two methods were in good agreement: all the fiber-optic sensor values fell within the vartiance of the gas chromatograph values.

For monitoring in unsaturated soils above the water table (radose zones). we tested the single-meatsurement sensor and a field gas chromatograph simultaneously at several soil-vapor monitoring points at Site 3(0). Again. the values were in good agreement. Moreover. Whereas the gas chromaltograph had reached its detection limit. the fiber-optic sensor readily made measurements at TCL: concentrations of <lo pph (rolume (o) volume. in air). These tests clearly demomstrate the semsitisity and accuraty of this new sensor. This censor should soon be an integral componeme of emironmentalmonitoring.

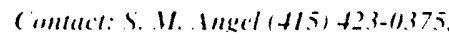

r. I. Malay $+15.5+2.3-175 \%$ ar

I. P. Wilamonich $+1,5)+22-6,5.3$ 


\section{Biodegradation of High-Explosive Wastes}

In our effort to develop methods for treating high-explosive (HE) wastes in soil and water, we have defined conditions under which microorganisms can degrade two common HE compounds, RIXX and HMX, to harmless byproducts. We are now designing a flow reactor for the treatment of HE-contaminated water.

\begin{abstract}
A clivilics involving high explosires (HE) al federal fatcilities. including DOE laboratories. hate resulted in the contamination of some soils and groundwater. No method is now allablable for eliminating such HE residues. but a promising strategs is hioremediation. which uses microorganisms native (1) the environment to transtorm halardous waste lo harmless heproducts. Our objective is 10 develop a hiological wstem for cleaning up HE-contaminated groundwater and wasewater. This renearch comsists of $(1)$ the isolation and adaplation of a microbial population optimized for degrading RDX and HMX. and 2 , the demonstration of a flom reatcor for continuous treatment of $\mathrm{HE}$ contaminated watler.

Microserganisms oblatined from HE IIsle streams are cultured in batch reateres containing nutrients plus low concentrattions of $\mathrm{HE}$. compounds. This environment stimulates the gromth of diserse microbial populations and allow natlual xelection woperate w produce a population $\mathrm{w}$ ith enhanced melabolic capabilities for $\mathrm{HE}$ desradation.

He hatc found that to maintain at viable microbial population during
\end{abstract}

degradation of RDX we must pros ide a separate carbon source. This process. known as cormetabolism. is needed when the compound of interest te. RDX) is degraded but does not provide the energy required to sustatin microbial metabolic activity. This phenomenon maties the degradation of $\mathrm{HE}$ comtaminants to envirommentall! acceptabic concentrations $i<l(x) \mu g / L)^{\prime}$ difficult because the microorganisms tend $(0)$ metabolize the mose readily ar ailable carbon source rather than the $\mathrm{HE}$ contaminant. In screening sudies. we have discovered that peptone (at mixture of protein derivatives) is a superior carbon source for supporting the eormetabolism of $\mathrm{HE}$.

Ling this approach. we have sucesstully demomstratled the hiodegradiation of RDX and HNX under acrobic conditions.2 L sing $\mathrm{HE}$ compounds labeled with carbon-14. we hate verified that these explosives can indeed be degraded to concentrations of < $<$ ()) () $119 / \mathrm{L}$. Carbon dioxide is the principal transformation product. The lace that this transformation occurs under acrobic conditions is significant becaluse this process does not lead to the formation of havardous byproducts (e.g... hydragines). which are known to arise from anaerobic degradation of these compounds.
We are now in the process of detining a strallege for tratting Wallers contaminated with HE. In collaboration with scientists at LCLA. " we are dereloping benchscate flow reactors to detime the optimum conditions for continuous treatment of $\mathrm{HE}$-contiminated water. The results of these studies will be used u design an upllow treallment system that will subseyucmly be losted in the fickd. By colatblishing at sysem for the biological degradation of RDX and HMX. We will be in a position to rapidly develop treatment strategies for other conventional HE compound as rell as for explosices currently under development.

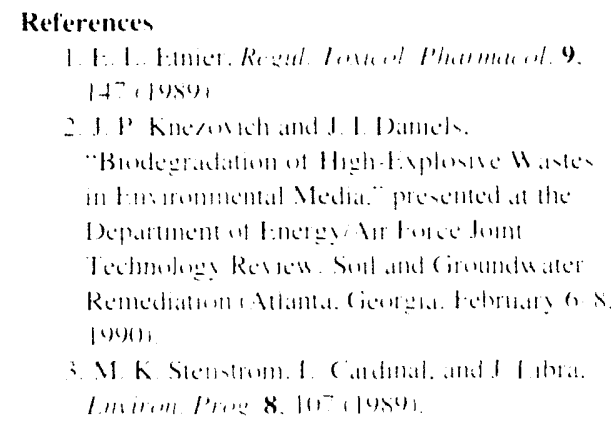

(antact: 1. P. Kncasich $1+151+22-11925$ 


\section{Biomedical and Environmental Science}

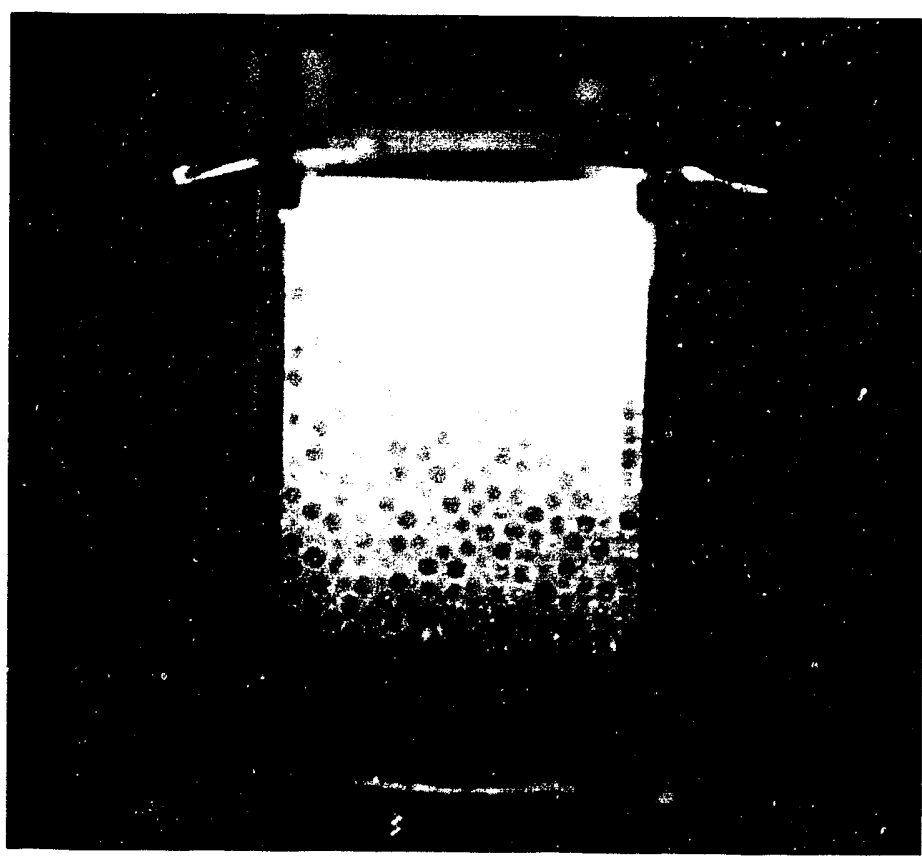

\section{Our research concerns range from potential health effects to the individual, to local ecological effects, to the global scale of such impacts as climate change.}

$\mathbf{T}$ he Biomedical and Environmental Research Program at LLNL is committed to a variety of research attivities in support of developing modes of nattional energy consumption with minimal health and environmental conseguences. Our concerns range from a variety of potential health effects from a modern chemically oriented civilization. to locial ecologicial effects. to the ultimate scale of such global impacts as climate change. We bring a multidisciplinary. large-scaale. technological approath to research in these areals and in related subjects of national concern.

Our laresest and perhaps mose exciting area of hiomedical research is the Human Genome Project. Progren

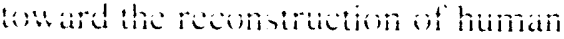

chromosome 19 has been excellent. and we have now processed over $8(0)()$ sizable fragments of DNA from this chromosome. Scores of human genes have been located on these fragments. oriented with respect to their surroundings. and localized on the chromosome. Many new methods have been developed to prepare DNA. amplify it by cloning and other methods. fingerprint fragments. characterize genetic properties. and begin the sequencing of selected regions.

We use fluorescence in situ hybridization (FISH) to locate short pieces of DNA within intact nuclej and to reveal their relative position in an individual chromosome. As

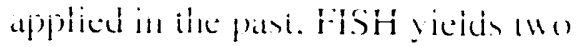
ranger of resolution. depending on whether the target sequences are mapped in metaphase (dividing) chromosomes or in interphase (nondividing) chromoromes. We have developed a third complementary approach using FISH that involves the large pronuclei present in hamster eggs fused in vitro with individual human sperm. The presence of human DNA elements in the sperm-derived pronuclei allows them to be used as targets for in situ hybridization of selected human DNA probes of interest. Our system can resolve closely spaced repeat elements of DNA specific to the region around centromeres. which are present on all chromosomes and function in the orderl! egregation of chromosomes during ceil division. 
Me work with a nework of 50 or s) external enllaboraters. distributing a arious parts of the chromesome and integrating results into our comprehensite datadsets. Important new work is also being done on databasing methods suitable for the complexits. scalle. and wide distribution of genomic resarch.

Rescarch on hiological dosimetry is also making great progress. Here the primary thrust is to develop and apply methods for measuring specific kinds of agent-induced changes in human subjects. The measurements can be used singly or can be combined into a powerful suite for use in dosimeters that can measure an individual s response (susceptibility to at medication. reconstruct doses recejed by accident or firm an environment. compare human to animal responses and thus improse extrapolation. or study the hasic mechanism of human toxicity. He are particularly interested in measures of chemical attack on DNA. mutation. and chromosome change. Procedures halle just heen put in plate (1) apply these methods to radiationexposed Sorice people from the Chernobyl aceident. and we hase similar studies underual in a dosen or so other worldu ide situations of signilicant human exposure. An interesting example of the exe methods is the application of acecelerator mats spectrometr! (6) measuring D.X. adduce in people. As reported lase cear. our method is operating at a ihousandfold greater sensitis it! than an! other method. and can literall! count one adduct per hundred cells. Al such lom doses. our latest studies are showing dramatic differences fless effect than predicted from higher doese in the human metabolism of commonplace ford mulatens.

Much of what we know ahout the hierarchical serelure as human hemopoles reontinuous gencration of mature ecll from a mall population of sem cell that elt-renew proliterale. and diflerentiales and it regulation is

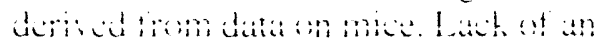
experimental model of human hemopoiesis has limited analy sis of the regulation of this syem in health and disease. With a human model. not only could we elucidate mechanisms underlying the development of human malignancies. such ats leukemiats, and immunologic disorders. including atloimmune discatses and acquired immunodeficiency discase. hut we could also design therapeutic strategies cancer chemotherapy and ultimatel! gene theraps / to modulate hemopoiesis and to amelioralc diseases. By modulating immunologic tolerance. we have developed a novel approach to creating an experimental model of human hemopoiesis in mice by introducing human stem cells prior 10 development of the rodent immune st stem. thereby circumventing the immune-rejection process of a host transplanted with foreign cells.

Risk assessment is an important focus of our environmental research. In recent years LLNL has provided signiticant methodological improsements in radiation and chemical applications of this subject. Reducing uncertainty in risk assessment is important to regulatory agencies. such as the L.S. Environmental Protection Agenc! (EPA) and others secking environmental health and sately. With funding from the EPA Office of Research and Development. we hate been examining the lack of precision (uncertainties) in current risk atsessments and methods for reducing the uncertainties. Rish is often represented as a simple produce of four factors: source term. exposure. fraction ahorothed. and oxic potency. True risk ean be more complex and includes comporal and spatial relations among the falcers. He uned ciase studies to heller characteries the uncertaints in human exposure models and the combined uncertain! in source. exposure. and dose-response modek. ()ur first calse study was haved on the volatile organio chemical ketrachlorothy lene IPC : in California water supplice deried from grounduater.

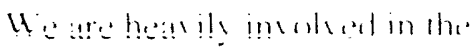
emsironmental anesment of the
Chermobyla acident. both with e.s. collaborators and with the Sorice. and we have spearleaded the radiologerical atsessments of the Marshall lskands and the Derada Test Site (NTS). ( nnce agarin. defining and reducing the uncertanties in risk determinations is one of our main themes. Planning has just hegon to proside a multiinstitutiomal thrust foward improving the science of risk assessment.

In 1986. the Basic Environmental Compliance and Monitoring Program (BECAMP). sponsored by the DOE/Nevadal Operations Office. was established to assess changes in radiologrical and ecologeical conditions at the NTS and to provide data for assessing compliance with environmental and radiation-protection regulations. LLNL is involved in such major BECAMP tasks as investigating the mosement of radionuclides in NTS soils and updating and developing human dose-assessment models.

Other envirommental activities include the development of remote probes for monitoring temperature. chemical species. and radiation: the exploration of microbial methods for environmental detoxification: studying the effects of pollution on agriculural ystems: and analyzing the moxement of water and dissolled chemicals in porous systems the photes on p. 56 shows laiser imaging of chemical flow in model porous media).

Our efforts in atmospheric and geophysical sciences are carried out in conjunction with the Physics Department and focus on modeling and understanding the various scales of normal and perturbed atmospheric behas ior. Of most immediate concern is the global climate initiative in which we are helping to compare models. improve predictive performance. beller incerporate eloud behavior. and hegin the efforts locouple such model of (xeanic and terrestrial ysems. Healso

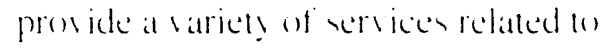
atmopherice releares of radiation and chemical losims.

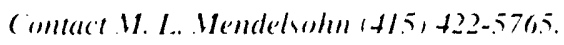




\section{High-Resolution \\ Interphase Gene Mapping Mapping}

Our refined system for mapping human DNA exploits the greatly extended length and volume of male chromatin in human sperm cells fused with hamster eggs. This technique allow's us to order and estimate distances between short pieces of DNA separated by as little as 20 kilobase pairs. mapped in metaphase (dividing) chromosomes with respect to chromosomal landmarks. such as bands. if they are separated by at least one or two megabase pairs. Probes can be ordered in interphatse (nondividing) chromosomes. which are less condensed than those in the metaphase stage. if they are separated by from 5 () kilobatse pairs (kbp) to I megabase pair.

We have developed a third complementary approach using FISH. which involves the large pronuclei present in hamster eggs fused in vitro with individual human sperm. The presence of human DNA in the spermderived pronuclei allows them to be used as targets for in situ hybridization of selected human DNA probes of interest. We found that pronuclear DNA is approximately three times less condensed than that in somatic interphases. making it possible to (a)

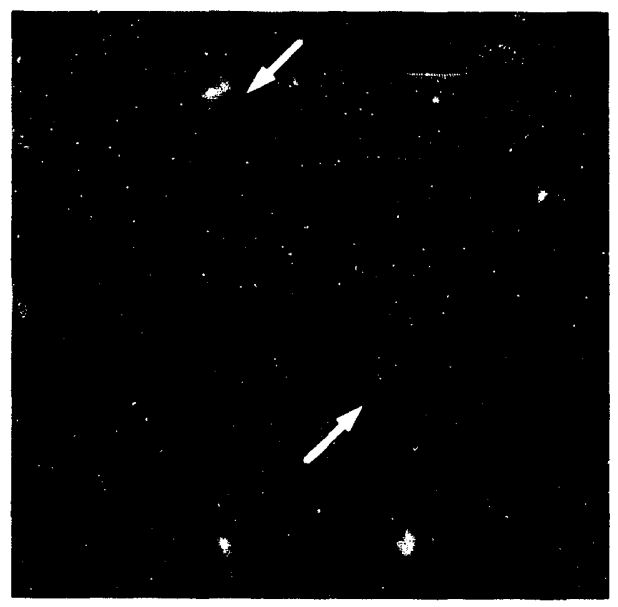

(b)

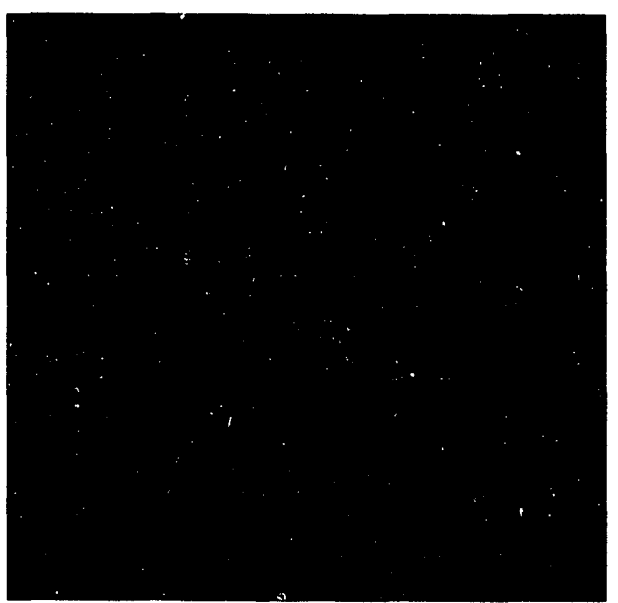

Figure 1. Genes on DNA from a single human sperm nucleus fixed on a microscope slide. (a) Arrows show the ends of the labeled strand. (b) Using a different optical filter, the order of the genes labeled in two colors is revealed as red, green, red. One of the genes labeled in red has multiple copies along the DNA strand. order individual genes along a stretch of DNA and to extimate distances between probes separated by only 20 to $50 \mathrm{~kb}$ ). Mearsuring the physical distance between fluorescent dots revealed uinder a microscope allows us to infer the actual length of DNA between them because we also found a linear relation between physical distances and DNA distances up to at least 1.2 megabase pairs. Our sy'stem can resolve closely spaced repeat elements of DNA specific to the region around centromeres. which are present on all chromosomes and function in the orderly segregation of chromosomes during cell division.

Figure la shows the network of chromatin fibers of a sperm pronucleus stained with the DNA-specific fluorescen dye. DAPI. Arrows identify the ends of the hybridized piece of DNA fiber. Figure Ib uses a different optical filter to show the order of three probes detected in two colors. red and green. These probes were hybridized to members of the carcinoembryonic antigen (CEA) gene family. The green and single red signals represent two different probes. The string of red dots represents a third probe that hybridizes to the pregnancy-specific glycoprotein (PSG). a closely related subset of the CEA gene family. The same prohe appears as a nonresolved cluster of dots in somatic interphase nuclei. thereby confirming the utility of our system for visualizing closely spaced repeat elements in the human genome.

(imlact: B. 1. Brandriff $(+1.5)+2.3-(1) 7.58$,

1. 1. Courdon +11.5$)+22-1.579$, or

B. I. Trask $(+1.5)+22-5706$. 


\section{Basic Environmental Compliance and Monitoring Program}

$\mathbf{T}$ he verata Ten Sike NTSi hat hatd radiation-monitoring program since the tirs nuclear"reipom-related to-k. In 1980. the Bask tenuirommental Compliance and Momiloring Program B BEC A.MP).

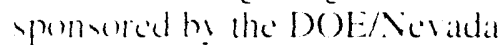
()perallom (oflice. "las estahlished (1) ares changer in radiological and cerlegical enditions at the XTS and (1) prosick dalla for anesering compliance with ens irommental and ratdiation-protedion regalations. BFC A.MP - -an outeromith of the

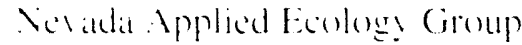
1.te(i) veds of plutomium at the XTS-integralle patricipante from L.NLL. Lom Alamon Nallonal L.aboratoly. the Desert Resadrch Institute. Pikcitic Vorthues L.ahoratory . and Resolde Electrical and bnemearing (o. L.L.V. is performing three BEC A.MP lasks: ims erleating radionuclide mosment in NTS whl apdating and dereleping humand dose-asesoment models:

program management and corordination.

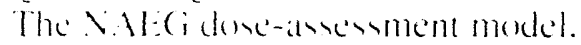
wheh extmate the dere wo man from ingersed and inhaled 230 - 2t19Pu. itsumer thatl a "reference man" lise in a Pu-comtaminaled enviromment and call omls plant and animals living in that cons iromment tregure 1 1. He pertormed a cembilis il! and uncertam andals on the model:

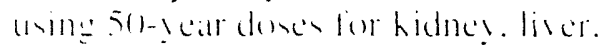
home. lomal hod!. upper respiratury

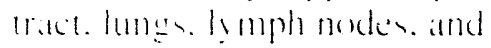

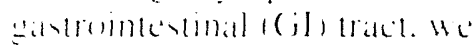

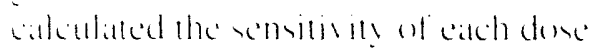
wan! une impul parameler hy holdmes all wher parameter al their nommal

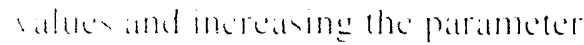

Our work on radioceology at the . Verada Te'st Site, including investigations on the movement of radionuclides in the e'nvironment and development of human dose-assessment models, is helping the DOE to meet new environmental regulations and radiation-protection standards.
(1) interest b! 10\%, Me used a Monlc Carlo approach to delemmine the relation between variance of (nutpul and input. and to charaterise the (ntput vartation for a mokest inpul larialiom.

Our ensitis its anals sis showed that inhalation is the critical pathwa!

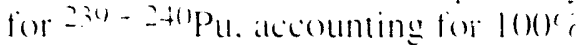
of the done to lung. upper respirattom! mact. honce and hidne?. Only the (il

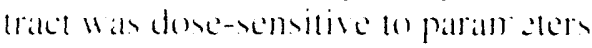
in the ingertion pathwa a receis ing yes, of the done viat ingestion. The uncertatin! and!sis shomed that onls a fere model parameters control the dose for a single organ. and all organs. except ly mph nodes. halle similar distributions of dose. Soil Pu concentration and factors controlling air Pu concentrations mone alfiect done.

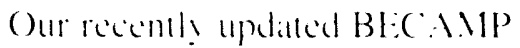
dose-ansement molel includes all semilicame rationuclide in the NTS

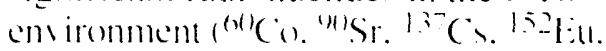

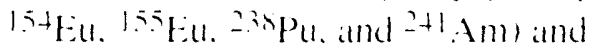
all exposure patho ats. including external expontur from gammat-cmitting radionuclider. Ite ane perlorming a sensitivity and uncertaint! analy sis an

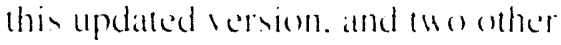
L.L.NL. groups are using the resuls: ane is incestgatting radionuclide mosement for use in sile-specific dose calculations: the other pros ide gruidane to the DOE in ansering NTS compliance with ensirommental regulations and radiation-proledion slandards and in designinge effectice restoration and radiatton-related monitoring programs.

(ontact: S. 1 . P'attom $4+1.5,422-1192.3$ at

J. R. hircher $115,+22-1+16$.

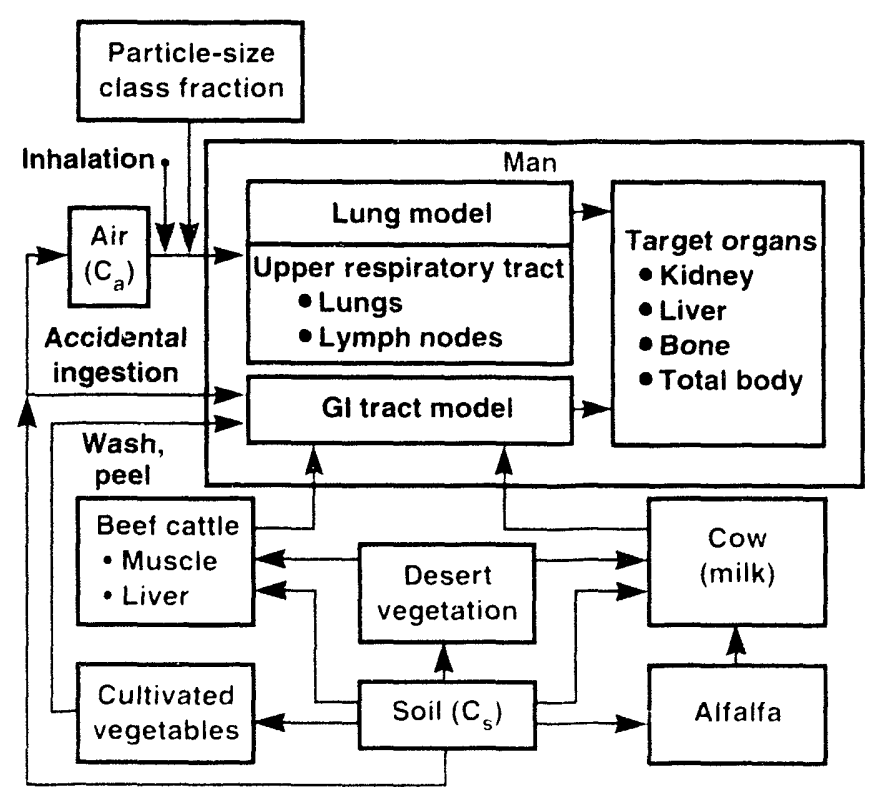

Figure 1. Major compartments in the NAEG doseassessment model. Arrows denote transfers of $\mathrm{Pu}$ between compartments, and the submodel for man is enclosed in a box. The term $C_{s}$ is the concentration of $\mathrm{Pu}$ in soil ( $p$ Civg), and $C_{a}$ is the concentration of $\mathrm{Pu}$ in air $\left(\mathrm{pCi} / \mathrm{m}^{3}\right)$. 


\section{Experimental Model of Human Hemopoiesis in Mice}

We are developing a new model of human hemopoiesis by introducing human fetal cells into immuno-incompetent rodents. Such an experimental model will be important in studying mechanisms underlying human malignancies and immunologic disorders, designing strategies for cancer chemotherapy and gene therapy, and ascertaining stem cell recovery following radiation exposure.

$\mathbf{T}$ he hemopoietic system is a complex. self-sustaining tissue that continuously generates cells from a small population of stem cells. which self-renew. proliferate. and differentiate. Mature cells ultimately appear in the circulation to perform many functions essential for survival.

Nuch of what we know about the hierarchicial structure of human hemopoiesis and its regulation is derived from data on mice. Enfortunateis. many kechniques

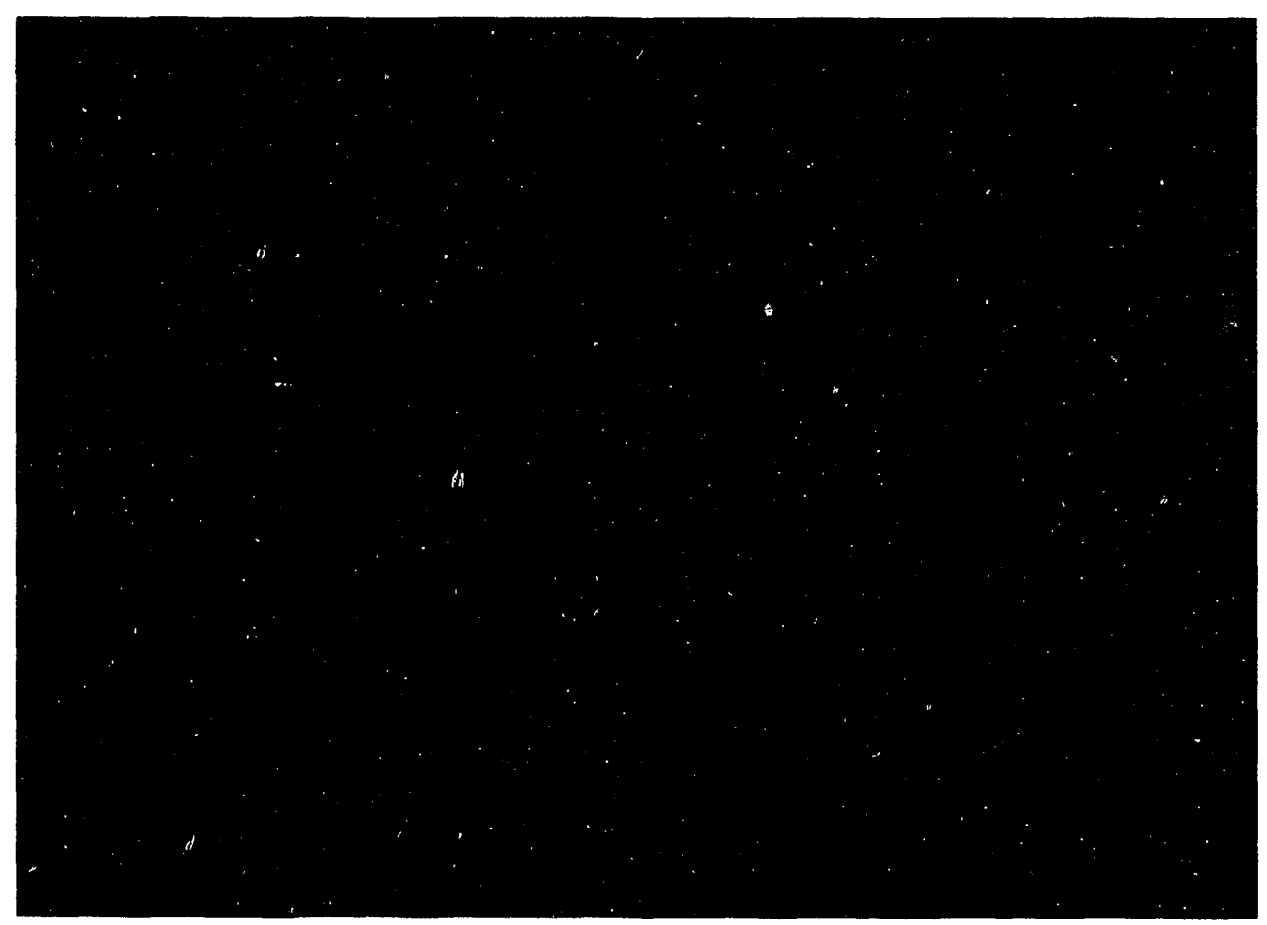

Figure 1. Detection of human cells transplanted into rodents. Human cells are detected by hybridizing with differentially labeled DNA probes, which are specific for either human or mouse DNA. Human cells fluoresce green, whereas mouse cells fluoresce red. used to study stem cells in mice cannot be applied to human studies. Without an experimental model of human hemopoiesis. in-depth analysis of the regulation of this system in health and disease has been limited. A human model would help us to analyze the hierarchical structure and regulation of human hemopoiesis and to elucidate mechanisms underlying the development of human malignancies. such as leukemias. and immunologic disorders. including 
during the early part of the second trimester should not be rejected by at recipient.

The second problem in transplanting tissters is that immuno-competent cells in the donor graft recognize the host rodent cells as foreign and mount their own immune response. To circumsent potential problems of graft is host disease. We transplanted human cells derived from fetal hemopoietic tissues directly into the placenta and abdomen of early second-trimester mouse fetuses. We monitored the presence of human cells in rodent fetuses and neonater using sensitive DNA-based detection strategies developed at LLNL. which rapidly identify human nucleic acid sequences. This work involved fluorescence in situ hybridization (FISI i) and in ritro DNA amplification using the polymerase chain reaction. We also uned an LLNL-dereloped flow-cytometric assay. which measures the expression of a human red blood cell protein. glycophorin (GPA). We used several lypes of host mice. including animals with genetic defects expected to facilitate engraftment or with inferior hemopoietic systems.

We have used two successive procedures for introducing human fetal stem cells into mouse fetuses. We initially injected the human cells directly into the placental disk (areal where fetal and maternal blood supplies are juxtaposed using a needle and syringe. Later. We used the intraperitoneal approach. delivering the cells through glass microcapillaries directly into the fetal abdomen. DNA-hased detection techniques demonstrated whether the injected cells entered the liver. the major hemopoietic organ at that stage and remained there during the second and third trimester. Species-specitic fluorescent DNA probes adereloped b) H. V. Hois of LLNL, differentiall! labeled mouse cells (red) and human cells gereen in a FISH-based assal (Figure 1). Three to five times more cells entered the fetus when "se used the intraperitoneal approach compared to injection into the placental disk.

Several animals receis ing human cells in utero showed evidence of human cell chimerism (e.g.. mixtures of human and mouse cells) in their hemopoietic tissues four to nine months after birth. The frequency and tissue location of human hemopoietic cells varied among animals. Human hemopoietic cells detected in rodent bone marrow. thymus, and spleen "lere present at frequencies between $0.0(1) 101 \%$. In one animal. analysis of peripheral blood using an assaly that detects GPA in human red blood cells revealed that $1.3 \%$ of the erythrocytes (red blood cells) were of human origin. The same animal contained $1.5 \%$ nucleated human leukocytes in peripheral blood and $0.15 \%$ human cells in bone marrow. Although our lineage mapping is not completed. human cells belonging to the erythroid and myeloid (white cell) lineages are also present in chimeric animals. The presence of human cells in multiple lineages two to nine months after birth in animals injected in latere suggests that a human stem cell was transplanted successfully and was capable of contributing $(0)$ and maintaining human hemopoiesis. Furthermore. our evidence that some mice carried human hemopoietic cells postnatally suggests that transplanting cells in mero is a reasonable approach for developing immunologic tolerance to specific foreign antigens. We will explore this concept by transplanting in ate'restem cells (o) induce tolerance to specifie antigens followed by postnatal bone marrou tramsplantation for discisc trealtment.

He expect hat development of our experimental model will facilitate studier of human hemopoiesis. For our ss stem to be widely applicable 10 studies of human health and discase. lle will have to improve the sucees rate in generating human-mouse chimeric hemopoietic sytems and increasing the level of human cell engraftment. We are pursuing several strategies to accomplish these objectives.

The availability of a model sytem in which human cells proliferate and differentiate will be particularly important for studies of hemopoietic stem cell recovery following acute radiation exposure and risk assessment based on measurements of genetic damage in peripheral blood cells. Furthermore. as new prenatal diagnostic techniques allow early delection of genetic diseatses and abnormalities, in lfteres transplantation of human hemopoietic stem cells for immune reconstitution of human fetuses with immune deficiencies is becoming increasingly important. Clinical applications of in tetero human stem cell transplantation for fetal treatment are being pioneered by our collaborators. Michatel Harrison and Alan Flake. at the Lniversity of Californial. San Franciseo. We expect that. in addition to creating an experimental model of human hemopoiesis. the lechniques te are des eloping will hate broad applications in identifying variables associaled with successtul stem cell transplantation in theres.

Contact: M. (i. Pallaricini $1+1.5)+22-50.51$ 


\section{Uncertainties in Assessing Risks from Groundwater Contamination}

Our case studies on variations of risk factors for individuals exposed to a carcinogen in water supplies suggest that decision makers should use uncertainty analysis in defining their strategies for increasing precision.
$\mathbf{R}$ educing uncertainty in rish alsersment is important to regulatery agencies, such as the L'.S. Em irommental Protection Agenc? (EP. A and others seching emsirommental health and sation. With funding from the LPA Office of Research and Derelopment. We hate heen examining the late of precision. or uncertainties. in current risk assessments and methods for reducing the uncertaintios.

Health risk within a population exposed to an ems ironmental contaminant is derived from a source term. the exposare function that comvert the soluce into the amount contiked by an individual, the organ or tisule done per unil exposure. and the toxic potency ansociated with the delisered done. True rish can be more complex and includes temporal and ypatial relations among the factors. vonetheless. in practice. risk is often represented an al simple product of four fictors: source term. exposure. fraction aboroted. and toxic potenc!

He used cane studies to betler chatraterize the uncertainty in human exposure models and the combined uncertaints in source. expostare. and dore-response models. Our firs cares studs war batsed on the rolatile orgeanie chemical tetrachlorothylene IPCE) in California waller supplies derived from groundwater. We dis ided our analy sie into five steps. first. He comsidered the magnitude and sariability of PC E concentration in California public " atter supplies. scond. we chatraterised pathus exposure factors (PEFs) for groundwater exposures and estimaled the uncertainty for eatch PEF. Third. we considered models describing uptake and metabolism to estimatte the relation between exposure and metabolized dose. Fourth. We considered the carcinogenic potency of the melabolized dose of PCE. Finally. We estimated the overall magnitude and uncertainty of increatsed rish 10 an individual selected at random from the exposed population. and explored the contributions to overall uncertainty.

The first step in our evaluation. source characterization. required that we estimate the magnitude and uncertainty of the population-alleraged concentration of PCE in water supplies. Ling 1986 datla compiled by the California Department of Health Services (AB I $8(1) 3$ datal). We estimated that 6.8 million Californians Here linked to public water systems "ith at least one well in which PCE had been detected. Although these data have limitations. we constructed a probability distribution that describes PCE concentrations in water supplies from the $\mathrm{AB} / 8(1) 3$ datlit.

In the second step. we identified methods for characterizing domestic PEFs and estimated the uncertain! for cach factor. He included ingestion of PCE in tap water. inhalation of P( IE tramberred frem tap water to indorer atr. and dermal uptate from shower and bath watler. We divided the uncertaints into contrihutions from phrsical and chemical propertics. batriations amonge microens iromments. such as household parameters. and variations amonge individuals (e.g.. body matss. breathing rates. and personal hahits).

Extensive evidence shows that at product of $\mathrm{PCE}$ melabolism. rather than the parent compound. is responsible for carcinogenicity in laboratory animals. To address this fate. We extimated the carcinogenic potency for $\mathrm{PCE}$ an a function of metabolized dose. As a result. the third step of sur analysis required us to define the relation between applied and metabolized dose. We derived this relation from an analysis of al ailable data on PCE exposures in the workplace. We used these data to characterize both the magnitude and uncertainty of the fractions of ingested. inhaled. and dermally atsorbed doses that are metabolized.

The next step was lo chatraterize uncertainty in potency. Carcinogenic potency here refers to the increase in cancer risk per unil dose al low dose levels. PCE has heen identified an al probahle human carcinogerl. with inconclusive direct er idence of human carcinogenicits. We predicted potency using the dose-fesponse extrapolation model adopted for regulatory purpose by the EPA. There are many sources of uncertain!s in E:PA potency estimates applied to humans exposed to PCE all doser far below those receised by rodents in experimental bioassaty. We addressed three major sources of uncertainty:

- Statistical extimattion correr of the multistage polemes parameter. 
andmonge that the dosererponse extrapolation model is ralid.

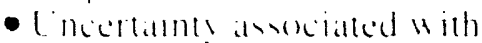
incerpecter cevarapolation of eyuiraleme effectice - Incertants ariving from different polency extmatles ohtanded from ditterent studies. species. sexes, or oberred cumor is pers.

Ne then calculated the onerall uncertatin! in estimalled risk to an indiridual exponed an PCE in groundwater. We uned at mathematical imolel that estimates the risk to an indisidual draw nat random from the pepulation. Incertaints in the model predictions thus comes from uncentanty in concentration data. exporare modek. done modek. and pretency entimales. An uncertain! analy is applied 10 mathematical molel molde determining the sartation or imprecision in an output function hased on the collective bariation of model inputs. $\mathrm{H}^{\circ}$ combined input sariatiom uning a Mome Carlo computer progeram in which catch inpul parameler is represented bs a probabilits function that defines the range of ialues for the parameter and the likelihood that the parameter hat at lalue in ans subintersal of that range.

Figure I how the mechanics of the Monte Carlo anals sis. He used 10.()(o) reperalled simulations of individual risk to determine probahilit! distribution of estimatted rish. For estimated lifelime cancer rish per individual. thie distribution had an arithmetic mean of one in one million. Howerer. there is a lo's probabilit! that the estimated risk could he more than 10 limes grealter and a 5 ; probabilits that the estimaled rivk eould be more than 25 times greater. An analy so of the comtributiom to 1 ariance of this entimaled rish ifigure 2) how that ahout $65 \%$, of the vartance in the cumulatise distribution of rish is attribuable a bariance in polene? 20), is allributable to valriance in concentration. Ior) is allributahle to sartance in the paramelers of the exporume molel. and 5'; is attributable (o) sariance in the paramelers used or comert exposure (1) metaholised dose.

Our work suggeses thall rist managere should be at are of the uncertains in rist estimates and include sach information in decisions and communications of risk to the public. The need an focus an redusing uncertainly before we develop more sophisticalled models is clear. (our findinges reinforce the view that decision makers should use an uncertaint! anal!sis to define srategies for reducing uncertaint! in rist astersment.

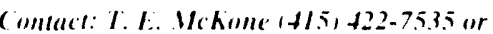
h. T. Bogen $+115+22-(16) 2$ ?

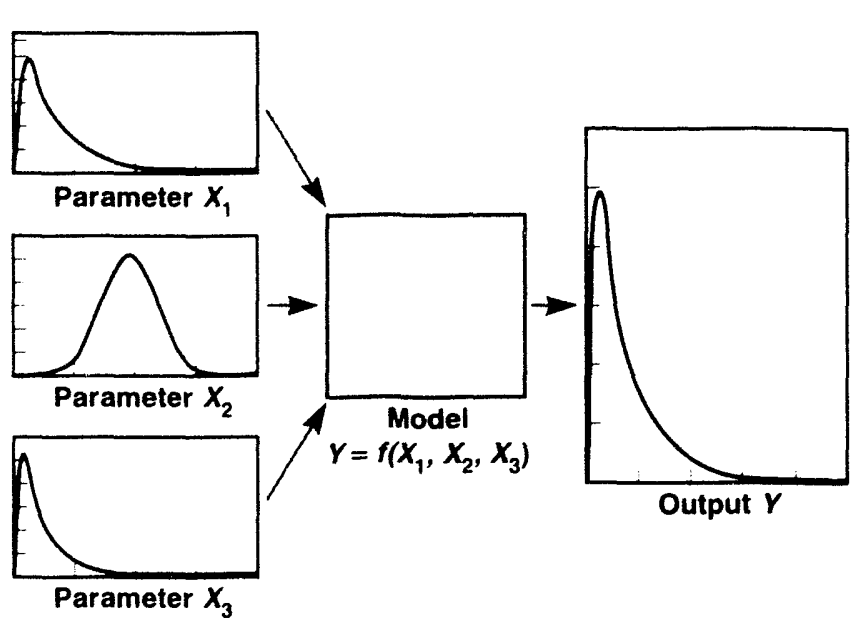

Figure 1. Example of an unmodified Monte Carlo sampling method in which simple random sampling is used to select each member of a triplet $X_{1}, X_{2}$ and $X_{3}$. The randomly sampled triplets are used in a model that relates the output function $Y$ to each input parameter by some function $f\left(X_{1}, X_{2}, X_{3}\right)$. When enough samples are used. the variance of output $Y$ reflects the combined impact of variances in $\mathrm{X}_{1}, \mathrm{X}_{2}$. and $\mathrm{X}_{3}$ propagated through the model.

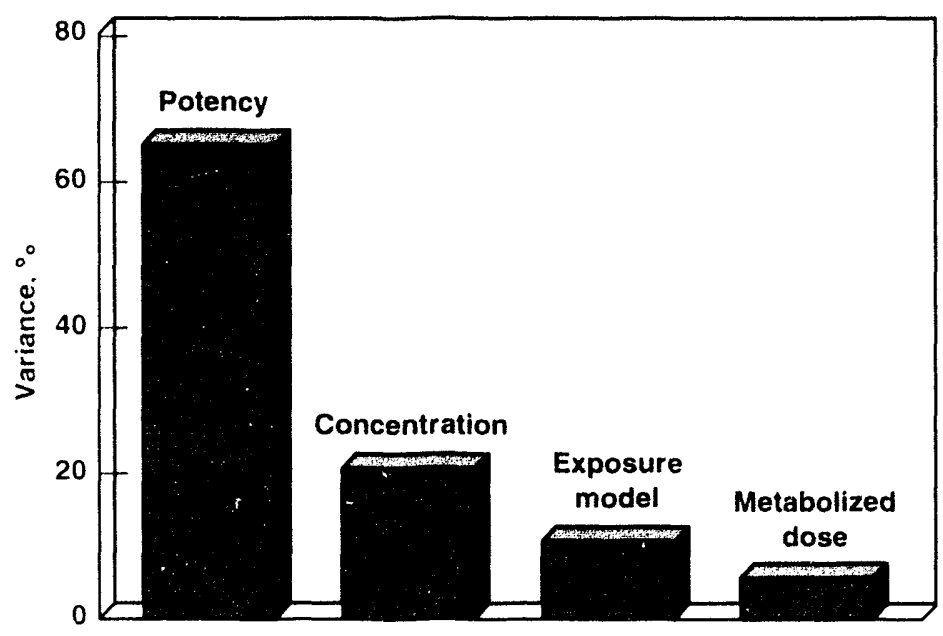

Figure 2. Variance attributable to each of four components in our risk calculation. About $65 \%$ of the variance is attributable to variance in potency of PCE in water. $20^{\circ}$ o to variance in concentration estimates, $10^{\circ}$. to variance in the parameters of the exposure model, and $5^{\circ}$ o to variance in the parameters used to convert exposure to metabolized dose. 


\section{Engineering}

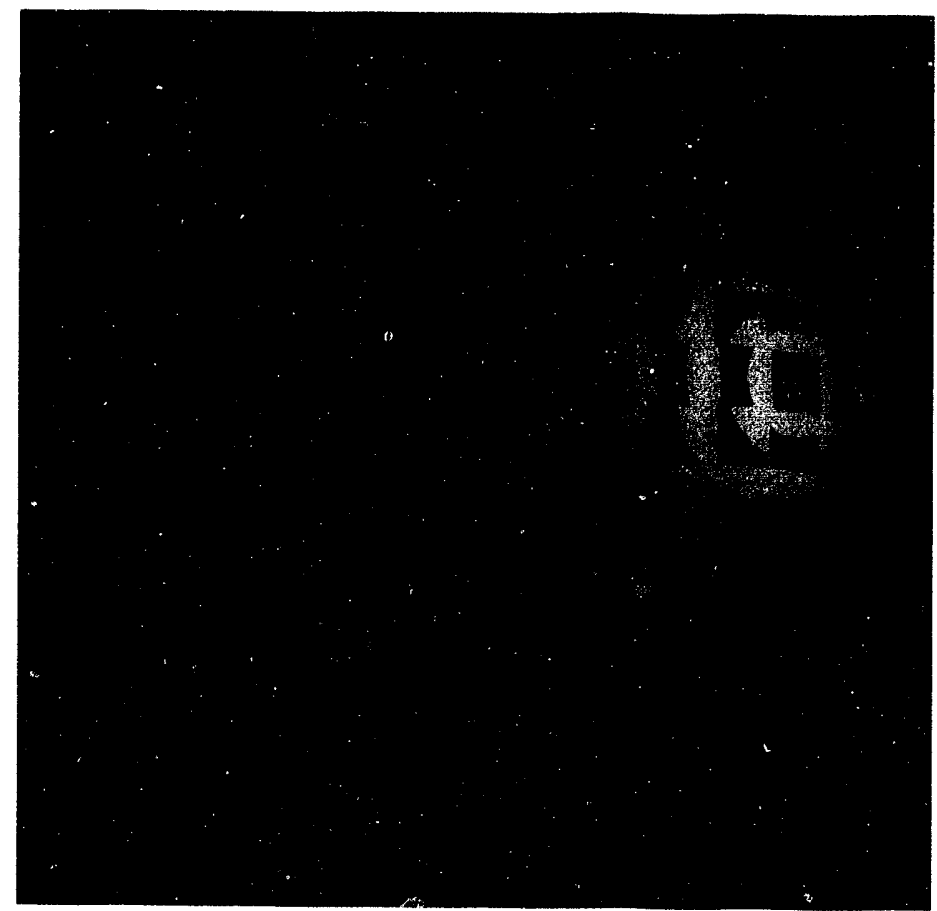

Engineering's missions range from technical support of Laboratory programs to researching technologies for current and future programs, technology transfer, and managing the Precision Engineering and Nuclear Systems Safety programs.

$\mathbf{E}$ ngineering has multiple missions-to provide the highest quality engineering and technical support to the Laboratory programs. to conduct a research program developing technologies that make future Laboratory programs possible or enhance current programs. to transfer current technologies to the private sector. and to manage the Precision Engineering Program and the Nuclear Sy'stems Safety Program. Engineering s research program is focused in eight technology areas. called Thrust Areas. which we helieve represent the highest potential return for our efforts:
- Computational electronics and electromagnetics.

- Computational mechanics.

- Diagnostics and microelectronics.

- Fabrication technology.

- Materials engineering and science.

- Microwaves and pulsed power.

- Nondestructive evaluation (NDE).

- Remote sensing. image and signal engineering.

The Thrust Area Leaders set the direction of the research. ensure its quality, maintain links with outside experts and aid with collaborative and crosu fertilization efforts.

Although many engincering advances and innovations are reported elsewhere in this issue by the programs, the articles in this section are representative of the work done through Engineering's disciplinary research program. For example. as a part of our work in the Fabrication Technology thrust area we are investigating how the modeling of molecular dynamics can help us understand the material removal process in both ductile and brittle materials. To accurately cut and polish metal and glass surfaces. we achieve nanometer tolerances with surface features measured on an atomic scale. To describe plastic deformation at this scale. We simulate our fabrication processes using 
molecular dynamies (.MID). Since the repuired computer time is enormous. lle use massitely parallel computer. He expect on heller eontrol the fabrication process. reduce coms. and improve yuality.

The work in diagnostics and microclectronics comtinuse to purh into uncomsentional activities. Microdynamico is expected lo have at resolutionar! impact on technolog! comparable to that of integrated circuits. Our len !cars of experience with microstructure lachnolog! enables us to matie early contributions to this promising field. Innowative applications are becoming more common beyond the routine use of microclectronices technolog! to fabricalte diagnostic sensors: sliders. gears. springs. microgrippers. electrontatic motors. mechanical logic operators. and resonant structures have bean built. These devices are expected of hate broad applications in the automotise. chemical. hiological. and medical industries and as components in miniature scientific instruments. Increased understanding of frictional forces in microstructures will allow us wo huild entire instruments on silicon chips.

We halle used a related technologs: to greatl! improse the iabrication of semiconductor lasers and fase photodetectors. which should improse future diagnostic st stems. Molecular heam epitasy is al echnique for coating Gats or other waters hy chemical reation with material of controlled chemica! composition. Focusing on growing graded-index. separalle-confinementheterostructure. satined-layser. single-quantum-ucll lavers. He hate achieved lasers of the highes efliciency. Our best lasers have shown the second lowest threshold current demsily reported for L .S. eroun lasers.

ling Enginering vextemsite underatinding af precision engincering. we hatce designed a certificallom of proces (COP) galleg for inspecting hemishell components at plant of the DOE nuclear weapons complex. This compuler-controlled. ultaprecision gatuge " ill certit! componends dimensiomal adecurate monitor manufacturing performance. and proside process control leedback: it 11 as designed to meet the requirements of lahorattrices and prodaction plants alike.

He hate dereloped all electrodeposited nickel-phosphorus coating for diamond machining: materials that are not ordinaril! diamond-surnable to the smoothes posible surfite texture. We have demonstrated that. for fabricating large optics and other precision parts. an electrodeposited Ni-P coating is more cont effective than the widely used electroles Ni-P coating. By reducing wear on the diamond torol. electrodeposited coatinges extend its life and reduce costs.

As a part of lase year's work we significantly improved our ahilit! 6 remole noise from images of space objects. stars. and satellites. We are continuing to enhance the image processing algorithms and to produce a lower-cost image capturing system.

() or computationally hased work focuses on four major atctisties. We are continuing to develop a model for the forming of superplastic materials: we expect 10 understand the constitutive eyuations for the malerial and how it flom sunder superplatsic conditions. We are alow modeling interadions between structure and soil during earthyuakes. which hate ver! important applications in the siting and derign of critical facilitics. To help eliminate heam breakup in induction lincar accelerallors. (uar Amos/Plate suite of coles will molel the mathines in 2D and 3D. Lalst! . We alle : thempting (1) understand the physic, if photexondective switching and to test the theors agains experimental data.

Engincering contrihutes to

lahoramer! programs in mam! other Wa! an well. He keep our falcilitios at the state of the art. adding capabilities as the! are dereloped. To our engibering codes. such as NIKE. DYNA. TSAR. and VIEW. we are adding new algorithms for pre- and post-processing such ats unstructured mesh generation. J-integral integration, and dispersive media modeling. We are collaborating an these codes with numerous industrial and university users. We continue to build on our materials knowledge in composites. casting processes, and ceramics. Optical. xray, and acoustic sensors are a continuing need: developing and integrating these units into meatsurement ystems is an ongoing effort. Other ongoing activities involve using massively parallel computers, vistalizing the esults of enginesing and scientific computations. extensions of grinding processes for brittle materials, and new techniques in NDE.

We have been successful in supporting the Laboratory programs with technologies and facilitices as they are needed. We expect to continue $t()$ do so and to make certain that our greatest assets, the engineers. associates, drafters. Lechnicians. mathinists and administrative people are recognized for the ir contributions.

Contact: t: A. Iafranchit+15, t22-8.3.5.5. 


\section{Molecular Dynamics Computer Simulations of Deformation and Tribological Phenomena}

We are simulating, with massively parallel computers, atomic-scale deformation of surfaces in order to better understand the fabrication of high-precision optical, electronic, and mechanical components.
Capabilities of matssively parallel computers such as the BBN-TC20)(0) and SPRINT-2. with the anticipation of the nexi-generation teratlops supercomputers. With this information. We expect to better control the fabrication precess. reduce costs. and improve yuality.

\section{Simulating Plastic Flow}

We hale developed several new Iyper of massively parallel computer simulations (o describe matterial
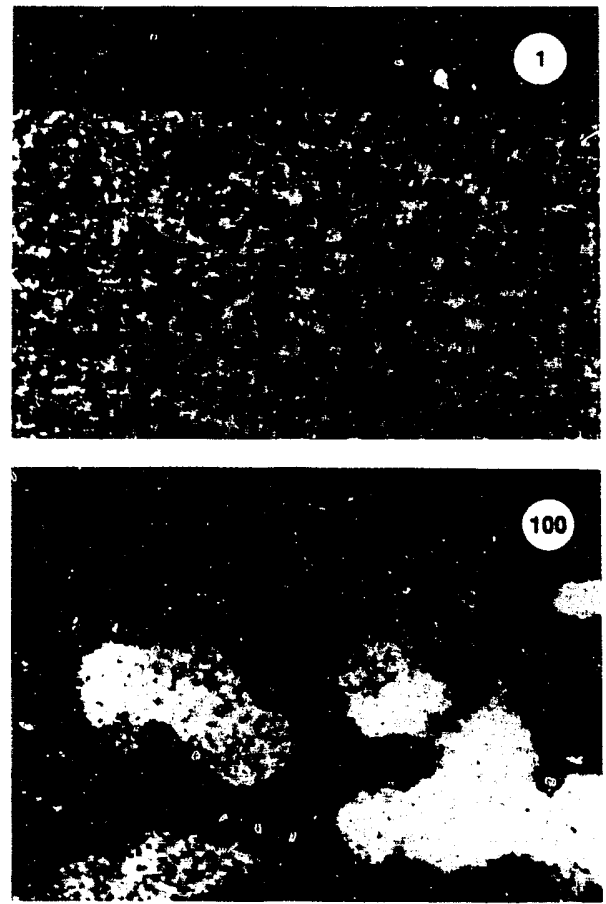
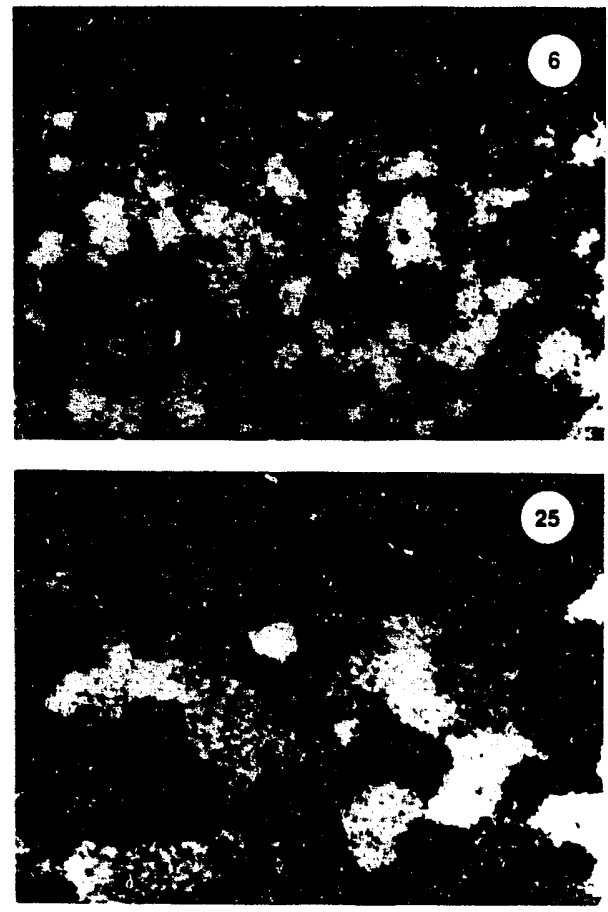

Figure 1. Four stages (clockwise frot. upper left) in the annealing of a million-atom. finegrained metal sampie. Each atom 's coloring represents its neighbors 'orientation, so the grains important to plastic flow are regions of nearly uniform color.

deformation. The simplest approach. MD. follow the motion of individual atoms. On the nanometer kevel, atoms are represented as interateting mass points and move on a picosecend time scalle. Eatch atom interacts with others through characteristic interatomic forces: the motion so governed then leads to macroscopic constitutive behatrior through a nonlinear. chanotic process that is relatively easy to model hut imponsible to calleulate antaly tically. At the atomic tevel. matterial deformation includes the nucleation and motion of lattice defects. such ats racancies, dislocations, and grain houndaries-all controlling macroscopic flow behavior.

Figure I show a typical atomiclevel computer simulation of a finegratined metal. Four frames from at computer-generated movice of the annealing process show the gradual

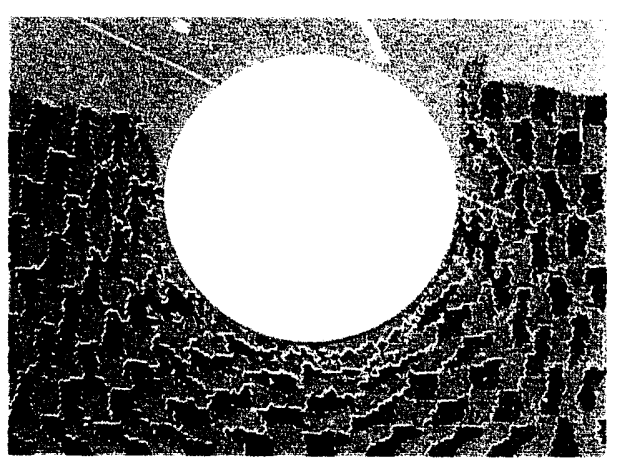

Figure 2. Final stage in the deformation of

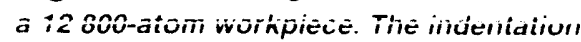
surface asymmetry macroscopically reflects microscopic chaotic dynamics. 
growth of graims on a nanosecond time scalk. In Figure 2. a rectangular block of tine-grained metal has been deformed by a hard eylindrical indentor to measure the metal" : resistance to plastic deformation (that is. hardness). The figure shows an interesting difference between our atomistic approach and the more conventional continuum mechanics approach (not show nl: at simulation hy the latter would result in a simmetric deformation (with the left and the right sides of the indentation perfect mirror images). while in our simulation the underlying nonlinear chatotic dy namics magnities smallscale atomistic thermal thetuations w) give large-scalle macroscopic differences.

The MD simulation follows the motion of individual atoms. while makroscopic continum mechanics averages over the underlying atomic struciure and treats the material as an elastic-plastic continuum. Computer models of a continum describe the material as at set of contiguous rones of matterial, which move and deform in response to specified boundary forces. In our recent work we are

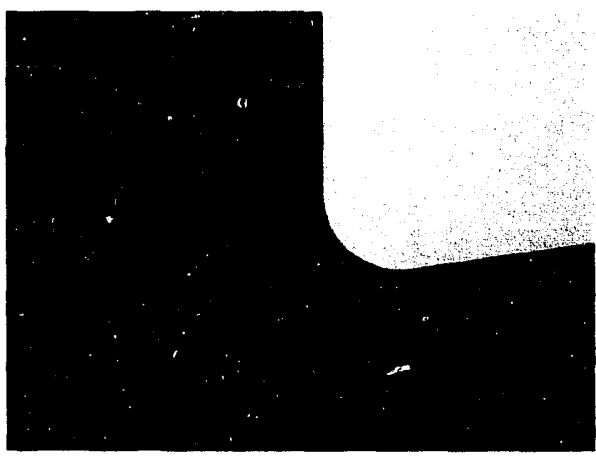

Figure 3. A snapshot from our steadystate MD simulation of crthogonal metal cutting. The simulation contains $10^{5}$ atoms in 200 layers. a 20- $\mathrm{nm}$ tool edge radius. an $8-\mathrm{nm}$ depth of cut, and a 100- $\mathrm{m} / \mathrm{s}$ cutting speed. The atoms are colored by the local value of the shearing stress-atoms near a dislocation edge (red) are under the highest stress. combining the two approaches: we treat a smaller part of the material. where deformation is most violent. atomistically and treat the remaining material. where deformation is relatively small and slow. as a continuum. We can thus address significantly larger time- and lengthscale problems without the proportionately large computer time and cost penalties usual with large MD simulations.

\section{Simulating Orthogonal Cutting and Indentation}

Tribology is the study of two interacting surfaces in relative motion. We began our MD studies of tribological problems with orthogonal metal cutting. Orthogonal cutting is an idealized model in which all of the atomic motion is constrained to two dimensions. Our simulations contain at most one million atoms. tip edge raddii $r \leq 20 \mathrm{~nm}$. and cutting speeds of $101010(0) \mathrm{m} / \mathrm{s}$.

Figure 3 is a snapshot from our steady-state variable-particle MD simulation of orthogonal metal cutting. The atoms are colored by the local value of the shearing stress. Our

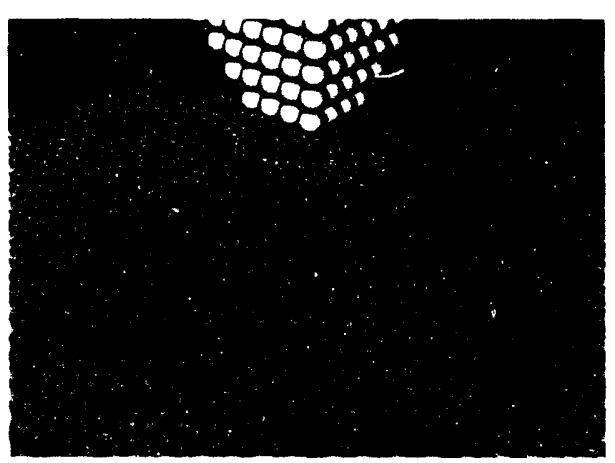

Figure 4. A snapshot from our quasistatic isothermal MD simulation of the indentation of a metal surface by a sharp diamond tool. We observe the resulting debris on the surface after the tool has been withdrawn. calculated cutting forces agres remarkably well with experimental measurements. We find an interesting result. We calculate at specific work (W) as the work per unit volume of material removed for both simulation and experiment. These data. when plotted versus the normalized depth of cut $(d)$, generate a universal curve. This curve has two distinct regions. For large relative depths of cut $(d / r)>I()) . W=(d / r)^{-(t) .2}$ and nearly all of the deformation occurs between grains (intergranular) with little or no deformation within the grains. For small relative depths of cut $(d / r<1) . W \approx(d / r)^{-(1)}$ and 1 all of the deformation oceurs within a single grain (intragranular).

Figure $t$ is a snapshot from our three-dimensional MD simulation of the indentation of a metal surfice by at sharp diamond tool. The computer experiment consists of indenting the tool into the surface at a slow. constant rate. Such micro-indentation experiments are the main experimental method of measuring surface hardness (load/contacl areal). Our simulation results are in agreement with experiment: the calculated elastic stress field agrees with the well-known Hertzian result: there is a critical load below which all deformation is elastic and above which the system yields plastically by creating a single dislociation: and the calculated hardness. at this nano length scale. is much larger than expected for macroscopic indentations. This nano-hatrdness corresponds io the ultimate yield terength of the material.

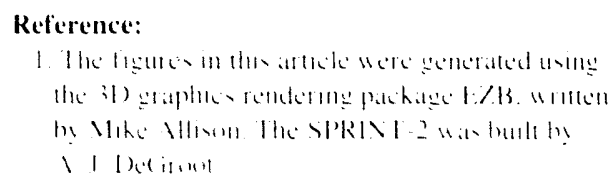




\section{Micromachines at LLNL}

$\mathbf{R}$ esearchers in microdynamics use the technology for fabricating integrated circuits to make microscopic mechanical devices with parts capable of movement. These devices are fabricated in place using a salcrificial latyer process and require no further anembly. Often their largest dimension is less than $100 \mu \mathrm{m}$ labout the diameter of a human hair). Among other devices. sliders, gears. springs. microgrippers. electrostatic motors mechanical logic operators. and resonant structures halle been huilt. These devices are expected 10 hatce broad applications as senors and actuators for use in the atutomotive. chemicall. hiological. and medical industries and ans components in miniature scientific inseruments. Microdynamics is expected to revolutionize technology with an impact comparable to that of integrated circuits. Our ten years of experience with microstructure technologg enables us 10 matie early contributions to this promising tield.

We derigned and boilt an arraty of miniature cantilever beams for use as at lest bed structure. This structure call be used as a deformable mirror in al laser beam scaunning syem ree Figure 1). We calculated that tens of wolts will give thexe beams ample deflection. The calculated resonant

\begin{abstract}
Working in microdynamics, a new field within engineering, we have adapted the technology for fabricating integrated circuits to build microminiature mechanical components capable of movement. Our array of cantilever beams (20 to $100 \mu \mathrm{m}$ long) can be electrostatically deflected and is likely to be used in laser scanning systems.
\end{abstract}

frequency of $-3(0) \mathrm{kHz}$ is quile useful for some laser scanning systems.

We fabricilted these heams using a sacrificial layer process. A $2-\mu \mathrm{m}-$ thick layer of structural material (we used polysilicon for the cantilevers is deposited and patterned over a 2- $\mu$ m-thick phosphosilicatte glass (PSG). The PSG is then elched alwaly. learing the free-standing cantilever beam. We deposit the polysilicon over the PSG islands by low-temperature chemical vapor deposition at $6055^{\circ} \mathrm{C}$. Many beams are fabricated simultaneously on a single 5()-cm-

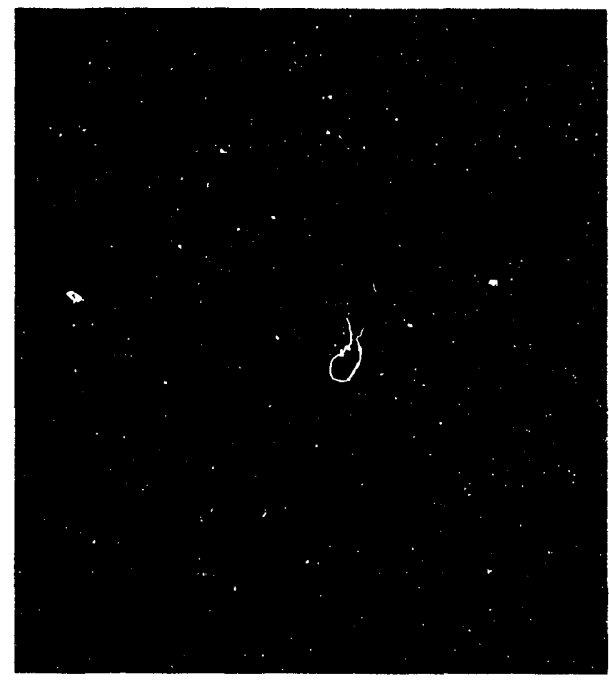

Figure 1. Scanning electron micrograph of miniature polysilicon cantilevers for use in a laser scanner. The beams are $20 \mu \mathrm{m}$ wide, $2 \mu \mathrm{m}$ thick, and from $2010100 \mu \mathrm{m}$ long. Their resonant frequency is as high as $300 \mathrm{kHz}$. diam silicen wafer. We placed the cantilevers in a jig and applied a 2()$-V$ DC current to them while maintaining the substrate al ground potential. observing motion through a lowpower microscope. We also applied an $\mathrm{AC}$ voltage of various waveforms and. using a strobe light, observed motion all all waveforms tip to $1 \mathrm{kH} /$. the highest frequency tested so far.

Cantilever beams fabricalted by the process described are likely to find use in Laboratory experiments that require laser scanning. Scan frequencies of several hundred kiloHerty appear achierable with the proper electrostatic excitation of the miniature beams. We are now ready to build on our experierice and lackle more chatlenging tasks. The use of microdynamics in the development of miniature scientific instrumentation appears attractive. and looks especially promising in miniature instrumentation for chemical analysis. We are therefore now planning (o) use microdynamics for designing miniature pumps and balser for chemical andalysis. a miniature spectrometer for use as an optical detector, and a miniature electrophoresis system for andyois of 'emical solutions.

(antact: I). R. Ciarlo $(+1.5)+22-8 \times 72$. 


\section{Advances in Molecular Beam Molecular Beam
Epitaxy}

We have used molecular beam epitaxy to greatly improve the fabrication of semiconductor lasers and fast photodetectors, which should improve future diagnostic systems.
$\mathbf{M}$ olecular beam epitaxy (MBE) is al lechnigue by which gallium arsenide (GaAs) or other wafers are coaled by chemical reatetion with materials of controlled chemical composition. Our primar! reatction is betheen arsenic or antimony and one or more of the group-lil metals gallium. aluminum. or indium. We heat the water (subutrater to 650 (1) ${ }^{\circ}$ and expose it to apors of gallium. aluminum. or indium. to arsenic or antimons. and io selected trate yuantities of dopants. such as vilicon or beryllium. Our single-cry lat substrate waters atre II picially $5(1)$ (1) $75 \mathrm{~mm}$ in diameter and 1$).+\mathrm{mm}$ thich.

Our he? adrances hale been in the area of photonic deviees. such at diode liner and uluahigh-yed phosodetectors. Our work on diode laners has focused on the growth of lasers with the formidable name graded-index. separate-confinementheterontructure. stained-latyer. singleyuantum-Mell i (SRINSCH) laser ifigure 1). The der ices the end product of decader of exolutionar! work. hate the highes efficiency of an! lavers. The 20 wafers we hale groun aroser the range of lasing wadelengthe from $87110967 \mathrm{~nm}$. The most widels uned figure of merit for diode lasers is threshoded current density: the current demsity at which lasing hegins. Our hese lasers hate show a a therehold current density of 179 $\mathrm{A} / \mathrm{cm}^{2}$ for a kength of $11.35 \mathrm{~mm}$ and a width of $19.1 \mathrm{~mm}$. This is the exend lomes value reported for L.S.

for the heghes yuallu! (sit.t) w he gersen by . MBE. the : mperature of the GaAs substrate wafer must remain above $5.50 \mathrm{C}$. For ultrahigh-speed photodetectors. we used our MBE system to grou GaAs at very lou substrate temperatures of $2(1){ }^{\circ} \mathrm{C}$. which had been reported to produce optically inative GaAs. However. as we suspected. the material is quite suitable for fast photoconductors. For any given response speed. it displayed the highes sensitivity of any material we used. We have applied for a patent based on the use of a gradedindex. AlGaAs owerlater in conjunction with the low-temperature Gats. This device structure allows the sensitivity to be optimized for a given speed of detection.

We halle atso uned MBE to grow many wafers with strainedlalyer superlattices to extend the photoresponse of our detectors farther into the infrared than the ().9- $\mu \mathrm{m} \mathrm{GaA}$. warclength limit. Our best-performing structures hate superlattices with alternating 1-nm-thick $\operatorname{In}_{x} \mathrm{Ga}_{1-x}$ As and $\ln _{x / 2} \mathrm{Gia}_{11-\mathrm{x} / 2}$, As layers to serve as the photoabsorber. Thus we can fabricate low-noise detectors with an overall efficiency of $10 \%$ for light with a wavelength of $1.06 \mu \mathrm{m}$. These detectors use vertical transport of the carriers. which is part of our longterm effort toward the fabrication of photocathodes with sensitivity to infrared light. This very desirable device (which is not commercially available) would match wavelengths used in liber-optic cables.

Finally. we have used our MBE system to grow single-crystal GaAs on silicon wafers. which we expect will have a very fast photoresponse. We have been able to etch away the silicon in (0.8-mm wide "windows." leaving a GatAs membrane used as a salturable absorber for generating ultrashort laser pulses.

Contact: R. Mariella $(+1.5)+22-89(1) 5$.

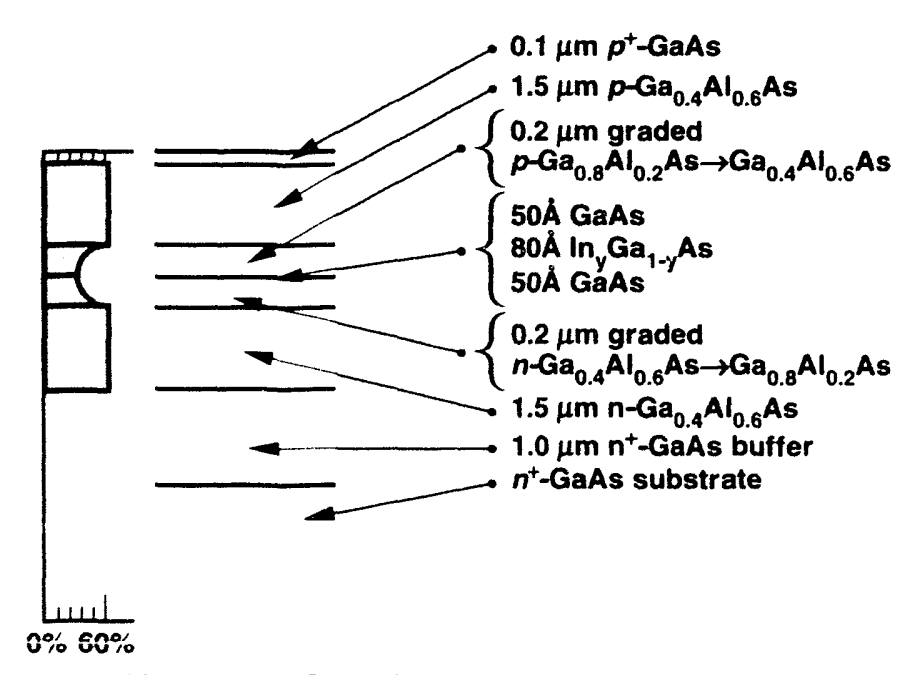

Al content in $\left.\mathrm{Ga}_{1-x} \mathrm{Al}\right|_{x} \mathrm{As}$
Figure 1. MBE layers used to fabricate GRINSCH lasers. 


\section{Certification of Process Gauge}

We have designed a computer-controlled measuring machine for the inspection of manufactured nuclear weapons components.
W e halle designed a certitication of process (COP) gallege for inspecting hemishell components at plants of the DOE nuclear weapons complex $1 \mathrm{NWC}$. This compulercontrolled. ultraprecision gauge is being developed for the Precision Flexible Manutaturing Systems (PFMS) Program. a cooperative DOE effort directed at reducing the health. sately. and ensirommental impact of manufacturing 14 eapons components from toxic and hatardous materials. It will be used in PFMS cells to certit: the dimensional accurac! size and contour of components, monitor manufacturing performance. and provide process-control feedhack.

Designed to meet the requirements of laboratories (L.L.NL and L. X. . L and production plants alike. the machine must be able w inspect the inner and outer surfaces of a hemishell component. held in at vertical-axis fixture, using multiple polar or azimuthal path scans of surfaces at speeds up $10625 \mathrm{~mm} / \mathrm{min}$. For production applications. the machine must be alecurate within $(1.75 \mu \mathrm{m}$ for inner and outer component surfaces and within $1.75 \mu \mathrm{m}$ for wall thickness measurements. and it must work with equipment that can automatically load and unload the components.

The (OP gauge hats three linear axes and one rolary axis (Figure 1 ). The component is mounted on the rotary table (C-axis) and transporiced on an independent. horizontal slide (Y-axis). Two displacement probes on vertical slides sean (lower Z-axis) the component s lower surface whrough a $f()()-m m$ hole in the center of the rotary lables and upper surface (upper Z-axis). A component on a rertical-axis rotary lable is constrained
Figure 1. The computer-controlled certification of process gauge is configured with three linear axes and one rotary axis to automatically inspect manufactured nuclear weapons components. Overall dimensions of the machine are $3.1 \times 2.0 \times 3.3 \mathrm{~m}$.

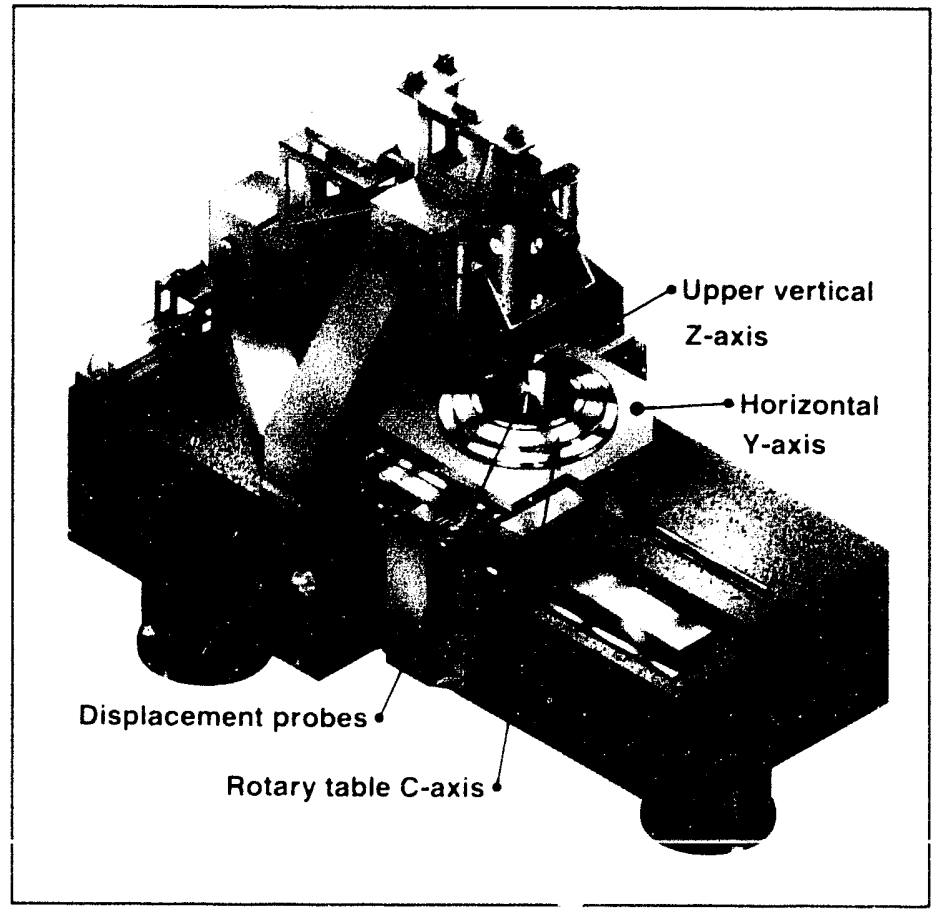

by gravit: and needs no holding device. Which through distortion. could impair accurate of measurement.

The COP gauge reflects our exlensive experience in designing precision machines and gatuge equipment: all bearings are hydrostatic air for minimum friction and optimum repeatability: laser interferometers operating in evacuated beam paths provide slide position feedhack: capstans drive the linear axes: and super invar. a low coefficient of expansion material. is used for thermally sensitive components (e.g.. the upper structure of the machine). In designing the gauge we applied L.L.NL-proven concepts to a machine that must be robust enough for a production emviromment. To ensure that performance goals would be met. we used extensive finite-element modeling (FEM) to optimize the machine static dynamic. and thermal behavior. We then merged results of the FEM analyses with other data $(1)$ create an error budget - an L.L.NI.developed analytical tool using known error sources of balance performance. risk. and eost objectives. and (o) predice orerall accuracy. The results of (sur error hudget analysis indicalle that accuracy requirements will be met.

The design of the (")P galuge is complete. and the mechanical systems are being fabricaled by our industrial partner. Rank Pneamo) (Keene. NH). We are developing the control and data acyuisition ysem. The protolype is scheduled for completion in 1992. and production sersions are scheduled (1) he imstalled all NWC facilities in FY 1905

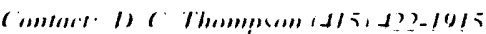




\section{Electrodeposited Nickel-Phosphorus Coatings Reduce the Cost of Diamond Turning Tools} have developed an electrodeposited nickel-phosphorus coating for diamond machining surfaces that are not ordinarily diamond-turnable. Our method will decrease the wear on the diamond tool and thereby reduce the cost of the operation.
D iamond tuming surface finishing uses single-point diamond look on a precision lathe under precisely controlled mathine and envirommental conditiom. Diamond fools are used when it is necessally to matchine the smothes pousible surface lexture. When the surfale to he cut is one of the preferred diamond-turnable mallerial 1 sach as copper. electroless nichel. or aluminums. surface textures as ymoth als $1 \mathrm{~nm}$ can he obtained. Surtaces that are not ordinarily diamond turnable esuch an beryllium. moly hdenum. and glass can be made s) hy heing colled with a surfitce that diamond look cian machinc.

Recont!. We hate demomstrated that for the fabrication of latrese optice and other precision parts. an electrodeposiled nichel-phosphorus ( Ni-P) colating is more cost effective than the widely med electroless Ni-P colting. The mont signilicant cost faterot is that the electrodeposited conting catuse less 11 cart on the dianond lowl. thereby extending the life of the $(x)$. A round-nosed diamond (co) normall! uned in diamond turning wear sut and its cutting edger receder from it erigenal prolite as the cutting divance increases. Figure la shous a profile of a dia mond forel used on clectroles Xi-1.3P and Figure ith show a smilar profile of a diamond mol uned an electrodeporited vi-1 tP. measurad all ditlerent culting distances matred on catch training of the loxt profile. A comparion of the protile

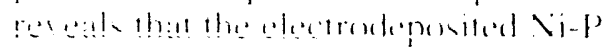

was not as damaging to the tool ats the electroless $\mathrm{Ni}$-P. In addition. the surface roughness of the electrodeposited Ni-P after cutting was $1.6 \mathrm{~mm}$ rms is $8.3 \mathrm{~mm} \mathrm{mms}$ for the electroless $\mathrm{Ni}-\mathrm{P}$. demonstrating that a smoother linish can be obtatined with electrodeposited Ni-P.

Electrodeposition offers a number of other advantages over electroless coatinge for diamond-turning applications. First. the electrodeposition process is considerably less expensive than batch-process electroless plating. Second. electrodeposition offers an order-of-magnitude greater deposition thickness and the possibility of reduced porosity. Typically. a minimum coatling thichness of $7.54 \mathrm{~m}$ is required and often ats much as $250 \mu \mathrm{m}$ is desired. This requirement taxes the capacity of many electroless nickel processes. Finally. clectrodeposition offers the possihility of producing alloss with > 1.5\%; pirosphorus (not obtainable with electroless plating). and allogs higher in phosphorus might proside still smosther finishes. These factors. logether with improsed tool life. make the electrodeposition process an attraktice and kes expensive allernative for conting objects that are not mormally diamondi-lurnable.

Vite

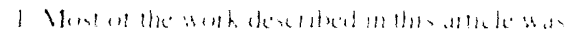

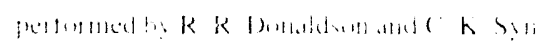

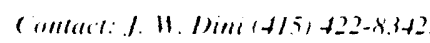
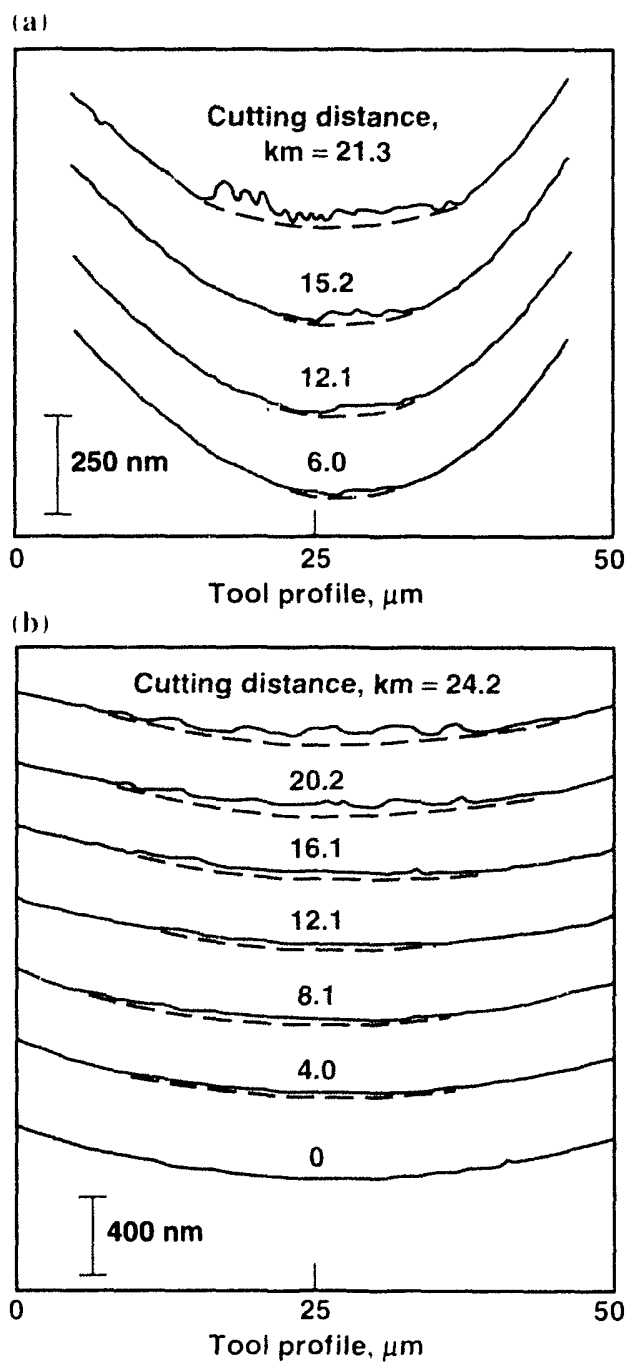

Figure 1. Profiles of diamond tools that have cut (a) electroless $\mathrm{Ni}-13 \mathrm{P}$ over a distance of $21.3 \mathrm{~km}$ and (b) electrodeposited $\mathrm{Ni}-14 \mathrm{P}$ over a distance of $24.2 \mathrm{~km}$. The leading edges of the tools are toward the left. The dashed profiles show the original profile of the tool, and the difference between the dashed and solid profiles represents the tool wear. 


\section{Physics}

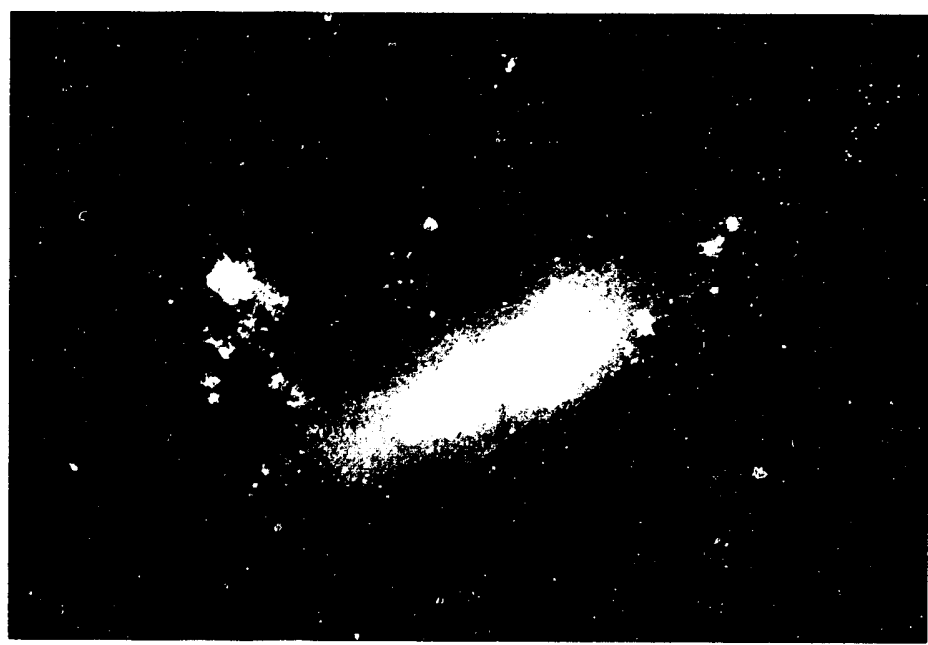

We exploit unique facilities and expertise in innovative long-term research for the nuclear weapons program, ranging from astrophysics to condensed matter and plasma physics, and involving developments in massively parallel computing.

$\mathbf{T}$ he mission of the Phesices Department is 10 pursue research in areas that are in the forefromt of phosice and are important to current and future Laboratory prostams. (o) exploit unicue facilities and expertise (1) initiate and carrs out high-leserage scientific and technological projects. to interat wigerously with outside atcademic and technical communities. and to recruit and develop outstanding scientises and leaders for the Lathorator!. To execute this mission the Department provides both leadership and support to major Laboratory programs, and is actively insoled in an increasing number of sther Department of Energes projects and rembursable efforts. It also puts strong emphasis on Explorator! Rescarch and Development projects and on participation in the various instituter devoled lo particular renceatrin atreas
The Department s traditional work has focused on innovative and longterm physics research that could have a significant impact on the nuclear weapons program. This effort has been concentrated in the disciplines of astrophyssics. attomic physics. condensed matter. nucleatr physics. and plasma physics. and in such computationally intensise pursuits as compressible hydrodynamics and transport theor!

Two articles describe the application of a basic research effort to an emerging major programmatic need. One highlights recent achievements in the derelopment of decetors for nuclear physics and highenerges physics. the other highlights massively parallel computing.

The new class of partick delectors must exploit the sers fast. radiationhard electronice cappahilities developed in the nuciear kes program. Ine seatreh for more-detailed understanding of the substructure of nuclei and nucleoms and for new exotic phases of nuclear matter requires larger accelerators that can handle increasingly complex experiments. Groups from the Physics Department are making major contributions $t(0)$ two international accelerator projects that should be in operation in the late 1990s: the Superconducting Super Collider (SSC). an S8 billion proton accelerator in Waxahatchie. Texas, and the Relativistic Heary Ion Collider (RHIC). a $\$ 50()$ million healy ion accelerator at Brookhaven National Laboratory.

The nuclear design program must effectively utilise the highly parallel supercomputers of the future to meet its design and sately groals for the next decade. The new hreed of supercomputers will be composed of hundreds or thousands of highpertomance microprocesses To help 
the Laboratory take ad antage of these new machines. all atgeressive Massively Parallel Computing Initiative 4 ats stated in 1988. Our project has broad participation from application groups both inside and outside the Laboratory.

Three other accomplishments are particularly noteworthy: a new lightelement opacity code. progress in "designer" materials with high energy densities. and the use of high-intensity. short-pulse lasers for laboratory experiments in weapons physics.

Opacity is a crucial material property in calculating the absorption and transport of radiant energs in a star. Lntil recently, the standard computer code for calculating the opacily of light elements wats at Los Alamos National Laboratory. Over the past seteral years we hate combined a tirst-principles description of the equation of state of matter with an accurate method for determining absorption cross sections to produce the henchmark code for astrophysical applications. It provided an answer to a long-standing astronomical purzle involving Cepheid variable stars.

The achievement of stable highenergy-density materials has always been a goal in the nuclear weapons program. Thanks o increasing computing power. two new alenues of research hate led to dramatic advances in this areat. First. we are looking for highly distorted nuclei with stable states several million electron volts above those of the normal nucleus. Several promising candidates hase heen computalional!: identified. and confirmation of the theory is being sought in a number of experiments. Second. we are performing (ab intio calculations of new molecular configurations in order to oblain more energetic hul stable forms of high explosice. In the longer run these lechniques should enathe analogens searches to be made for materials with high tensile strengths. excellent dactility. and other valuable characteristics. As computer power increases still further and experience is gatined in choosing the calculational starting point. the method should become a valuable practical tool in designing new materials.

We are continuing our efforts to exploil advances in laser technology: and diagnostics to carry out laboratoryscale experiments in weapons physics (in conjunction with the nuclear lest and laser programs). Very-short-pulse lasers can excite cold matter to a hightemperature. high-density "frosen" state (no hydrodynamic motion). We are working on both the experiments and their interpretation to infer important details of the properties of matter characteristic of early stages of a nuclear weapon s history. Small high-intensity lasers can create population inversions in certain target media. which in turn could lead to tunable laboratory x-ray lasers. Even in the absence of lasing action. the phenomena could provide intense pulses of UV and $x$-ray photons that would be very cost effective for Heapons effects studies.

Recently. an increasing portion of our work has been directed toward projects funded outside the nuclear weapons community. In large measure this represents the successful transfer of expertise developed in those programs 10 other problems of national importance. Three articles in this section highlight some of our current work along these lines: the innovative Brilliant Pebbles program supported by the Strategic Detense Initiative Organization. GlLD. a revolutionary doping technology for producing defect-fice bipolat transistors, and studies of the global carbon cycle with accelerator mass spectrometry. Our work in other climate-related projects is eomtinuing (o) increase in volume, and He hate significant intiatioes in atmospheric chemistry. in developing corpled atmospheric-oceanic mokels. and in utilizing the echnologies dereloped in Brilliant Pebbles for innowative approaches to measuring important emvironmental parameters. The long term goal in this area is o develop a combined program of theory. modeling. and experiment that can produce thorough understanding of the crucial issues in global climale change.

We are continuing to foster outside collaborations and interations through a number of institutes. For example. we sponsor a number of ad anced mathematical projects, such as neural network modeling in the Institute for Scientitic Computing Research. and we hate responsibility for the Plasma Physics Research Institute. which has begun a new effort in nonlinear computational plasma physics. In addition. the LLNL branch of the Eniversity of Californiat s Institute for Geophysics and Planetary Physics (IGPP) has very saceessful and active programs in astrophysics, highpressure physics, and seismology.

The MACHO project described in this section is led hy scientists from the IGPP. and represents an imaginative approach to "secing" the dark matter in the universe. The estimated total mass of our galaxy alone is over ten times greater than its estimated visible mass. As in the universe als a whole. most of the material in our galaxy must therefore be composed of some unknown form of dark matter. The search for dark matter is a top priority in both astronomy and particle physics. In contrast to theories that dark matter takes exotic forms. we hate proposed that it is made of objects like our planet Jupiter that are simply tor distant to be visible, and we have devised a way of searching for them. We are carrying out experiments of find this missing mass using observations of the Latrge Magellanic Cloud shown on p. 72).

Comact: (: R. Tarter (+1.5)+22-4169. 


\section{Designing Particle Detectors for the Future}

H igh-energ: and nuclear phs sics. entering nes eras in the search for more-detailed understanding of the substructure of nuclei and nucleons and in the search for neu exotic phase of nuclear matter. require larger accelerators of handle increasingly complex experiments.

He are making major contributions to two international accelerator project that should be in operation in the late 1 yyor: the Superconducting Super Collider (SSC) an $\$ 8$ billion proton accelerator in Waxahatchic. Texas. and the Relativistic Heasy Ion Collider (RHIC) a 550() million healy ion accelerator at Broshhaven National Laboratory.
We are playing a major role in the development, design, and pending construction of two proposed particle detectors that will provide new insights into nuclear matter at extremely high energy and matter densities.
L.L.V. : expertise in superconducting magnets. large precision structures. advanced electronics and electro-optics. computing. and project enginecring makes us an attractive partner and potentially a major contributor in these new areas of basic research. Both facilities will need large general-purpose detectors. We have joined leading groups to build the detectors. The itso projects are technically rather similar although their scale and physics goals are quite different.

The SSC project is a large international collaboration among many institutions worldwide: we are

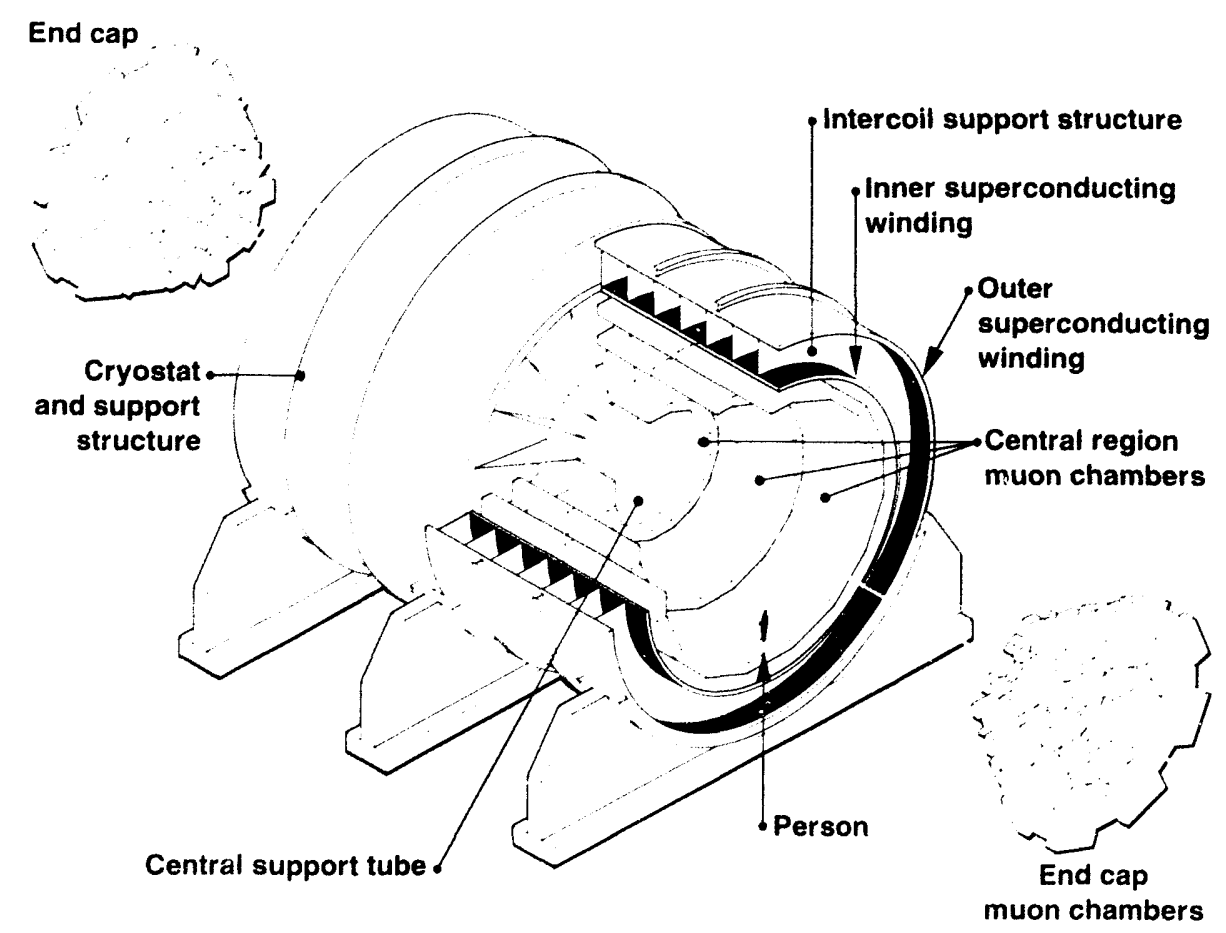

Figure 1. The magnet and the muon chamber system for the proposed project at the SSC. working with the Kurchatos Institute in Moscons lo design a very large superconducting magnet for detecting high-energy muon particles. and with group from several other laboratories to design very large precision muon chambers.

In computations. our Massisely Parallel Computer Initiative (see p. 75 ) is providing hardware and expertise 10 study new. efficient ways to analyze and simulate data from the detector at CERN (the prototype for the SSC projec(l).

If the technical proposats are accepted and funded ffor an entimated \$50) million). We expect to play major roles in constructing and installing the magnet and muon chambers in Texas (see Figure l).

The DiMuon project also incolves muon particles as a primary signal. but at a much lower energy in an en ironment with a high multiplicity of more strongly interacting particles (mostly pions). LLNL ' Magnetic superconducting toroidal magnet and providing much of the overall systems engineering for this project in the proposal stage. We are laking major responsibility for the design of the muon chamber subsystems. Which will be similar to some of the chambers currently proposed for the SSC The final proposal will be developed oner the next year. Its succeen will depend largely on how well we and our collaborators can match our physice goals to available resources restimatted between $\$ 2()$ and $\$ 3.3)$ million. If the project is suceestul. we would again expect of lathe responsibilit; for ignificant constructom all the facility

Comlact: H. C. Britt $1+15,+22-4513$ Fusion Energy group is designing a 


\section{Moving Toward Massively Parallel Computers}

W care on the threshold of a fundamental change in the approach w building supercomputers. Cnlite the raditional approatch. which unes one or a few powerful but expensive processors. the new approach will une large numbers of high-pertormance but relatively inexpensite microprocessors Horking in parallel. In recent tears. great performance gains have been made in microprocesores. and they are beginning 60 orertake traditional supercomputers for scalat applications. Moreoser. the! will soon rival supercomputer in vector-processing performance. The adrances will make posible a new breed of supercomputers. eatch composed of hundreds or thomands of highperformance microprocessors.

To help the Laboratory ahe adrantage of these new machines. an ageresile Masilel! Parallel Computing Initiatice was started in 198xi. Succes in massively parallel computing is measured by progeress in applications. So far we have focused (1) vhort-term progress in applications that will enable the Laboratory to exploil masisel! parallel machines within a bear or iso. Our project has broad participation trom application group both inside and outside the Laboratory. 'tie athiesed good performance for salar-dominated coder. ar could he expected from the relatively high performance of current RISC miereprocesorers on calar-dominatced code. Ling 32

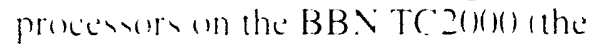

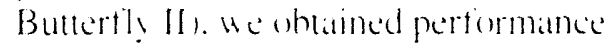
at high as len limes that of a single-

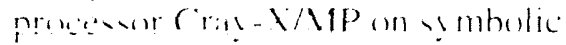

We are developing a new supercomputer concept in which large numbers of high-performance microprocessors working in parallel will provide unprecedented power for addressing the complex computational problems of interest to LL.VL. implicit Monte Carlo photon transport. For partially rectorized code. such as a three-dimensional neutron-transport code. we used 48 processors and oblained performance equal to that of a single-processor Cray-Y/MP.

Future massively parallel mathines will be far more powertul. The farsest microprocessor now avalable in the workstation market is four times as fast. on scalar-dominated code. as the microprocessor used in our BBN TC2()(0). Single-chip rectorprocessing units were announced last year that give performance of zo() Miflops iflops atre floating point operations per secend. He expect that large-scale parallel machines with such rector-processing units will appear in the next tew years.

It is clear that massicel parallel machines will offer the Laboratory an entirely new computational capabilit! in a vear or perhaps two years time.
Massisels parallel machines that provide an aggregate scalar performance of more than 80 times the capacity of a conventional supercomputer will be ar ailable during this time. These same machines will provide an aggeregate vector performance that is four to eight times faster than what will be obtainable from a consentional supercomputer. At this point. outclassed for scalar workloads and will give lackluster pertormance for vector workloads.

The Massively Parallel Computing Initiative is positioning the Laboratory to take advantage of the new breed of supercomputers as they arrive. We will either be using massivel! parallel computers for production computing by the end of 1993 or we will not be superiomputing.

Contact: E. I). Brooks $I I 1+115,+2.3-7.341$ comsentional supercomputers will be

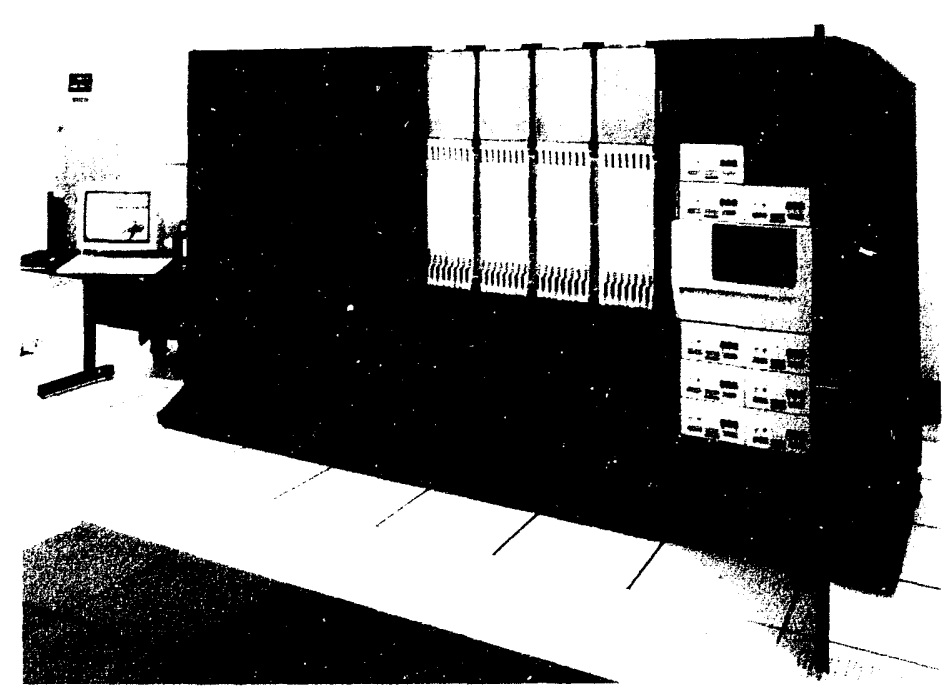

Figure 1. As a step toward a massively parallel computing system. the 63-node BBN TC2000, in use at LLNL for one year. was recently upgraded to 126 processors. 


\section{Brilliant Pebbles}

T he Brilliant Pebbles concept for the Strategic Defense Initiative Organization (SDIO) consists of identical. highly capathle small spacecraft deployed in lou-earth orbit that. through high-selocity collisions. will stop ad anced ballistic missiles and their components in flight. While subject to human command and control. each spacecratt can detect and hunt down missiles orer distances of thousands of hilometers without external aid. These Pebhles. roughly I $\mathrm{m}$ long. can be huilt and deployed with existing L'.S. technologe for roughls SI million each. A thousand of them should provide very effective wategic defense against an atcidental or unauthorized missile latunch or agatins Third World missike threats.

The objectie es of our test program are lo demonatrate interceptor

\section{We have made progress in design and testing of the Brilliant Pebbles spacecraft and its sensor package, as nell as substantial developments in companion technologies, such as missile-tracking software.}

performance that is scalable to actual design specificitions. and of detect. track. and intercept an accelerating target in its boost phase at typical ICBM/Brilliant Pebble closing velocities. In developing the test rehicles. we work in parallel to reduce mass and to increatse the performance of all components.

The mission of the first flight test. launched from NASA , Wallops Flight Facility in August 199(). Was (1) lest first-generation Brilliant Pebbles components and the operation of the sensors and attitude-control system in space. to demonstrate stabilization of the probe with respect to the stars. and to acquire and track an accelerating source. The probe withstood the launch stresses and functioned until the fairing separation. when a malfunction damaged either
Figure 1. President Bush visited LLNL in February 1990 to receive an update on Brilliant Pebbles technology. Here he receives a scale model of a Brilliant Pebble spacecraft from Dr. Lowell Wood.

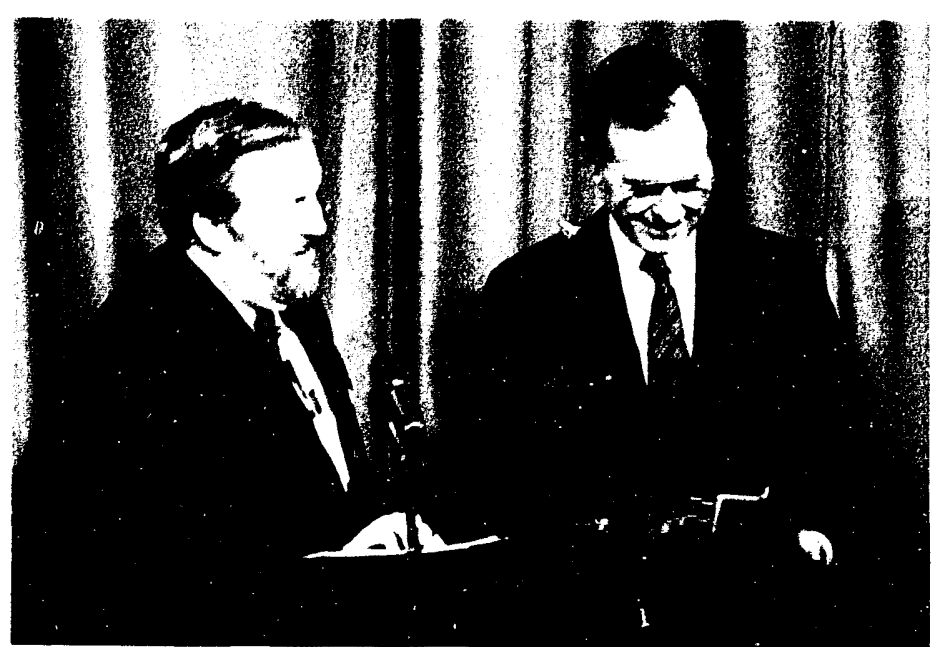

the tramsmilting or power subststems. causing a loss of telemetrs. We plan four more flight tests in coming years all in compliance with the Anti-Ballistic Missile Treats. The second such test. conducted in April 1991, successfully realized nearly all of its objectives.

In 1990) the Brilliant Pebbles project had several successes. including outstanding advances in companion technologies. During Operation Desert Storm. on reyuest from the Air Force Space Command and SDIO. We developed a prototype sistem. PHAROS. for reall-time tactical ballistic missile warning. Computing missile trajectories from early-warning satellite data and displaying missile locattions on highresolution maps. PHAROS predicts their flight positions and uses digital terrain elevation datat to improse estimates of the launch location for better targeting. The software runs on an 8-C CU Silicon Graphics superminicomputer: the geographic data cover two million square miles and require 8 Ghytes of memors. By predicting the impact point and probable threat zone for the launched missile. PHAROS enhances Warning and aids missile intercept. PHAROS (an also display historical data on launches and order of battle for later analysis.

Comtact: H. S. Scott $+1.51+22-7294$ or J. E. Marion II +1 !) $+2.3-6788$. 


\section{Advancing BiCMOS Technology}

We have developed an innovative laser process that, for the first time, allow's the most modern silicon semiconductor technology (BiC.MOS) to be built on insulating substrates. Cltimately, this type of technology will produce very-high-performance memories and microprocessors for advanced commercial, space, and military computing systems.

thermal anneiding lechnologien repuired to electronically actis atte the depants also create electrical hom circuits in the :mitter and collector. rendering the circuit nonfunctional.

One solution in lo derelop improsed substratle that will eliminate the defects. This approach. howerer. delity the introduction of Bic MoS ecthonology until suitable substrater become als ailable. We hate therefore turned instead a immos ation in processing 60 minimis the defocts: we hatce dereloped gat immersion later doping ( (ill.D)) a lechnolege! that sufficiently reduce the thermal cycle to a proint al which delects are

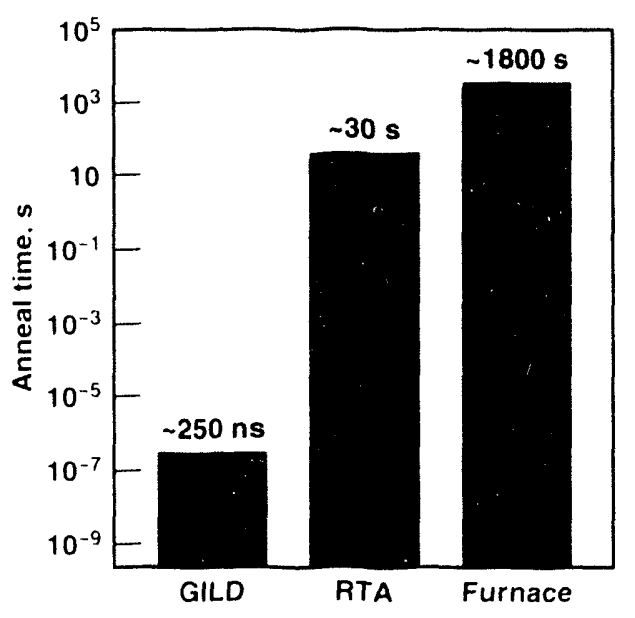

Figure 2. The GILD laser technology at $1000^{\circ} \mathrm{C}$ is a million times shorter than the typical rapid thermal annealing (RTA) technologies and a billion times shorter than a furnace anneal. The significantly shorter thermal cycle of GILD results in the virtual elimination of defects in the silicon. inventifiant, Todin! imperted matterial can thus he uned os derelop high-pertormance Bic $: M() \mathrm{S}$ procesese. which will be further improsed an high-yualit! subutritter become al atilathe.

The (ill. D process unes a pulsed laser operatting at $30 \mathrm{ngm}$ (6) melt the silicons surface. Doping accurs when impurity atoms. present in the gas phase above the water. diffuse inte the molen silicon. The molten material regrom an electrically atcise. damlagefree lisers. The laser process reduces the thermal eycle for dopant actisation 10 nancesecond-at million to a billion times horter thatn com entional heatting kehnicyer (t)igure 2). Defects atre virtually eliminaled. As a result. his proces allow simple fabricittion of hase regiom les than l(1) nom in width on ans subutrate material.

The (ill.i) project has secesestull! built the first thin-base bipolat transistors in silicon on sapphire using the pulsed-laner proces

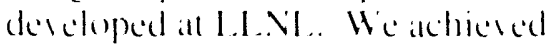
nermal transister operation at base "ridth betucen 80 and 1.5() $\mathrm{nm}$ derpite the high number of defect $(-1)^{+}\left(\mathrm{m}^{2}\right)$ in the mallerial.

He are now worhing w improse the performante of the hipolat tramsintor and we deselop the highperformatnce submicrometer ( Nos dericer mecersally lor a Bic Mos

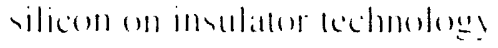

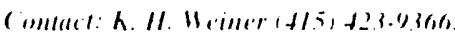
temperature anneal and to short circuit the emitter to the collector.

Figure 1. Defects in the narrow base regions of a simple bipolar transistor allow diffusion pipes to form during a high- 


\section{Accelerator Mass Spectrometry Yields New Findings on the Carbon Cycle}

New information on the global carbon cycle will lead to more-aceurate predictions of global climate change.
$\mathbf{U}$ ndervtanding the global carton crele is an important sep cow ard accurately predicting global climate change and mahing energe? policier on stch isules as holl 10 minimise the greenhouse effect. With the small rample capathilities mest at ailathle with atcelerator mats spectrometry A.MSs. we can une

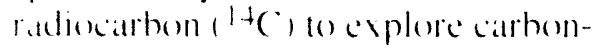
ack denamics in reservois that until now rere difficule to stud! hecittere of their vimall catrben contemt. Both collaboratice and in-house

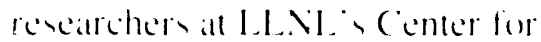
Accolerator Man Spectrometrs are tud ing the mechaniom and rater of carbon cycling in organic matter in soll and exean sediments and dismoled in wreams. lakes. and groundwatler. Three tinding from our 199() worh arce particularl! intriguing.

He uned the infiltration of bombproduced $1+c$ a trateh the atcumulation. tramsport. and decat! of organic matter in temperate and tropical fores soik. Resule shous that carbon turnoser is more than tuice as rapid in tropical forest soils an in lemperate soils. As much as 70 's of the orgatnic matter in upper soil horizom has been replaced since the end of atmospheric testing in the carly 1960). (Our results imply thatl. in response on humand disturbances. resersoirs of soil organic matter can hold or releare carbon and alfece atmospheric (O) 2 concentrations aver decades.

Me also used bomb-produced $14 \mathrm{C}^{\circ}$ (1) participale in the first study erer conducted of the origin. trameport. and eycling of dissolved organic carbon in a lorested Watcrshed. Disuleded organic carben plays an important role in the chemistry of freshuater sy sem that are emsitive to acid rain. affecting the charater. mobility. and loxicit! of metals and other pollutants. The presence of sienilicant quantitice of bomb-
Figure 1. Carbon balance for a region of the continental slope off the northeastern U.S.. derived from our AMS radiocarbon data. Units are milligrams of organic carbon per square meter per day.

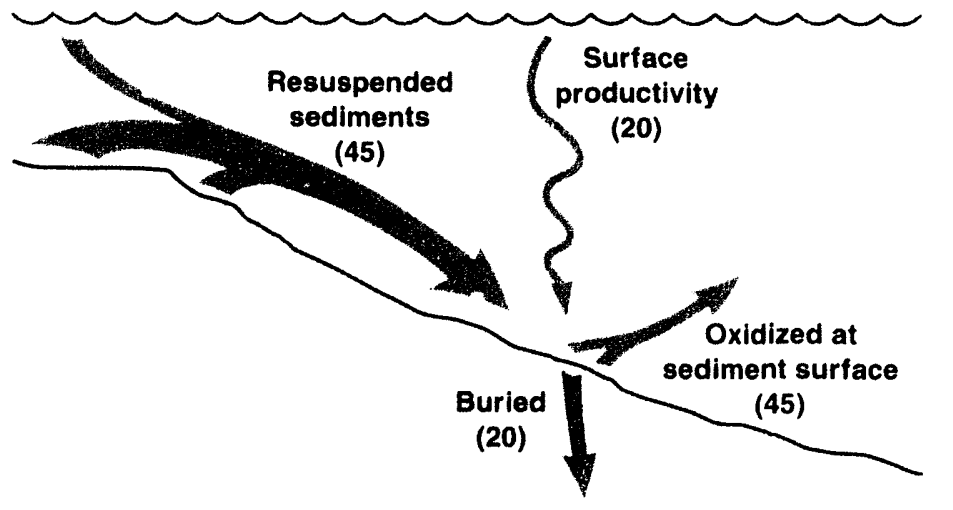

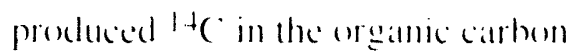
that 1 an dissoleded in streams. letlands. and late " water of this central ( Intario Matter bed indicates that the curnoser time of much of this material is rapid. He entimate that there is at least at 50$)^{\prime}$ ' turnoser of dissoleded organic carbon within a 30-sear period. The implication is that humatn activitien, including the impact of acid rain. can signilicantly allece dissolved or gante carbon and is pollutant interactions in natural rillersheds. (Our studs war done in collaboration with reseatrehers al the Center for (iroundwater Studien all the C'nisersity of Watterloo. (Ontartio.

to has been hypothesised that organic-rich sediments found on the continental vope of the northeistern l'mited Stater represent at rapid accumulation of carbon preduced by nest photosy nthetic atetivity. If this theors is correct, the alccumblation could represemt a significant portion of the une plained "missing sink" of (O), that is derived from forsil-fucl burning. (our meisurements of the radiecarben content of these organicrich sediments and of particulate mallerial suspended in the orerly ing water column conclusidely hou that the sedimemts come from the

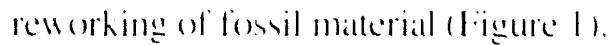
()ur finding therefore contradicts the hypothesis that the sediment represents recents prodeced organic matler. We collaboraticed on thie profece with

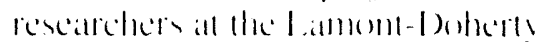

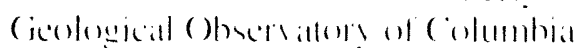
Iniceill. Nour roth.

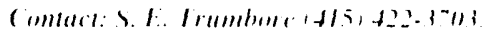




\section{The MACHO Project \\ Explores Dark Matter in Our Galaxy}

M ost material in our galasy. the Milk! Was. is thought of be composed of some unknown form of dark matter cevidence for which is oreruhelmingl. The total man of our galaxy is estimated by examining the nearly circulat motion of the gias and stars around its center and applying Newlon' latus (much an anclysis of planetary orbits reveals the sun's matss. The estimalte obtained is over ten times greater than the estimate of the lotal mass in visible tars cohtained by calculations from the fotal light emilled hy the galaxy). Mos of the material in our galax! must be some unhnown form of dark matter. Astronomers hate established that this dark matter does not lie in the plane of the Milk! Wat. Where most stars are found. but must instead fill a huge encempansing sphere hnown as the halo.

Of the many hypotheses about the composition of dark matter. perhaps the mose conservative-because it does not posit exotic forms of matter-is that the dark matter is made up of sojects like sur planet Jupiler. objects called massise compace halo objeces i.MACHOS. He see Jupiter because it is very chese (by astronomical standatids) and reflects sunlight. If moved to a Is pical distance for an ohject in the halde. rat. 30.00() light sears. it would be invisible to astronomers.

Searching for thexe whjects requates an imaginatio indirect technique. (Onc uar alyggested in 1986. W'sen a MACHO mores dose (1) the line of vight between farth and

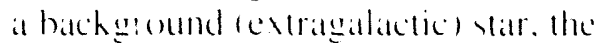

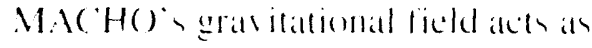

One of the most intriguing questions in asirophysics is what makes up the ubiquitous dark matter. We are examining the possibility (one of several) that it is made up of vast numbers of objects like Jupiter. an amplifying lens and the star appears brighter. If the MACHO comes very close to the line of sight. large amplificition is possible. Since the MACHO is mosing. this amplification is transient: the time variation of such all event could be predicted precisely. For eximple. by monitoring the hrightnesses of stars in the Magellanic Clouds. our nearest neighbors (Figure 1). astronomers could search for these erents and thus determine the presence or absence of MACHOs.

The difficulty with this proposal is the extremely low rate of events. The brightnesses of millions of stars would have to be recorded nightly for several vears. This task proved too daunting for astronomers until a group at L.LNL. demonstraled that it was technically feasible. The project now involves atstrophysics groups at LC Berkeley and the Australian National L nis ersity. The science team is adlapting the 5() -in. telexcope of Australiat : Mt. Stromlo Observatory for the project. An optical system under construction will enable the telescope to record the brightnesses of millions of stars nightly. The MACHO leam plans system integration in late 1991 and expects to begin recording data lor a four-year period. In four vears there should be at definitive answer to the question: Do MACHOs make up the dark matter in the Milk! Way.?

Comtact: C: K. Alcock (41.5) +2.3-0660 or T. S. Axelrod $1+1.51+2.3-17.36$.

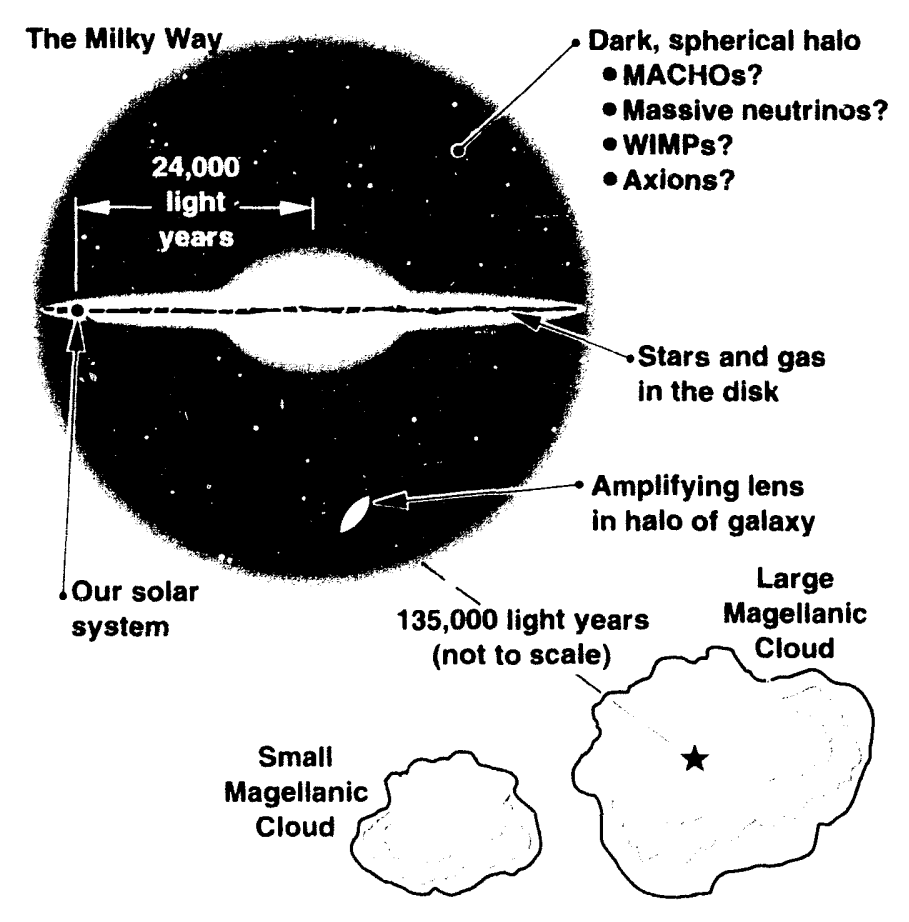

Figure 1. The Milky Way seen schematically in relation to the Magellanic Clouds and a predicted typically located MACHO amplifying lens. (WIMPS are hypothetical, weakly interacting massive particles.) 


\section{Chemistry and Materials Science}

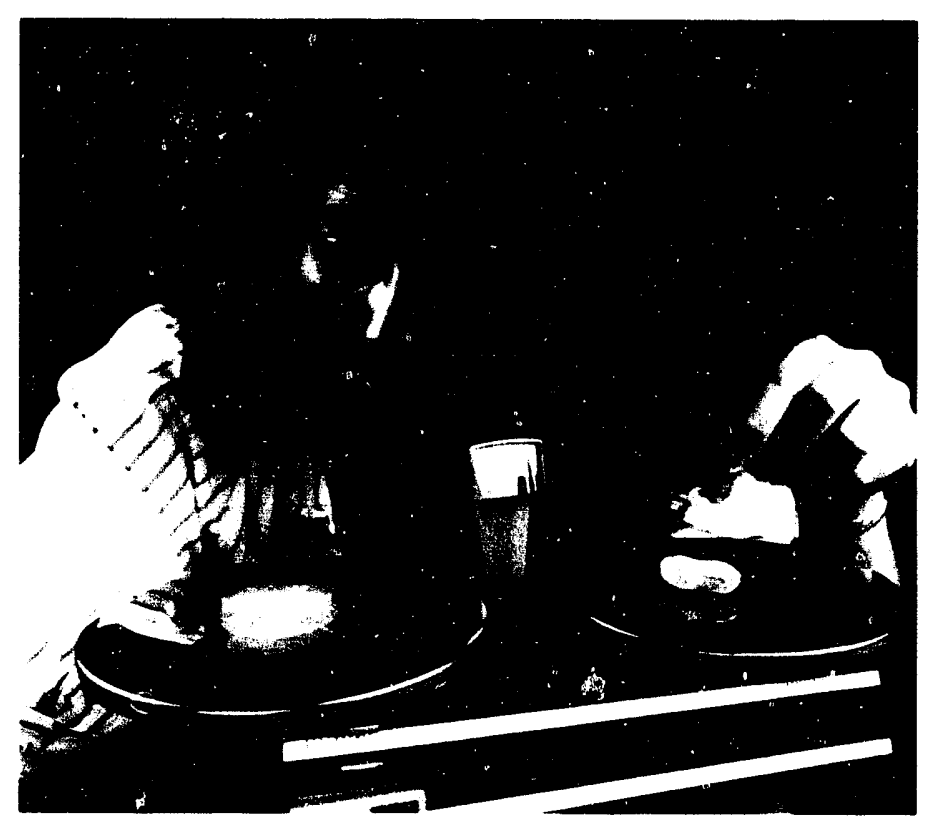

\section{In support of the Laboratory's mission in defense systems, lasers, and fusion, we devote major efforts to creating materials with unusual properties that increasingly require characterization on the nanometer (atomic) scale.}

T he Chemistrt and Materials Science Department deloter mator programs 10 ynthesicing. charaterizing. and apply ing new material in support of the

Latherator: - miwion. Mant of the material are unetul under estreme condition af lemperitture. presure. density. andior howil: ensironment. and are charditeri/ed bs unu ual encre: denvels or kebel at pertedtorn. The recereh piogram at the Deparment are tokuced an ceral aresa-

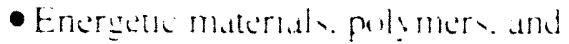
umpiallo
- Ceramics. metals. and alloys lespecially plutonium).

- Surtaces and intertaces.

- Adlanced characterization methods k. E... ynchroton radiation).

- Vivel malerial teg. highimperature superconductors).

Man! of these project are directly related to L.L.NL: i program in detense Ysems. lavers. and fusion.

In lyon the Invitute fir

Tramactunium Solence, ince renamed the Cilenn T Scathrye Invitute, W is

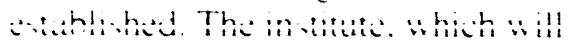
smpharlec clucatlon and tranning a

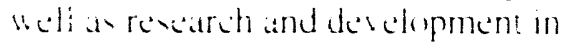
the wence and tecinoles of the healy elements. will begin operations in FYYI. The initial agenda of projects will reflect the recommendations of a Junc 1 - () workshop attended by most of the L. S. xcientists in the field.

Vumerous scientitic projecs in the Department operate on the nanometer caale, the dimenuion of one or at few atom. Since man! charateriation methed in iommon une have: resolutions in nanometers, the propertice of substances must now be interpretce on that wate. While

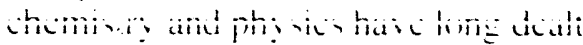
with anc or a few atom or molecules expectally it they are in an ordered 
arraty . the length scale of materials science had been in the range of micrometers. Bridging the gap is not stralightforward. When does a collection of atoms begin to resemble the bulk materials? We can now pertorm detailed studies of electronic states in a small cluster of atoms and can compare them with staltes in bulk matter. as one of the articles that follow describes. We are using synchrotron radiation photoemission to examine the occupied valence electronic structure of nanoweter-scale clusters of semiconductors. To examine size dependence. semiconductor clusters with very narrow size distributions in the condensed phase. He use a unique wetchemical method to grow and attich nanoristals to the metallic substrates. He have demonstrated that cluster size affects the valence band maximum.

Also on the nanometer scalle. we have used the scanning tunneling microscope (STM), or atomic force microscope. to observe the location at which a simple chemical reation (the oxidation of graphite) oceurs. We are investigating the surfacereaction kinetics over a large range of reactivities. reactant pressures. and exposure times. The scanning tunneling microscope employs a probe whose point is a single atom: a small amount of electric potential is applied to the probe. and the current between the point of the probe and the substrate varies so that atomic-scale variations in surfice roughness an be measured. STM allowis us to look at the physical and electronic structure of surfaces with atomic resolution. The intrinsic senvitivity of the method is so high that wer! low reaction rates can be obuerted-one reation all a time. so to speak. Similarly. hy cherer extension of existing >ras absorption techniques. "le can follow the depesition of a single later of atom on a substrate in real time. Thi kechnique. called quich evended x-ra! aborption tine structure (QFE.AFSi. has heen uned in the studs of multilaser structures that are produced h: deporiting alcernating layers of substances. Though the process can be followed with nanoscale resolution. the multilayers themselves are thick even on a microscale. These materials hate the potential for extremely high mechanical performance that approacios their theoretical strengths.

The Department has devoted a major effort to studying novel hightemperature superconductors. One question of special significance to the study of these malerials is the distribution of the electrons in them. i.c.. their electronic structure. We have developed sophisticatted experimental methods for studying the electronic states in these compounds.

The recovery of plutonium from a variety of complex mixtures is trequently difficult and can generate una: ceptable new wastes. We have developed a new highly efficient technique that uses electrochemical reduction to recover metallic plutonium. Mediated electrochemical oxidation can destroy hazardous Maste at ambient temperatures and convert mixed (hazardous and radioactive) waste to transuranic waste. Converting dissolved organic compounds to carbon dioxide and water in such a process avoids the high-temperature actinide volatilization that can occur during incineration. Other plutonium-related projects deal with investigations of refractory materials to contain liquid plutonium.

The synthesss of low-density microcellular feams has become a specialty of the Department. The early work was done with silica in the form of aterogels and resulted in an R\&D I(x) award in 1990. More recently. organic aterogels synthesized from resorcinol or melamine and formaldehyde hate been characterized and shown to hase extratordinary optical and thermal properties as well as rers low demsitices.

In another sy nthesis specially of the Department. organic themiss hate discorcred new reation paths lo ynth-sise cnergetic high-nitrogen compound with lou somitivit! (1) accidental detonation. We hate derie ned and are synthesizing an insensitive energetic matterial that is about 10\%, more energetic than TATB We have also used tunable lasers to control chemical reaktions that otherwise would be driven solely by thermal energy and be controlled by the latts of probability and statistics. Until now besides adjusting system temperature. little could be done to direct the reacting molecules into or away from a specific reaction channel. Tunable lasers enable us to excite indisidual electronic. vibrational. and rotational states within a molecule. controlling chemical reactions by exciting a specific mode of the molecule that is directly coupled into the dy namies of the desired reaction.

The program that specializes in the study of cryogenic hydrogen isotopes and compounds continues to make advances in the very difficult effort to spin polarize the deuterium and tritium spins in solid D-T. A recent new application of solid-tritium technology has been to label high-molecularweight compounds such as proteins and large peptides with tritium at high specific activity. (Exposing these compounds to gaseous tritium leads to much lower specific activity than we desire.)

New methods of characterization continue to be at the forefront of the Department s activities. Recent accomplishments include the acquisition of a +-MV accelerator for ion implantation and ion-beam-based analytical applications such as particleinduced $x$-ray emission and Rutherford backscattering. X-ray tomography has been developed as an imaging tool for a number of applications in the matterials science of composites-for example. a nominvasive study of the behavior of a carbon tiber in a matrix.

The Department also participales in a bariely of energ-related programs from oil-shate reconery lo biomimetic compoutads for methane axidation.

(ontact: T. T. Sugihara (155) +2.3-5.351. 


\section{Modeling the Electronic Structure of High-Temperature Superconductors}

In our research, focusing on the oxide superconductors, we have experimentally rendered and theoretically modeled the details of the electronic structure of $\mathrm{IBa}_{3} \mathrm{Cu}_{3} \mathrm{O}_{7}$ using positron two-dimensional angular correlation of annililation radiation.
(ACAR). angle-restued photecmission ypectrose(1)! 1. ARPESI. and de Hata-1 all Alphen effect meastrements-proside complementar! details about clectronic structure.

AC AR measures bulk clectronicsructure propertice hy stud! ing the clectron momentum demsity of oriented single crystals. Positronclectron amnihilation carries direct intormation ahout electron momentum in the concident annihilation gammal rass. This information is collected hy measuring the desiation from collinearity of the
Figlipe 1. Grayscale image of the consolidated and corrected data sets for YBCO. The circles define the outer limit of the subtraction process: white is high. black is low. Note the two linediscontinuities running parallel to the [100] direction and symmetrically placed from the center of the momentum distribution. convincing evidence of a Fermi surface.

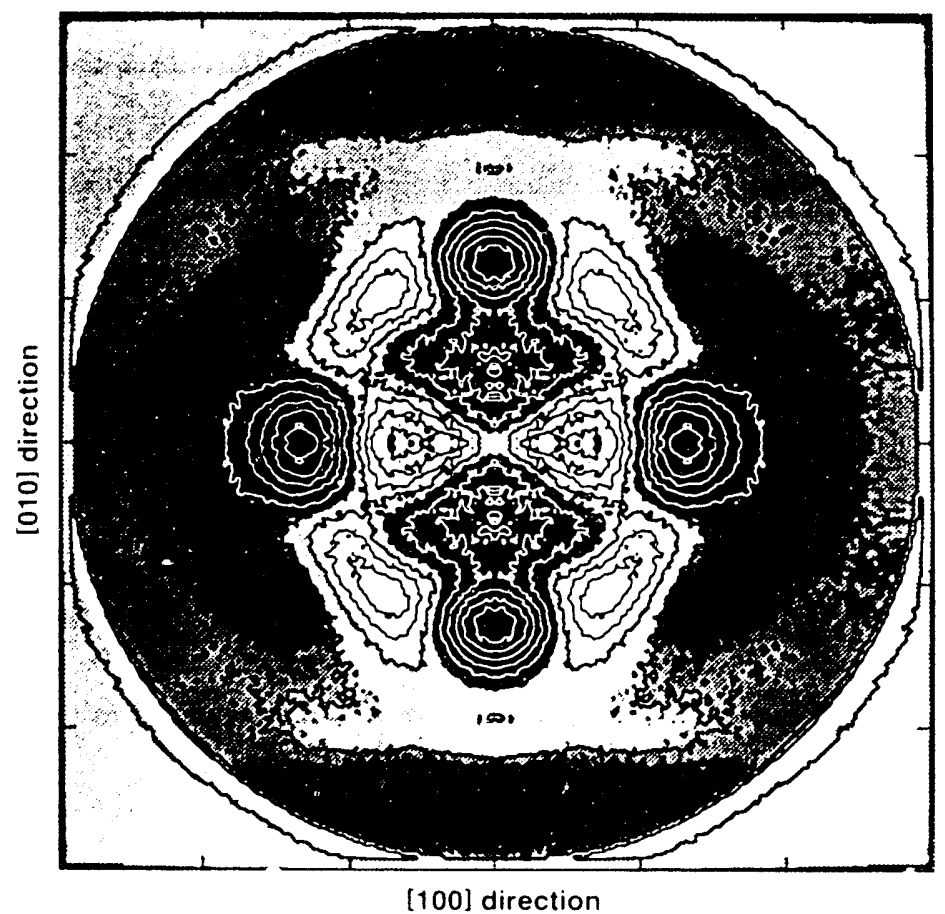

annihilation gatmma rats in a pair of larege-arcal position-somsitice detectors. Becalus AC AR is much less ensitio to surtiac affects than ARPLS. it can be used to determine the overall copologe! of the Fermi surfiace in a single measurement. On the other hand. ACAR is an allclectron cechnique: as a result. in basically ionic malerials. such as $\mathrm{YBa}_{2} \mathrm{Cu}_{3} \mathrm{O}-1 \mathrm{YBCO}$. it suffers from a poor signal-bo-noise ratio. Thus. useful studies reyuire experiments with good statistics on crystals of extratordinarily high quality

We recently completed ACAR measurements on YBCO Crystal: without a m boundaries li.e.. lwinfiec) alt ultrahigh lesels of stattistical precision. He hate also performed measurememts on unique samples of l.al $1.57+\mathrm{Sr}_{0.126}(\mathrm{Cu})_{+}$(L.SCO). We are collaborating in this work with rexarchers from the L niversity of Texals all Arlinglon. the Lniserits of (aliformia at Dasis. and the eniversity of Tokyo.

The YBC() measuremems Mere pertinmed on a matrix of crystats that

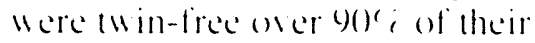
surface akcomplished hy anncaling under compressioms. Meastarements of magenetic sunceptibility revealed that all the crystals hecame superconducting abouce $2 \mathrm{~K}$. The iste of (1)! germatlon is eriticall! important: carlice we had found that positroms will localis alomer the (u () chatms and we thus hnew that the yuality of the dalla might he 
alfected by oxygen point defects of oxygen disorder in this part of the crystal.

The rat gammatgammat coincidence datil, corrected for the geometric efficiency function of the detectors. vielded a virtually featureless isotropic electron momentum distribution. However. subtraction of a radial isotropic average of the spectrum from itsell reveals the rich features associated with the directional bonding. and. hopefully. With the itinerant or delocalized electrons in the Fermi seat. The observed symmetry. shown in Figure 1 , is indeed what we expected from eontributions related to the $\mathrm{Cu}-\mathrm{O}$ chatins in the untwinned samples. Note the two line discontinuities running parallel to the |l()()| direction and symmetricall! placed frem the center of the momentum distribution. The breats are significant al 10 standard deviations in the data and thus are clear. nommodel-dependent. comvincing evidence of a Fermi surface at that position.
The position of the experimentally observed Fermi surface is in good agreement with that expected from band theory. The real-momentum calculations of Bansil, I single-zone calculations of Picketl. - and our own results all predict the Fermi surface shees that we see from the crossing of a hand associated with the (u-O chains (Figure 2). There is even agreement between the data and the shape of the Fermi surface. Theory predicts that there are other Fermi surface features associated with either $\mathrm{CuO}$ plane bands or hybrid states. although to date wa have no independent confirmation of these feallures in our diata.

The observation of a Fermi surfate on the CuO planes requires either much higher statistics or a difierent system where the positron is spatially drawn to the perowskite plane region. With this objective in mind. We have used the LLNL 2DACAR spectrometer to perform a similar measurement on single crystals of LSCO that have a sharp superconducting transition at $30 \mathrm{~K}$.

\section{(a) Experiment}

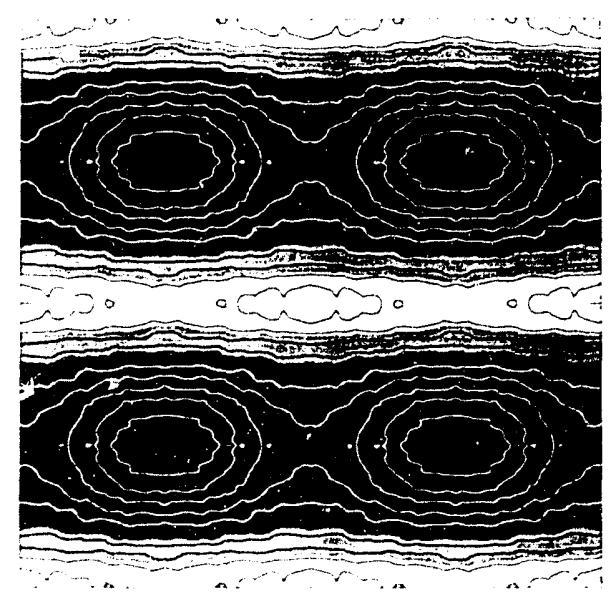

(b) Calculation

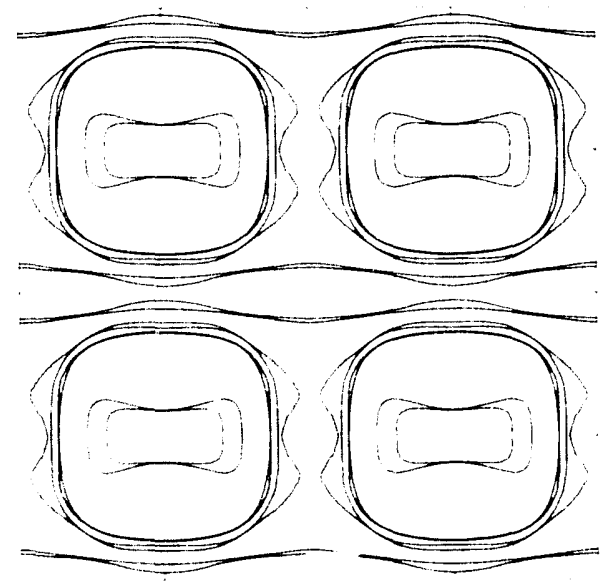

Although the samples are tetragonal overall at the temperature of the measurement, we found that longran'se planar orthorhombic domains may exist in the tetragonal phase. To verify this, it wats necessary to analyze the data within an orthorhombic cell. Figure 3 compares the experimental datal with a rigid-band calculation. The correspondence between theory and experiment is very good, indicating a square Fermi surface lying just inside the orthorhombic zone.

Refierences

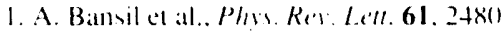
(1985).

2. W. HE Pichell. R. I: Cohen. and H. Krakatter. Phis. Rer. B+2.87+6 (19)0).

Contact: R. H. Hon'ell (\$15) \$22-1977. P. A. Sterne (115) +22-25/(), or H. J. Filuss (-1)5) $\$ 2.3-666.5$.

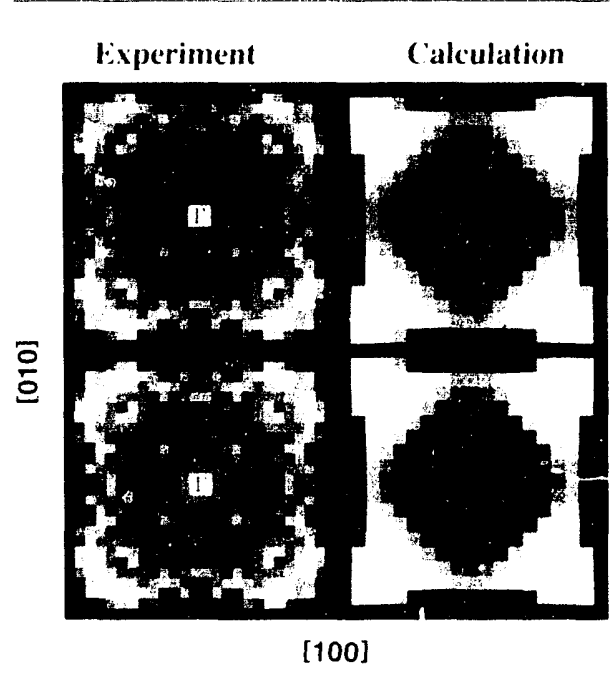

Figure 3. Comparison of experimental data for LSCO (left) with a rigid-band calculation (right). The agreement between experiment and theory suggests the existence of a Fermi surface arising from the CuO planes.

Figure 2. The position of the experimentally observed Fermi surface in YBCO (a) and the theoretical calculation of Fermi surface sheets arising from the crossing of a band associated with the $\mathrm{Cu}-\mathrm{O}$ chains (b). Note the good agreement. 


\section{Electrochemical Oxidation of}

\section{Hazardous and
Radioactive Wastes at
Ambient Temperature Hazardous and
Radioactive Wastes at
Ambient Temperature Hazardous and
Radioactive Wastes at
Ambient Temperature}

W e have studied the mediated electrochemical oxidation (MEO) of several organic substrates to carbon dioxide $\left(\mathrm{CO}_{2}\right)$. We used $\mathrm{Ag}(\mathrm{II})$. generated by the anodic oxidation of Ag(l . to oxidize organic compound dissolved in an aqueous phase.' The electrochemical reactor had a gold rotating-cylinder anode. The stationary platinum cathode was separated from the anode by porous ceramic diffusion barriers or ion-exchange membranes.

The cell was charged with $40 \mathrm{ml}$ of anolyte, which consisted of $0.5 \mathrm{~m}$ $\mathrm{AgNO}_{3}$ and $3.25 \mathrm{MHNO}_{3}$ and a smaller volume of substrate. The cell
We are exploring mediated electrochemical oxidation for destroying hazardous waste at ambient temperatures and for converting mixed (hazardous and radioactive) waste to transuranic waste. The ultimate conversion of dissolved organic compounds to carbon dioxide and water in such a process avoids the high-temperature actinide volatilization that can occur auring incineration. current was maintained at $67.3 \mathrm{~mA}$. well belou the limiting current for Ag(II) generation. Reactions were conducted in a closed vessel so that all $\mathrm{CO}_{2}$ could be captured. Gasphase concentrations of $\mathrm{CO}_{2}$ were periodically determined by mass spectrometry and converted to mass. At high substrate concentrations. oxidation occuried near the anode surface, and the bulk $\mathrm{Ag}$ (II) concentration was approximately zero. At low substrate concentrations, some $\mathrm{Ag}(\mathrm{II})$ existed in the bulk anolyte.

Figure I shows the data obtained during $\mathrm{MEO}$ of benzene and ethylene
Figure I. $\mathrm{CO}_{2}$ evolution during MEO by Ag(II) of (a) ethylene glycol, initial concentration $0.2 \mathrm{M}$ and (b) benzene, initial concentration $0.0 .075 \mathrm{M}$. The cell temperature was $33^{\circ} \mathrm{C}$, because of ohmic heating of the electrolyte.
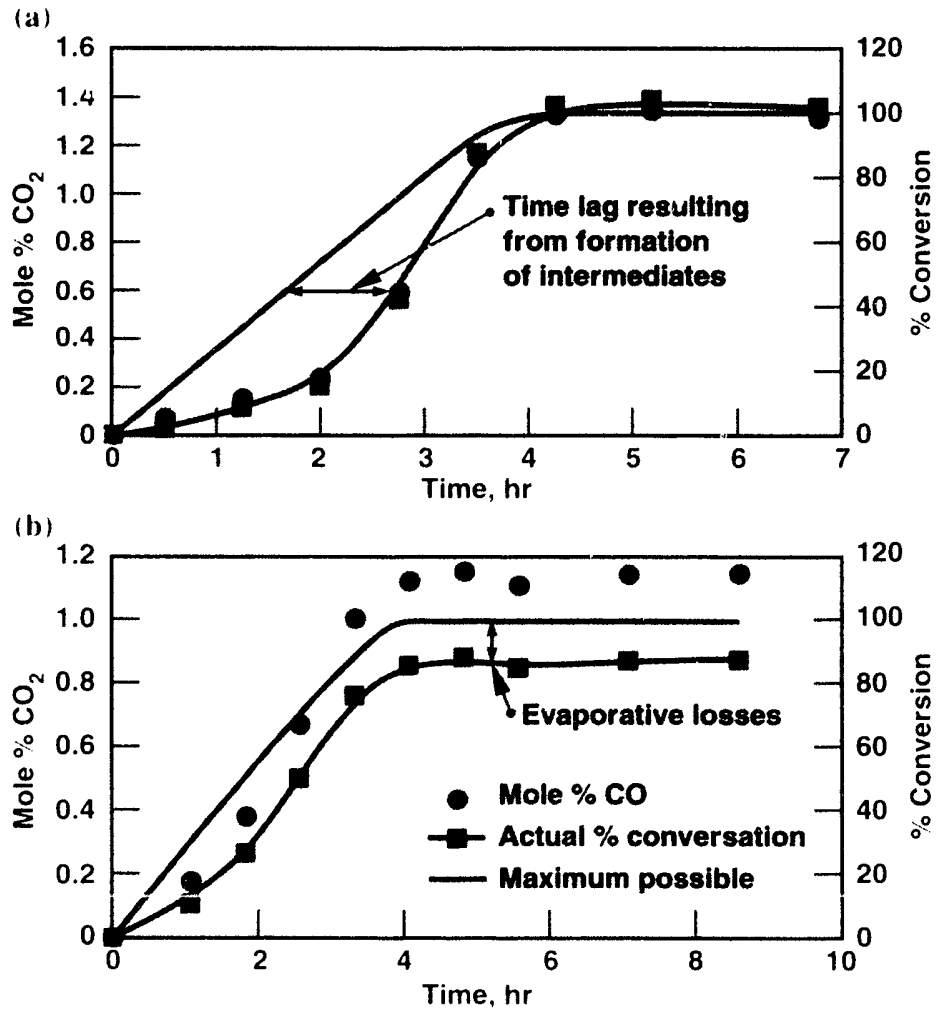

glycol. The colored line represents the maximum possible conversion of substrate to $\mathrm{CO}_{2}$. on the basis of the $\mathrm{Ag}$ (II) generated. Points represent individual $\mathrm{CO}_{2}$ concentration measurements. from which actual conversion was calculated (represented by the solid curve, which is a "best fit" to actual data points). The lag in the conversion to $\mathrm{CO}_{2}$ arises from the accumulation of chemical intermediates in the anolyte before the formation of $\mathrm{CO}_{2}$. In the case of benzene, ultimate conversions of less than $1(\%) \%$ are due to evaporative losses from the anolyte. All benzene in the anolyte was oxidized.

Reaction paths were established by gals chromatography with mass spectrometry for benzene. We have learned to suppress reactions that result in the nitration of aromatic compounds in nitrate-based electrolytes. Reaction steps resulting in oxygen addition are favored.. .3

\footnotetext{
References

I. D. F. Siecke. "Blectrohemical Destruction of

Toxic (Organic Industrial Wasle." Platimum Melal, Reriew $34(1) .10-1+(1900)$.

2. J. ( . Farmeret at., "Denign of Electrochemical Reatcon for Imhanced Dissolution of Plutonium ()xide" presented at the 178th Mecting of the Eiectrochemical Sociely. Seallle. WA. ()etuber

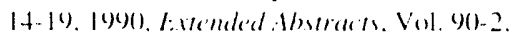
Ahe. No. $72+10.31-10.32$

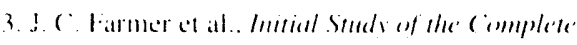

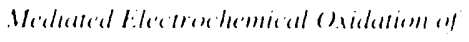

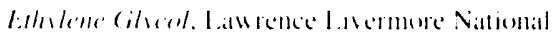

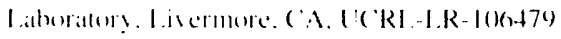
(|)
}

Confact: .) (: Farmer (41.5) +2.3-9777. 


\section{High-Performance Nano-Engineered Multilayer Materials}

A tomic and near-atomic materials engineeringl a aquires procedures for reproducibly synthesizing materials and design tools allowing the property of interest to be optimized. Physical vapor-deposition multilayer synthesis allows such control. Multilavers are depth-periodic sructures fabricated from alternating layers of elemental materials. alloys or compounds. Multilayers in attomic engineering hate periods smaller than four atomic layers $1-1 \mathrm{~nm}$ ): multilayers in microstructure engineering have greater periods.

Control of composition and microstructure at the atomic level gives microstructured materials the potential for extremely high mechanical performance. approaching the theoretical strength of metal. and allow - control of flaws that often limit mechanical performance. Samples up 10 $2(0) \mu \mathrm{m}$ this $k$ and $2.3(0) \mathrm{cm}^{2}$ in areal containing more than 40.000 lavers having periods of from 0.510 f(j) $\mathrm{nm}$. have been synthesized using elemental copper. zirconium. titanium. chromium. tantalum. lungsten. and platinum. and the alloys Monel (70) $\mathrm{Ni} / 30 \mathrm{Cu}$. 304 stainless steel. and tungsten-rhenium ( $26 \%$ ).

The mechanical properties of copper/Monel ( $\mathrm{Cu} / \mathrm{M}$ ) multilayers are representative of the relationships observed between synthesis process and structure and properties. Figure 1 show rensile strengtho of equatlayer-thichness $\mathrm{Cu} / \mathrm{M}$ multilayers thicker than $25 \mu \mathrm{m}$. has ing periods of $(0.510200 \mathrm{~nm}$. as a function of the multiliter period ads. Also shown is the censile strength of copper as a function of grain sie and distocation
We are engineering nanostructure multilayer materials at atomic and near-atomic scales. These materials have the potential for extremely high mechanical performance that approaches their theoretical strengths. subgrain size. Three regions of structural scale dependence are shown. Region 1 is characteristic of polycrystalline materials: is inversely proportional w the square root of the grain size. Region 2 is a new structural-scale domain for which there is no accepted therry. Iil Region 3 the multilavers become chemically uniform because of the very thin latyers.

The theoretical strengths of copper and nickel are 1.2 GPa and 2.4 GPa respectively: by a simple rule of mixtures argument. the maximum strength expected for $\mathrm{Cu} / \mathrm{M}$ multilayers is -1.6 GPat. The strength observed at $d \approx 2.5 \mathrm{~nm}(-1.15 \mathrm{GPa})$ is greater than $70 \%$ of simp: a theory. This is the first time such high strengths have been observed in "hulk" samples and indicates the potential of nanostructure multilayer grain/subgrain size strengthening materials: such strengths had been attainable only with perfect microscopic whisters ( $\leq t \mathrm{~mm}$ diam).

We are becoming able to fabricate "designer" materials by controlling structure at formerly inaccessible fivels: the fact that the macroscopic properties of nanostructure multilayer materials depend on microstructure. which in determined by the synthesis process demonstrates this. The scientilic understanding needed to guide application of these new materials should advance rapidly. giving rise to new scientific and technological opportunities.

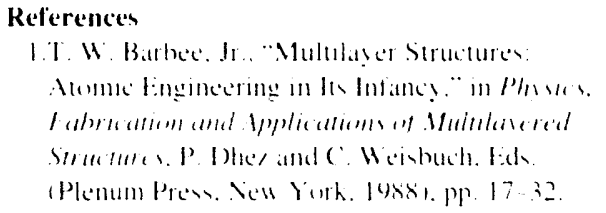

Contact: T. W. Barbee, Jr. (\$1.5) \$2.3-7796.

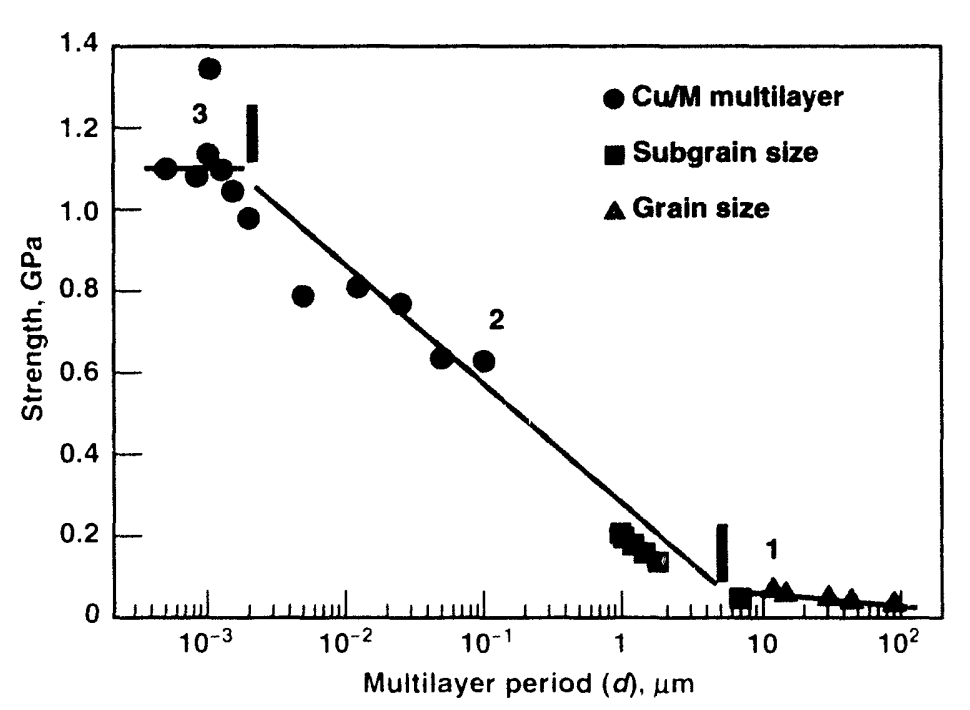

Figure 1. Tensile strengths of equalthickness Cu/M multilayers having periods of $0.5 \mathrm{~nm}$ to $200 \mathrm{~nm}$ and bulk copper are shown and compared as a function of $d$, the multilayer period, and bulk copper grain size and subgrain size. The regions of structural scale dependence are (1) $d \geq 1 \mu \mathrm{m}$.

(2) $1 \mu \mathrm{m} \geq d \geq 0.003 \mu \mathrm{m}$. and (3) $0.003 \mu \mathrm{m} \geq d$. 


\section{Compound Semiconductor Nanocrystalline Clusters}

We are examining the occupied valence electronic structure of nanometer-scale clusters of semiconductors with synchrotron radiation photoemission, using a unique wet-chemical method to grow and attach nanocrystals to the metallic substrates. Cluster size affects the valence band maximum.
W 2 are investigating the size dependence of the electronic structure in compound semiconductor nanocrystals. In these monodisperse (single-size) clusters. the finite size

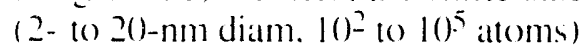
and crystallinity may combine to create affects such as novel variations of the compound soptical properties and caltalytic capabilities. To examine size dependence. we must prepare semiconductor clusters with very narrow size distributions in the condensed phase. He routinely synthesize clusters of $\mathrm{CdS}$ of 2 to 2) $\mathrm{mm}$ with diameter distributions of 3 to 10\%; in our laboratory. In the very early stages of growth. the small crystallites all grow in parallel and are distributed uniformly in size. By terminating the eryal growth at this stage with an organic terminating moiets. Which "caps" the cluster surface. we can capture the crsstallites.
By judiciously selecting the organic group. We can adjust cluster solubility. Moreover. the organic group can be bifunctional. so that the noncapping end can be used to attach the clusters to a variety of substrates. We have developed methods to attach the clusters to Au and Al surfaces using short chain alkanes as bridges (see Figure 1).

The occupied electronic structure of the clusters was probed with photoemission, using synchrotron radiation from the 4-m NIM beamline on the $1-G e V$ ring. Aladdin. at the Liniversity of Wisconsin Synchrotron Radiation Ceriter and from Beamline 8-2 at the Stanfore! Synchrotron Radiation Laboratory. The novel use of the alkane-chatin attachment of the cluster (o) the metal substrate is essential for avoiding sample charging. The quality of the sample preparation was confirmed by several other methods (see Figure 2). and the dista ibution of

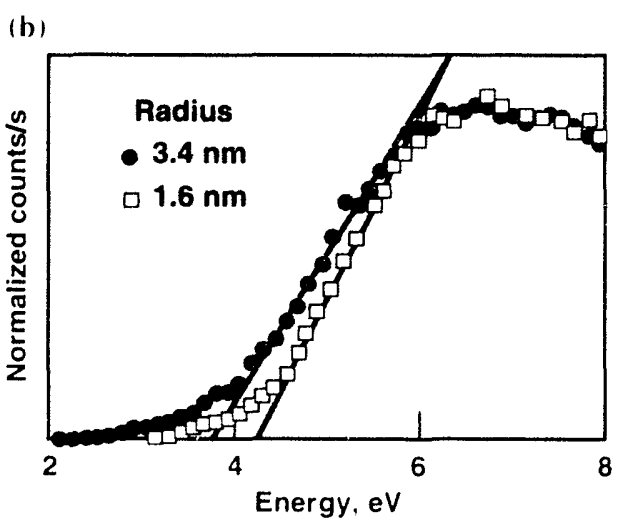

Figure 1. (a) Attachment of CdS clusters to Al substrate via alkane chains. (b) Shift of valence band maximum with cluster size. cluster diameters is $10 \%$ or less of the mean diameter.

The valence band maximum depends strongly on cluster size. Our crystallites are on the order of the bulk semiconductor exciton diameter and thus show yuantum size effects. We hatre observed these effects in photoemission spectra obtained for CdS clusters ranging from approximately $2107 \mathrm{~mm}$ diam. The clearest result of these experiments is that the valence band collapses in the smaller clusters (see Figure 1). That is. the valence band maximum moves to smaller binding energies as the nanocrystals increase in size. This shift is due to both a quantum confinement in the initial state and sizedependent fïnal-state charge solvation.

Contact: J. ( $;$. Tobin $(+1.5)+22-72+7$.

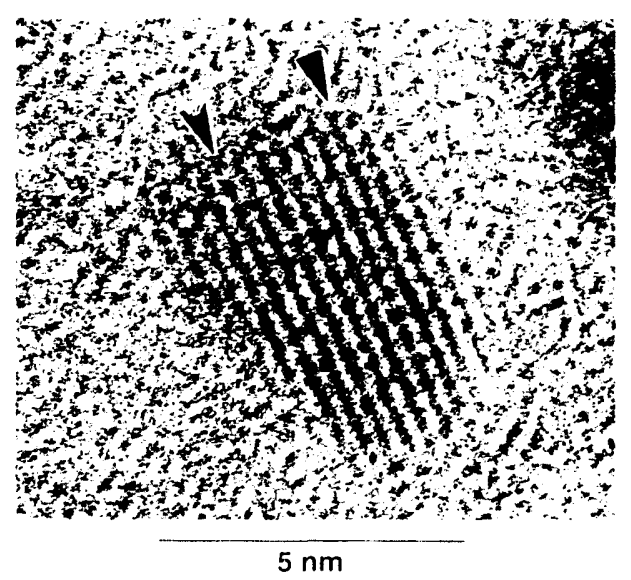

Figure 2. Transmission electron micrograph of a 4-nm GaAs nanocrysiat on a metal grid (taken at the National Center for Electron Microscopy, Lày nce Berkeley L aboratory by A N Goldstein) 


\section{Nanometer-Scale Studies Using Scanning-Probe
Techniques Scanning-Probe
Techniques}

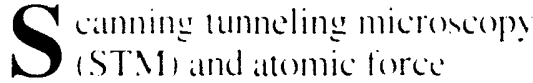

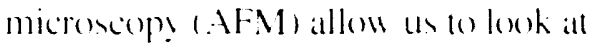
the pho sical and clectronic structure of surfaces wh ithomic resolution. The scamning tummeling microscope emploss a probe whose point is a single atom. A small amount of electric potential is applied to the probes. and the current hetween the probe point and the substrate is monitored so that atomicscale variations in surface roughness can be meatsured. In AFM. the probe is attached to a micreantilever arm and is brought inte contatet with the substritc. The dellection of the cantilever is monitored as the prohe is scanned acress the surfiace.

He hate for the first time. used STM $M$ inserigate surfate-gaktion hineties al specific reation sites orer a large range of reativities. reatctant pressures. and exposure times. He studied the kinetics of high! ordered P!rolytic graphite (HOPC i) gasificatton hy oridation atl specific allomic sites: 140 healed HOPCicomentionally for longterm mearurements and by short-pulse laser heating for millisecond exposures. He uned STM 10 locale reaktion sites. such as sepson the hasal plane of HOP(i and to measure their reativity by determining the rate of atom remosal at the site dee to the reatetion. The reation probabilits at such a site is expressed as the fraction of reactants strihing that sice that undergen at chemical reaction. Figure I bous the reaction probabilitices of three sites (m) HOP(i with ox! gen in atir all atmospleric pressure an a function of

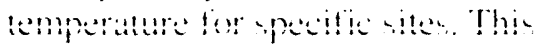
figeure demomstratles that we ciall

We use scanning tunneling microscopy to investigate the surfacereaction kinetics of materials over a large range of reactivities, reactant pressures, and exposure times as well as atomic force microscopy to study the morphology of surfaces.

determine reaction probabilitices orer a range of 12 orders of matenitude. down to a rate that corresponds to the removal of ahout one atom per site per day. Also shown is the much higher reatction probability of o/one (all at partial pressure of -1.3() $\mathrm{kPa}$. In addition. He can tatie ad antage of the high electric tield and the incense clectron current between the STM tip and the specitic site to enhance. on the nanometer scale. the local reation probabilies of azone by more than an order of magnitude.

We have used AFM to study the morphologes of insulator surfaces. I ving AF.M we halle helped in a search for deposition parameters of pols mer coatinges that lead to the smosthest implosion targess for laser fusion applicattions. In multilayer coatings. We have charatcerised, in unprecedented detail. defects in highly reflective coatting that may contribute to the damage threshold. and we have observed changes in the coatings" surface mophologs from exposure an laser pulses with fluences belou the damage threshold.

Scamning-prohe lechniques sach als STM and AFM can be used in conditions in which no other techniyue can function. Thes can be used for surface-reaction kinetics sudies for a large range of reatction rates and chemical enviromments (e.g. high latelum. gases all and ahore atmospheric pressure. and liquid environments) and for both insulating and conducting surfaces. Such reaction conditions are important in emvirommental corrosion. Waste product containment, first wall stability. and for materials in space. Modified seanningprobe techniques maty be used. on the nanometer scale. for imaging and. using STM-or AFM-induced eflects for physical or chemical maskless lithograph!

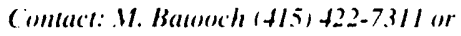

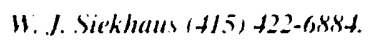

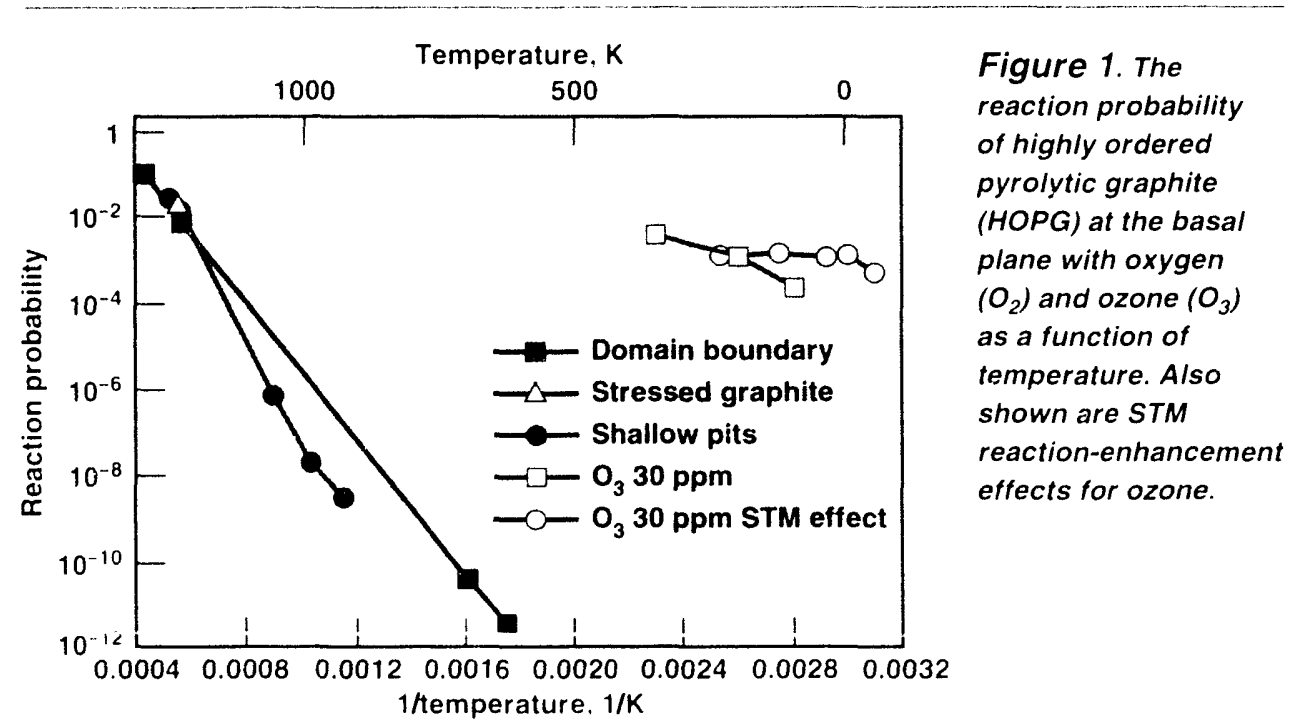




\section{The Synthesis of New Insensitive Energetic Materials}

\section{We have designed and are synthesizing an insensitive energetic material that is about 10\% more energetic than TATB.}

$\mathbf{T}$ he synthesis group of the Energetic Malterials Section identifies and symthesizes new. insensitive compounds predicted to perform beller than 1,3.5-triamino1.3.5-trinitrubenzene (TATB). TATB is currently aceepted as the standard in "insensitive high explosives." which play an important role in the design of nuclear and conventional weapons. Its lach of sensitivity to spark. friction. or impact and its excellent thermal stability are well documented.' Howerer. because of its low energy content. alternatives (1) TATB have long been desired.

We are synthesizing several new insensitive energetic compounds that are predicted to be 10 (6) 30$)^{\text {is }}$ more energetic than TATB. We designed into these molecules properties believed to contribute to the "enhanced" insensitivity of TATBa high degree of hydrogen bonding. good thermal stability. and graphitic crystalline structure. To accomplish this tee incorporated known. small. insensitive molecules with a large degree of hydrogen bonding (NQ and ANTA. see Figure 1 , into the target compound as substituents on an energetic heterocyclic backbone. The targel compounds also have a high nitrogen content. which should give them higher molecular density and heat of formation than TATB. both important contributors to the performance of an explosice. Finally. the synthetic schemes for these molecules are amenable to scale-up and are relatively inexpensive.

We have recently synthesized a target molecule that compares farorably with TATB in spark. friction, and impact sensitivity. and whose performance, based on preliminary results, appears to be about $10 \%$ better than TATB. With TATB. it is one of the few energetic compounds that do not react on our impact machine $(>177-\mathrm{cm}$ drop height). In comparison, $\operatorname{HMX}(1,3.5 .7-$ tetranitro-1.3.5.7-tetratadeyclooctane) reacts at a drop height of $3.3 \mathrm{~cm}$. This new material is also thermally stable. with a decomposition point of $3300^{\circ} \mathrm{C}$ (that of TATB is $3500^{\circ} \mathrm{C}$ ). We are in the process of scaling up the synthesis of this material in order to make detailed performance measurements.

The Energetic Materials Section has dereloped a protocol for designing. synthesizing, and evaluating new molecules, which this effort illustrates; it is a multidisciplinary approach.

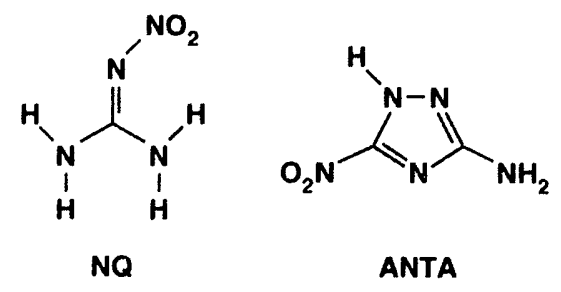

Figure 1. Small, insensitive molecules, nitroguanidine (NQ) and 3-amino-5-nitro1,2,4-triazole (ANTA). supported by a large database of known energetic materials. The first step of the protocol is to identify larget molecules and then develop their synthetic schemes. Their performance is then approximated through energy prediction codes such as TIGER or CHEQ. When the code predicts the molecule to be sufficiently energetic to warrant further investigation. we synthesize small amounis for small-scale safety tests. These safety tests provide the chemist with a means of comparative assessment of the material's sensitivity to spark, friction, and impact. We may then sciale up the synthesis and determine performance by front surface velocity measurements or a cylinder shot. We add the measured performance datal to our database and use them to further refine the predictive codes.

\footnotetext{
References

I. S. I. Rice and R. 1. Simpons. The l'mesual

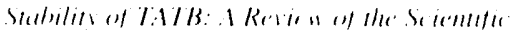

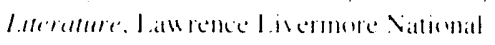

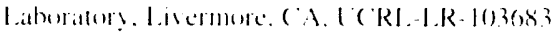
$1100(j)$.
}

Contact: P. I. Pagoria (+1.5) $+2.3-1)+7+7$, C. I. C (or) $(+1.5)+22-6.311$, or A. K. Hitchell $(+1.5)+22-7994$. 


\section{Bond-Selective Laser Chemistry}

$\mathbf{M}$ os chemical reactions are driven by thermal energy and are controlled by the laws of probability and statistics. Molecules with sufficient energy to react proceed along the most accessible reaction pathw aly into one of several possible sets of products. Other than adjusting the system temperature. little could be done to direct the reacting molecules into or allay from a specific reaction channel. Now. however. tunable lasers enable us to excite individual electronic. vibrational. and rotational states within a molecule. Chemical reactions can be controlled by exciting a specific mode of the molecule that is directly coupled into the dy namics of the desired reaction. ixe can excite a specific bond in a molecule !o a vibrational state that is highly locialized allong a particular bond and then break the labeled bond with at second photon of sufficient energy.

We used three pulsed lasers to demonstrate bond-selective photodissociation (Figure 1). A tunable $\checkmark$ isible laser furnished the initial

We have demonstrated that the selective excitation of certain localized vibrational modes within a molecule can alter the normal statistical outcome of a chemical reaction.

excitation along the bond of interest. A fixed-frequency laser provided the ultraviolet photedissociation pulse to break the bond. A tunable ultraviolet laser determined the identity and energy-state distributions of the product fragments.

We chose water to demonstrate bond-selective chemistry for its simplicity and its accessibility with our laser system. The overtonestrelching vibrations in $\mathrm{H}_{2} \mathrm{O}$ and its deuterated analog. HOD. showed very high bond localization. We excited the fourth overtone of the $\mathrm{OH}$-bond stretch and photodissociated the $\mathrm{O}-\mathrm{H}$ bond with 266-nm light:

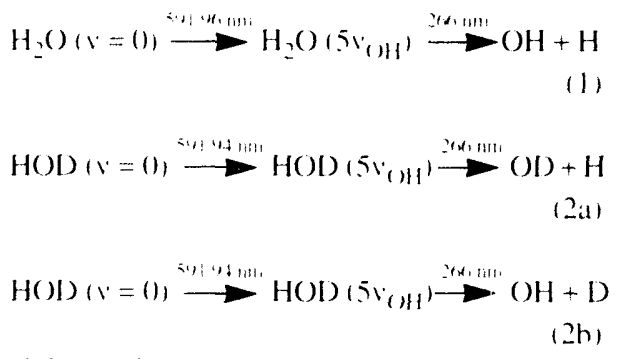

Where $5 \%$ oH indicates that five quanta of vibrational energy have been placed in the $\mathrm{O}-\mathrm{H}$ bond starting from the ground state having zero vibrational quantat $(1=0)$.

Endispersed laser-induced fluorescence detected the collisionally relaxed fragments. While both product channels in the photo-dissociation from the $5 \mathrm{~V}^{\prime} \mathrm{OH}$ overtone state in HOD (Reaction 2 ) are nearly isonergetic and therefore equally probable. only the OD-radical product appeared. Figure 2 show's the production of $\mathrm{OH}$ and $O D$ in a 1:2:1 mixture of $\mathrm{H}_{2} \mathrm{O}: \mathrm{HOD}: \mathrm{D}_{2} \mathrm{O}$. For HOD. the $\mathrm{OD}+\mathrm{H}$ reaction channel dominates completely over the $\mathrm{OH}+\mathrm{D}$ reaction channel conly the $\mathrm{OH}$ fragment appears for the $\mathrm{H}_{2} \mathrm{O}$ ). This striking result arises because of the highly localized overtone wavefunction along the O- $\mathrm{H}$ bond in HOD $\left(5 \mathrm{v}^{\circ} \mathrm{OH}\right)$ and in its projection on the upper-state potential-energy surface alway from the equilibrium geometry and well down into the $\mathrm{OH}+\mathrm{D}$ exit channel.

Contact: ( : (;. Stevens $(+1.5)+22-6201) 8$ or W. E. Conaway $(+1.5)+2.3-4.5 .38$.

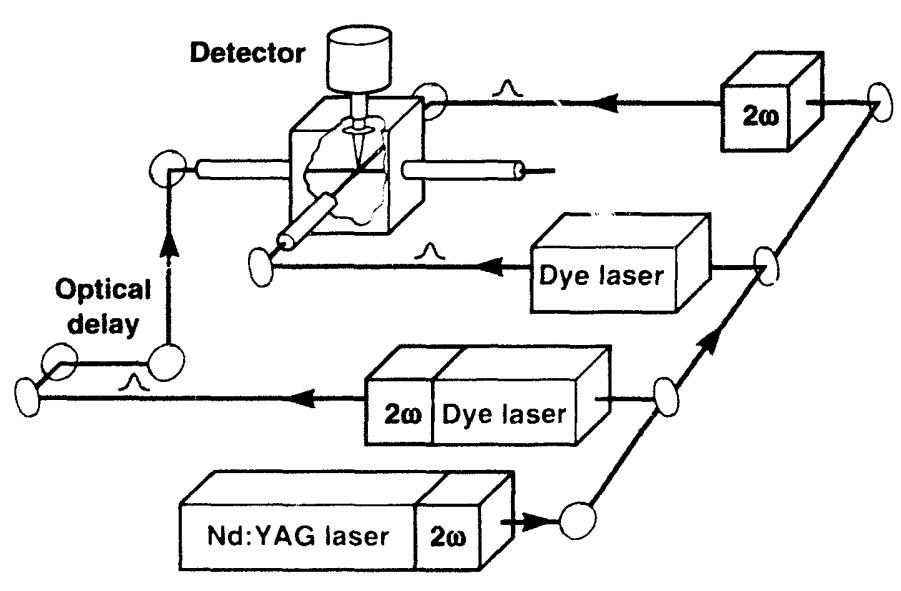

Figure 1. Pulsed laser sys:em for bond-selective photodissociation experiments.

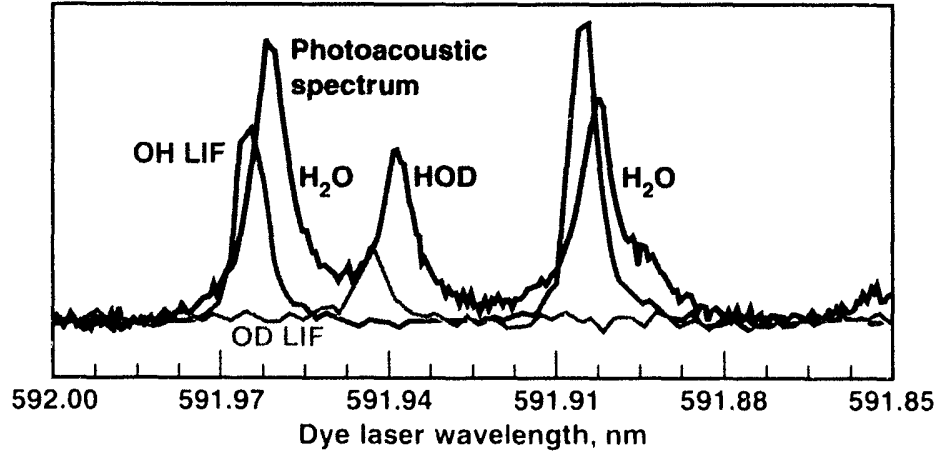

Figure 2. $O H$ and $O D$ laser-induced-fluorescence (LIF) action spectra showing the photodissociation product fragment identity for two rotational transitions in $\mathrm{H}_{2} \mathrm{O}(5 \mathrm{~V} \mathrm{OH})$ and one rotational transition in $H O D\left(5 \mathrm{v}_{\mathrm{OH}}\right)$. The photoacoustic absorption spectrum independently identifies the location of the overtone transitions. 


\section{Computations}

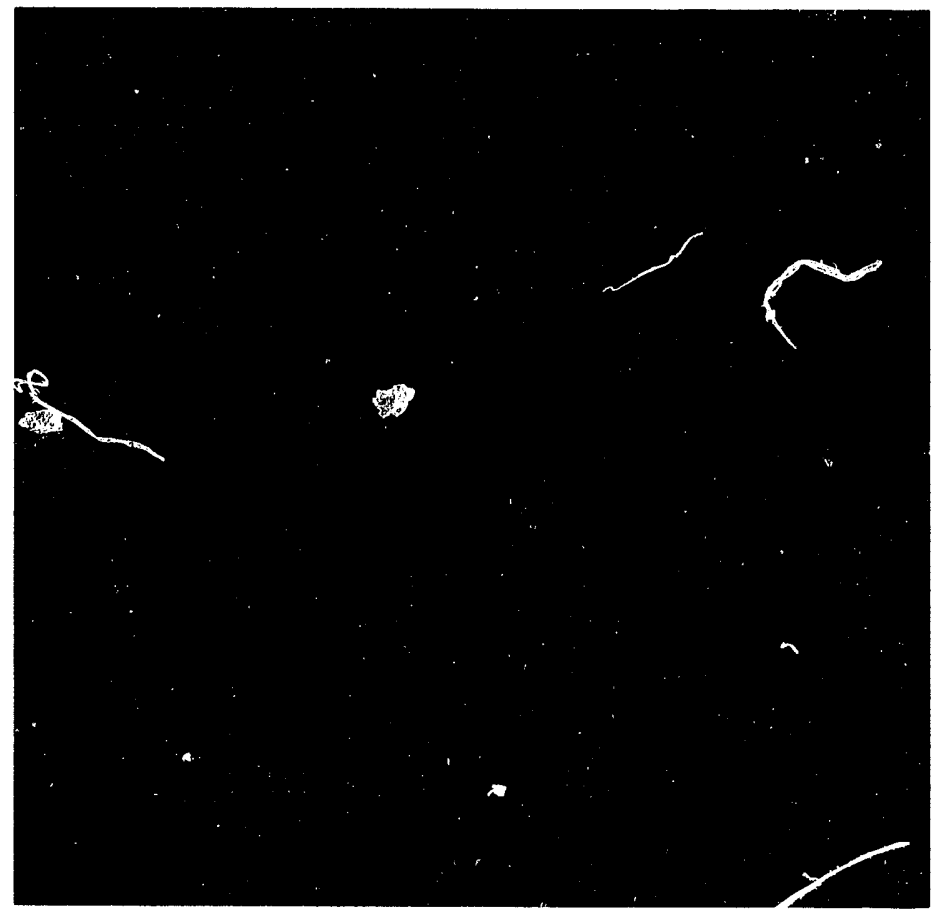

\section{Among the challenges being adr'ressed by the Computation Directorate ar e massively parallel computing and distributed computing, cost constraints, the need to keep simulation algorithms current, and the need for rapid visualization of scientific data.}

$\mathbf{T}$ le Computation Directorate is dedicated to providing highquality computing services to the Laboritory, the Department of Energy. and other organizations as approved by the DOE. The Directorate works to ensure that their computing requirements are effectively and efficiently served. This mission is particularly challenging since the computing field is changing rapidly on many fromts. The adrent of massively parallel computing archilectures. the new lechnologies for distribated computing. the increasing need to control softuatre costs. the continuing need to re-examine the algorithms required for scientific simulations. and the need for data visualization of high-speed computing results are but a few of the challenges that are carrently facing the computer industry.

The Computation Directorate satisfies a diversity of needs. For example. as computers have enabled researchers to address increasingly large. complex problems.

commensurately voluminous data output has orerwhelmed conventional display and analysis techniques and has farered reliance on scientific visualisation. The Computation Directorate has created the (omputer Graphics laboralory to help researchers select appropriate computational aids from the confusing array of visualization hardware, software, network interfaces, and output formats, so they can integrate these to present their data in the desired format.

In addition to the work highlighted in the articles in this section. the Computation Directorate has made notable accomplishments in solving complex problems on massively parallel architectures. in using objectoriented technology lo re-engineer a prototype real-time system. and in studying surveillance systems for the U. S. Air fince. 
The ahilit! to numericall! model neurral-and charged-particle trameport is of eructial importance to everal Laboratory programs and other misioms. One of the geals of the Computing and Mathematics Research Disision (C.MRD) is lo derelop effectise numerical techniques for solving these problems on current and future generation of supercomputers. CMRD s approach combines mathematical analy ses of existing and proposed methods w ith numericial experimentation on 1 arious architectures. Specificilly. the have developed a research code to perform the deterministic solution of the neutron transport equation and the computation of the effective criticalits of three-dimensional assemblies uning the BBN TC -z(kx). The TC-2(k)(x) was acyured for LL.NL , Massirely Parallel Computing Initiatise and incorporates 6.3 . Motorola 88104 RISC microprocessors. each of which is located on a separate board. or node. along with a 16-hilobyte calche and 16 mesabyter of local memors. CMRD researchers have obtained a level of performance using +8 processors of the TC-2()(x) that is competitive with a partiall! vectorizable version of the code ruming on a single (ral Y/MP) processor. To obtain this performance. they explicitly specit? and exploit datia lecality and data dependence using domain decomposition and dy namic joh scheduling. Given the scalability designed into the TC-20)(0) architecture. as well as the prospect of more powerful microprocessors than those in the current model. these preliminary results indicate that a significant increase in performance could be realized in a production machine based on this architecture.

The Application Development Department (ADD) within the Computation Directorate provides software development expertise in areas such as physical simulation and modeling. real-time data acquisition and control. database management. graphics. and communications. This past year. within the Special lsotope Separation group. ADD and Electronic, Engineering (EE) personnel used object-oriented software development methods in parallel with a prototyping ef fort to deselop a real-time monitor and control computer system. The prototype was used to define and clarify the requirements for the ystem. The oblectoriconted approwh was used to capture and decument those requirements. The resulting description of the $?$ stem 14 at then used to migrate the prototy pe an at high-quality first-sersion production ystem. This combined approach helped to orercome mant of the problems ly picall! ansrecilled with prototy ping alone.

The Techonoleg Information Ststem. Program (TISP) within the Computation Directorale conducted a study of the Joint Surveillance System (JSS) for the L'S. Air Force Tactical Air Command. This vtud! gren out of earlier work in prototyping an interface between an over-the-horizon radar and the JSS. The JSS serves both the l'niled States and Cancida. and it includer the sensors. communication linhs. processing ystems. and displaty centers. The study erablished detatl of the current $m$ stem. projected growth needs of the sysem for the next deciade. and proposed an architecture for that grouth.

Contact: R. R. Borchers $(+1.5)+22-98711$ or J. E. Ranelletti $(+15.51+22-37 \% 2$. 


\section{Projection Methods for Incompressible Fluid Flow}

$\mathbf{T}$ he dynamics of incompressible lluids play a central role in fields as disere as gliobal climate modeling. lurbulent combustion. pollutant transpont. and encergy production. all included in the DOE and L.L.NL misioms. Man! of these phenomena are mol well understoud. For many of the pe problems. the dy namices are three dimensional. and two-dimensional calculations camnot adeyuately model the How. The three-dimensional chatracter of these flows makes the derelopment of numerical algorithms for their solution especially challenging. Although other phenomena of this type cin he addressed in mo dimensions. inherem instabilitien in the flow impose particuarly stringent requirements on the numerical algorithms used to solve th:m. Before we can significantly

\author{
Advances in our understanding of the basic mechanisms of \\ incompressible fluid flow require the development of high-resolution \\ algorithms and numerical methods that accurately describe these \\ complex, multidimensional problems.
}

adrance our understanding of the basic physical mechanisms and provide effective models for engineering applications, we must develop highresolution algorithms and numerical methods that accurately describe these two- and three-dimensional incompressible fluid flow problems.

Projection methods. a critical component of this effort. are based on a second-order fractional-step scheme in which the terms describing diffusion and convection are advanced without solving the incompressibility condition. The resulting intermediate solution is projected onto the space of discretely divergence-free velocity fields. The nonlinear convective terms in the equations are treated by higher-order upwinding procedures, first introduced for hyperbolic conservation laws. that

\section{Figure 1. Interaction of an asymmetric vortex ring with a density interface.}

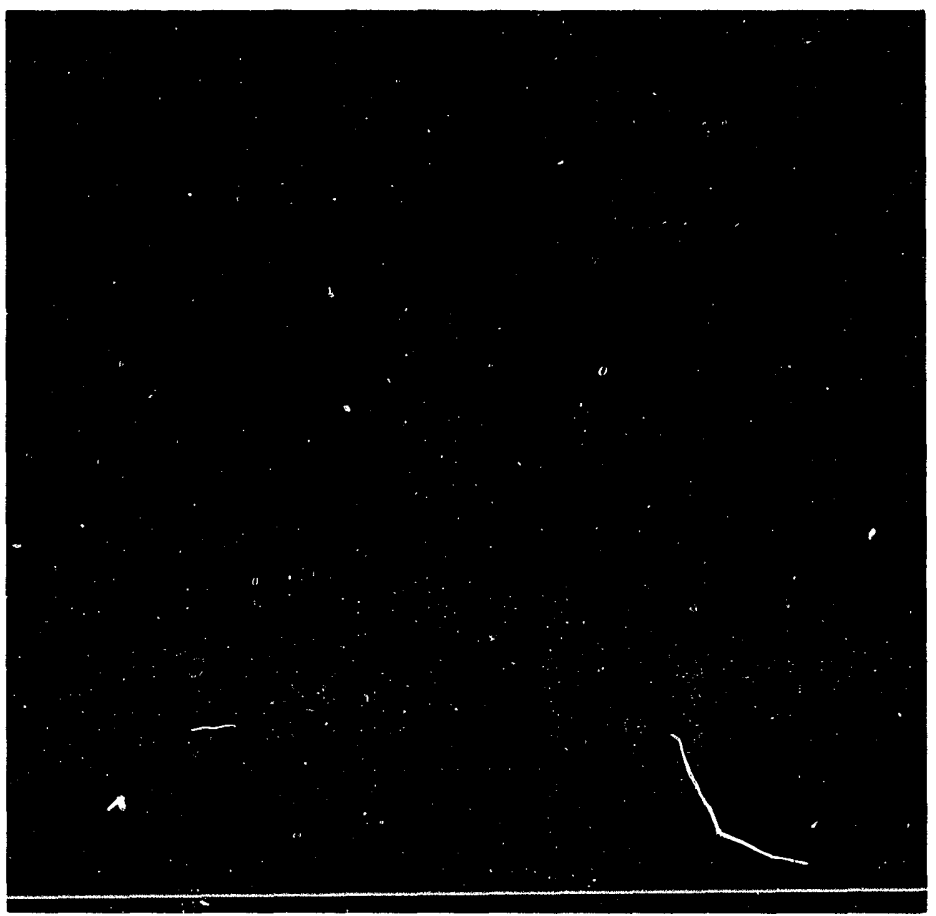

remain stable and nonoscillatory even for nomsmosth flows and low fluid viscosities. This procedure makes it possible to resolve the detailed structure of the flow and to handle the wide range of length scalles characteristic of many flows of scientific and engineering interest. Here we present two examples illustrating the use of projection methods.

\section{Flows in Density-Stratified Media}

Flows involving fluids of differing densities are found widely in both nature and technology-for example. the interaction of a ship or submarine wake with a thermocline. the collision of a buoyant thermal with a temperature inversion. and the interaction of a vortex flow with a flame front. This problem also serves as a generic model for turbulent mixing and entrainment across sharp density interfaces.

When a vortex-dominated flow interacts with a sharp density interface. the dynamics are characterized by the interation of the baroclinically generated rorticity with the existing field of the vortex. This generation of baroclinic vorticity by the interaction of nonparallel gradients of pressure and density results in a richness of structure and breadth of scale that present a formidable computational challenges.

Most work in this field has used the Boussinesy approximation. in which momentum effects due to sariations in demsity are ignored and the dependence of emperitlure on the demeit! is accombed for he a linearised forcings term that couplen the momentumand mats-comsertation eyuatloms.

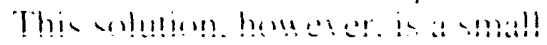


ampliade approximation and introdues a nonphysical symmetry (1) the equations. Our method alonds such approximation: by repressing the standard projection with espect to a density-Heighted inner f roduct space. it allows spatial-density variation to occur in the discrete eo lations in a "natural" was. The ia" rface between the lower- and highe - viensity fluids requires no special 1 eilment: ii is simply captured in the course of solving the mass-ce nservation equation.

In Figure 1. we show twa "ilculation of a vortex ring colliding with a siurp density interface. Density contours are shown on the right, vorticity contours on the left. The interface deforms slightly with the approach of the vortex ring. rising into a gentle bubble and generating baroclinic vorticity along itself. Small pockets of light fluid. officet slightly to either side of the core of the ring. are scooped from above the interface and injected into the hean! fluid. The haroclinic vortecity is peeling vorticity of the opposite sign from the primary ring. reducing the strength of the primary ring and creating secondary and tertiary rings. Finally, the bubble collapses: this creates a strong backflow jet that is unstable. and gravity waves propagate out along the interface.

In Figure 2. we show the calculation of a weaker vortex ring approaching the same sharp density interface. Even though the interface is nominally flat. haroclinic vorticity is still generated. As the cortex ring approaches the interface. a layer of counter-rotating vorticity is formed. The vortex expands. again peeling vorticity of opposite rotation from the interface. which rolls up into secondary and tertiary rings. These rings orbit around the primary ring. resulting in the familia ebound phenomenon. The counter-rotating vorticity pulls fluid back tow ard the smmetr! axis. creating a urong backllow jet. Bu this time. the original ring is almost completely annihilated.

\section{Three-Dimensional Calculation of the Transition to Turbulence}

A heuristic description of the distribution of vorticity in transitional and fully turbulent flows, which has emerged over the last decade. employs a collection of stretched. folded. and pinched vortex tubes. As the vortices stretch their local relocity fields intensify. and conservation of energ: dictates that they must fold so that adjacent patches of counter-sign vorticity can cancel out. This inturmal picture has been supported by the experimental observation of tightly curved (hairpin) vortices in turbulent boundary layers and in free shear layers. Hairpin vortices have been associated with bursts of turbulence. and there is speculation about a connection between hairpin vortices and the formation of singularities in the Euler and Navier-Stokes equations.

The existence and role of such singularities are central concerns in the study of rorticity dynamics. That wery steep gradients exist on small scales is beyond dispute. That the vorticit! increases wildly as the volume of its support collapses onto a fractal set can be persulasively demonstrated. An issue that remains open to speculation and debate. however. is that. for smooth initial data. solutions to the three-dimensional Euler equations become singular in finite time.

Such singularities are important because they would dominate the vorticity dynamics and play a critical role in the transfer of energ! from the inertial to the dissipative scales. Indeed. the existence of a singularity would suggest that the macroscopic effect of dissipation is independent of the viscosity thus linking the geometry of singularities to the dynamics of the inertial range. Therefore. the structure of a singularity, the scenarios leading to its formation. the time scale on which it occurs, and the dynamics of the postsingularity regime are all significant issues in our attempt to understand the transition to turbulent fluid flow:

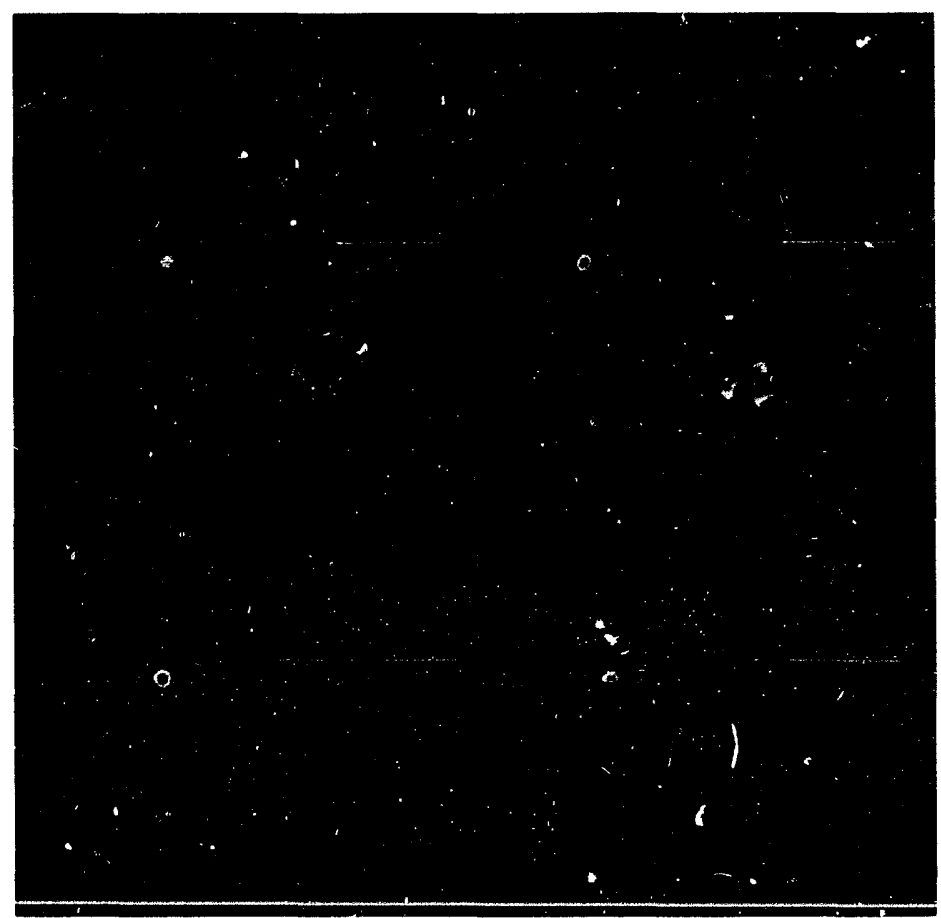

Figure 2. Interaction of a weaker vortex ring with the same density interface as in Figure 1. 
We hate uned a secondurder projection method for the incompresible Euler equation- to vily the evolution of a transversely perturbed. coflow ing jet in a triply periodic domain. Figure 3 show the

(a)

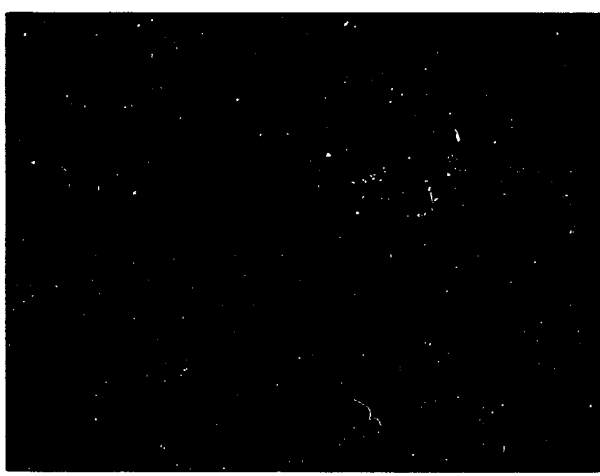

(c)

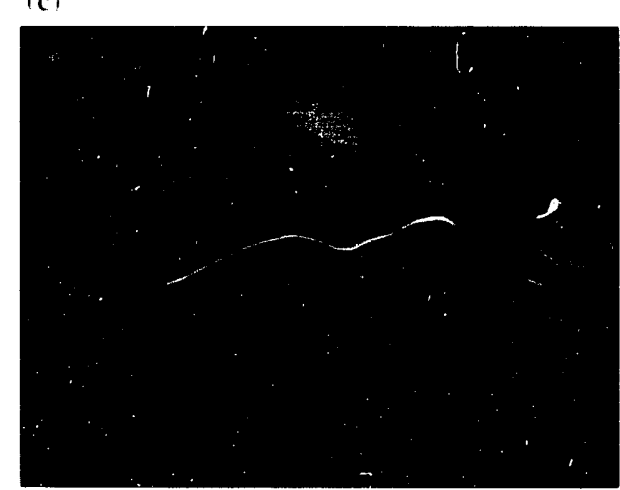

esolution in time of a tracer field initialized on the surfatce of maximum vorticity. Figure + reveals that strong vorticity intensification persists (6) the limits of the grid resolution that we can currently achieve. A volume

(b)

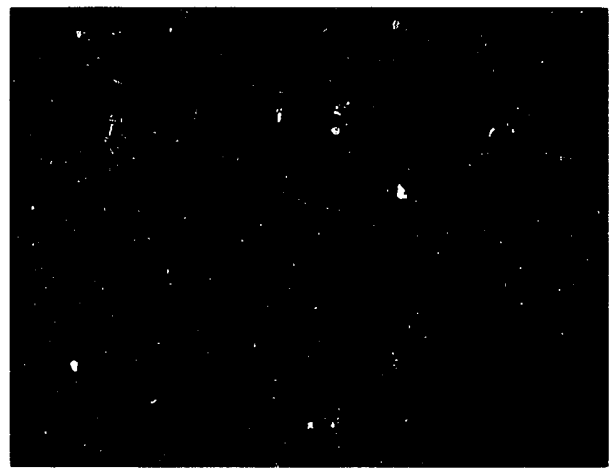

(d)

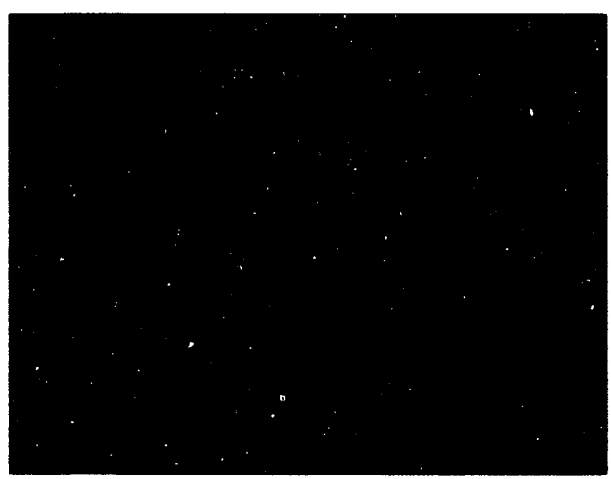

Figure 3. Evolution in time of a tracer field initialized on the surface of maximum vorticity of a transversely perturbed coflowing jet.

Figure 4. Maximum vorticity in the jet shown in Figure 3 as a function of time for calculations at coarse. medium. and fine resolutions.

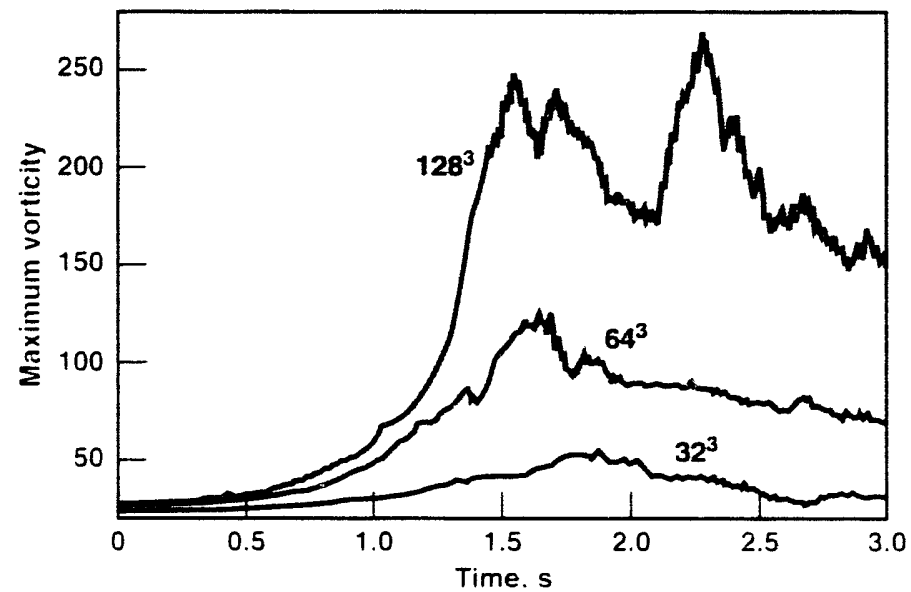

rendering of the magnitude of the lorticity at the time of the vorticity blow up (Figure 5 ). indicates that the intensification is localized to the hairpin ytructures. Onset of vorticity intensification is accompanied by a decaty in mean kinetic energry.

suggesting that the Euler equations break doun and are subject to a viscous regularization analogous to that of shocks in Burgers equation. In the postsingularity regime. We observe reconnection events. continued decay of kinetic energy, and emergence of an inertial range in the energy spectrum.

These two examples illustrate the progress we are making in developing numerical methods for solving challenging fluid dynamics problems. With the addition of adaptive mexh refinement. which enhances local resolution as demanded by the evolving flow structure. they should lead to even faster and more accurate approaches for studying the man! important problems involving incompressible fluid flow.

(ontact: 1). Marcus $(+1.5)+22-4672$ or J. Bell $(+1.5)+22-71115$.

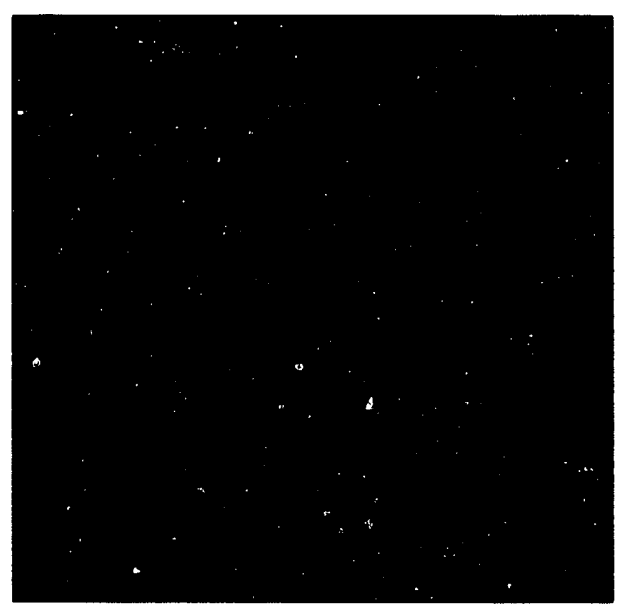

Figure 5. Volume rendering of the magnitude of the vorticity at the iime of the blowup. 


\section{A New Scientific Visualization Facility for Laboratory Researchers}

M ajor advances in the speed and power of scientific computers over the past deciade have enabled researcher to computationally model and analyze increasingly large and complex problems. including many of the scientific grand challenges r such as studies of ozone depletion and global warmingl. As the problem. have hecome larger and more complex. so has the related datat output. which often is so voluminous as to be nearly incomprehensible when displayed in the usual format of line graph and lise of numbers. Interpreting the output of computer analy ses hat become a major problem in man! area of revearch.

The visualization of scientific data has increaned in complexity and rophistication with ad ances in sientific computing. Two-dimensional plots and tables of number have been supplemented with three-dimensional surfaces and wolumes, which can be interactively manipulated on powertul graphic workitation. The ability to tran-form data u ith rotation. scaling. hading. and lighting offer wientist a mean of quickly and intuiticel!

is computers have enabled researchers to address increasingly iarge and complex problems, commensurately voluminous data output has overwhelmed conventional display and analysis techniques and has favored reliance on scientific visualization. The Computer Graphics Lab (CGL) was created to help researchers select from the confusing array of visualization hardware, software, network interfaces, and output formats and integrate these to present their data in the desired format.

grasping the form of the data. Adranced visualization techniques arailable with current took include volumetric slicing. ino-surfiaces. manipulation of complex geometric surfaces. image processing. and animation of two- and threedimensional data.

Lnfortunately. using scientific isualization on a particular project is not yet at straighttorward task. Researchers are faced with the dual tash of selecting appropriate computational aid from at confusing arrat of visualization hardware. softivare. networh interfaces. and output formats and then integrating these diserse components to present their data in the desired format. Fell researchers hate either the time or the expertice to effectively contront these dual tarhs. and a need yuichly developed for an organized form of asistance for visualization efforts.

To provide this asistance. the Litermore Computer Center opened a Computer Graphics Lab ICGL, equipped with advanced $\checkmark$ isualization hardware and roftuare. Included in CGL are a Silicon Graphic: worhstation: an animation wftware package. Warefiont : Adranced Visualizer. that is uned in commercial and academic animations: and at variety of other hardware and softu are resolirces cosering a range of coss and performance capahilitie Thus. CGL has visualization resource that can match requirements for man! types of data and budgets.

CGL staft are aldalable to ansist researchers in developing visualization techniques both for interatively analyzing data and for creatively display ing data in sarious media. including videotupes. slides. transparencies. and color hardeops. This assistance can be at one-time effort or mas continue for the duration of a project.

Revearchers interested in visualization can learn more athout the cupabilitien of CGL through regularl! sheduled demonstrations of the sisualization softurare and hardware and through a publication. lis:alization .rotes. that provider the latest information on sisualization techniquer and CGL atcisities.

Contact: C. L. Hunter $1+1.51+22-16.5$ 


\section{Administrative and Institutional Services}

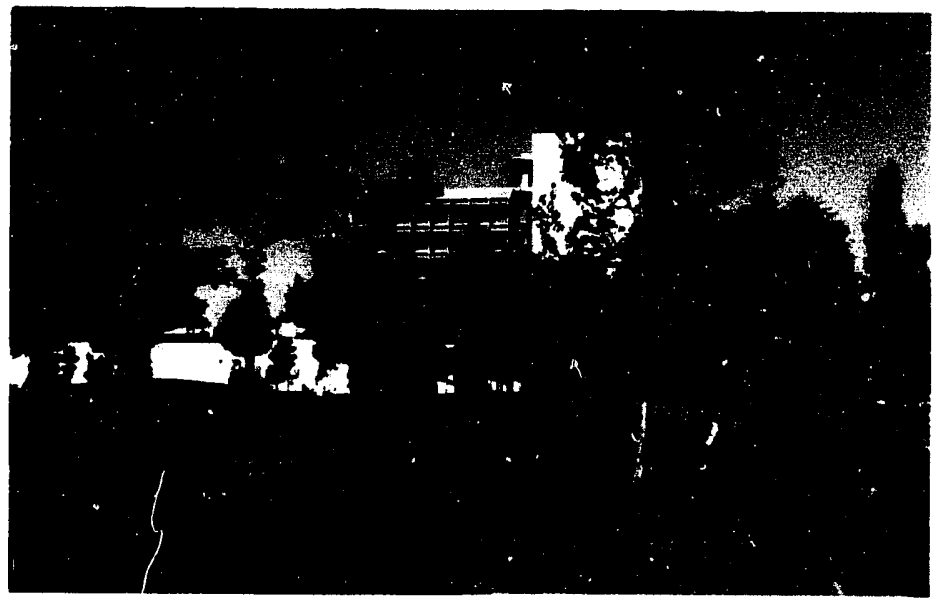

\section{The Laboratory is as large as many major business enterprises and requires extensive administrative and institutional services to support its programmatic missions.}

\begin{abstract}
A dministrative and institutional services provide the important support functions that enable the Laboratory's programmatic work to be performed. Some of these functions, such as procurement and environmental safety and health $(E S \& H)$ specialties, support

Laboratory programs directly; others, such as community relations and technology transfer. connect the Laboratory to a larger community. The Center for Technical Studies of Security. Energy. and Arms Control provides a focus for Laboratory interaction with a wide-ranging. national-security-policy community.

The Laboratory's business and plant management operations are major. complex functions. In terms of scale. the Laboratory financial and plant operations are as large as those of a major business enterprise. The
\end{abstract}

1991 operating budget exceeds $\$ 1$ billion: construction and equipment budgets add another $\$ 100$ million. The Government's total investment in facilities is in the area of $\$ 2.5$ billion; investment in experimental and basic equipment adds another $\$ 1.5$ billion. The University of California employs more than 8200 persons at the Laboratory, and another 2000 to 3000 persons are on site in various contracted support roles.

Operational support for the Laboratory (at its main site and Site 300) as well as for the large employee population is provided by organizations reporting to the Director's Office and the Associate Director for Plant Operations. The Plant Operations Directorate is made up of organizations for Hazards Control, Plant Engineering. Health Services, Information Services. Environmental Protection, and
Quality Assurance. About 1700 employees within that directorate have responsibility for maintaining and improving the facility, equipment, and business information infrastructure, and for assisting all LLNL organizations in achieving the Laboratory's commitment to ES\&H excellence. A number of operational activities in the Directorate reflect the Plant Operations staff's ES\&H commitment and expertise. For example, the Environmental Protection Department has developed both operational and modeling techniques. some discussed elsewhere in this issue, to facilitate detoxifying and cleaning up sites (at the Laboratory and elsewhere). The Hazards Control Department published a booklet. Safety Experience 1990), that summarizes safety information for Laboratory managers and staff. Hazards Control 
hats also begun a systematic review of the methods of classifying hazards at major Laboratory facilities. Plant Engineering completed. on time and within budget. a major structural safety upgrade of Building 111: Plant Engineering also completed a Sewer Diversion Facility as part of our overall sewage effluent control program. The facility allows sewage to be diverted. if necessary. for analysis and cleanup to prevent disruption of the local municipal water reclamation plant. ES\&H training has been expanded Laboratory wide.

Health Services continues to develop a progressive occupational health program using the Laboratory : new medical facilities. This year the Laboratory established a new policy that prohibits smoking in virtually all facilities: smoking cessation services are provided to support the Laboratory"s new policy. General employee training regarding LL.NL's new substance-abuse policy and services began in spring 1991. The Laboratory has implemented random drug testing for about 120 emploses. who participate in the Personnel Assurance Program. which is administered by Quality Assurance and which provides special oversight and support services for employees who work directly with nuclear materials.

Plant Engineering has facilitated major savings in the use of water and electricity. For example. groundwater from treatment wells is now being used to supplement commercial water supplies for cooling towers. Water consumption has been reduced by 196; since 1990. In addition. increased reliability $w$ ill te reallzed from a recent decision to obtain electricity primarily from the Western Area Power Administration and only secondarily from commercial sources.

Key Laborator! husines. human resources. and financial management o.. nizations report to the Director"s Office. The Assurance Review Office. Safeguards and Security. Business Operations, and the Office of Management Review are part of the Deputy Director's organization. while Human Resources. Laboratory Counsel. Public Affairs, and the Controller report to the Director. Education Programs and the Employment Equity and Compliance Center report to the Principal Laboratory Associate Director. The complexity and scope of the Laboratory"s operations provide major challenges for these organizations. For example. to respond to the challenge of safeguarding an ever more complex facility, the Laboratory s Safeguards and Security organization has increased vehicle searches and expanded protection measures for sensitive facilities and materials. A new Laboratory-wide classified document control system has been put in place to facilitate document inventory and control.

The Laboratory Controller's organization provides financial management in support of LLNL missions by assuring integrity and accountability in accordance with generally accepted accounting principles. The Controller's office hats aggressively pursued productivity gains through automation of financial ystems. Recent system upgrades include a new general ledger. a budget data integration system that uses artificial intelligence features. and a state-of-the-art accounts payable system.

The Business Operation. organization. which includes the Procurement. Supply and Distribution and the Business Services Departments, is responsible for a full range of business management actisities at the Laboratory. including some $\mathbf{S t 0 ( )}$ million annually in procurements. tratvel. mail, automobile fleet. shipping and receiving. and warehousing services In addition 10 its day-to-day operational activities. Business Operations is implementing a new property-management system that will include a major new database and a network of Property Coordinators to acsure appropriate control of and accountability for Government property throughout the Laboratory. Also in 1991. Business Operations conducted a vendors fair. designed to bring together small. and potential Laboratory purchasers. Through its newly established office wastepaper recycling program. Business Operations recycled 26 tons of paper in June 1991 alone.

The University of California's "Plus 5" Program. in which several hundred Laboratory employees were eligible for early retirement incentives. was one of a number of new initiatives administered by the Human Resources organization. Employment Equity and Compliance Center staff worked closely with Human Resources and line management to successfully complete the requirements of a Conciliation Agreement with the Office of Federal Contract Compliance. The Conciliation Agreement was entered into following the 1987 OFCCP Compliance Review. The Director established a Workforce Diversity Task Force to enhance the Laboratory"s ability to manage diversity in the future workforce. LLNL 's ability to conduct its research programs depends on and demands high quality administration and operations functions. Laboratory business. human resources, and plant management functions are committed to support the Laboratory"s rescarch program while assuring compliance with regulatory requirements and standards.

Contact: P. E. Coyle, III +15, \$2.3-7786,

l). K. Fisher $(4151+22-3.343$, or

(i. II. Camphell i $1151+22-5217$. 


\section{Technology Transfer at LLNL}

Technology transfer is an important mission for the DOE laboratories. LLNL's Te hnology Transfer Initiatives Program oversees the transfer of Laboratory-developed technology to private industry to help the U.S. compete successfully in a technology-driven global economy. LLNLindustry collaborations also enhance the Laboratory's technology base.

$\mathbf{T}$ he Technology: Transfer Initiatives Program is becoming more visible as an increasing number of L'S. companies are discovering that LL.VL technologies can help provide solutions to important realworld problems. Laboratory core technologies. developed over the sear in fields such as nondestructive craluation and engineering. computer modeling and simulation. laser lechnolog: supercomputing systems. materials science. biotechnology. and energ! . are producing important technology transfer successes.

\section{Commercial Applications for Laser Capabilities}

Sercral major L'.S. companies hat come to recognize that LLNL's lascr-related technolog! base could be an important element in helping the L'.S. compete internationally. A potentialis far-reaching program was undertaten. with funding from the Detence Adranced Renearch Projects Agenc! lo atd at small New York company develop the world's first laner-driten. point-source $x$-ray lithography ysem. Building on the Lathoralor! , Medium-Pourer SolidState Laser (.MPSSL, Project. LLNL researcher are collahorating with cientists at Hampshire Instruments we help develop a commercial x-ra! lithography ystem that should help the ('S. to compete in the manutacture of the next generation af microcomputer chips

Another direct outerow th of the MPSSE Project in the development of a lightweight. compact. solid-state laser that can be pumped by a dense array of laser diodes that is cooled using a unique patented microchannel cooling technique perfected at LLNL. This laser device is under design and a demonstration system is being built for a major L.S. aerospace company. The technologies that evolve from this project will likely open up the market for low-cost. medium-power. solid-state lasers for commercial and industrial applications.

A new type of lasing material. based on the mineral colquiriite (as typified by LiCaAlF $6 \mathrm{Cr}^{3+}$ ). invented at the Laboratory for laser applications. has been patented and licensed to several companies interested in using the material in various laser products. Licensees currently are working on products ranging from laser illuminators to LV light sources for lithography ifor use in the semiconductor industry).

Over the past two decades. the DOE and Congress have systematically supported the development of one of the largest concentation of laser R\&D resources in the world at LLNL. resulting in the world-leading efforts for inertial confinement fusion and laser isotope separation. The intrastructure so established has led to the formation of the Center for Applications of Laser and ElectroOptic Technologies (C ALEOT). targeted to hecome a major national asset for applications-reriented laser and electro-optic technologices

Building on the Vational Competitiveness Technologes Transter Aci of 1989. CALEOT 14 ill promote joint ventures between LLNL and L!.S. industry. Operationally. CALEOT identifies national needs in which LLNL participation is relevant. develops technologies to satisty the everchanging markets, and interacts with responsible agencies. industries, and individuals to develop support for joint ventures. In turn, the DOE and Defense Programs benefit by having outside. laser-based technologies and techniques come full circle. through CALEOT, for in-house utilization in a variety of DOE projects.

\section{Energy-Related Technologies}

We have formed a consortium with five oil companies to evaluate the performance of an existing LLNL pilot oil-shale retorting plant and to proceed with the design of a scaledup facility for possible precommercial testing. The DOE will provide a significant amount of support. and each industry participant will provide funding as well as technical expertise and in-kind contributions. This Oil Shale Consortium is expected to continue for at least three years.

Interest in the Laborator! s work in petroleum geochemistry continues (1) grow. With six more companies joining Phase II of the Petroleum Geochemistry Project. Fourteen companies now co-fund. with DOE. experiments and computer modeling related to petroleum generation and migration in the suburface. The computer eode PMI()D. which couples the chemistr! of oil and gats 
generation to the physical processes squeezing it out of its source rock. was transferred to these companies through this co-funding agreement.

The Laboratory also continues to investigate ways to convert methane gas to more complex hydrocarbons for possible use in the economic conversion of natural gases to products such as fertilizers or liquid fuels. This research is funded jointly by the DOE and the Gas Research Institute (GRI): support has recently been committed for another three years.

\section{Computer Modeling and Software}

GRI also helps fund the development of the FEM $3 \mathrm{~A}$ computer program. FEM3A can simulate the probable dispersion of heary gases accidentally released into the atmosphere: it has been verified in extensive field tests at the Nevada Test Site. The program is recognized as one of the most accurate models for healy gas dispersion modeling available any where in the world. and is being evaluated for possible use as a standard for the natural gas industry.

In one of our most successful technology transfer efforts to date. Distributed Computing Solutions. (DISCOS ). a Division of General Atomics. has licensed and commercialized LL.NL' L NIX-based file management system. Marketed as the LniTree Central File Manager. the softuare is the product of a 10-year development program at LL.VL. DISCOS has made a major corporate commitment to the commercialization effort. and has already installed LniTree on several supercomputer ststems throughout the world.

They have also established licensing and partnering arrangements with major computer manufacturers and softuare "ysem suppliers. including IBM. Digital Equipment Corporation. Control Datát. Convex Computer
Corporation. TPS Computing. Aptec Systems. and Amdahl Corporation. With this broad array of partners and licenses. DISCOS expects UniTree to capture the market in mass-storage.

LLNL continues to work with GA and DISCOS on further refinements of the UniTree system by contributing to the revision process and serving as a test site.

\section{Nondestructive Engineering and Evaluation}

LLNL's modeling and nondestructive evaluation capabilities are gaining wide-spread attention from industry. A special instrument developed at the Laboratory for performing 3D $x$-ray tomographic microscopy (XTM) has potential for evaluating microscopic structures in composite materials and synthetic fibers. Collaborative arrangements with two major L.S. firms to investigate the application of XTM were initiated last year. When these technology transfer projects are cumpleced. XTM will likely be available for practical use by U.S. industry in performing nondestructive evaluation and improving the quality and reliability of L.S. products.

\section{Advanced Manufacturing Initiative}

The DOE Defense Programs. Advanced Manufacturing Initiative seeks laboratory projects that will aid L.S. manufacturing industries. In 1991. LLNL was awarded S4.2 million for a number of exciting projects. The XTM mentioned above is being funded through this initiative. In addition. a collaboration was established among LL.NL. the National Center for Manufacturing Sciences (NCMS). and KT-Swasey la major L.S. machine tool supplier). Lnder this agreement. the Laboratory will join with KTSwasey in a project to improve the accuracy and quatity of KT-Swase? next-generation machine toul for application in the turning-machine market. The techniquen to be demonstrated by LLNL will be made arailable to all NCMS member companies under a special licensing arrangement between NCMS and the Liniversity of California.

Also selected under the Advanced Manufacturing Initiative were three laser projects designed to aid major L.S. companies. One with a U.S. automobile firm will lead to the development of a solid-state laser that maly eventually be used on a production line for welding. Tuo projects will use LLNL is highly reliable and effective copper vapor lasers for micromachining and for processing of materials.

Two other projects are funded by the Initiative. In the first. LLNL researchers will work with a vehicle engine manufacturer to analyze internal engine-wear characteristics. In the other. we will work with an aluminum producer to develop advanced superplastic aluminum for a large aircraft manufacturer.

\section{Biotechnology}

Technolog! transfer is particularly active in the hiotechnolog! field. A number of LL. LL-developed technologies have been transferred to industry re.g... our high-speed flow cell sorter) and we expect that several major advances will be announced bs our commercial partners. In addition. in 1990. LL.VL was named by the DOE is a National Center for the Human Genome Project. We have entered into licensing and collaborative agreements with several companies (1) explisit the commercial potential for Laboratory-developed lechnologien and sofiuare for une in the (jenome Project nationalls.

Cimtact: (;. R. Warkuth +15, \$2.3-1.3+1. 


\section{The Center for Technical Studies of Security, Energy, and \\ Arms Control}

Issues of international security, arms control, and energy supplies are major world concerns. The Center was founded to bring unique Laboratory knowledge and experience to bear on these important issues.
$\mathbf{T}$ he Center for Technical Studies of Security, Energy, and Arms Control was established at LLNL in 1988 to provide scholars from universities and other institutions, student interns. and Laboratory scientists with the opportunity to use the knowledge and experience of LLNL programs in studies of international stability and security. Under the aegis of the Center. visiting scholars and specialists conduct research and interact with LLNL scientists in a mutually beneficial exchange of information and ideas.

Specifically, the Center supports critical studies of significant national issues by Laboratory personnel: hosts visiting scientists and scholars on sabbaticals. fellowships. or professional leave: and supports postdoctoral interns. The Center also conducts seminars, symposia. and workshops in collaboration with other institutions. An integral element of the Center's program is the publication and dissemination of Center-sponsored work: in the last two years. reports of seven major studies have been published.

During 1990, the Center sponsored 18 seminars by outstanding scientists and respected thinkers from the national-security and arms-control community (Figure 1). Among the guest speakers were Dr. Tyrus Cobb. a former special assistant to President Reagan who spoke about the current political forces shaping the Soviet Union: Dr. Richard Wagner. a former Assistant to the Secretary of Defense (Atomic Energy) who spoke about methods for maintaining adequate forces in an era of reduced tensions and defense budgets: and Professor John Lewis of Stanford University. who spoke about China's military restructuring and force capabilities.

In October 199(). the Center sponsored a workshop on "The Role of Nuclear Weapons in the Year

\section{Figure 1. On}

7 February 1991, Dr. Tyrus Cobb, former special assistant to President Reagan, spoke about "Gorbachev and the Future of Soviet Power." This was one of 18 seminars sponsored by the Center during a 12-month period.

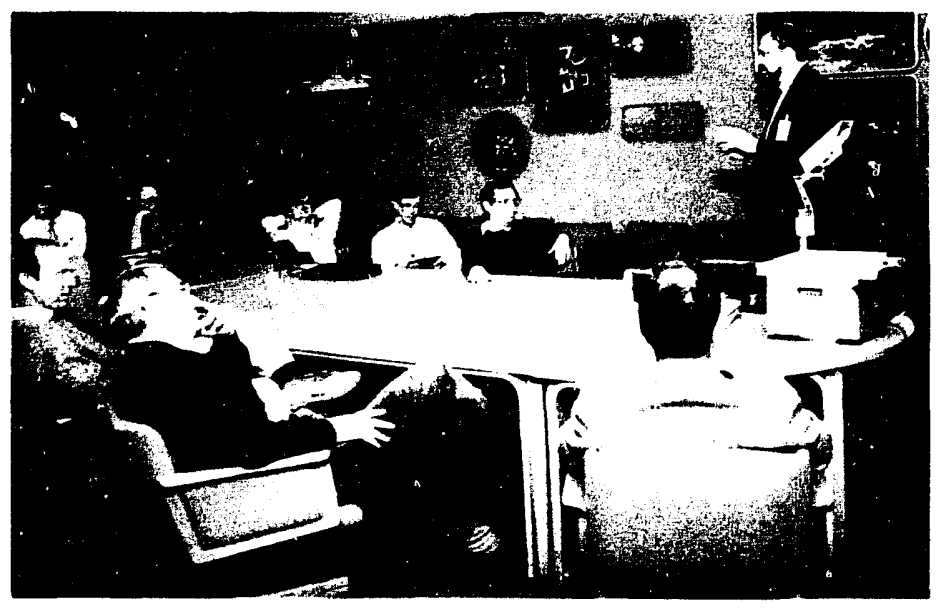

2000." The three days were devoted to discussions of the roles and missions of nuclear weapons in the decades to come, the emergence of the nuclear proliferation problem. and the impact on the nuclear stockpile of the rapid changes occurring in the Warsaw Pact and elsewhere in the world. McGeorge Bundy presented a luncheon talk on "Deterrence in the 90s-What Can Past Experience Teach Us"?" Edward Teller gave the banquet address on opportunities presented by the relaxation of tensions between the East and West. The talks given at this workshop have been published in a Laboratory report (UCRL-JC-106361).

The Center, together with the Laboratory`s Defense Programs. sponsors an intern program in Arms Control and Nationai Security Affairs. This year. a doctoral candidate from the Massachusetts Institute of Technology is spending nine months at the Center pursuing research on the role of the U.S. weapons laboratories in the formulation of U.S. national security policy. A consultant has also been hired to write a history of the Plowshare Program.

The issues of international security and energy supplies continue to be major concerns for the world. In the year to come. we expect that the Center will be very active in arms control and security affairs. We also expect next year that the Center will become involved in some energy issues in which the Laboratory can make a unique contribution.

(ontact: W. E. Zagotta $(+1.5)+22-0.523$. 


\section{LLNL's Commitment to Science Education}

$\mathbf{I}$ n 1989. President Bush and the 50 state governors. gathering "to establish clear national leducation | performance goals." declared that. in the L.S. by the vear 200).

- All children will start school ready to learn.

- At least 9orí of high-school students will graduate.

- Students leaving grades 4.8 . and 12 will be competent in such subjects as English. mathematics. science. history. and geography.

- Students will lead the world in science and mathematics achievement.

- Every adult will be literate and equipped to compete in a global economy and to exercise the rights and responsibilities of citizenship.

- Every school will be drug- and violence-free.

In 1990. Secretary of Energy Watkins directed the national laboratories to work with the schools to create programs that stimulate interest in technology and science. LL.NL Director John Nuckolls has accordingly committed the increased involvement of Laboratory employees. The April 1991 issue of Encrgy and Technolegr Re'vidu describes the Laborators involvement in science education ${ }^{i}$ : here 1 e summarize these activities.

LL.NL; education programs have one goal: to increase scientific literac! and spark students interest in science and technology. Our 29 programs and activities for kindergarten through high school. 28 for colleges. and 5 graduate program reach some

The Laboratory has over 60 innovative programs and activities to inspire students with an interest in science, help train teachers to teach science, and attract women and minorities to science and engineering careers .

10.000 students and teachers a vear. In summer workshops, the Laboratory trains teachers to update their knowledge and develop new curricula.

Through the Bay Area Science and Technology: Education Consortium. the area s laboratories, universities. and industries become involved with Bay Area school districts. especially those with high minority enrollments. We have designed many programs. particularly for female and minority students, to promote science as a career choice. We are working with the American Indian Society for Engineering and Science to encourage Indian high-school students to stay in school and go on for a college degree. We also present science workshops for elementary-school teachers from the Narajo reservation. and are working with faculty at the Narajo Community College to upgrade their science and preengineering program.

Our program for Historically Black Colleges and Universities (HBCLs) is meant to better enable these institutions to provide quality education in science and engineering. such as by upgrading their curricula. For example. we helped Southern University and Jackson State University develop bachelor"s degree programs in hazardous materials management and Alabama A\&M University establish a doctoral program in physics. We hale collaborative agreements and other connections with $12 \mathrm{HBCL}$.

We have several programs for minority graduate students. As members of the National Consortium for Graduate Degrees for Minorities in Engineering. we provide financial aid and summer engineering internships. The National Physical Sciences Consortium (NPSC). composed of government laboratories. universities, and companies, awards full-tuition fellowships and generous stipends for up to six years for graduate studies in physical science. In return. the students work for two summers for an NPSC employer. such as LLNL.

We offer summer institutes in physics and other sciences for talented undergraduates from across the country. In the High School Supercomputing Honors Program, some 6() students attend a two-week immersion in science and computing. using the Cray supercomputers of the National Energy Research Supercomputer Center (NERSC). We will soon reach many more students, thanks to Cray Research Inc. A donated Cray-XMP/14 supercomputer has been installed at NERSC for the sole use of highschool science and math classes nationwide: students need only a modem and a personal computer at their home or school to access this system.

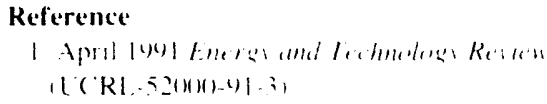




\section{Making LLNL a Center of ES\&H Excellence}

$\mathbf{T}$ he responsibility and accountability for ES\&H. from the Director down through associate directors. program leaders, and line managers. has been significantly enhanced this year with a number of administrative and operational actions. Among the actions taken. each associate director has appointed an assurance manager to develop plans for conducting ES\&H activities and to monitor ES\&H implementation within each directorate. These assurance managers also serve as members of a Laboratory-wide ES\&H working group. This working group assists ES\&H support organizations (e.g.. by reviewing documents and procedures) and provides a forum for ensuring uniformity and information sharing across the Laboratory.

An essential element for ensuring ES\&H accountability is the training of all the managers. supersisors. and staff. Two new training courses have been developed specifically for managers and supervisors to provide a framework for communicating management's and DOE's priorities for ES\&H-related activities. Numerous other specialized training courses are in place and still others are being developed. In key areas. the Laboratory has quickly instituted training. For example. more than $3(0)()$ employees have received training this year in the proper handling and packaging of hazardous waste generated in Laboratory research and operations. In addition. new training manuals have been

The Laboratory is continuing to strengthen its commitment to environmental, safety, and health (ES\&H) issues. This commitment is reflected in recent clarifications of $E S \& H$ responsibilities and oversight, specific actions to comply with DOE orders, and innovative research and development.

developed. a Laboratory ES\&H Training Manager as been appointed. and a Laboratory-wide training database is being developed.

Enhanced oversight is a key element for ensuring that ES\&H responsibilities are properly executed. The Director has assigned the Deputy Director to assist him in discharging his ES\&H oversight responsibilities for both programmatic and institutional areas. An ES\&H Council. composed of associate directors and chaired by the Deputy Director, has been established to develop policy and provide oversight.

In addition, an Assurance Review Office. also reporting to the Deputy Director. has been formed to ensure that timely ES\&H assessments are conducted and that follow-up actions are taken and to conduct independent. appraisals. An ES\&H self-assessment plan is required for each organization at the Laboratory: the Assurance Review Office reviews these plans and oversees their implementation.

In other actions. ES\&H support has been streamiined and strengthened by the naming of an associate director with primary responsibility for ES\&H support. This action underscores management s commitment to ES\&H artivities throughout the institution and programs. It also provides a focal point for interaction with the DOE on ES\&H issues.

The recent Tiger Team atssessment of the Laboratory by the DOE (Figure 1 ) highlighted at number of areas requiring additional ES\&H effort. We have developed an Action Plan and have commitled substantial resources to address these and other related ES\&H issues. To ensure that items are addressed in a cost-effective manner, a project manager has been named to coordinate the Action Plan activities.

Because many of the ES\&H challenges faced by the Laboratory are common to other DOE facilities. we have initiated a vigorous research and development program to develop innovative solutions to these complex problems. The Environmental Technology Program was organized to research, develop. demonstrate. test, and evaluate innovative technologies for reducing the costs and increasing the effectiveness of environmental restoration and waste management. The program comprises six elements: (1) hazard assessment and risk management, (2) characterization. monitoring, and analysis, (3) subsurface (groundwater and soil) remediation. (4) waste treatment, (5) waste minimization, and (6) education initiatives. This program draws from the Laboratory's many strengths and capabilities developed in the course of other DOE-sponsored work. Relevant strengths and capabilities include the development. design. and analysis of large. complex engineered systems and field tests: advanced instrumentation. measurement, and calibration capabilities; sophisticated numerical simulation of systems and processes: and specialized material development and manufacturing expertise. In turn. the program provides kechnologies to the defense 
complex and to other national and international users to support waste treatment and waste minimization activities and to expedite the resolution of subsurface contamination problems. A number of these research projects are described elsewhere in this issue (see the Environmental Technology section ). Funding for these projects comes from the Laboratory. Directed Research and Development Program. the DOE. and other agencies.

Notable among these activities is the groundwater cleanup project underway at the Livermore site. Most of the contaminants are solvents used by the Naly to clean airplane engines when the site served as a naval air station during World War II. Several promising cleanup methods are being investigated-oxidation of the contaminants with hydrogen peroxide and ultraviolet light. solar energy and bremsstrahlung radiation. These processes break down the contaminants into harmless byproducts like carbon dioxide and water. We are also investigating methods to increase the efficiency of contaminant extraction from the subsurface. including the injection of steam coupled with induction heating and the use of staggered pumping schedules (smart pump and treall. For the hydrogen peroxide/ultraviolet light method. we have installed the first two of several treatment plants. Groundwater is pumped to the surface and treated It hours a day. The purity of the treated water is comparable to that of locally a ailable drinking water: it meet all drinking-water standards. Treated water from one facility is used on site in our cooling towers or is sent to a holding pond used for irrigation: treated water from the other facilit! is discharged into an unlined ditch and allowed to soak into the ground.

We are also researching and dereloping hioremediation techniques. in which innocuous microorganisms. native to the emviromment. are used to tramsform hazardous waste into harmless byproducts. Microorganisms isolated from the contaminated areal can be progressively cultured in the laboratory in media containing nutrients. glucose. and low concentrations of the contaminant. Natural selection operates to stimulate the grow th of a diverse microbial population with an enhanced metabolic capability for degrading the contaminant. The microbes can then be released back into the contaminated area where they will metabolize the contaminant and release water and carbon dioxide and other harmless byproducts. We are focusing our initial bioremediation efforts on fuel hydrocarbons at the Livermore site and on high-explosive waste that has accumulated at Site 3()$($, our nonnuclear testing facility in the hills about $25 \mathrm{~km}$ southeast of Livermore. If successful, these lechniques will find widespread use at other DOE facilities where fuel hydrocarbons hale been released and where high-explosive research and development is conducted: it should also be possible to adapt the bioremediation strategy to other contaminating compounds.

In summary. the Laboratory has a growing ES\&H program. We have put in place important institutional changes to enhance our ES\&H performance in our everyday operations. and we halve a vigorous research and development program to find solutions to challenging ES\&H issues. Our intent is to continue to be a good neighbor by protecting our employees, the public. and the environment. and $t o$ achieve excellence in ES\&H on par with our scientific and technical accomplishments.

Contact: C. T. Alonso (\$15) $+22-4776$ or D. K. Fisher $(+1.5)+22-3.34 .3$.

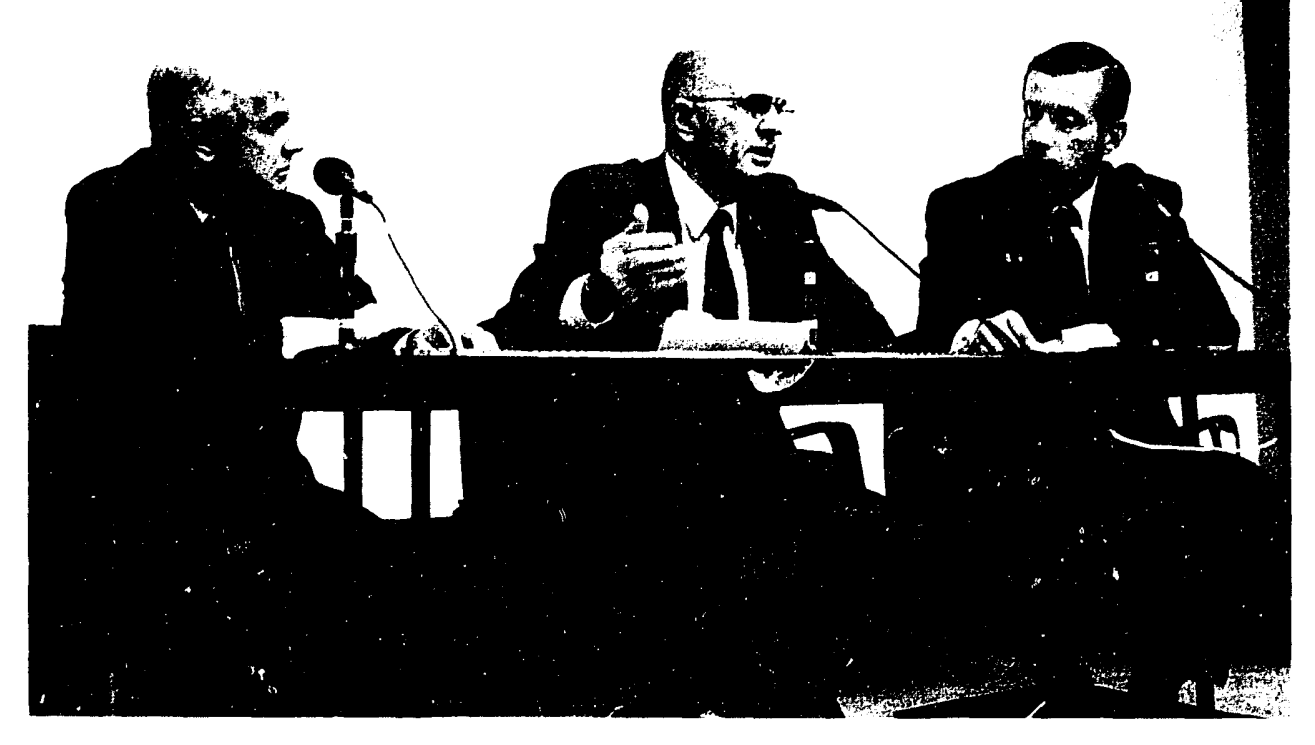

Figure 1. The results of the DOE Tiger Team Assessment were announced to the Laboratory by Director of Public Affairs Charles Biederman (left). Laboratory Deputy Director Duane Sewell (center). and Associate Director for Plant Operations Dennis Fisher (right). 


\section{LLNL and Public Understanding}

W e recognize that LLNL's operations can affect the surrounding community. and thus we strive to keep the community informed about Laboratory activities and to promote an understanding of the Laboratory's activities. missions. goals. and achievements. LLNL's formal interface with the community. the Public Affairs Office. was recently reorganized into four groups-the New's Bureau. Science Communications. Employee Communications. and Area Relations-10 serve the Laboratory and the community better.

The New's Bureau informs local and national media about fastbreaking new's and recent LLNL adrances in science and technology. In April 1991. the bureau arranged a visit by ABC TV"s "Good Morning America" show to tape stories on silica aerogels. cermets. and multithin layers. The News Bureau also handles inquiries from the media. issues new's releases. holds news conferences. publishes Newsline. and staffs a new AM radio station that airs news during commute hours and the noon hour.

The Science Communications group disseminates science and technology new's to leading science publications in the L:S. and worldwide. It maintains contact with these publications to determine their information needs. recommends

\section{The Laboratory is committed to being a responsive and responsible member of the Livermore, Tri-Valley, Central Valley, and Bay Area communities.}

topics for articles, and arranges interviews with Laboratory spokespersons. The Science Communications group recently helped develop stories about LLNL work in Scientific American and The New York Times.

Employee Communications works to meet employee information needs. Surveys have shown that LLNL employees are one of the most effective ways of communicating with the public, and thus it is doubly important to keep them clearly and completely informed about the Laboratory. Employee Communications also develops and implements employee communications programs such as Alcohol and Substance Abuse Prevention (ASAP) and Security Awareness For Employees (SAFE).

Area Relations is responsible for maintaining relations with the community-businesses. the public. special interest groups. civic groups. and area governments. The Area Relations group obtains input from the community as to the information desired from the I_aboratory and then designs programs to deliver that information. In addition. it oversees L.LNL's Visitors Center: during 1990. more than 20.00() people visited the center. The Area Relations group also coordinates a number of volunteer programs. including the Speakers Bureau. a Science and Engineering Boy Scouts Explorer
Post. and the Technical Volunteers Program.

Several annual community-outreach events are growing dramatically in popularity. For example. some 100) employees volunteered time and creativity to design, build. and staff this year's High-Tech Halloween. which included a haunted house and exciting science demonstrations. and was attended by more than 3000 children and adults. LLNL also cosponsors the "Expanding Your Horizons" conference. aimed at encouraging young women in grades 6-12 10 pursue careers in science and math: more than 100 Laboratory employees helped make this year's conference the most successful ever.

In October, the Laboratory holds its annual HOME (Helping Others More Effectively) Campaign to raise funds for local service agencies. This year. 45 agencies participated in a "fair" to showcase their efforts and help kick off the fund-raising drive. In 1990. Laboratory empioyees donated more thar. $3.65 .(0)(0)$ to the HOMF Campaign.

The commitment of LLNL employees to volunteer work was clearly reflected in the results of the first Employee Volunteer Survey. Of the 1057 employees responding. 887 reported that in 1989. they volunteered a total of 152.294 hours to various Laboratory and community projects.

Contact: C: H. Biederman $(41.5,+22-4.599$ 


\section{Index of 1991 Laboratory Achievements}

For further information on the activities reported in this issue. contact the individuals listed below.

The State of the Laboratory. 1

Defense Systems. 4

The 1489 Warhead Development Program. 6

Research in Nuclear Weapon Safety. 8

Nuclear Weapons Priduction Complex of the Fucure. 10

Nuclear Test-Experimental Science Program Innovations for Greater Qualit!.

Productivit!. and Fificieine! 12

Soviet Monitoring of L'S. Nuclear Tests. 13

High-Explosives Testing. 14

Mix Experiments with the Nova Laser. 16

Simulating Threats to the Securits of Defense Assets. 17

Adranced Conventional Weapons, 18

Arms Control and Treat! Verification. 20

Laser Research. 22

Nor a Lipgrade. 24

Beam Smoothing on Nova. 26

Microthin Lenses. 27

Differential Optical Profilometry System. 28

Adranced Applications Program. 29

Lranium Atomic Vapor Laser lsotope Separation. 32

Plutonium-Processing Technology for Complex 21. 34

Robotics for Automated Plutonium Processing. 36

Innovative Applications of AVLIS Technologs. 37

Magnetic Fusion Energy loverview). 38

Microw ave Tokamak Experiment. 40

The International Thermonuclear Experimental Reactor. 42

Energy and Earth Sciences. 4

LL.VL: Oil-Shale Project, 46

Locating Subsurface Steam Reservoirs Lsing Seismic Tomography. 47

Epinodic Nonequilibrium Fracture-.Matri, Flow and Waste Repository Performance. 48 Environmental Technology Program. 50

In Situ Microbial Filter. 52

Destruction of Mixed and Hazardous Wastes in Molten Salt Media. 53

A Fiber-Optic Sensor for Monituring TCE. 54

Biodegradation of High-Explosive Wastes. 55

Biomedical and Environmental Science. $\mathbf{5 6}$

Highh-Resolution Interphase Gene Mapping. 58

Baric Environmental Compliance and Monitoring Program. 59

\begin{tabular}{|c|c|}
\hline J. H. Nucholls & $(+1.5)+22-5+3.5$ \\
\hline W.F. Scanlin & $(+115)+23-6810$ \\
\hline J. V. Tyler & $(+15)+23-1307$ \\
\hline K. C. Johnson & $(+15)+22-6.584$ \\
\hline K. D. McKinley & $(415)+22-8189$ \\
\hline G. L. Mara & $(+15)+23-6353$ \\
\hline L. J. Ferderber & $1+151+23-7789$ \\
\hline R. M. Alire & $(+15)+22-2+19$ \\
\hline R. C. Weingart & $(+15)+22-4.565$ \\
\hline J. D. Molitoris & $1+1.51+23-3496$ \\
\hline R. M. Toms & $(+15)+23-9828$ \\
\hline M. Finger & $(+15)+22-6370$ \\
\hline D. W. Dorn & $(+15)+23-5196$ \\
\hline J. I. Daris & $(+15)+23-9818$ \\
\hline A. J. Ler! & $1+151+23-8729$ \\
\hline J. D. Lindl & $(+151+22-5430$ \\
\hline H. T. Powell & $(+15)+22-61+9$ \\
\hline ‥ M. Ceglio & $(+15)+22-8251$ \\
\hline C. J. Mauger & $(+15)+23-7682$ \\
\hline E. V. George & $(+15)+23-3939$ \\
\hline R. S. Hargrove & $(+15)+22-6178$ \\
\hline L. Gray & $(+15)+22-1554$ \\
\hline G. A. Armaritrout & $(415)+22-1594$ \\
\hline R. C. Stern & $(+15)+22-6213$ \\
\hline D. Balduin & $1+151+23-1+15$ \\
\hline S. Allen & $1+151+23-2676$ \\
\hline A. J. Glans & $(4151+22-9804$ \\
\hline R. N. Schock & $(+15)+22-6+77$ \\
\hline L. W. Younker & $(+15)+22-(1720)$ \\
\hline R.J. Cena & $(+151+22-7336$ \\
\hline J.J.Zucca & $(+15)+22-4895$ \\
\hline L. J. Hutchings & $(+15)+2.3-0.354$ \\
\hline T. A. Buscheck & $(+15)+23-9.390$ \\
\hline J. L. You. Jr. & $(+1.5)+22-3.521$ \\
\hline R. T. Tạylor & $(+15)+22-56.52$ \\
\hline R. B. Knapp & $1+151+23-3328$ \\
\hline J.F. Cooper & $(+15)+2.3-66+9$ \\
\hline S. M. Angel & $(+15)+23-1) 375$ \\
\hline P.F. Dale? & $1+151+2.3-1750$ \\
\hline F. P. Milanmich & $1+151+22-6838$ \\
\hline J. P. Knezwich & $(+1.51+22-(1) 925$ \\
\hline M. L. Mendelswhn & $(+1.5)+22-576.5$ \\
\hline B. F. Brandriff & $1+1.51+2.3-11758$ \\
\hline L. A. Gordon & $1+151+22-1574$ \\
\hline B. I. Trask & $(+151+22-5766$ \\
\hline S. F: Paitun & $(+151+22-1) 923$ \\
\hline I. R. Kercher & $1+15,+22-1+16$ \\
\hline
\end{tabular}


Experimental Model of Human Hemopoiesis in Mice. 60

Lncertainties in Assessing Risks from Groundwater Contamination. 62

\section{Engineering. 64}

Molecular Dy namic Computer Simulations of Deformation and Tribological Phenomena. 66

Micromachines at LL.VL. 68

Advances in Molecular Beam Epitayy. 69

Certification of Process Gauge. 70

Electrodeposited Nickel-Phosphorus Coatings Reduce the Cost of Diamond Turning Trols. 71

Phycics. 72

Designing Particle Detectors for the Future. 74

Moving Toward Massively Parallel Computers. 75

Brilliant Pebbles. 76

Adrancing BiC:MOS Technology. 77

Accelerator Mass Spectrometry Yields New Findings on the Carbon Cycle. 78

The MACHO Project Explores Dark Matter in Our Galaxy. 79

Chemistry and Materials Science. 80

Modeling the Electronic Structure of High-Temperature Superconductors. 82

Electrochemical Oxidation of Hazardous and Radioactive Wastes at Ambient Temperature. 84

High-Performance Vano-Engineered Multilayer Materials. 85

Compound Semiconductor Nanocrytalline Clusters. 86

Vanometer-Scale Studiev Lsing Scanning-Probe Techniques. 87

The Synthesis of Neu Insensitive Energetic Materials. 88

Bond-Selective Laser Chemistry 89

Computation. 99)

Projection . Methods for Incompressible Fluid Flow. 92

A Veu Scientific Visualization Facility for Laboratory Researchers. 95

Admini-trative and Institutional Services. 96

Technolog: Transter at L.L.VL. 98

The Center for Technical Studies of Security. Energy. and Arms Control. 100 LL.NL V Cimmitment to Science Education. 101

Making LL.VL a Center of ES\&H Excellence. 102

LL.YL and Puhlic Lnderstanding. 104
M. G. Pallavicini

T. E. McKone

K. T. Bogen

E. A. Lafranchi

W. G. Hoover

J. Belak

D. R. Ciarlo

R. Mariella

D. C. Thompson

J. W. Dini

C. B. Tarter

H. C. Britt

E. D. Brooks

W. S. Scott

J. E. Marion II

K. H. Weiner

S. E. Trumbore

C. R. Alcock

T. S. Axelrod

T. T. Sugihara

R. H. Howell

P. A. Sterne

M. J. Fluss

J. C. Farmer

T. W. Barbee. Jr.

J. G. Tobin

A. P. Alivisatos

V. L. Colvin

M. Balooch

W. J. Siekhaus

P. F. Pagoria

C. L. Coon

A. R. Mitcheil

C. G. Stevens

W. E. Conaway

R. R. Borchers

J. E. Ranelletti

D. Marcus

J. Bell

C. L. Hunter

P. E. Coyle. III

D. K. Fisher

G. W. Campbell

G. R. Marguth

W. E. Zugotta

M. Perry

C. T. Alonso

D. K. Fisher

C. H. Biederman
$(+15)+22-5651$

(+15) +22-7535

$(+15)+22-0602$

$(+15)+22-8355$

$(+15)+2+4055$

(415) +22-6061

$(+15)+22-8872$

$(+15)+22-8905$

$(+15)+22-1^{\prime} 15$

$(+15)+22-83+2$

$(+15)+22-+169$

$(+15)+22-4513$

$(+15)+23-73+1$

(+15) +22-7288

$(415)+23-6788$

$(415) 423-9366$

$(+15)+22-3703$

$(415)+23-0666$

(415) 423-1736

(415) +23-8351

(415) +22-1977

(415) 422-2510

$(+15)+23-6665$

(+15) +23-9777

$(415)+23-7796$

$(415)+22-7247$

(415) 643-7371

(415) 642-2148

(415) +22-7311

(+15) +22-6884

(415) +23-0747

(+15) +22-6311

$(415)+22-7994$

(+15) +22-6208

$(+15)+23-4538$

(+15) +22-9870

$(+15)+22-3782$

$(+15)+22-4672$

(415) 422-7105

$(+15)+22-1657$

$(+15)+23-7788$

$(+15)+22-3343$

$1+151+22-5217$

$(+15)+23-13+1$

$1+15,+22-0525$

$(+15)+23-3177$

$(+15)+22-4776$

$(+15)+22-3343$

$(+15)+22-4549$ 

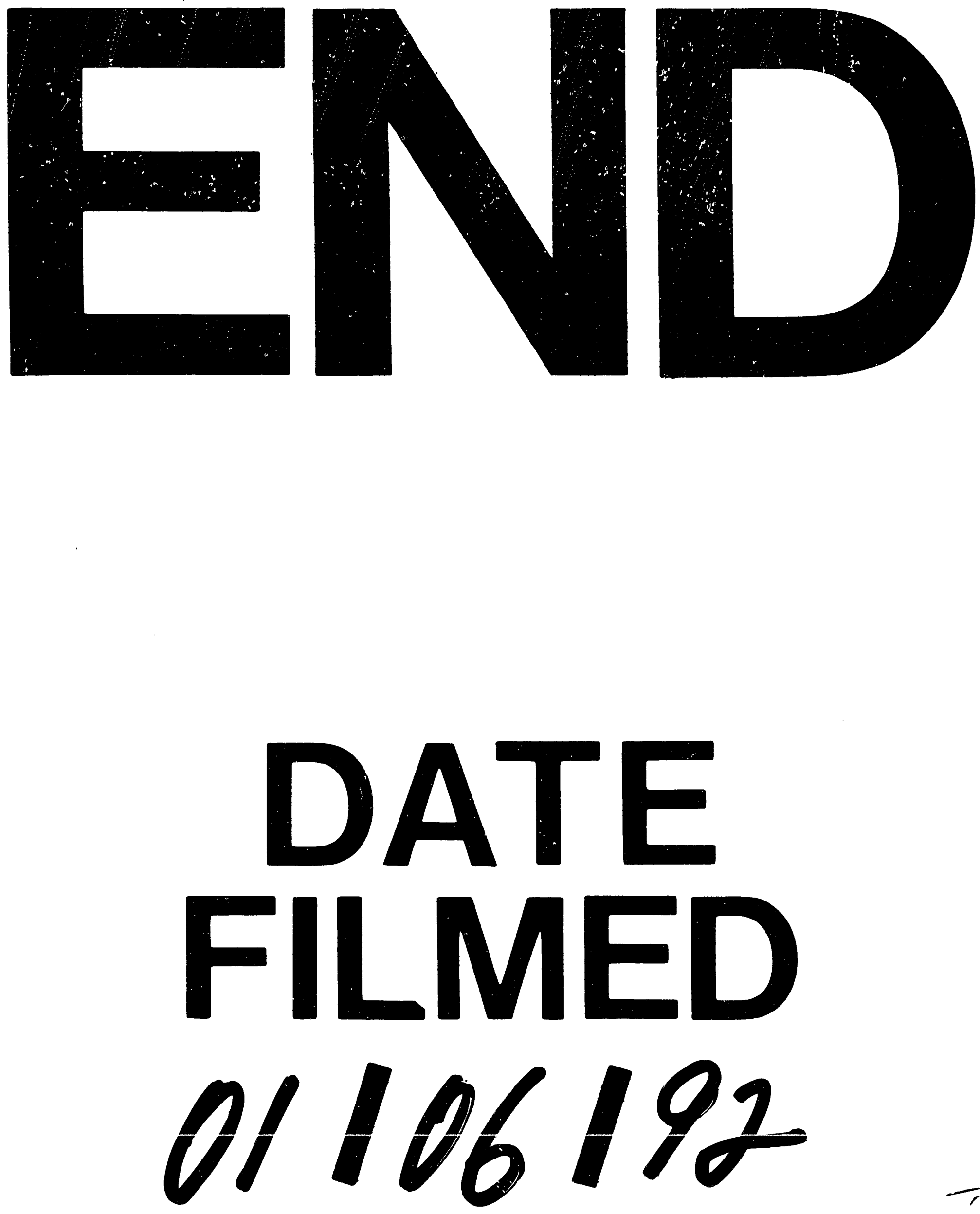
